UNIVERSIDADE DE BRASÍLIA

FACULDADE DE TECNOLOGIA

DEPARTAMENTO DE ENGENHARIA CIVIL E AMBIENTAL

MÉTODO PARA ANÁLISE DA VULNERABILIDADE DOS NÓS INTERMODAIS DA REDE DE TRANSPORTES DE CARGA BRASILEIRA

LEONEL ANTONIO DA ROCHA TEIXEIRA JUNIOR

ORIENTADOR: PASTOR WILLY GONZALES TACO

DISSERTAÇÃO DE MESTRADO EM TRANSPORTES

PUBLICAÇÃO: T.DM - 014/2015

BRASÍLIA / DF: OUTUBRO - 2015 
UNIVERSIDADE DE BRASÍLIA

FACULDADE DE TECNOLOGIA

DEPARTAMENTO DE ENGENHARIA CIVIL E AMBIENTAL

MÉTODO PARA ANÁLISE DA VULNERABILIDADE DOS NÓS INTERMODAIS DA REDE DE TRANSPORTES DE CARGA BRASILEIRA

LEONEL ANTONIO DA ROCHA TEIXEIRA JUNIOR

DISSERTAÇÃO SUBMETIDA AO PROGRAMA DE PÓS-GRADUAÇÃO EM TRANSPORTES DO DEPARTAMENTO DE ENGENHARIA CIVIL E AMBIENTAL DA UNIVERSIDADE DE BRASÍLIA COMO PARTE DOS REQUISITOS NECESSÁRIOS PARA OBTENÇÃO DO GRAU DE MESTRE EM TRANSPORTES.

APROVADA POR:

PASTOR WILLY GONZALES TACO, Dr. (ENC/UNB)

(ORIENTADOR)

FABIANA SERRA DE ARRUDA, Dr. (ENC/UNB)

(EXAMINADOR INTERNO)

LUCIANY OLIVEIRA SEABRA, Dr. (IGD/UNB)

(EXAMINADOR EXTERNO) 


\section{FICHA CATALOGRÁFICA}

\section{TEIXEIRA-JUNIOR, LEONEL ANTONIO DA ROCHA}

Método para Análise da Vulnerabilidade dos Nós Intermodais da Rede de Transportes de Carga Brasileira [Distrito Federal] 2015.

xv, 131 p., 210297 mm (ENC/FT/UnB, Mestre, Transportes, 2015).

Dissertação de Mestrado - Universidade de Brasília. Faculdade de Tecnologia.

Departamento de Engenharia Civil e Ambiental.
1. Transporte de Carga
2. Nós Intermodais
3. Vulnerabilidade
4.Sistema de Transporte
I. ENC/FT/UnB
II. Título (série)

\section{REFERÊNCIA BIBLIOGRÁFICA}

TEIXEIRA-JUNIOR, L. A. R. (2015). Método para Análise da Vulnerabilidade dos Nós Intermodais da Rede de Transportes de Carga Brasileira. Dissertação de Mestrado em Transportes, Publicação T.DM- 014/2015, Departamento de Engenharia Civil e Ambiental, Universidade de Brasília, Brasília, DF, 131 p.

\section{CESSÃO DE DIREITOS}

Autor: Leonel Antônio da Rocha Teixeira Junior.

Título: Método de Análise da Vulnerabilidade dos Nós Intermodais da Rede de Transportes de Carga Brasileira.

É concedida à Universidade de Brasília permissão para reproduzir cópias desta dissertação de mestrado e para emprestar ou vender tais cópias somente para propósitos acadêmicos e científicos. $\mathrm{O}$ autor reserva outros direitos de publicação e nenhuma parte dessa dissertação de mestrado pode ser reproduzida sem autorização por escrito do autor.

Leonel Antônio da Rocha Teixeira Junior leonel.teixeira@dnit.gov.br, leonel.teixeira@gmail.com 


\section{DEDICATÓRIA}

Dedico esse trabalho a DEUS.

Dedico ao meu pai Leonel Teixeira (em memória), pois foi inspirado em sua perseverança e combate.

Dedico esse singelo exemplo de bom combate ao meu filho Leonel Antônio. 


\section{AGRADECIMENTOS}

Agradeço a Deus pela dádiva da vida, sem Ele, que é amor, vida, tudo, nada seria possível. Aos meus pais, Salete e Leonel, por tudo que me proporcionaram, em especial na educação, e que junto com meus irmãos Mônica, Marcia e Eduardo uma feliz vida em família, meus portos seguros. Aos meus cunhados e cunhada Eduardo Jorge, Lorenzo e Marcia, sobrinhos e sobrinhas, Eduardo Jr. Murilo, Adriano, Maria e Sofia, a Aline que está comigo na educação de nosso filho, pelo incentivo nas ausências necessárias. Agradeço ao meu filho Leonel Antônio que me dá força e vontade de persistir. Aos meus familiares que sabem da importância desse trabalho para minha vida, pelas palavras de incentivos e estímulos - muito obrigado!

Aos amigos do DNIT, Adailton Dias, Olimpio Pacheco e André Nunes pelo apoio dados para que eu pudesse concluir esse trabalho. Aos amigos do DNITGeo, Claudia, Diego, Raphael, Daniel, Ernesto, Flávio, Roberto, Eliezer, Heider. Aos recém chegados Weslane, Juliano, Luis, Lindolfo. Também aqueles que já passaram por lá Verner, Felipe, Lucas, Moreno, Fagner, Iana, Karina, Rodrigo, Ticiano, Renato, Marcão. Aos amigos da COPLAN, Carlos Abramides, Sandro, Nilo, Carlos Eduardo, Erich - muito obrigado!

Aos professores e colegas da Universidade Federal do Pará pela formação recebida na Graduação em Engenharia Civil, nas pessoas do professor Roberto Serra Pacha e professora Ana Maria Seráfico, e na Especialização em Computação Gráfica, na pessoa do professor Remo Magalhães - muito abrigado!

Aos professores e colegas do Programa de Pós Graduação em Transportes - PPGT onde sempre busquei conhecimento para embasar minha vida profissional, desde os tempos em que era aluno especial, especialmente aos amigos pesquisadores do Grupo em Comportamento em Transportes e Novas Tecnologias, Zuleide Feitosa, Marcelo Sampaio, Edwin Fernando - muito obrigado!

À turma de 2013, onde ganhei novos amigos: Rony, Luca, Gal, Gerardo, Adriana, Walysson, Jean, Emmanuel, Edwin, Wesley, Hudson. Em especial Aline Maia, que me apoiou nos momentos finais da minha dissertação - muito obrigado!

Ao meu orientador professor Pastor Willy Gonzales Taco que me ajudou a desenvolver este trabalho e que sempre, com serenidade e firmeza, me apoio e me orientou - muito obrigado! 


\section{RESUMO}

A dissertação visa contribuir para o estudo da vulnerabilidade de nós intermodais da rede de transporte de carga brasileira, visto as exigências relativas ao Sistema Nacional de Viação, que configura a rede brasileira de transporte de carga em grande escala. A estrutura da rede de transporte é constituída por arcos e nós, o nó intermodal é o elemento que permite o transbordo da carga de um modo de transporte para outro. Portanto, incita a questão sobre qual vulnerabilidade pode ser observada nos nós intermodais, tendo em vista a influência dos fatores de localidade, acessibilidade e funcionalidade. Para isso, o objetivo dessa pesquisa é desenvolver um método para análise da vulnerabilidade dos nós intermodais de rede intermodal de corredor logístico brasileiro, por meio de tais fatores. Para tanto, e por meio do levantamento de referencial-teórico, acerca de rede intermodal brasileira de transportes de carga, nós intermodais e vulnerabilidade de redes de transportes, foi desenvolvido o método. Esse método estabelece um indicador de vulnerabilidade de cada nó, do conjunto em análise. No processo de análise é necessário atribuir valores dos atributos e estabelecer distribuições de influências referentes aos fatores de localidade, acessibilidade e funcionalidade. Para observar a influência relativa desses fatores na vulnerabilidade devem ser estabelecidos diferentes cenários baseados nessas distribuições de influência dos fatores. O método foi aplicado em estudo de caso em nós intermodais da rede intermodal de transporte de grãos, oriundos da produção do Centro-Oeste, do corredor logístico Sudeste. O método demonstra aplicabilidade como uma ferramenta para observa a vulnerabilidade e as influências dos fatores de localidade, acessibilidade e funcionalidade dos nós intermodais, e com isso apoiar o planejamento e decisões sobre a aplicação de recursos.

Palavras chaves: transporte de carga; nós intermodais, vulnerabilidade, sistema de transporte. 


\begin{abstract}
This paper aims to contribute in the study of the vulnerability of the intermodal nodes of the brazilian cargo transportation network as established by the national transportations system guidelines that configures the cargo network in large scale. The structure of the transportation network is constitute by arches and nodes, were the node is the element that allows the transfers from one transportation modal to another. Therefore, brings the question of what kind of vulnerability can be observed in the intermodal nodes regarding the influence of locality, accessibility and functionality factors. In other to do so, the objective of the research is to develop analysis method of the intermodal nodes vulnerability of the brazilian logistical corridors through these factors. The method was developed by theoretical survey regarding brazilian cargo transportation intermodal network, intermodal nodes and transportation network vulnerability. In the process of analysis, it is necessary to define attribute values and establish influence distribution of the locality, accessibility and functionality factors. The method was applied in a case study in the grain intermodal transportation network of the center western region production of the southeast logistical corridor. The method demonstrated it's applicability as a tool to observe the vulnerability and influence of those discussed factors, supporting the planning of resource allocation.
\end{abstract}

Keys word: cargo transportation network, intermodal nodes, vulnerability, transport system. 


\section{LISTA DE SIGLAS E ABREVIATURAS}

ABAG - Associação Brasileira do Agronegócio.

ABCR - Associação Brasileira de Concessionárias de Rodovias

ANTAQ - Agência Nacional de Transporte Aquaviário

ANTT - Agência Nacional de Transportes Terrestres

CFA - Conselho Federal de Administração

CIL - Centro Integrado de Logística

CNT - Confederação Nacional de Transporte

DNIT - Departamento Nacional de Infraestrutura de Transportes

ICS - Índice da Condição de Pavimento

IDE - Infraestrutura de Dados Espaciais

INDE - Infraestrutura Nacional de Dados Espaciais

IPCC - Intergovernamental Panel on Climate Change

ISTEA - Intermodal Surface Transportation Efficiency Act

GCTNT - Grupo de Pesquisa em Comportamento em Transportes e Novas Tecnologias

GPS - Global Position System - Sistema de Posicionamento Global

OTM - Operador de Transporte Multimodal

PIL - Plano Integrado de Logística

PPGT - Programa de Pós Graduação em Transportes

PNLT - Programa Nacional de Logística e Transportes

PNV - Plano Nacional de Viação

SNV- Sistema Nacional de Viação

SPNT - Secretaria de Política Nacional de Transporte

TKU - Tonelada Quilômetro - Útil

UNB - Universidade de Brasília

WEF - World Economic Forum 


\section{SUMÁRIO}

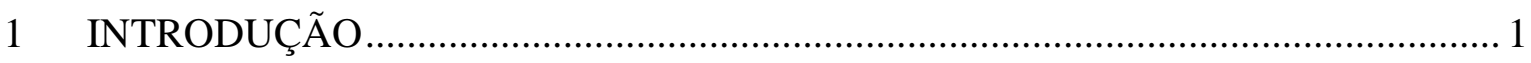

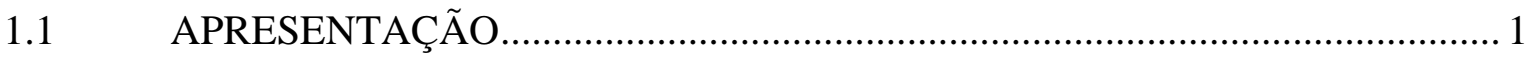

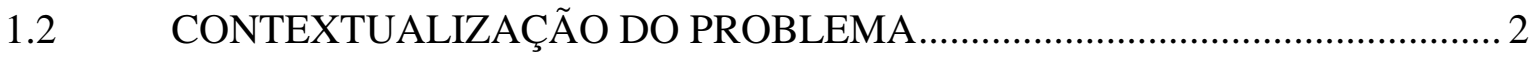

1.3 DELIMITAÇÃO DO PROBLEMA …………………................................ 4

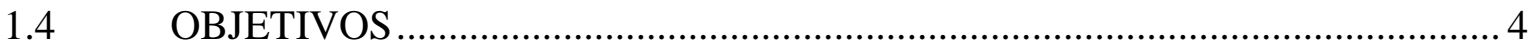

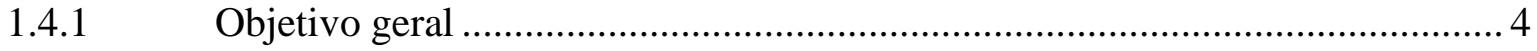

1.4.2 Objetivos específicos ....................................................................... 4

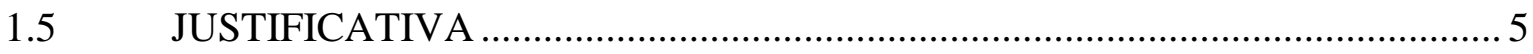

1.6 METODOLOGIA E ESTRUTURA DA DISSERTAÇÃO …………………...... 6

2 REDE INTERMODAL DE TRANSPORTE DE CARGA .......................................... 9

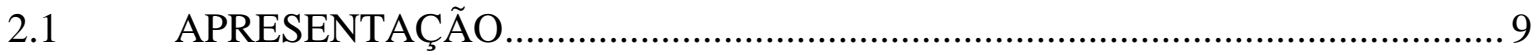

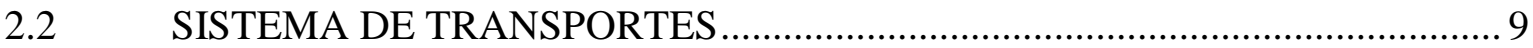

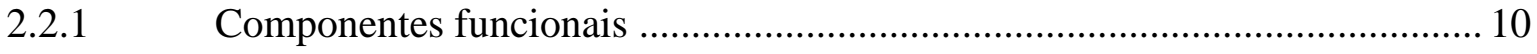

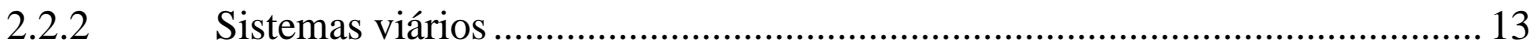

2.2.2.1 Sistema rodoviário ............................................................................ 14

2.2.2.2 Sistema ferroviário …………………………………………….... 15

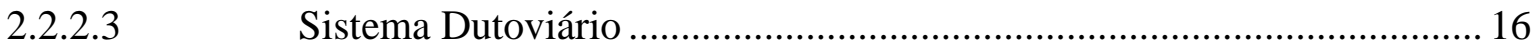

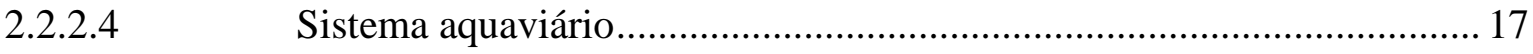

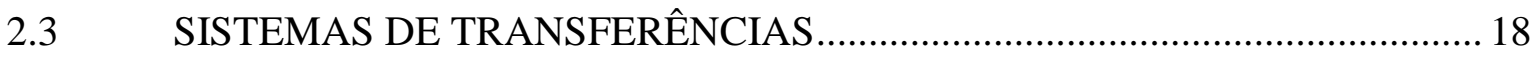

2.3.1 Componentes do sistema de transferências ....................................................... 21

2.3.2 Ambiente de interação entre os componentes dos sistemas de transporte ...... 23

2.4 REPRESENTAÇÃO GRÁFICA DE REDES DE TRANSPORTES …............... 32

2.4.1 Considerações sobre representação gráfica ...................................................... 32

2.4.2 Representação gráfica de transferências modais - Nós Intermodais ................ 35

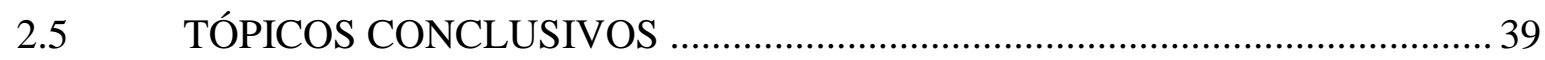

3 VULNERABILIDADE E NÓS INTERMODAIS DE TRANSPORTE DE CARGA ..... 40

3.1 APRESENTAÇÃO................................................................................ 40

3.2 CONCEITUAÇÃO DA VULNERABILIDADE …………………………….... 40

3.3 VULNERABILIDADE E NÓS INTERMODAIS DE TRANSPORTE DE

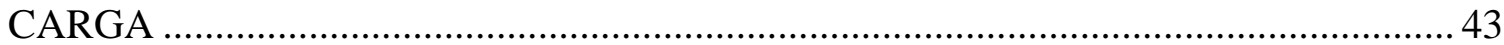

3.4 FATORES CONSIDERADOS PARA A ANÁLISE DA VULNERABILIDADE EM NÓS INTERMODAIS DE TRANSPORTE DE CARGA ………………………......4 48

3.4.1 Vulnerabilidade entre ambiente e rede e entre ambiente e fluxo. ..................... 49 


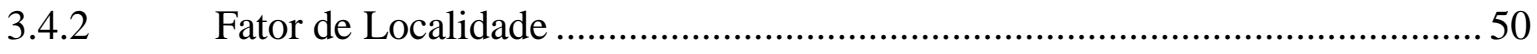

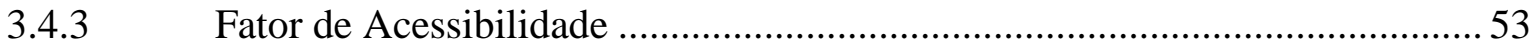

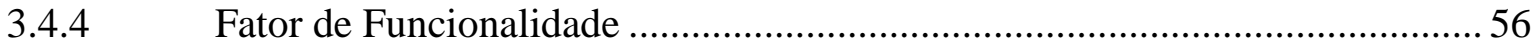

3.4.5 Critérios de influência e atributos do fatores na Vulnerabilidade de Nós

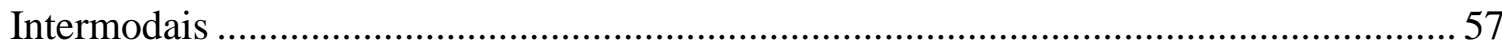

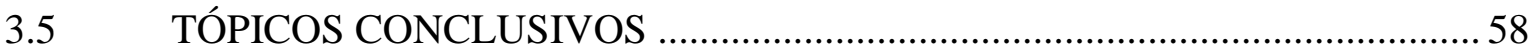

4 MÉTODO DE ANALISE DA VULNERABILIDADE DE NÓS INTERMODAIS DE

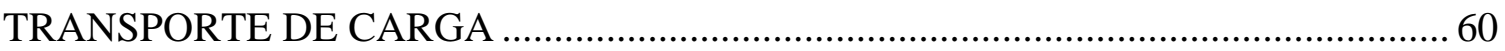

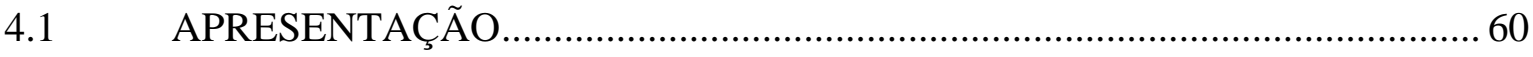

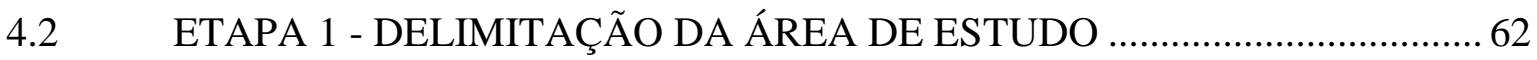

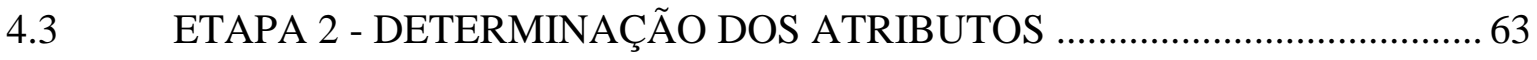

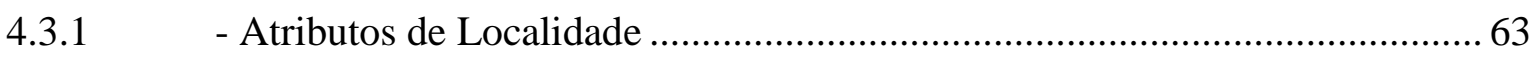

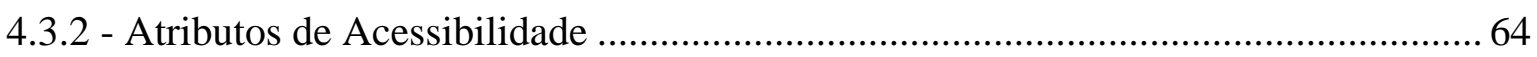

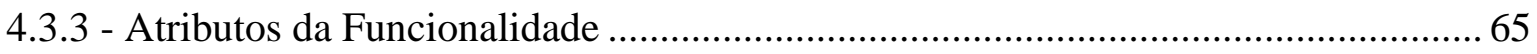

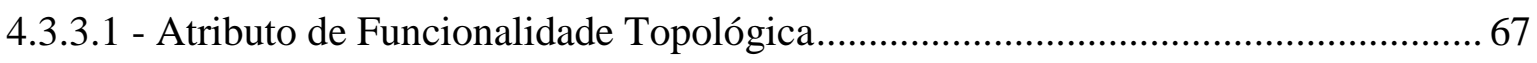

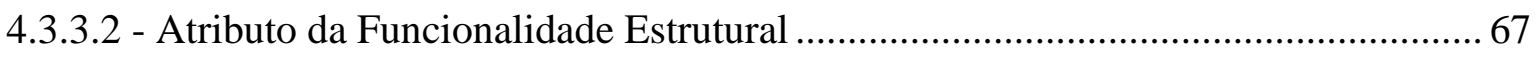

4.3.3.3 - Combinação entre os fatores de localidade e acessibilidade................................. 68

4.4 ETAPA 3 - HIERARQUIZAÇÃO DOS FATORES (CENÁRIOS) ....................69

4.5 ETAPA 4 - DETERMINAÇÃO DA VULNERABILIDADE DOS NÓS INTERMODAIS DE TRANSPORTE DE CARGA ….................................................. 72

4.5.1- Definição da Equação do Modelo de Análise da Vulnerabilidade............................. 72

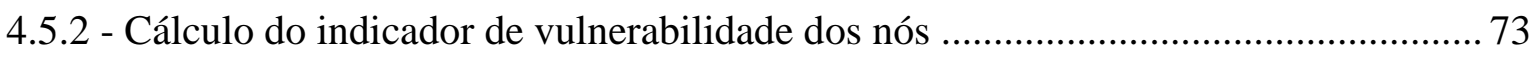

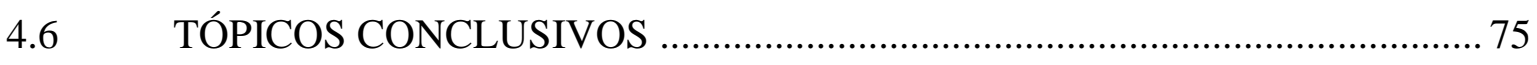

5 ESTUDO DE CASO - ANÁLISE DA VULNERABILIDADE DE NÓS INTERMODAIS DE TRANSPORTE DE CARGA DO CORREDOR LOGÍSTICO

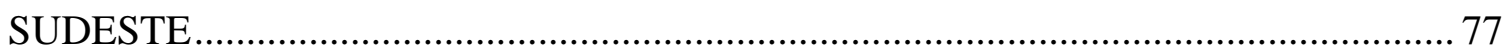

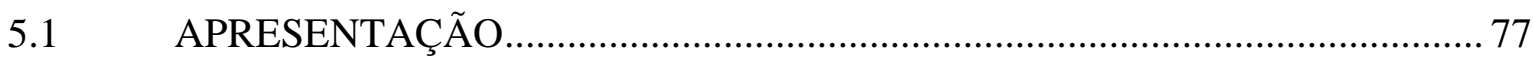

5.2 DELIMITAÇÃO DE ÁREA DO ESTUDO DE CASO..................................... 77

5.3 DETERMINAÇÃO DOS ATRIBUTOS POR MEIO DA CARACTERIZAÇÃO

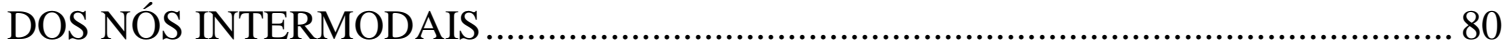

5.3.1 Determinação dos atributos de Localidade e de Acessibilidade...................... 81

5.3.1 Determinação dos atributos de Funcionalidade topológica ............................... 82

5.3.2 Determinação dos atributos de Funcionalidade estrutural................................ 83

5.4 HIERARQUIZAÇÃO DOS FATORES - INDICAÇÃO DE CENÁRIOS ......... 85

5.5 DETERMINAÇÃO DA VULNERABILIDADE DOS NÓS INTERMODAIS

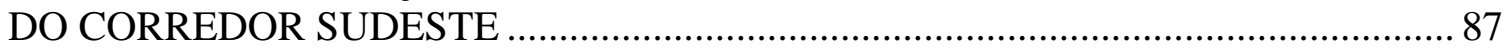

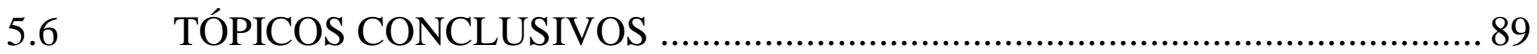




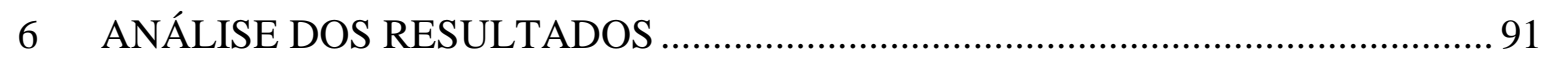

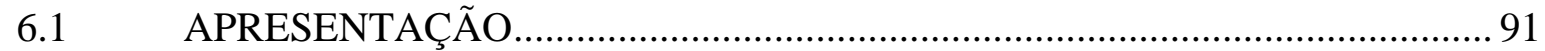

6.2 RESULTADOS DA APLICAÇÃO DO ESTUDO DE CASO ……………….... 91

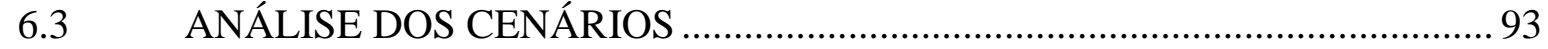

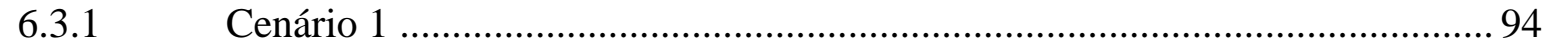

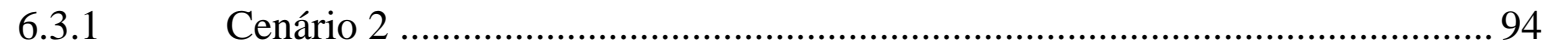

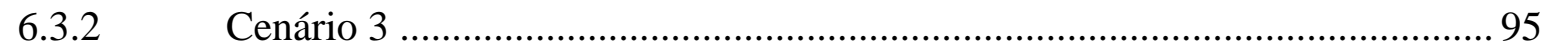

6.4 ANÁLISE DOS NÓS INTERMODAIS...................................................... 95

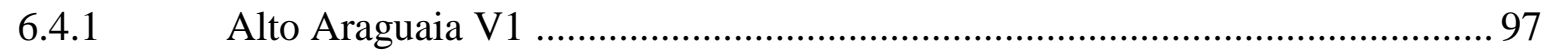

6.4.2 Cáceres V2 e Cáceres V3 ………………….......................................... 98

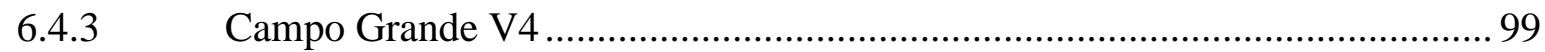

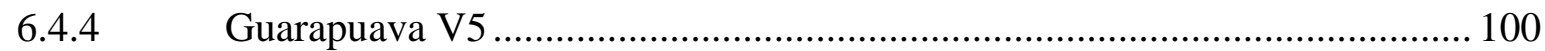

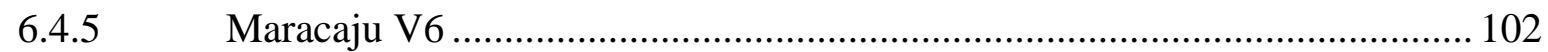

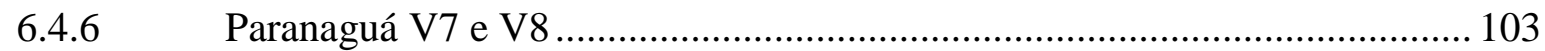

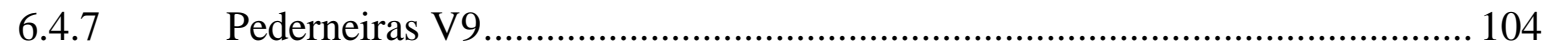

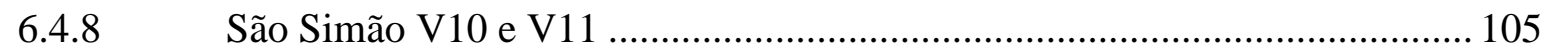

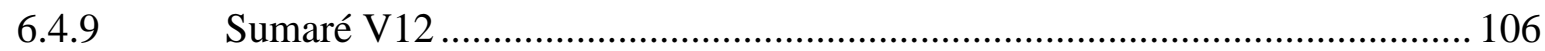

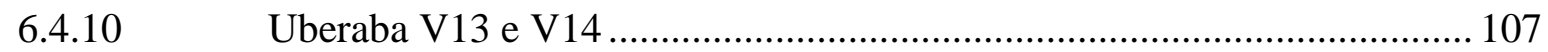

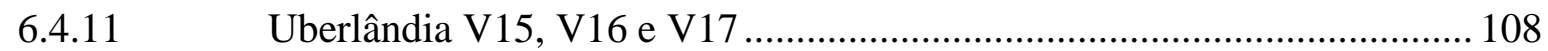

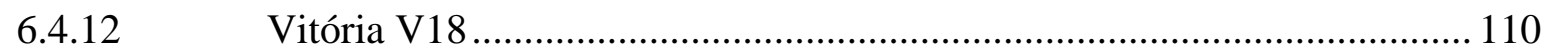

6.5 ANÁLISE DA VULNERABILIDADE DO CORREDOR LOGÍSTICO.......... 111

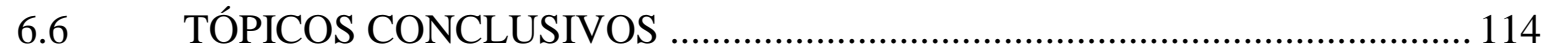

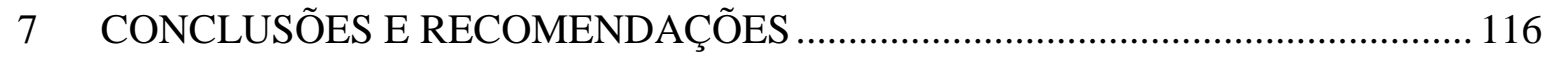

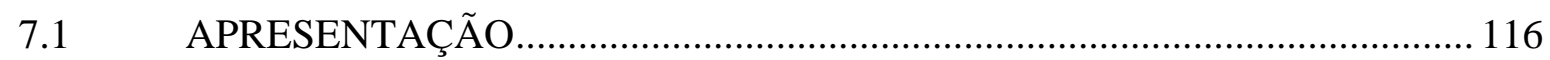

7.2 AVALIAÇÃO DO MÉTODO PROPOSTO ………………………………...... 116

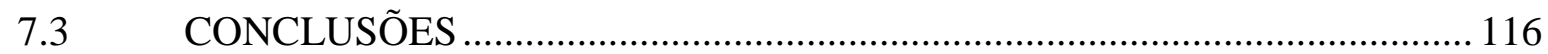

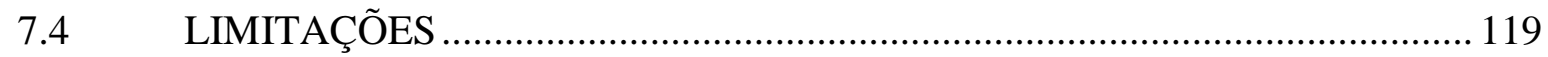

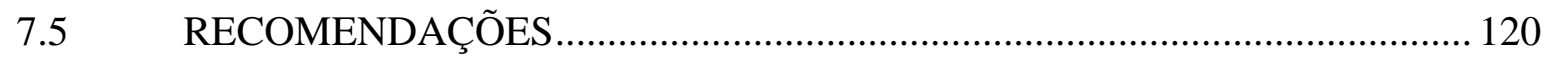

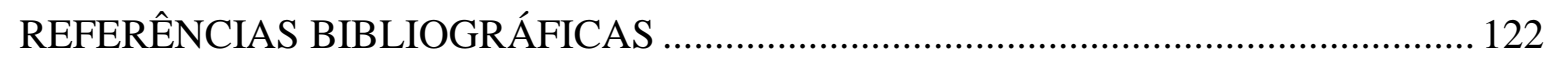

ANEXO 1 - NÍVEL DE CENTRALIDADE DAS CIDADES E LOCALIDADES ......... 125

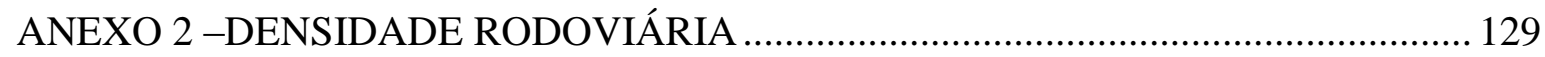

ANEXO 3 -DADOS DE TERMINAIS INTERMODAIS .................................................. 130 


\section{LISTA DE FIGURAS}

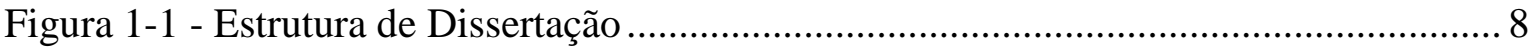

Figura 2-1 - Componentes de Sistema de Transportes....................................................... 12

Figura 2-2 - Subsistemas do sistema de transferência/nó intermodal. ................................ 21

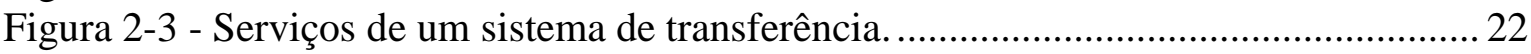

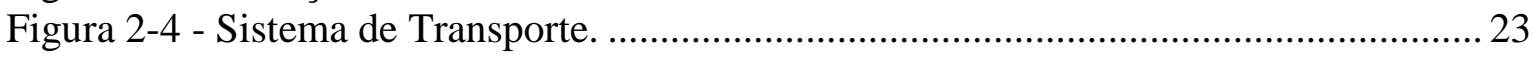

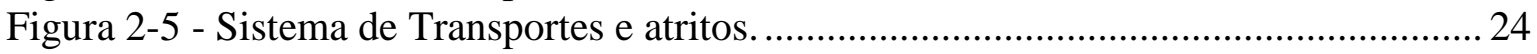

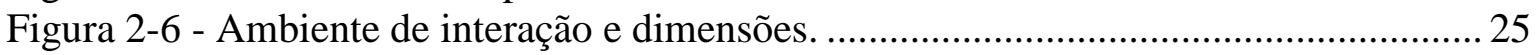

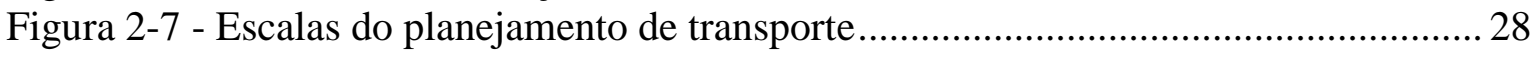

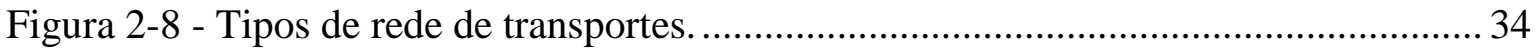

Figura 2-9 - Representação gráfica de redes de diferentes modais. .................................... 35

Figura 2-10 - Exemplos de representação de nós intermodais. ............................................ 36

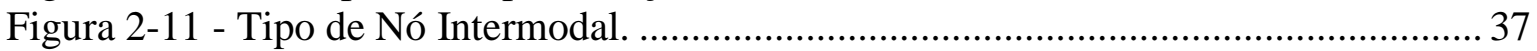

Figura 3-1 -Interações da vulnerabilidade Ambiente-Rede e Ambiente-Fluxo.................. 42

Figura 3-2 - Nó Intermodal sem distúrbios de funcionamento......................................... 47

Figura 3-3 - Fatores de associação vulnerabilidade entre ambiente, rede e fluxo................ 50

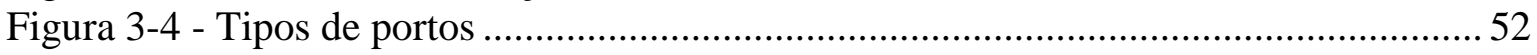

Figura 3-5 - Influência dos fatores e critérios na vulnerabilidade ................................... 57

Figura 4-1 Etapas básicas do método de análise da vulnerabilidade...................................61 61

Figura 4-2 - Corredores Logísticos e Transferências Modais do PNLT..............................62 62

Figura 5-1 - Delimitação de área do estudo de caso Corredor Logístico Sudeste................ 78

Figura 5-2 - Mapa de localização dos nós intermodais do estudo de caso ........................... 81

Figura 5-3 - Rede de nós do corredor Sudeste e tipo de intermodalidade.......................... 83

Figura 6-1- Escala de influência na vulnerabilidade do nó intermodal Cenário 1.............. 94

Figura 6-2 - Escala de influência na vulnerabilidade do nó intermodal Cenário 2............. 94

Figura 6-3 Escala de influência na vulnerabilidade do nó intermodal Cenário 3................ 95

Figura 6-4 - Localização dos nós e densidade rodoviária federal .................................... 96

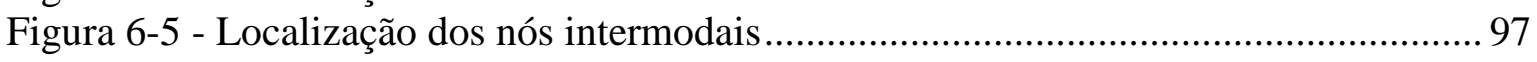

Figura 6-6 - Alto Araguaia V1 - Localidade e Acessibilidade. ......................................... 98

Figura 6-7 - Cáceres V2 e V3 - Localidade, Acessibilidade e Funcionalidade.................... 99

Figura 6-8 -Campo Grande V4 - Localidade e Acessibilidade ........................................ 100

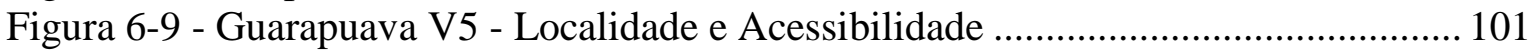

Figura 6-10 - Maracaju V6 - Localidade e Acessibilidade............................................... 102

Figura 6-11 - Paranaguá V7 e V8 - Localidade e Acessibilidade. ..................................... 103

Figura 6-12 - Pederneiras V9 - Localidade e Acessibilidade............................................ 104

Figura 6-13 - São Simão V10 e São Simão V11 - Localidade e Acessibilidade................ 106

Figura 6-14 - Sumaré V12 - Localidade e Acessibilidade................................................... 107

Figura 6-15 - Uberaba V13 e Uberaba v14 - Localidade e Acessibilidade........................ 108

Figura 6-16 - Uberlândia V15, V16 e V17 - Localidade e Acessibilidade ........................ 109

Figura 6-17 - Vitória V18 - Localidade e Acessibilidade ................................................ 110

Figura 6-18 - Cenário 1 - distribuição espacial dos níveis de vulnerabilidade.................... 111

Figura 6-19 - Cenário 2 - distribuição espacial dos níveis de vulnerabilidade................... 112

Figura 6-20 - Cenário 3 - distribuição espacial dos níveis de vulnerabilidade.................... 113

Figura 6-21 - Distribuição espacial da vulnerabilidade dos nós no corredor ..................... 114 


\section{LISTA DE QUADROS}

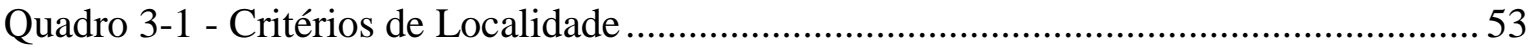

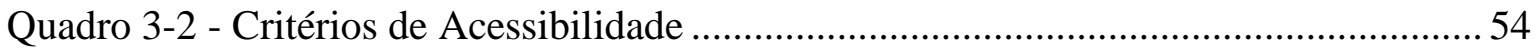

Quadro 3-3 - Critérios de Funcionalidade topológica …....................................................56

Quadro 4-1 - Interação entre os fatores de localidade e acessibilidade ................................69

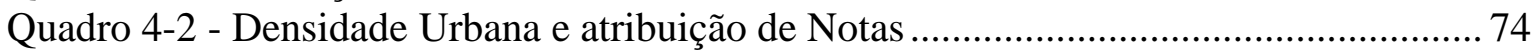

Quadro 4-3- Densidade Rodoviária, atributos e notas......................................................... 74

Quadro 4-4 - Tipos de transferências e nota de integração ............................................. 74

Quadro 4-5 - Notas atribuídas a cada intervalo dos atributos de funcionalidade................. 75

Quadro 5-1 - Localidade e intermodalidade do nós Intermodais da área de estudo............. 79

Quadro 5-2 - Interação entre os atributos de localidade e acessibilidade ............................ 80

Quadro 5-3 - Caracterização do Indicador Urbano e Densidade Rodoviária dos Nós ......... 80

Quadro 5-4 - Tipos de indicador urbano e densidade rodoviária e notas atribuídas ........... 81

Quadro 6-1 - Escala Indicador Urbano e Densidade Rodoviária ........................................ 96

Quadro 6-2 - Tipo de vulnerabilidade por combinação dos cenários em V1 ...................... 98

Quadro 6-3 - Tipo de vulnerabilidade por combinação dos cenários em V2 e V3 ............. 99

Quadro 6-4 - Tipo de vulnerabilidade por combinação dos cenários em V4 ..................... 100

Quadro 6-5 - Tipo de vulnerabilidade por combinação dos cenários em V5 .................... 101

Quadro 6-6 - Tipo de vulnerabilidade por combinação dos cenários em V6 ..................... 103

Quadro 6-7 - Tipo de vulnerabilidade por combinação dos cenários em V7 e V8 ............ 104

Quadro 6-8 - Tipo de vulnerabilidade por combinação dos cenários em V9 ..................... 105

Quadro 6-9 - Tipo de vulnerabilidade por combinação dos cenários em V10 e V11 ....... 106

Quadro 6-10 - Tipo de vulnerabilidade por combinação dos cenários em V12 ................ 107

Quadro 6-11 - Tipo de vulnerabilidade por combinação dos cenários em V13 e V14 ..... 108

Quadro 6-12 - Tipo de vulnerabilidade por combinação dos cenários em V15,V16, V17 109

Quadro 6-13 - Tipo e representação de vulnerabilidade em V18 ..................................... 110 


\section{LISTA DE TABELAS}

Tabela 4-1 - Valores estimados dos coeficientes a partir da hierarquização das variáveis . 72

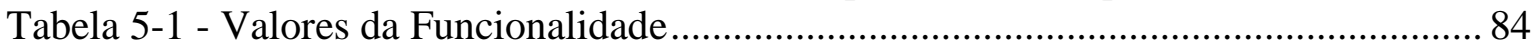

Tabela 5-2 - Valores dos fatores e equações da vulnerabilidade por nó. ............................ 85

Tabela 5-3 - Valores estimados dos coeficientes a partir da hierarquização das variáveis . 87

Tabela 5-4 - Cálculo da vulnerabilidade dos nós intermodais Cenário 1 ............................. 87

Tabela 5-5 - Cálculo da vulnerabilidade dos nós intermodais Cenário 2 ............................ 88

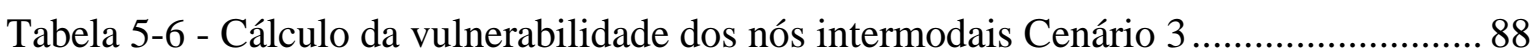

Tabela 5-7 - Determinação da vulnerabilidade dos nós intermodais por cenário ................ 89

Tabela 6-1 - Classes de vulnerabilidade dos nós intermodais e intervalos de valores ........ 92

Tabela 6-2 - Representação das classes de vulnerabilidade dos nós por cenário .................92 92 


\section{LISTA DE EQUAÇÕES}

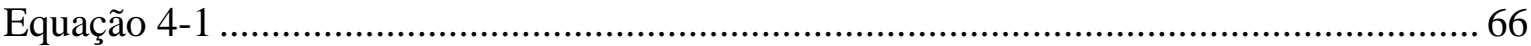

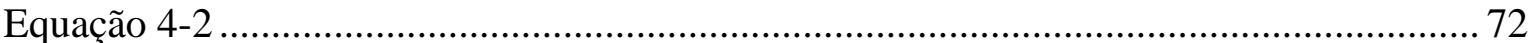

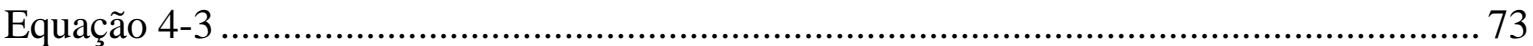

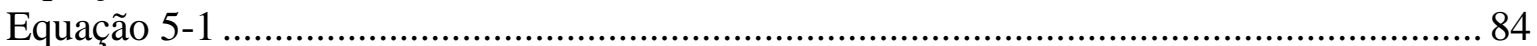

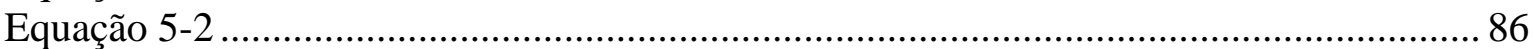

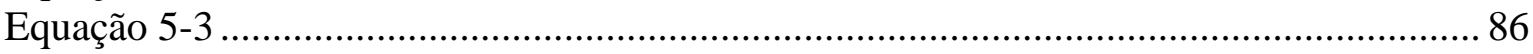

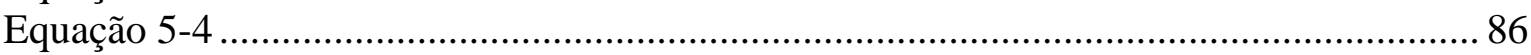




\section{INTRODUÇÃO}

\subsection{APRESENTAÇÃO}

Conforme os fins e propósitos preconizados em documentos oficiais a rede de transporte intermodal brasileira tem abrangência nacional (Brasil, 1973; 2011). A política de transporte visa alcançar o nível das exigências relativas à eficiência de sistemas de transporte, na expectativa de reduzir os seus custos e possibilitar a ampliação de benefícios considerando a escala geográfica territorial/espacial brasileira.

A estrutura de redes de transporte é constituída por um conjunto de elementos - arcos e nós - interligados por onde fluem e circulam os meios de transporte. Os nós são geralmente os pontos de maior relevância da rede intermodal, sendo as ligações entre esses nós são feitas pelos arcos. Em rede intermodal os arcos são de modos de transportes diferentes. Em terminologia de rede, usam-se os termos arcos e nós. Um nó intermodal é considerado como o componente da rede de transportes que permite o transbordo da carga de um modo de transporte para outro.

Os sistemas de transferências são pontos de conexão da logística e transporte e considerados elementos estruturantes dos sistemas de transportes de cargas, eles exercem a função de pontos intermodais, pontos de conexões definidos como elementos estruturantes da logística e os corredores logísticos configuram áreas territoriais de atuação da política de logística e transporte nacional, conforme a Secretaria de Política Nacional de Transportes apresentado em (Brasil, 2012).

É importante considerar quais os fatores mais influentes na composição da vulnerabilidade dos nós e estabelecer uma análise comparativa entre eles, em um determinado corredor logístico. Isto torna possível a indicação do nível de vulnerabilidade de cada nó e do corredor como um todo. A análise desses fatores permite fundamentar a formulação do indicador dos nós intermodais de determinado sistema de transportes ou corredor logístico. 


\subsection{CONTEXTUALIZAÇÃO DO PROBLEMA}

Para analisar o comportamento da rede intermodal de transporte, é necessário entender as relações e influências de seus componentes com o ambiente. $\mathrm{O}$ entendimento dessas relações e influências exige métodos de análises que permitam uma abordagem mais realista, pois são grandes os desafios para a melhoria da competitividade da logística brasileira, visto que o Sistema Nacional de Viação - SNV configura uma ampla rede nacional de transportes com a responsabilidade de estruturar a circulação de pessoas e cargas para o desenvolvimento e a consolidação de territórios, através da disponibilização da infraestrutura de transportes.

Fundamental para o desenvolvimento econômico e social do Brasil, a rede intermodal de grande escala corresponde à estrutura de circulação composta de elementos da infraestrutura física: trechos rodoviários, ferroviários, hidroviários, das instalações portuárias, contornos urbanos e outros elementos. Portanto, nota-se que critérios que influenciam no funcionamento do nó intermodal têm a ver com sua Localidade.

A esses componentes físicos acrescentem-se os elementos lógicos, como planos, políticas e sistemas de informações. (Razzolini-Filho, 2009; Brasil, 1973; Brasil, 2011). No SNV, são estabelecidos os componentes planejados e em construção. Em razão dos desafios e entraves, e também pela dimensão e escalas do SNV, um trecho planejado pode ficar décadas sem mudar sua condição para trecho implantado, e mesmo nunca ser implantado, tais os entraves de toda ordem e as exigências de grandes investimentos. A implantação física destes componentes é para permitir melhor fluidez na rede, ou seja, garantir a acessibilidade.

A estrutura viária inclui pontos de acesso e de conexões no ambiente construído que permita a circulação de pessoas e cargas, conforme visto em Magalhães (2004), Galindo (2009), Morlok (1978) e Manheim (1980).

O SNV permite a circulação de fluxos de transporte no território nacional e pode ser associado a uma relativa vulnerabilidade que é inerente aos elementos da infraestrutura física construída para circulação, pois, tal elemento está sujeito a uma queda de 
acessibilidade ocasionada por sua baixa eficiência na infraestrutura da rede de transportes. Conforme abordado por Pricinote (2008), Wolf (2012), Erath (2011), Cunha-Filho (2014) e Pipicano (2014) a vulnerabilidade de um componente da rede de transportes pode produzir consequências negativas por causa da diminuição da capacidade e eficiência. Pode até mesmo levar à completa interdição de circulação em determinado trecho.

No entanto analisar a intermodalidade implica observar a função dos componentes responsáveis pelo transbordo de carga entre um modo de transporte e outro, o grau de intermodalidade e observar os fluxos unidirecionais de entrada e saída nos nós intermodais e identificar e quantificar os equipamentos e serviços de intermodalidade. A funcionalidade do nó intermodal também é destacada como um importante critério para avaliar sua influência na vulnerabilidade.

A melhoria da competitividade brasileira é necessária para garantir os ganhos de produtividade de grande relevância econômica e social e a ampliação da intermodalidade do sistema nacional de viação passa pela implantação de nós intermodais, todos a configurar componentes de rede intermodal.

Em razão de sua importância para a economia, os pontos de transferências modais possibilitam uma forte interação e relacionamento com o contexto urbano regional. A intermodalidade permite a mobilidade de produtos entre as regiões, favorece o desenvolvimento socioeconômico, pode permitir que a produção nacional fosse colocada em novos mercados de forma mais competitiva.

Para isso implicam na ampliação, desenvolvimento e implantação de serviços de transferências, o que requer tanto a consolidação dos sistemas viários dos diferentes modais em superfície terrestre e aquaviária, bem como a integração física e lógica desses sistemas que configuram um sistema nacional intermodal de transportes.

Como exemplos, pode-se citar o porto de Santos e o terminal intermodal de Pederneiras, ambos no estado de São Paulo e também a plataforma logística, conhecida como porto seco, em Anápolis, estado de Goiás. São exemplos de nós intermodais e que são componentes de uma rede intermodal de transportes de carga. 


\subsection{DELIMITAÇÃO DO PROBLEMA}

Pelo menos três fatores podem caracterizar os nós intermodais: Localidade; Acessibilidade e Funcionalidade. Ocasionais falhas ou queda de função dos nós intermodais correspondem certa vulnerabilidade e pode-se considerar que pelo menos esses três fatores influenciam essa vulnerabilidade.

O problema que este trabalho levanta é constituído pelos nós intermodais de determinado corredor logístico, revelando os pontos estratégicos desses nós e do sistema de transportes de cargas. Qual a vulnerabilidade indicada nos nós intermodais, tendo em vista a influência dos fatores de localidade, acessibilidade e funcionalidade?

\subsection{OBJETIVOS}

\subsubsection{Objetivo geral}

O objetivo geral desta dissertação é desenvolver um método para análise da vulnerabilidade dos nós intermodais de rede intermodal de corredor logístico, por meio dos fatores de localidade, acessibilidade e funcionalidade.

\subsubsection{Objetivos específicos}

Como objetivos específicos têm-se:

i. Analisar os fatores de localidade, acessibilidade e funcionalidade associados à vulnerabilidade dos nós intermodais, considerando as influências das relações ambienterede e ambiente-fluxo.

ii. Formular indicador de vulnerabilidade do nó intermodal com base na influência da localidade, acessibilidade e funcionalidade.

iii. Classificar os nós intermodais do corredor logístico com base no indicador de vulnerabilidade.

iv. Aplicar o método para analisar a vulnerabilidade de nós intermodais em um estudo de caso delimitado em um conjunto de nós de corredor logístico. 


\subsection{JUSTIFICATIVA}

A magnitude dos problemas enfrentados no sistema de transportes modais no Brasil justifica os esforços despendidos na busca de soluções. Para implantar uma rede intermodal nacional de transporte e seus componentes, exigem-se, para o seu planejamento, a construção, manutenção e operação e métodos de análises realistas, em razão dos desafios da competitividade da logística brasileira.

A escolha do tema também se justifica pelos desafios enfrentados pelo transporte de cargas, pelas perdas econômicas acarretadas pela deficiência da infraestrutura, o que amplia as situações de vulnerabilidade. De acordo com Naves (2012), o Brasil perde uma safra inteira nas rodovias a cada 7,7 anos. Os ganhos de produtividade no campo, muitas vezes, são anulados diante da precariedade da malha viária. O custo dos transportes afeta a competitividade dos produtores.

A vulnerabilidade da rede de transporte tornou-se tema de pesquisas em países como Austrália, Estados Unidos e Japão com a finalidade de assegurar e manter a infraestrutura de transportes em funcionamento (Cunha - Filho, 2014).

No Brasil, até o presente momento, são poucos estudos sobre vulnerabilidade em redes de transportes, o que torna necessário identificar os fatores que influenciam a vulnerabilidade na rede. Algumas Universidades têm iniciados estudos sobre vulnerabilidade e redes de transportes e incentivando pesquisadores a propor soluções em nível urbano local, regional e nacional. A UnB, através do Grupo de Pesquisa Comportamento em Transportes e Novas Tecnologias (CTNT/UnB) no âmbito do Programa de Pôs Graduação em Transportes PPGT, se dedica a estudos e pesquisas sobre vulnerabilidade na rede viária urbana, transporte coletivo - VLT, no sistema na rede aérea, no sistema rodoviário de carga vulnerabilidade do Sistema Nacional de Viação.

Como contribuição ao Grupo de Pesquisa este trabalho tem o propósito de contribuir abordando os elementos nós da rede intermodal de carga, configurada pelo SNV para pesquisar a vulnerabilidade dessa rede de ampla escala geográfica. A partir da análise do conjunto de Nós Intermodais de uma rede intermodal de transportes, são detectados os 
pontos de transferências modais mais estratégicos e mais importantes. Uma análise que se pretende útil para o planejamento de investimentos ou medidas de controle para mitigar a vulnerabilidade de do corredor logístico.

Este estudo também se justifica pela relevância para análise das relações e interações entre o ambiente e a rede, entre o ambiente e o fluxo. Portanto, vê-se a necessidade de ampliar o conhecimento acerca dos componentes e interações da rede de transportes intermodal do Brasil, para o que os estudos acadêmicos possam contribuir de forma eficiente.

Considerando que uma análise com base na vulnerabilidade da rede intermodal nacional favorece medidas e ações para o ciclo do planejamento, a justificativa principal para realização deste trabalho é contribuir com o conhecimento científico sobre a rede intermodal e da infraestrutura, tanto as implantadas quanto as planejadas, que compõem os sistemas de transportes no Brasil. Utiliza-se, neste trabalho, a terminologia de nó intermodal. Observe-se que o nó intermodal, sob a ótica da vulnerabilidade, é importante em relação aos demais componentes da rede de transporte. Esta reflexão ajuda na caracterização do corredor diante da necessidade de ampliar a intermodalidade do Sistema Nacional de Viação.

Para analisar os nós intermodais, é necessário entender suas relações e influências com o ambiente, tanto da rede que corresponde à estrutura construída, quanto dos fluxos atendidos. $\mathrm{O}$ entendimento dessas relações e influências exigem métodos de análises diante dos desafios da competitividade da logística brasileira.

\subsection{METODOLOGIA E ESTRUTURA DA DISSERTAÇÃO}

A metodologia desta dissertação dividiu-se em quatro fases:

A primeira fase é composta pelos capítulos de introdução e os de revisão bibliográfica. A introdução corresponde ao capítulo 1 aborda o projeto de pesquisa, que apresenta o problema, a hipótese, a justificativa, a metodologia e a estrutura da dissertação. A revisão bibliográfica é dividida em duas partes correspondentes aos capítulos dois e três da dissertação. O segundo capítulo aborda a rede intermodal de transporte de carga configurada nacionalmente pelo SNV e pelo PNV e também trata da representação gráfica, 
para facilitar as análise e apresentação dos resultados. O terceiro capítulo a vulnerabilidade e nós intermodais. A vulnerabilidade e nós define os critérios e os fatores de influência da vulnerabilidade dos nós intermodais.

A segunda fase trata do desenvolvimento do método que é apresentado no quarto capítulo, o desenvolvimento da proposta do método e no capítulo quinto é apresentada a aplicação do método de estudo de caso do corredor logísticos do centro - oeste, com uma amostra de 18 nós intermodais. A aplicação, do método para análise da vulnerabilidade dos nós intermodais, consiste nos procedimentos organizados em cinco subfases: i) delimitação do estudo de caso, ii) determinação dos atributos de localidade e acessibilidade dos nós, e de funcionalidade, topológica e estrutural, iii) hierarquização de critérios por meio de cenários de influência; iv) determinação da vulnerabilidade por nó intermodal.

A terceira fase corresponde ao capítulo sexto de análise dos resultados do estudo de caso do corredor centro-oeste. Este corredor é destinado ao escoamento do fluxo de carga da produção de grãos. A amostra de dados corresponde a um conjunto de nós intermodais do corredor logístico Sudeste e de escoamento de fluxos de grãos da região Centro-Oeste. Nesse sexto capítulo são realizadas as análises dos resultados obtidos no capítulo quinto e são aprofundadas análises dos resultados obtidos abordando o comportamento dos nós diante aos cenários indicados; a vulnerabilidade dos nós atribuídas diante dos fatores de localidade, acessibilidade e funcionalidade e a distribuição espacial, dos nós no corredor logístico centro oeste. Essa fase contempla, ainda, o sétimo capítulo composto pelas conclusões e recomendações. Contém síntese do trabalho com as conclusões relacionadas ao problema e objetivos estabelecidos. Enfatiza o objetivo e as contribuições da pesquisa, discute o modelo apresentado, comenta as limitações da pesquisa, sugere melhorias e adaptações ao modelo e ao método propostos, realiza generalizações acerca do objeto de estudo e apresenta trabalhos relativos ao tema.

Por fim, têm-se as referências bibliográficas e os anexos. O Anexo 1 apresenta o indicador urbano, o Anexo 2, a densidade rodoviária, e o Anexo 3, funcionalidade topológica e estrutural. A Figura 1-1 apresenta as fases da metodologia e os capítulos da estrutura da dissertação. 

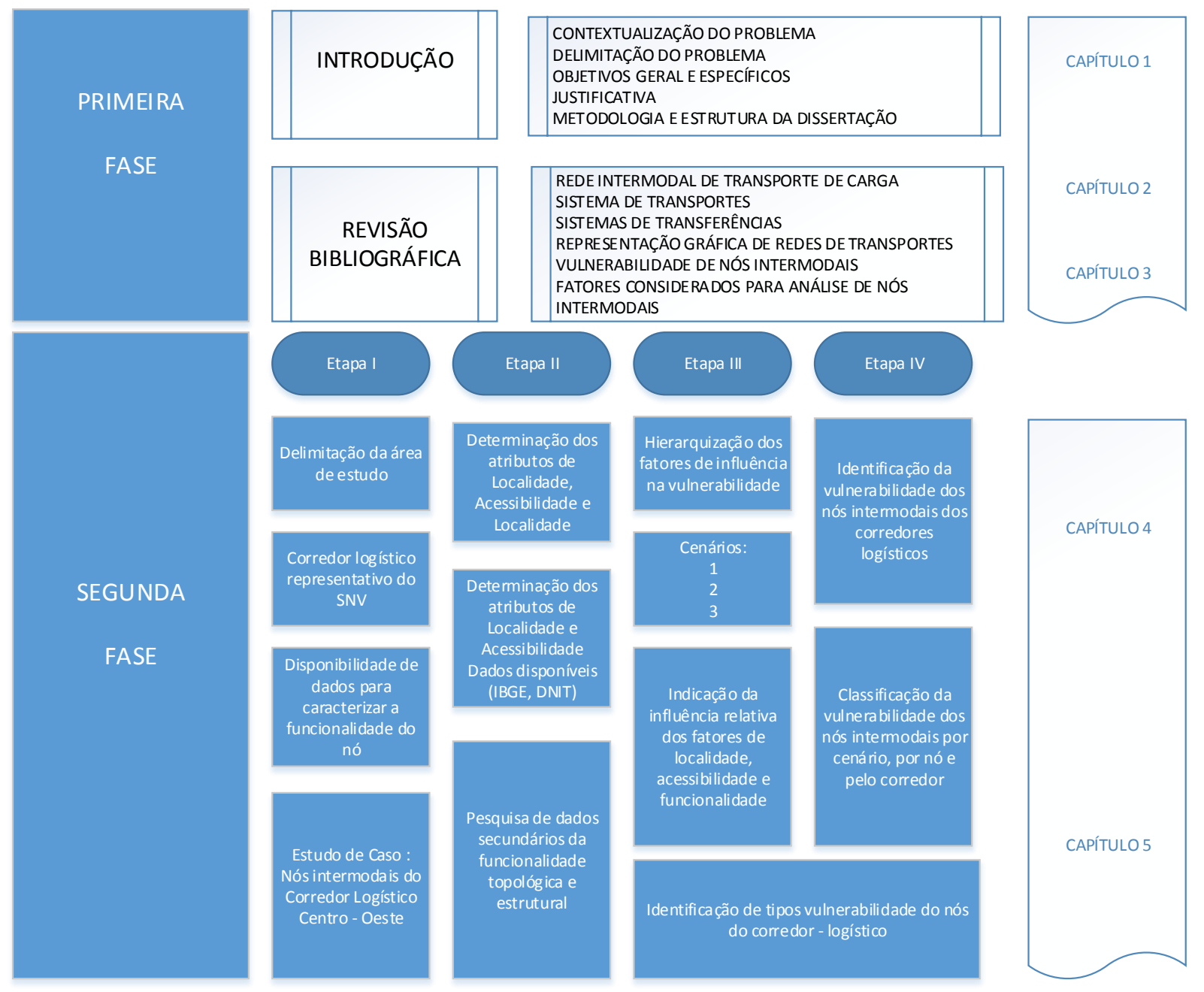
REDE INTERMODAL DE TRANSPORTE DE CARGA
SISTEMA DE TRANSPORTES
SISTEMAS DE TRANSFERÊNCIAS
REPRESENTAÇÃO GRÁFICA DE REDES DE TRANSPORTES
VULNERABILIDADE DE NÓS INTERMODAIS
FATORES CONSIDERADOS PARA ANÁLISE DE NÓS
INTERMODAIS

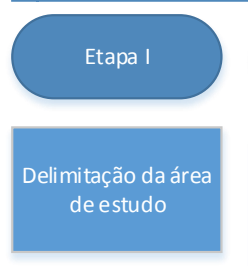

Etapa II
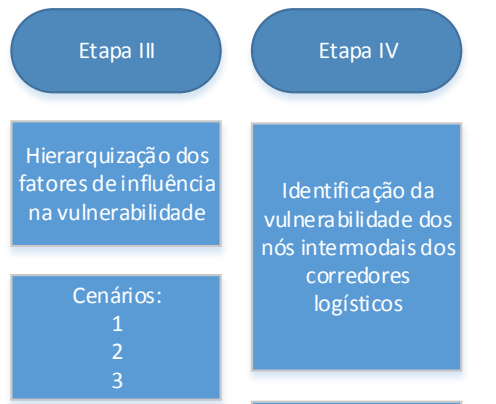

Corredor logístico representativo do SNV
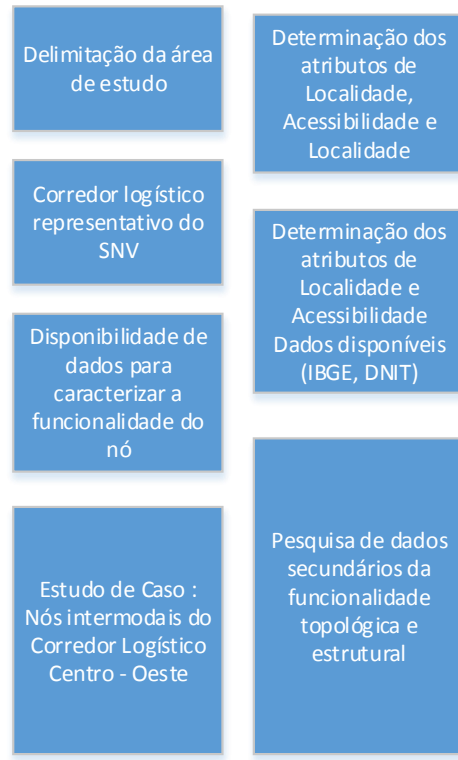

Determinação dos

atributos de

Localidade e

Acessibilidade

Dados disponiveis

(IBGE, DNIT)
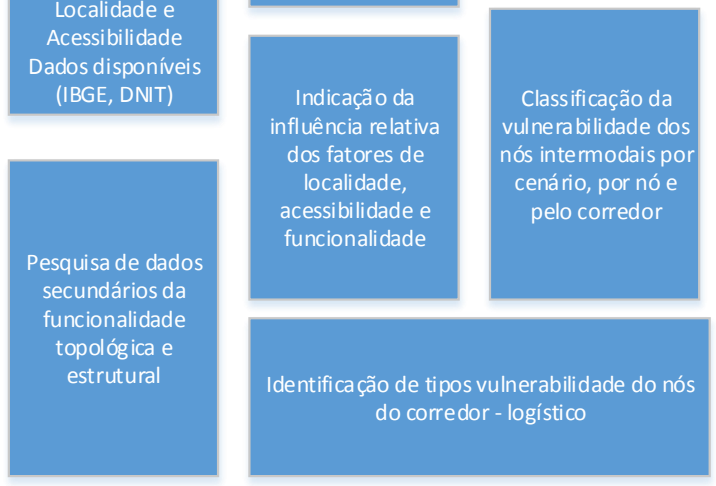

TERCEIRA

FASE

Referências

Bibliográficas
Análise dos resultados

Conclusões e recomendações
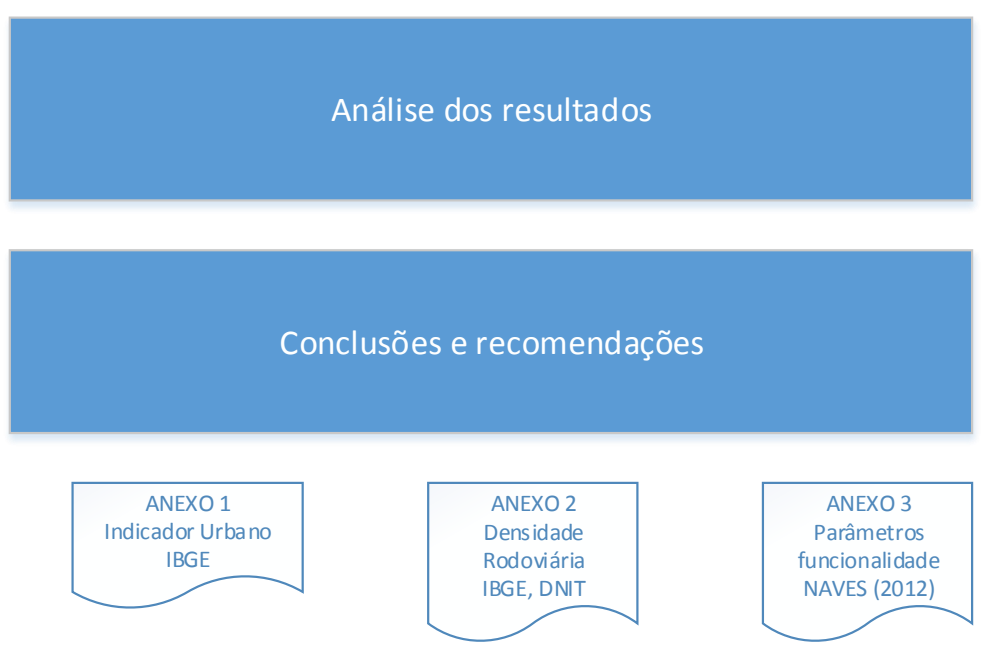

Referências

bibliográficas e ANEXOS

Figura 1-1 - Estrutura de Dissertação 


\section{REDE INTERMODAL DE TRANSPORTE DE CARGA}

\subsection{APRESENTAÇÃO}

O presente capítulo aborda a rede intermodal de transporte de carga para enfatizar as características intermodais da rede nacional de transportes e sistemas de transporte. Busca destacar o elemento de rede com a atribuição de possibilitar a operação de transbordo de carga entre os modais. Essa rede corresponde ao SNV que é um dos principais instrumentos da política nacional de transportes com amplas finalidades e objetivos preconizados pela política de transportes.

A representação gráfica de rede de transportes é abordada mediante teorias e modelos de representação gráfica de redes das principais medidas de configuração espacial utilizadas nas análises de redes de transportes. Esse embasamento é necessário para que a representação da rede nacional intermodal de transportes cumpra com os propósitos da análise da vulnerabilidade ao possibilitar a analise espacial dos dados representativos do nó intermodal. A seguir, são revistos conceitos e teorias de rede de transporte e sistemas de transportes.

\subsection{SISTEMA DE TRANSPORTES}

Conforme apresentado, no capítulo de introdução, os desafios da infraestrutura da rede de transportes compreendem o planejamento para realização desta infraestrutura e constituição de uma rede intermodal por meio da implantação e gestão dos subsistemas rodoviário, ferroviário, dutoviário e aquaviário (marítimo, fluvial, cabotagem) e aeroviário.

Em cada modal, têm-se uma rede de transportes própria e as combinações configuram uma rede intermodal. O SNV como a mais ampla rede de transportes, uma rede de transportes em grande escala, comporta vários sistemas de transportes e em diferentes modais. Os pontos de transbordo têm o destaque fundamental para intermodalidade dos transportes. Na terminologia da teoria dos grafos em redes de transportes esses pontos são chamados de nós. (Sudakov et al., 2007). Um conjunto desses pontos conforma uma rede de nós e configura uma estrutura espacial que suportam as ligações dadas pelos arcos e pela natureza dos fluxos. 
Tendo em vista que o presente trabalho refere-se à rede intermodal nacional, é importante destacar que foi a partir do Simpósio Internacional de Confiabilidade de Rede de Transportes, em sua terceira edição, (Third International Symposium on Transportation Network Reliability) realizado em Haia, em julho de 2007, que se deu início a uma abordagem sobre redes de transporte de grande escala, geralmente aplicada em redes do modal rodoviário, mas não exclusivamente, conforme relatado em Taylor (2012).

\subsubsection{Componentes funcionais}

Um sistema de transportes possui componentes físicos e componentes lógicos, conforme apresentado por (Galindo, 2009; Papacostas, 1987; Taaffe, et al., 1996; Manheim, 1980; Morlok, 1978). O componente físico representado pela infraestrutura física é composto dos trechos rodoviários, ferroviários, hidroviários, das instalações portuárias, contornos urbanos e outros elementos.

Para Rodrigue et al. (2006) os sistemas de transporte, quando bem desenvolvidos e eficientes, oferecem altos níveis de acessibilidade. Desta forma, aqueles sistemas de transportes menos desenvolvidos têm níveis mais baixos de acessibilidade. $\mathrm{O}$ sistema de transporte é considerado um elemento chave para geografia do transporte e da geografia em geral, pois configura a expressão direta da mobilidade, quer em termos de pessoas, mercadorias ou informação.

Um conceito geral utilizado por Morlok (1978) é de que o sistema de transportes é um agrupamento de elementos dos tipos arcos e nós e ligações. Deve atender a finalidade de deslocar determinado objeto de um ponto de origem para um ponto de destino.

Os elementos de um sistema de transportes são interdependentes, portanto interagem e influenciam o comportamento do todo e entre eles, portanto se observa o conceito de totalidade. Para Bertalanffy (1968) a totalidade do sistema é afetada pelo comportamento dos componentes, pois cada componente exerce influência nos demais, concomitantemente ao sistema como um todo.

A concepção de um sistema pode ser realizada através de basicamente três tipos de elementos. Para Bertalanffy (1968) um sistema para servir como o objeto de análise pode 
ser investigado, considerando-se o número de elementos conforme os tipos e de acordo com as relações observadas entre os elementos. Essas relações ocorrem entre os elementos e desses com o meio ambiente. Então dado o número e tipos de elementos e as relações entre os elementos e o meio ambiente o desafio é a realização de estudos e análises destas relações com alto grau de realismo.

Pode ser atribuída ao sistema de transporte a definição de uma instância da rede de transporte, dotada de finalidade técnico-operacional de transportar determinado objeto de um nó de origem a um nó de destino. Esses pontos são componentes desta rede ou sistema. A finalidade técnica-operacional é atribuída pelo planejamento de Transporte.

Manhein (1980) apresenta as categorias em componentes físicos e componentes institucionais lógicos. O componente físico é composto pela infraestrutura, equipamentos, instalações, já os componentes lógicos são as estruturas normativas, de gestão, políticoinstitucional, de produção, de informação, dentre outras. Portanto, para que exista o componente físico é imprescindível à configuração do componente lógico disposto através de instrumentos legislativos e normativos de todo o ciclo do planejamento do transporte.

No âmbito do componente lógico, é importante destacar o potencial dos sistemas de informação e comunicação que, com o avanço tecnológico das comunicações permite, um melhor desenvolvimento de soluções integradas, inclusive envolvendo redes sociais e redes colaborativas. Em Razzolini-Filho (2009) são apresentados conceitos sobre transportes e modais com suporte de Tecnologia da Informação - TI e Sistema de Informações - SI. Ele destaca sobre a necessidade de integração entre os diferentes modais. O suporte tecnológico é fundamental para que a integração entre os modais seja mais eficiente e também a integração entre os componentes funcionais lógicos e físicos. Os sistemas de transporte possuem um conjunto de componentes funcionais comuns, apesar da grande variedade de componentes em geral e de meios de transporte. Esses componentes funcionais podem ser classificados em: contêineres; veículos; vias; interseções; terminais e planos operacionais. Os veículos e contêineres se relacionam por meio dos arranjos espaciais das infraestruturas, instalações fixas e padrões de fluxos, conforme apresentado por (Morlok, 1978) que entende os contêineres de forma ampla para transporte de pessoas ou cargas. 
Entre os componentes principais e subsistemas dos sistemas de transportes, segundo Manhein (1980) são relacionados como principais: o sistema de carregamento (veículo, esteira, duto); sistema viário; instalação de transferência, sistema de manutenção e sistema de gerenciamento. Para Galindo (2009), os subsistemas podem ser comuns para mais de um componente ou sistemas, com destaque para o sistema de controle e direção e sistema de suporte à carga, que transmite o peso da carga e do próprio veículo para um meio de suporte.

O ciclo de um sistema de transporte envolve o planejamento, construção, implantação e operação. A rede física desta infraestrutura de transporte deve traduzir fisicamente o planejado pelas políticas públicas de transporte e que faça cumprir suas finalidades relacionadas aos benefícios com eficiência em relação aos custos de transporte. Portanto, a vulnerabilidade inerente aos sistemas intermodais de transportes produz reflexos e consequências no nível da eficiência da rede ou sistema de transportes que depende do funcionamento do conjunto e de cada componente individualmente. A Figura 2-1 apresenta os componentes principais de um sistema de transportes destacados por Morlok (1978).

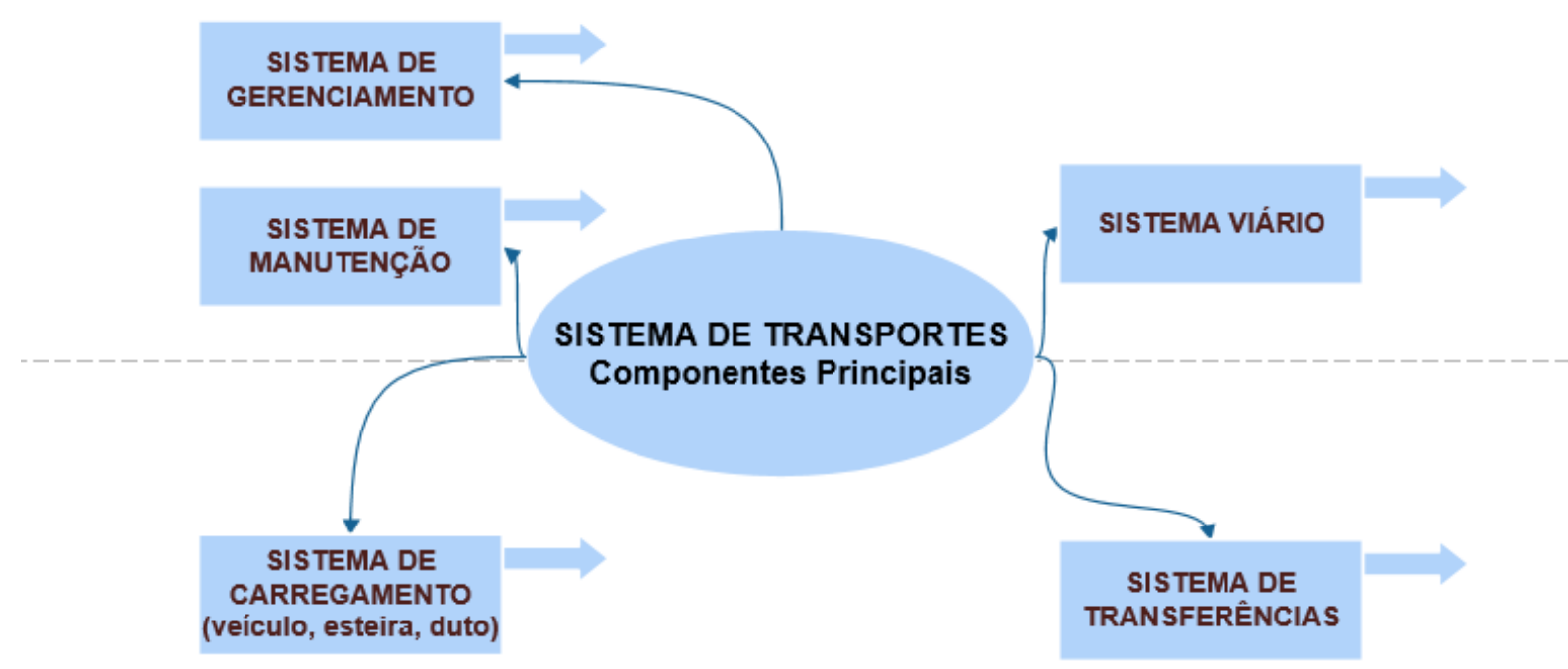

Figura 2-1 - Componentes de Sistema de Transportes.

Fonte: adaptado a partir de Morlok (1978) 


\subsubsection{Sistemas viários}

Os sistemas viários têm a função de suportar os fluxos que estão diretamente associados à sua capacidade. Numa definição ampla, fluxo é a quantidade de movimentos passados num ponto durante determinado tempo. A quantidade de movimentos está diretamente relacionada com a capacidade do sistema viário e pode ser representada pelo volume ou massa (peso) para quantificar o fluxo, que está sempre relacionado ao tempo e às características da carga em deslocamento, a qual pode ser de líquido, de sólido, de gás ou mesmo uma informação ou conceito.

Existem diversas naturezas de fluxos. Portanto, as características dos fluxos estão diretamente ligadas ao tipo de rede em análise. Fluxo em ciência de redes, em geral, é um conceito amplamente utilizado e aplicado em análises de variados tipos de rede, e pode inclusive assumir significados e valores diferentes, Silva, (1994). Nas redes elétricas e hidráulicas, como em um sistema dutoviário, por exemplo, os fluxos são contínuos ao longo dos arcos, bem diferente dos fluxos em sistemas rodoviários, onde têm um padrão em ondas. Portanto, a confiabilidade do fluxo é um atributo fundamental para os sistemas de transportes, Suchman (1990).

O transporte no Brasil, principalmente nos fluxos de cargas, é predominantemente rodoviário e a matriz de transportes brasileira é tida como desbalanceada. Segundo dados do Ministério dos Transportes em Brasil (2012), 58\% dessa matriz é a parte representada pelo modal rodoviário, $25 \%$ pelo ferroviário, $13 \%$ pelo modal aquaviário e $4 \%$ por outros. O transporte de carga pelo modal rodoviário está com um valor elevado quando comparado com o de países com as mesmas dimensões, como Rússia (8\%) e Estados Unidos (32\%).

A infraestrutura física implantada ou planejada que compõe o Sistema Nacional de Viação é composta de trechos rodoviários, ferroviários, hidroviários, aeroviários, incluindo também, os portos, aeroportos, terminais, acessos, entre outros componentes. A construção desta infraestrutura e sua alocação no território produz uma importante transformação sócia econômica regional. Desde a etapa de planejamento e projeto da rede de transportes até sua implantação e efetiva operação que podem ser observados diferentes impactos diretos e indiretos no meio ambiente, Brasil (2014). 
No que se refere ao planejamento da infraestrutura nacional de transportes o Plano Nacional de Viação e o Sistema Nacional de Viação, instituídos pela Lei n ${ }^{\circ}$ 5.917, de 10 de setembro de 1973 e Lei $\mathrm{n}^{\text {o }}$ 12.379, de 6 de janeiro de 2011 são os instrumentos que estabelecem os trechos das rodovias, ferrovias, hidrovias, os portos e os aeroportos de ligações regionais e nacionais. Brasil $(1973 ;$ 2011). São partes da base legal da rede nacional de transportes terrestre, aquaviária e aeroviária. O SNV configura um sistema intermodal de grande escala e o PNV estabelece os grandes eixos para o desenvolvimento e integração territorial.

\subsubsection{Sistema rodoviário}

O modal rodoviário caracteriza-se por sua simplicidade de funcionamento, principalmente se comparado aos outros meios de transporte. Indicado para curtas e médias distâncias e para transporte de cargas de maior valor agregado, tem como grandes vantagens a baixa necessidade de manuseio de carga - o carregamento pode ser realizado diretamente de um ponto a outro - e menor exigência no tipo de embalagem. As desvantagens estão relacionadas à baixa capacidade de carregamento e ao alto índice de roubo de cargas. $\mathrm{O}$ modal rodoviário caracteriza-se por baixos custos fixos, altos custos variáveis e maior flexibilidade segundo apresentado por CFA (2013) no Plano Brasil de Infraestrutura Logística.

A infraestrutura de transportes no Brasil, segundo dados do Departamento Nacional de Infraestrutura de Transportes - DNIT, a malha rodoviária conta com mais de 1,7 milhões de quilômetros, sendo que, cerca de 200 mil quilômetros são pavimentados, e em torno de 11 mil são de pistas duplicadas.

Segundo ANTT (2015), o Brasil tem cerca de 2.271.386 (dois milhões, duzentos e setenta e um mil e trezentos e oitenta e seis) veículos de transporte de carga, conforme os tipos, assim especificados por: utilitário leve de 0,5 a 1,49 toneladas; caminhonete/furgão, entre 1,5 a 3,49 ton.; caminhão leve entre 3,5 a 7,99 ton.; caminhão simples entre 8 a 29 ton., caminhão trator; caminhão trator especial; reboque; semirreboque e veículo operacional de apoio. 
Para a Associação Brasileira de Concessões Rodoviárias - ABCR (2015), que mede o índice do fluxo de veículos nas estradas concedidas à iniciativa privada a tendência da série de veículos pesados tem sido de queda. Em 2015, o índice registrou queda de 1,6\% no primeiro trimestre na comparação com o mesmo período do ano passado, e, em 12 meses, o fluxo de veículos pesados teve queda de 6,3\%. Na comparação de março contra fevereiro, considerando os dados dessazonalizados, o fluxo de veículos leves caiu 1,2\%, e o de veículos pesados registrou crescimento de 4,3\%, resultando num índice geral positivo de $1,7 \%$.

\subsubsection{Sistema ferroviário}

O modal ferroviário é recomendável para longas distâncias e grandes quantidades de carga. O baixo consumo de energia por unidade transportada e menores índices de furtos e acidentes em relação ao modal rodoviário, por exemplo, são as principais vantagens. As desvantagens estão na limitação de sua flexibilidade de trajeto e no percurso mais lento. Além disso, o elevado custo de investimento, manutenção e funcionamento de todo o sistema são outras desvantagens conforme destaca CFA (2013) no Plano Brasil de Infraestrutura Logística.

Silveira (2007) destaca vários aspectos positivos quanto à escolha dos modais ferroviário e hidroviário para o transporte de determinados tipos de cargas, como grãos, farelos, minérios, fertilizantes etc., com menor degradação ambiental em relação ao rodoviário, valor baixo do frete, não existência de congestionamentos, baixo índice de acidentes, menor perda de cargas e maior constância ao longo do trajeto e portanto eleva a competitividade das mercadorias nos mercados nacional e global. A partir da segunda metade dos anos de 1990, várias empresas optaram por utilizar a intermodalidade como meio de transporte de cargas no Brasil.

Quando se analisa a malha ferroviária, observa-se um decréscimo em relação à década de 1950, principalmente devido à falta de investimentos, por muitos anos, nesse modal. A malha que chegou a ultrapassar os 37.000 quilômetros nos anos 50, conta hoje com cerca de 30 mil quilômetros em operação, principalmente por meio de concessões ao setor privado de acordo com (Cunha-Filho, 2014), e apesar da redução da malha constatou-se 
um aumento de 56\% na carga transportada, com o minério de ferro e o carvão mineral representando $74 \%$ do total dos transportes.

\subsubsection{Sistema Dutoviário}

Modal dutoviário é o modo de transporte efetuado por tubos ou dutos, e tem como vantagens: maior segurança, dispensa de armazenamento, simplificação da carga e descarga, custo reduzido de transporte, menor índice de perdas e roubos. Desvantagens: maior possibilidade de ocasionar acidente ambiental, limitada capacidade de serviço e custos fixos elevados.

Os custos operacionais do modal dutoviário podem ser minimizados se temos facilidade em energia elétrica para bombeio e se usamos a gravidade para impulsionar o fluido nos dutos em trechos onde o terreno permite. Os oleodutos, gasodutos e polidutos são o meio mais seguro e econômico para transportar grandes volumes de petróleo, derivados e gás natural a grandes distâncias.

O modo dutoviário é indicado para o transporte de grandes volumes de fluidos, sobre a rede de trechos dutoviários, Drumond (et al., 2011) apresenta uma análise comparativa das dutovias no Brasil e nos Estados Unidos da América, a malha de trechos dutoviários no Brasil tem uma densidade de $0,6 \mathrm{mil} / / \mathrm{Km} 2$ com cerca de $5.300 \mathrm{Km}$. É de cerca de 25 vezes menor do que a estadunidense.

Os serviços de transportes das refinarias até as indústrias petroquímicas através da rede dutoviária tem grande vantagem por ser de modo continuo. No entanto, em relação ao tempo de trânsito o modal dutoviário é o mais confiável já que são praticamente nulas as interrupções que possam causar variações neste tempo, desde que o sistema de bombeio seja altamente confiável.

$\mathrm{Na}$ construção de dutovias, o trajeto deve ser estudado de modo a produzir o menor impacto ambiental possível. Observamos também que em geral os impactos ambientais para a construção de uma dutovia são menores que para a construção de uma rodovia com a mesma extensão. 


\subsubsection{Sistema aquaviário}

No modal aquaviário, o deslocamento de cargas e passageiros é realizado em superfícies aquáticas comumente, nos mares, rios e lagos, e também nos canais artificias, nas eclusas e noutros dispositivos para o deslocamento sobre água. Esse modo de transporte tem alta capacidade de carga, permite o deslocamento de centenas de milhares de toneladas. É, portanto, uma grande vantagem para grandes volumes de carga. $\mathrm{O}$ custo pode ser até três vezes menor que o ferroviário e oito vezes inferior ao rodoviário.

A maior desvantagem desse tipo de transporte é que ele ocorre de terminal a terminal exigindo a participação de outros modais, principalmente o rodoviário, o que pode tornar o deslocamento de produtos inviável a curtas distâncias. Portanto, é mais indicado para grandes volumes de carga e longas distâncias.

O transporte aquaviário pode ser classificado em marítimo, fluvial e/ou cabotagem ou mesmo uma combinação entre esses tipos de sistemas aquaviários. O Sistema Aquaviário brasileiro segundo Brasil (2011) é composto de: vias navegáveis; portos marítimos e fluviais; eclusas e outros dispositivos de transposição de nível; interligações aquaviárias de bacias hidrográficas; facilidades, instalações e estruturas destinadas à operação e à segurança da navegação aquaviária.

Segundo dados da ANTAQ (2013), o Brasil utilizava cerca de 13 mil quilômetros de vias navegáveis, sendo que existe um potencial disponível naturalmente de 29 mil quilômetros, podendo ainda, se realizadas obras de infraestrutura, aumentar esse número para 44 mil quilômetros. No Brasil observa-se uma discrepância com o potencial de oferta e o atualmente utilizado. O modal aquaviário tem como principal carga os granéis sólidos, representando $59 \%$ da carga transportada, sendo que o minério de ferro representa $37 \%$ deste valor.

No entanto, o modal aquaviário brasileiro enfrenta desafios. Para Pereira (2008), um cenário bastante diverso pode ser verificado nos sistemas de movimento fluviais realizados na região amazônica. De um lado, cursos de grandes rios são viabilizados como hidrovias pela técnica moderna (monitoramento por satélite, uso de GPS, etc.), tal como é o caso da 
hidrovia Madeira-Amazonas (projeto de Parceria Público-Privado) por onde é escoada parte significativa da soja produzida no Brasil central.

De outro lado, um transporte fluvial "não moderno", ou seja, que é realizado apenas em função dos interesses locais (o transporte de passageiros ou ainda da produção ou do consumo realizados no interior da própria região) é praticado com o uso de embarcações e portos extremamente precários.

Para que elementos estratégicos da modernização e avanço das redes de transporte no Brasil viabilizem a instalação e a extensão dos novos sistemas de engenharia no território, são necessários arranjos normativos, bases jurídicas e territoriais. Tem-se a Lei de Modernização dos Portos, de 1993, que permite a instalação de terminais privativos, operados por grandes corporações do agronegócio, que investem na infraestrutura de escoamento da produção.

\subsection{SISTEMAS DE TRANSFERÊNCIAS}

Em 2012, segundo dados do Plano Nacional de Logística e Transportes, Brasil (2012), a distribuição modal da matriz brasileira de transportes regionais de cargas (com e sem minério de ferro) é ainda mais desbalanceada. Ao se retirar o minério de ferro da matriz de transporte de carga, o modal rodoviário tem ainda mais destaque, chegando a $68 \%$ do transporte de carga, e as metas para a matriz de transportes brasileira para 2025 têm $30 \%$ de participação rodoviária, $35 \%$ ferroviária e $29 \%$ aquaviária de acordo com Plano Nacional de Logística e Transportes, revisado em 2011.

Contudo a matriz de transportes brasileira entrou na última década num período de mudança, com uma tendência de diminuição da participação do modal rodoviário. Isso vem se tornando realidade, devido aos investimentos feitos nos modais ferroviário e aquaviário. Como exemplo, por meio da política de modernização dos portos preconizada em Brasil (1993), foi possível a permissão de instalação de terminais privativos, operados por grandes corporações do agronegócio, que investem na infraestrutura de escoamento da produção com a operação de terminais fluviais nos municípios de Porto Velho, em Rondônia, Itacoatiara, no Amazonas e em Santarém no estado do Pará. 
Mesmo com essa meta de redução da participação do modal rodoviário, esse modal é importante e sempre será necessário, visto que o transporte adequado é um transporte multimodal, no qual os modais se complementam no espaço, para conseguir redução de custos e otimizar o transporte como um todo, conforme (Cunha-Filho, 2014).

A intermodalidade requer tanto a consolidação dos sistemas viários dos diferentes modais bem como a integração física e lógica desses sistemas, isso implica na ampliação, desenvolvimento e implantação de um sistema nacional intermodal. Para isso ser possível, é necessária a construção de terminais de integração entre os modais e atendimento das condições exigidas para cada situação. Ao acrescentar o modal aeroviário integrado aos três modais anteriormente citados, a infraestrutura logística de transporte será bem mais competitiva (CFA, 2013).

Os sistemas de transporte intermodal são utilizados para viabilizar o transporte e diminuir os custos. Em geral, utiliza-se o modal dutoviário para grandes volumes de granéis líquidos a grandes distâncias, com origem e destino entre tanques e instalações de transferências para os modais rodoviário e/ou ferroviário, o que depende das características da distribuição e dos clientes finais. O modal aquaviário é o mais indicado para exportação, principalmente quando se trata de distâncias transoceânicas e grandes volumes. Já o modal aéreo somente se justifica em casos de urgência, tal como em situações de guerra ou epidemias e para o transporte de volumes bem menores.

A integração pode ocorrer entre vários modais: aerorrodoviário, ferrorrodoviário, aquaferroviário, aquarrodoviário ou ainda mais de dois modais. É importante destacar as distintas propriedades em relação aos modos de transporte. A utilização de mais de um modal agrega vantagens a cada modal, o que se verifica no nível de serviço e custo. Combinados, permitem uma entrega porta a porta a um menor custo e um tempo relativamente menor, buscando equilíbrio entre preço e serviço.

O modal rodoviário usualmente não requer a formação de estoque por operar com a capacidade em volume relativamente baixa em comparação com o volume que os modais ferroviário e hidroviário que requerem altos volumes, e por consequência necessidade de 
formação de estoque. Tem-se também a comparação em relação ao número mínimo de transbordo. Enquanto o rodoviário pode ir de 'porta a porta' sem a necessidade de transbordo, no modo ferroviário é necessário pelo menos um transbordo e no aquaviário e dutoviário pelo menos dois transbordos, conforme visto em Pereira (2009).

O transporte de cargas representa uma significativa parcela dos custos até ao valor final das mercadorias. Esse fato repercute diretamente no aumento dos gastos dos indivíduos e famílias com a compra de produtos e, até mesmo, na queda do consumo dos bens, diante de dificuldades ou mesmo impossibilidade de acesso por parte população.

Os sistemas de transferências são pontos de conexão da logística e transporte e considerados elementos estruturantes dos sistemas de transportes de cargas apresentado em Brasil (2012). Eles exercem a função de pontos intermodais. No Plano Nacional de Logística de Transportes - PNLT, os pontos de conexões são definidos como elementos estruturantes da logística, como os armazéns de grãos, balanças de pesagem veicular, portos secos, indústrias esmagadoras de soja; e usinas. Os postos da Policia Rodoviária Federal, postos de pesquisa veicular e praças de pedágio também são definidos no PNLT como elementos estruturantes, bem como os sistemas viários rodoviários, ferroviário, dutoviário, hidroviário, aeroviário e multimodal.

Em relação à terminologia e considerando a escala de investigação, o ponto ou nó intermodal, pode ser chamado de plataforma logística. Rosa (2004) apresenta uma tipificação das plataformas logísticas levando em conta a categoria de serviços, que é basicamente composta por terminais de recebimento/despacho de mercadoria, de transbordo de carga e terminal intermodal no grupo de serviços de transporte. Ele classifica de I a IV o nível de serviço oferecido pelo terminal intermodal que, além de serviços transporte, oferecem outros serviços como movimentação, manutenção do terminal, serviços de gestão, acabamento de produção e serviços de informação.

O conceito de plataforma logística pode ser mais amplo, englobando o potencial de gerar negócios e soluções. Portanto, promove interações entre áreas como: política, economia e ambiente. Envolve uma diversidade de atores, tais como: embarcadores, operadores logísticos, autoridades públicas municipais, estaduais, nacionais, dentre outros. 


\subsubsection{Componentes do sistema de transferências}

Basicamente, um sistema de transferência é composto das áreas de embarque/desembarque, armazenagem/estoque e de suporte à carga e dos serviços para veículos e serviços de direção e controle. O dimensionamento das áreas está diretamente relacionado aos tipos de modais e sistemas viários e às características da transferência. Tipo de carga, volume, tempo e custo são fatores importantes para o funcionamento do sistema de transferência. A Figura 2-2 ilustra um nó de um sistema de transferência com a conjunção das áreas operacionais e de serviços e a representação de acessos de entrada e saída.

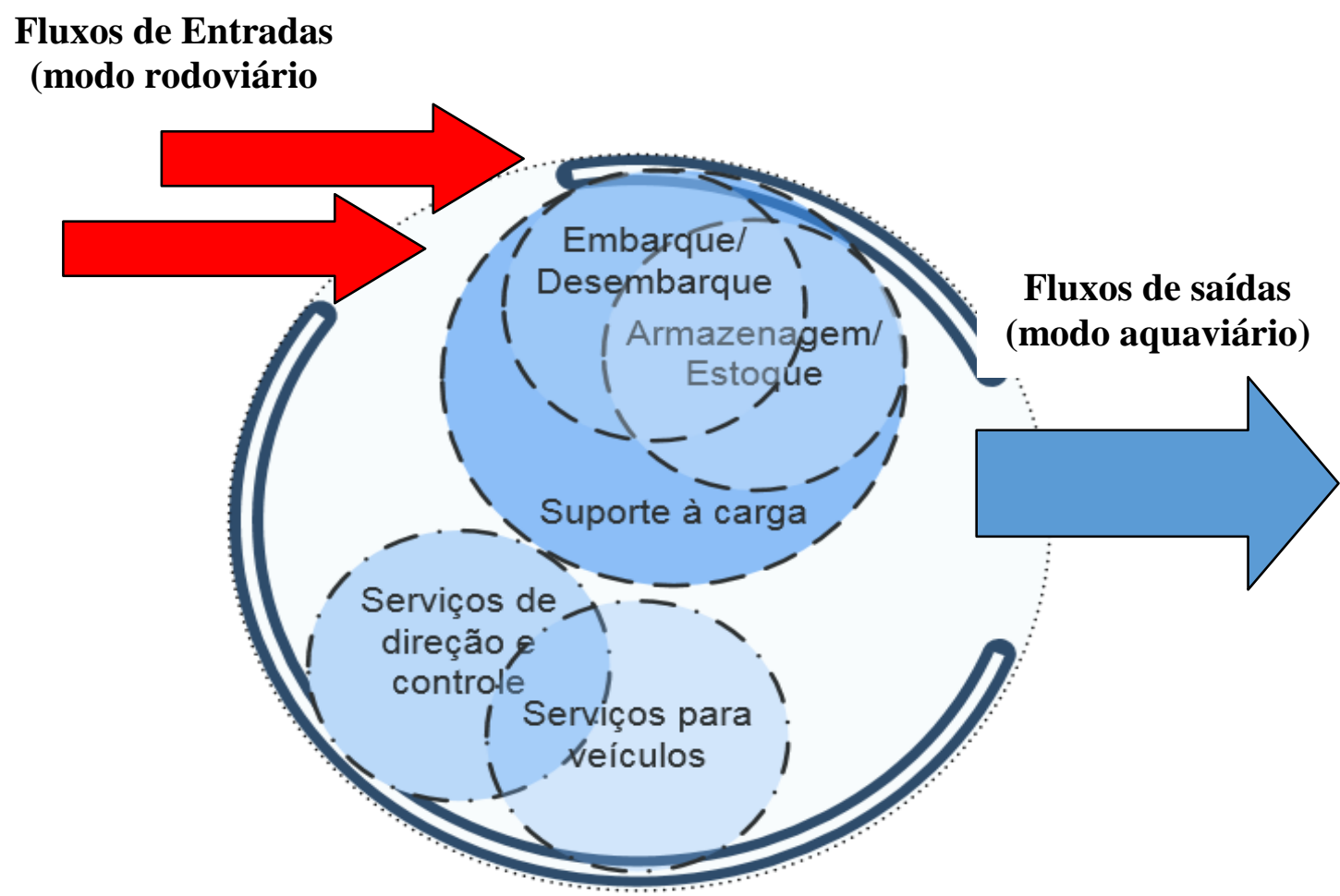

Figura 2-2 - Subsistemas do sistema de transferência/nó intermodal. Fonte: Elaborado pelo autor

Os fluxos de carga que passam pelo nó são objeto dos serviços disponibilizados e são características dos sistemas viários envolvidos naquela transferência. O tipo de carga é determinante no dimensionamento dos serviços do sistema de transferência. Os nós intermodais estabelecem as conexões da intermodalidade e requerem uma gestão compartilhada dos serviços comuns aos diversos gestores e operadores do sistema. 
Os principais serviços de um sistema de transferência modal podem ser agrupados em serviços de transportes e serviços de armazenagem. Os serviços de armazenagem correspondem aos serviços de consolidação e desconsolidação, fracionamento de cargas e controle de estoque. A Figura 2-3 ilustra o agrupamento dos serviços de armazenagem no sistema de transferência.

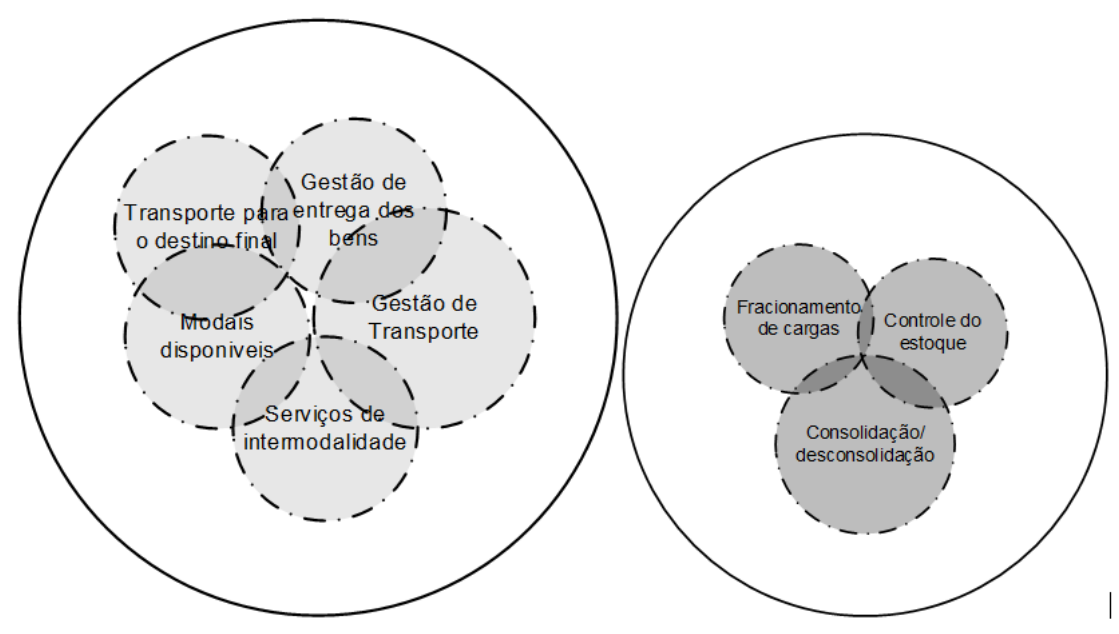

(a)

(b)

Figura 2-3 - Serviços de um sistema de transferência.

Fonte: elaborado pelo autor

Elementos essenciais de transbordo de cargas de um determinado subsistema para outro subsistema modal diferente, as instalações de transferências modais devem corresponder aos sistemas de embarque e desembarque, sistema de serviços para o veículo, sistema de estocagem e sistema de suporte ao passageiro ou carga um dos principais componentes dos sistemas de transportes. Desta forma a qualificação da acessibilidade pelo sujeito e pelo objeto de transporte é de suma importância para o entendimento da eficiência quanto sua manutenção ou projeção.

Morlok (1978) adota a representação clássica de sistema para representar um terminal de transporte. Para ele, o processo é estabelecido para receber determinado fluxo de entrada e expedir um fluxo de saída, conforme ilustra a Figura 2-4: 


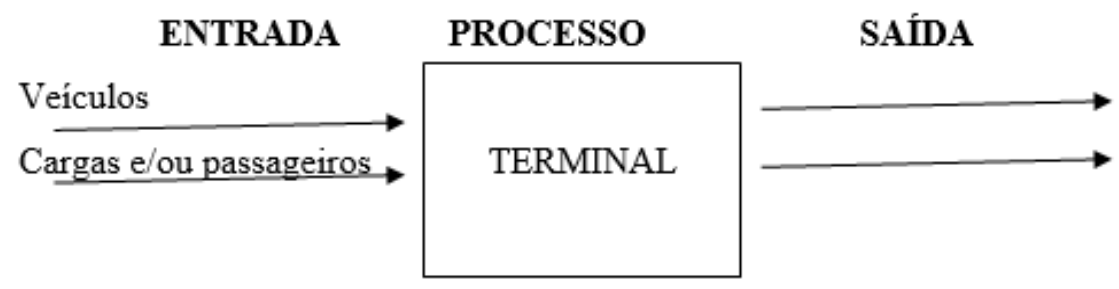

Figura 2-4 - Sistema de Transporte.

Fonte: Morlok (1978)

\subsubsection{Ambiente de interação entre os componentes dos sistemas de transporte}

As transferências modais são elementos do Plano Nacional de Logística de Transportes PNLT (Brasil, 2012), e correspondem a pontos de conexões e elementos estruturantes da logística. Desta forma, exercem grandes influências nas áreas onde estão localizadas. O termo transferências modais e nós intermodais são sinônimos neste trabalho. A utilização do termo nó intermodal é para enfatizar a terminologia usada em análise de redes de transportes.

Devido ao porte e/ou a importância econômica os pontos de transferências modais, têm uma forte interação e relacionamento com o contexto urbano regional e configura também um componente de máxima relevância econômica e social. Como exemplo podemos citar o porto de Santos ou mesmo um porto em uma hidrovia interior ou a plataforma logística em Anápolis, Goiás.

Taaffe (et al., 1996) utilizam o conceito de Hinterland para analisar a influência do nó intermodal através de indicadores demográfico e social. Por outro lado, Rodrigue (2006) busca analisar as deficiências de interação entre as diferentes redes de transportes, ou seja, a fricção e o atrito dessas transferências influenciam e comprometem a eficiência do transporte, como ilustrada na Figura 2-5. Desta maneira, a interação espacial afeta a eficiência e reflete nos custos totais. 


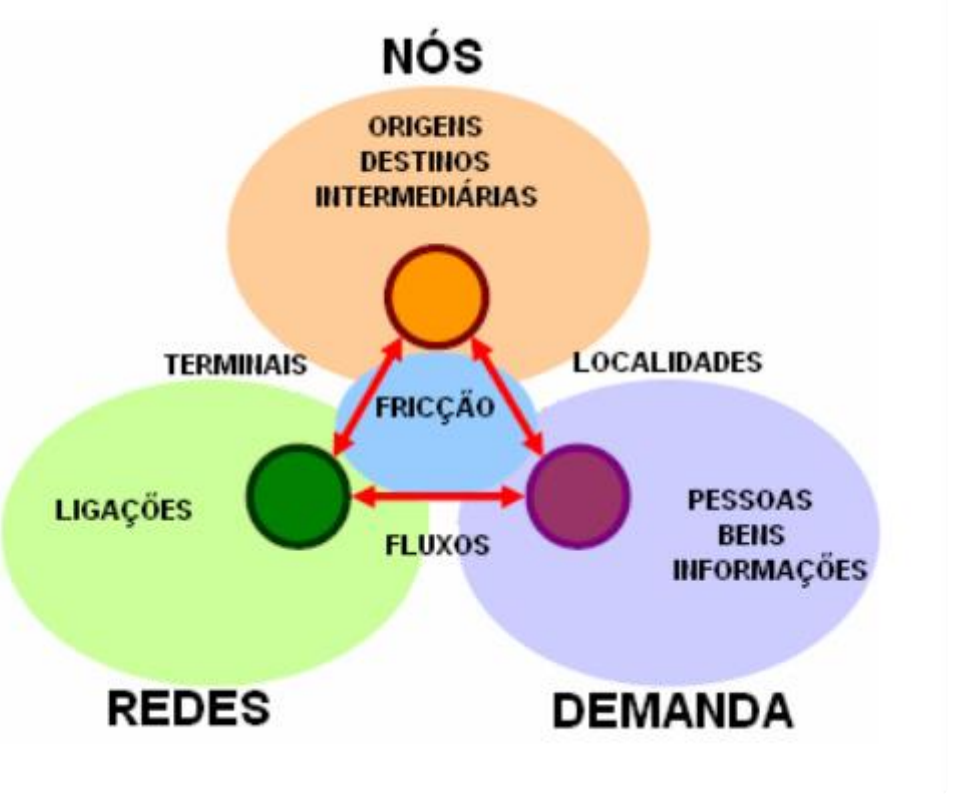

Figura 2-5 - Sistema de Transportes e atritos.

Fonte: Rodrigue (2006) - modificado

Para Rodrigue (2006), interação espacial é um movimento realizado de pessoas, mercadorias e informações entre uma origem e um destino, é a relação de demanda e oferta de transporte ocorrida ao longo de um espaço geográfico. As interações espaciais abrangem uma grande variedade de movimentos, tais como viagens para o trabalho, migrações, turismo, uso das instalações públicas, a transmissão de informações ou de capital, as áreas de atividade de varejo, comércio internacional e distribuição de mercadorias no mercado. A maneira como o espaço é organizado pelos locais concentradores de infraestrutura pelas atividades econômicas e as suas relações define a estrutura espacial dessas interações.

Como afeta diretamente a configuração territorial e econômica existem casos no Brasil em que um processo de revisão da poligonal que delimita a área do porto organizado geralmente requer a realização de um trabalho conjunto para debater a mudança e formação de consenso para definição de nova poligonal. Como exemplo, tem-se o caso do Porto de Paranaguá, cuja revisão de sua poligonal deve ser em conformidade com a nova Lei dos Portos. Portanto, a busca do consenso inclui a participação da comunidade afetada e de representantes do legislativo. De acordo com a nova legislação todas as novas áreas portuárias devem ser licitadas pela Secretária Especial dos Portos. 
Para Ferreira (2006), as redes de transportes devem ser observadas e analisadas num ambiente mais amplo, pois seus componentes interagem com entidades de naturezas diversas, as influenciam e também são fortemente influenciadas por elas. A esse ambiente, o citado autor denominou de Ambiente de Transporte.

No entanto, Almeida (2008) por considerar que tais entidades não dizem respeito apenas à entidade rede, mas sim a um conjunto maior de forças, adotou a denominação Ambiente de Interação ao ambiente que interage com a rede de transportes por meio das dimensões topológica, cinética e adaptativa, conforme ilustrado na Figura 2-6.

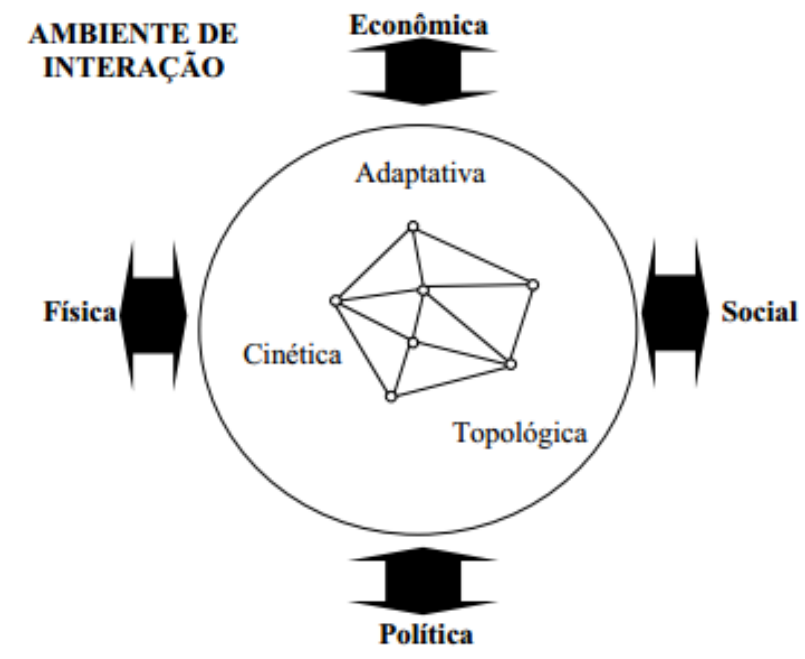

Figura 2-6 - Ambiente de interação e dimensões. Fonte: Almeida (2008)

Essa interação produz alterações de naturezas distintas: econômica, social, política e física. Tais alterações possuem características específicas que produzem efeitos no meio e na própria rede. Tais efeitos denominados efeitos da rede de transporte e podem ser considerados como efeitos diretos, econômicos e indiretos da rede de transportes.

Para Rodrigue (2006), redes de transportes dependem de um conjunto de atributos: locacional, topológicos, modal ou estrutural. $\mathrm{O}$ atributo locacional é composto pelo ajuste geográfico da rede de transporte representado pelo tamanho, forma, posição, orientação e o número de arcos e nós. O atributo topológico estrutural é constituído de aspectos estruturais da rede, como a dinâmica da rede e os padrões que podem existir, como a capacidade da rede de transporte. Para o atributo modal, identificam-se as características 
modais da rede com a representação da infraestrutura e o fluxo de veículos que circulam, podendo incluir na rede informações como tipo de tráfego, volume e sentido.

As informações e sistema de comunicações de gestão estão relacionados às propriedades socioeconômicas e à dimensão adaptativa a que se refere Almeida (2008) na dimensão da gestão, governança e controle - adaptativa e na socioeconômica. Desta forma a dimensão adaptativa conforma relações e influências no componente institucional lógico que deve orientar a implantação dos componentes físicos e as ações de operação dos sistemas de transporte.

A Tecnologia da Informação - TI se apresenta fundamental para ampliar a competitividade e apoiar no planejamento de transportes. A CFA (2013) propõe o termo modal infoviário como o modo de transporte que permite o tráfego de uma enorme quantidade de dados que facilitam os processos no transporte de cargas. De maneira que além de informações, é possível transportar pelas infovias uma série de mercadorias como jornais, livros, projetos gráficos, fotos, músicas, filmes, serviços de educação à distância e outros produtos de informação.

Para Nunes (2007) um fator importante que vem contribuindo com a gestão logística e de transporte é a evolução acelerada da tecnologia da informação, assim como a automação de sistemas concomitante aos avanços gerenciais de operação e de inovação tecnológica dos equipamentos de transferência e de manuseio.

Verifica-se, a partir desse período, um relativo aprimoramento da logística e das infraestruturas visando aumentar os fluxos materiais e a realização de várias funções de maneira qualificada, tais como: sistema de transporte integrado de cargas, operacionalização de terminais, armazenagem, transbordo, acompanhamento da carga ao longo do trecho via GPS (Sistema de Posicionamento Global), entre outras. Tudo com o intuito de diminuir custos e tempos de viagem, de transferência e de manipulação de carga.

A utilização de tecnologias ligadas à informação é um fator fundamental para a integração dos modais e atividades diversas, sendo muito difundidas nos Estados Unidos, Europa e Japão, mas ainda incipientes no Brasil, sendo um fator que conduz, dentre vários aspectos, 
ao desperdício e perda de parte das cargas transportadas. (Silveira, 2007). Essa incipiência é um fator bastante desfavorável, pois conduz ao desperdício e perda de parte das cargas transportadas.

$\mathrm{O}$ uso de sistemas e redes de informação conjugado às redes de transporte tem sido ampliado para controlar e monitorar os sistemas de transportes. O controle sobre as tarefas de deslocamento da carga e manobra dos veículos através de recursos de rastreamento por GPS ou rádio frequência fornece mais precisão nas operações de transporte e monitoramento de cargas.

Dentre outros elementos estratégicos da modernização e avanço das redes de transporte no Brasil, é preciso destacar os arranjos normativos, novidades jurídicas (e territoriais) que viabilizam a instalação e a extensão dos novos sistemas de engenharia no território. Grande parte das novas redes de infraestrutura (rodovias, ferrovias, hidrovias, etc.), tanto as que se encontram em implantação quanto as que constam dos planos plurianuais de investimentos da União e dos governos estaduais, está sendo realizada a partir de parcerias entre o capital público e o privado, ou seja, orientada por um planejamento muito mais comprometido em atender às demandas da produção estratégica o que pode divergir dos interesses da sociedade como um todo (Pereira, 2009).

Para Almeida (2008), as redes de transporte não são definidas somente pela existência de infraestrutura física, mas por uma visão mais ampla. Assume-se uma rede de transporte como uma estrutura física constituída por elementos de um sistema de transporte e por elementos abstratos como desejos, ações, relações existentes entre a infraestrutura de transporte e o meio onde se inserem, os componentes lógicos como os sistemas de informações. O grau do relacionamento entre os elementos definirá a intensidade das alterações geográficas que ocorrerão no meio e as transformações e dinâmicas territoriais e regionais.

O objetivo essencial do Plano Nacional de Viação é de permitir o estabelecimento da infraestrutura de um sistema viário integrado, assim como as bases para planos globais de transporte que atendam, pelo menor custo, às necessidades do País, sob o múltiplo aspecto econômico-social-político-militar. A redução destes custos torna a economia mais 
competitiva, o que leva a resultados socioeconômicos importantes para o desenvolvimento do país (Brasil, 1973). A Lei $n^{\circ}$ 10.233/1973 dispõe sobre a reestruturação dos transportes aquaviário e terrestre, com a instituição do Conselho Nacional de Integração das Políticas de Transporte - CONIT, com atribuição de propor políticas nacionais de integração dos diferentes modos de transporte.

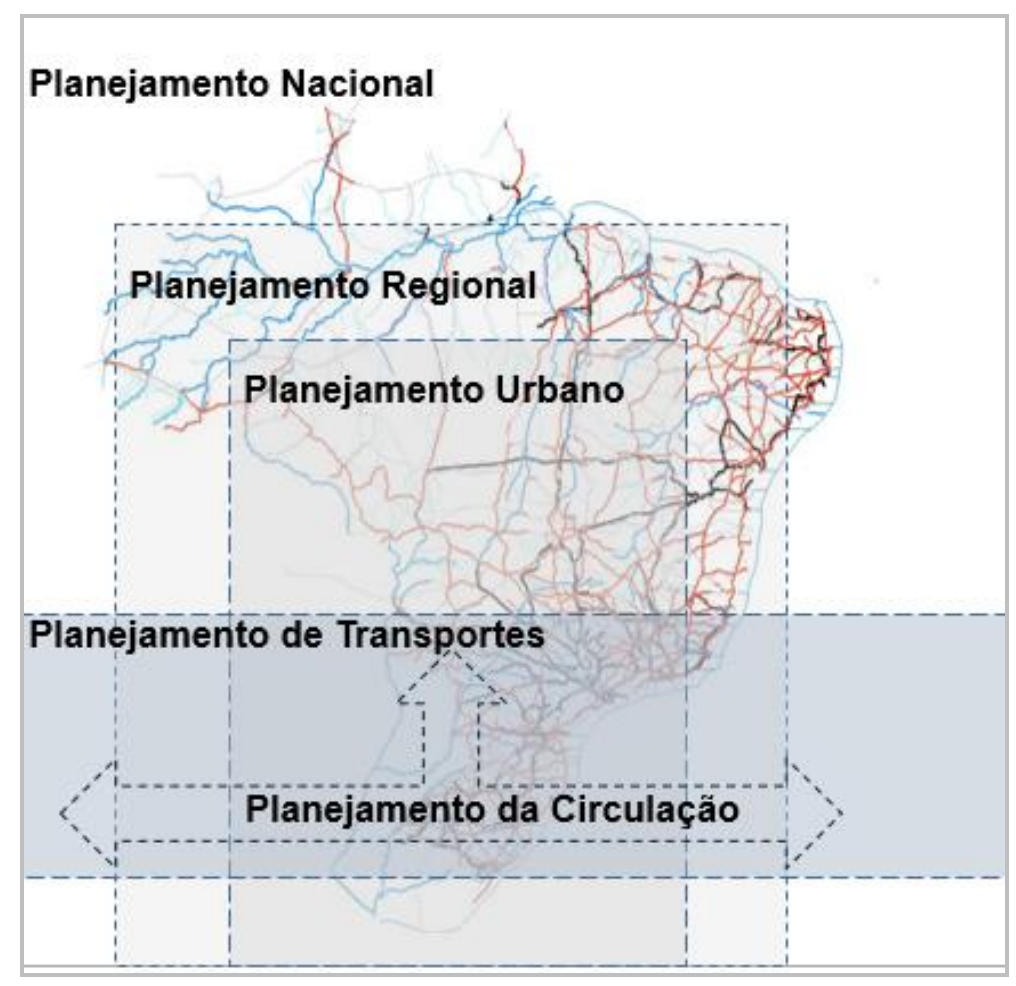

Figura 2-7 - Escalas do planejamento de transporte Fonte: Magalhães (2004), modificada

A Figura 2-7 ilustra essa abordagem de integração e transversalidade do planejamento de transportes com os demais planejamentos territoriais e com o planejamento de circulação desde a escala urbana, escala regional e nacional. O planejamento de transporte no que se refere à rede intermodal de grande escala exerce influência e implicações nos diversos níveis de planejamento, desde o planejamento nacional, no planejamento regional bem como no planejamento urbano e no planejamento da circulação. Portanto, requer a integração de políticas públicas nos diversos níveis e escalas de atuação.

Meta importante da política nacional de transportes é dar gradativamente maior equilíbrio à repartição modal de transportes considerando a necessidade de racionalizar o uso do modal rodoviário e a utilização de cada modal de acordo com sua principal vocação. (Brasil, 
2012). Para equilibrar a matriz tem-se a necessidade de reduzir em termos relativos a participação do modal rodoviário e ampliar a participação dos demais modais. Demonstrase, portanto que é visível a preocupação com desenvolvimento dos outros modais e de sistemas intermodais e multimodais.

Galindo (2009) destaca que, depois dos componentes da rede implantados, têm-se a necessidade de ações de manutenção permanente. Esta rede física de componentes implantados é um grande indutor das dinâmicas sociais. Mesmo depois de sua implantação esses impactos exercem grande importância nas dimensões social e econômica. Causam impactos na operação do sistema de transporte e nas interações entre as dimensões e mais ainda com a dimensão ambiental.

Contudo no contexto internacional a realidade referente aos transportes fluvial e intermodal é muito diferente da brasileira. Nos EUA foi promulgada uma lei, em 1991, chamada ISTEA, "Intermodal Surface Transportation Efficiency Act" (Lei da Eficiência do Transporte Intermodal de Superfície), para contemplar o setor de transportes com uma regulamentação mais atualizada e condizente com as recentes demandas e transformações da economia e da sociedade estadunidense e mundial, elucidando uma otimização do escoamento de cargas e pessoas (Silveira et al, 2007).

Bastante utilizado a expressão Custo Brasil se refere às deficiências existentes no sistema de transportes, como infraestruturas precárias e obsoletas, falta de investimentos e modernização, meios e vias de transportes ineficientes etc. A expressão alcunhada não é nova. No entanto, o Custo Brasil permanece no presente. Segundo o World Economic Forum WEF (2014), o Brasil está em 114. ${ }^{\circ}$ lugar entre 148 países no quesito infraestrutura. No quesito logística, perdeu 20 postos no ranking de $45^{\circ}$ para $65^{\circ}$ lugar, entre 160 países. Para Associação Brasileira do Agronegócio - ABAG (2015), a perda da competitividade da economia brasileira é um problema sistêmico e sua correção demandará um enorme esforço da parte do governo e do setor privado para recolocar o Brasil na rota do crescimento. As exportações de produtos manufaturados que é uma das áreas mais afetadas pelos altos custos e pelas ineficiências, como as observadas na infraestrutura e serviços de transportes. 
A baixa competitividade brasileira é fomentada por diversos fatores, tais como as deficiências no planejamento integrado, no desenvolvimento de projetos, no investimento de recursos em infraestrutura e na capacidade de execução. Essa baixa competitividade tem direta relação com o aumento dos custos, um círculo prejudicial ao desenvolvimento do país. As consequências são graves pois gera menos exportação e menos integração com os vizinhos sul-americanos e também integração regional e nacional e o baixo atendimento e nível de serviço dos serviços de transportes (CNT, 2014).

Algumas medidas adotadas são observadas para redução do Custo Brasil, como, por exemplo, a opção de algumas empresas na utilização maior da intermodalidade para transporte de cargas. Essa medida permite a redução do custo de transporte, o que eleva a competitividade dos produtos brasileiros, visto que a grande parte da produção agrícola, dos estados do centro- oeste, é transportada por longas extensões territoriais.

A relação entre custo e a disponibilidade de infraestrutura para sistemas de transportes pode ser exemplificada com a relação entre custos e a disponibilidade de elementos da infraestrutura física, conforme Naves (2012) apud Ballou (2001) demonstra por meio da curva de armazenagem composta da relação entre os custos e o número de armazéns no sistema de distribuição, o comportamento de tipos de custos relacionados com o número de armazéns no sistema de distribuição, o que destaca a relação infraestrutura versus custos. Numa rede intermodal o número de elementos e a tipologia são bastante relevante para análises relacionadas aos custos.

Conforme apresenta Silveira (2007), o atendimento dos fluxos de cargas, presentes e futuros, representa importante desafio para ampliar a competitividade e reduzir custos. A criação de novas alternativas e novas conexões intermodais devem estar estruturadas na cooperação e integração entre os diversos modais. A intermodalidade favorece o surgimento de novos centros de distribuição e armazenamento de cargas, criando nós de convergência de mercadorias no espaço geográfico.

O Ministério dos Transportes através da SPNT entende que um obstáculo para a implantação e operação de Centros de Integração Logística é fortemente influenciada pelos custos dessa implantação (Brasil, 2014). Dessa forma, em todo o ciclo de planejamento 
devem ser considerados critérios associados à localização do empreendimento, desde a escolha do terreno até a execução do projeto, pois para a instalação dos projetos previstos no território brasileiro requer-se a ocupação de grandes áreas.

Os empreendimentos de centro logísticos relacionados no portfólio do Ministério dos Transportes exigem altos investimentos e devem considerar os fatores relacionados à distância de centros urbanos, onde custos de aquisição de áreas são inferiores, bem como ao custo de construção das instalações e às adequações necessárias na infraestrutura existente disponível e nas novas infraestruturas planejadas.

O aprimoramento das infraestruturas e do sistema de transportes com destaque para intermodalidade significa dinamizar a economia local, regional e nacional, gerando resultados positivos a toda sociedade. A circulação no território deve ser fluida, evitandose ao máximo os obstáculos e empecilhos que prejudicam a intensificação dos fluxos materiais e imateriais e as interações espaciais (Corrêa, 1997).

Os serviços de transbordo precisam, portanto, estar dentro de padrões de eficiência e produtividade para que a intermodalidade garanta a competitividade da produção agrícola nacional. Além de garantir a racionalização do sistema logístico brasileiro, a eficiência dos terminais de transbordo pode levar à redução do fluxo de caminhões nas rodovias, carentes de infraestrutura (Teixeira, 2010).

A combinação do uso de caminhões para transportar produtos, de regiões mais deficientes em infraestrutura, até o local onde já exista o modal ferroviário ou hidroviário garante maior eficiência e menores custos. O modal rodoviário devido a sua maior capilaridade é complementar aos demais modais. Desta forma, ganha relevância o papel dos operadores dos terminais de transbordo multimodais e intermodais brasileiros.

Para CNT (2014), a eficiência das infraestruturas de transporte é determinada por seu funcionamento e disponibilidade nos locais, pelas condições da demanda e pela adequação aos propósitos de sua finalidade. Quando tais condições não se observam, as ineficiências resultantes acarretam em impactos negativos em toda a cadeia de transporte, quer para os operadores, quer para a população economicamente ativa ou para o ambiente. 
Para o Conselho Federal de Administração, através de seu Plano de Infraestrutura Logística em CFA (2013), é desejado que a intermodalidade fosse mais utilizada no Brasil, pois permite a mobilidade de produtos entre as regiões brasileiras, favorecendo tanto o mercado externo como o mercado interno e, portanto, amplia a competitividade do país.

\subsection{REPRESENTAÇÃO GRÁFICA DE REDES DE TRANSPORTES}

\subsubsection{Considerações sobre representação gráfica}

A utilização da Teoria dos Grafos é importante em análises de redes de transportes para representar os principais aspectos das propriedades estruturais e topológicas e identificar as conectividades e ligações inerentes aos componentes da rede.

Uma definição de rede de transportes pode ser expressa como um conjunto de arcos e nós. Componentes da rede de transportes, os arcos permitem a ligação entre os nós e representam a medida que deve ser percorrida que permite a realização de deslocamentos de objetos no espaço geográfico. Essa medida pode ser observada em relação à distância, tempo e custo. O objeto se desloca de um ponto de origem para um ponto de destino. Pelo deslocamento do objeto é possível extrair medidas como: a distância que o objeto percorreu e o tempo despendido no trajeto.

Os termos da teoria dos grafos usados no campo de transporte podem ser relacionados com objetos geográficos reais nos quais os nós e os arcos podem representar características específicas desses objetos. Como exemplo, os terminais podem ser representados por nós, assim como rodovias, hidrovias, ferrovias, por arcos, conforme visto em Almeida (2008). Atributos importantes com uso associado aos grafos comumente estão relacionados aos fluxos terrestres, aquaviários e aéreos.

Uma notação comum da teoria dos grafos pode ser expressa por $\mathrm{G}[\mathrm{N} ; \mathrm{A}]$ que pode ser entendido pelo um grupamento $(\mathrm{G})$ de um conjunto de nós $(\mathrm{N})$ que são conectados através dos $\operatorname{arcos}(\mathrm{A})$. Para uma rede intermodal tantos os arcos como os nós contêm atributos e propriedades específicas. 
Os arcos geralmente são associados a um modo de transporte e os nós são associados com o tipo de transferência modal que operam. Segundo Ferreira (2006), a orientação de um grafo determina um tipo de relação entre seus arcos, que é justamente a relação de acessibilidade. Os grafos, segundo a orientação de seus arcos, são classificados em diretos ou orientados; indiretos ou não orientados e mistos. Um grafo direto $\mathrm{G}$ [N; $\mathrm{A}]$ é definido como um grupo finito $\mathrm{N}$ de elementos não ordenados e um grupo $\mathrm{A}$ de pares ordenados de elementos de $\mathrm{N}$.

Para cada componente da rede, podem-se atribuir valores ou medidas de impedância que representam o comportamento dos fluxos, dependendo da análise a ser realizada. Tempo e custos são medidas usuais em análise de redes. Tudo depende da natureza da análise que se quer abordar no estudo de caso e sob a perspectiva de atribuição de valor aos fluxos a notação agrega o fator $\mathrm{W}$. Portanto, tem-se como notação geral comumente utilizada: $\mathrm{G}$ $[\mathrm{N}, \mathrm{A}, \mathrm{W}]$, onde $\mathrm{N}$ representa o conjunto de nós com o conjunto de arcos é representado por $\mathrm{A}, \mathrm{e} \mathrm{W}$ que indica pesos (weights).

Desde o seu surgimento até os dias atuais, as estruturas reticulares, ou redes, têm como função principal a distribuição e circulação de pessoas e objetos. Contudo, o objetivo principal do estudo de redes é compreender a lógica e a produção desses movimentos, bem como a sua distribuição e a extensão no espaço geográfico. Com este enfoque, há tempo que se estuda e analisa um grande número de redes atuantes no território como redes urbanas, de comércio, de transportes, etc. (Pereira, 2009).

Tanto o fenômeno de rede quanto a sua análise não é novo. Ambos aparecem na ciência geográfica com a preocupação de construir esquemas interpretativos que enfocam, sobretudo, a questão das distâncias e da articulação de agentes e pontos no território, com inspiração principalmente na questão da técnica conforme apresentou (Dias, 2005).

Para Taaffe et al. (1996), as ligações principais (linkages) devem ser destacadas e representadas como os corredores principais (trunkline). Os critérios basicamente são os grandes fluxos; a capacidade física e o nível de serviço. Esses mesmos critérios são válidos para os nós (nodes). A capacidade de armazenamento e a localização dos nós intermodais são atributos importantes. Dados de população, densidade demográficas, frota de veículos 
entre outros, são utilizados em investigações das relações entre os componentes físicos do sistema de transportes e componentes das dimensões social, política, econômica, (Almeida, 2008; Rodrigue (2006). Através da identificação desses atributos uma rede de transporte de grande escala é mais bem representada.

Os nós são importantes pontos de origem e destino no espaço e os arcos são as ligações físicas entre esses pontos ou nós. De maneira que identificar a importância destes pontos remete a sua localização e às características do espaço regional, aos aspectos socioeconômicos e ambientais e também à própria intencionalidade dos transportes.

Na Figura 2-8, Morlok (1978) apresenta tipos de redes de transportes: (a) Rede em grade (grid network); (b) Rede radial (Radial network); (c) Rede anel-radial (Ringo-radial network); (d) Rede em árvore ou espinha (Spin network); (e) Rede hexagonal (Hexagonal network), (f) Rede delta ou triangular (Delta network).

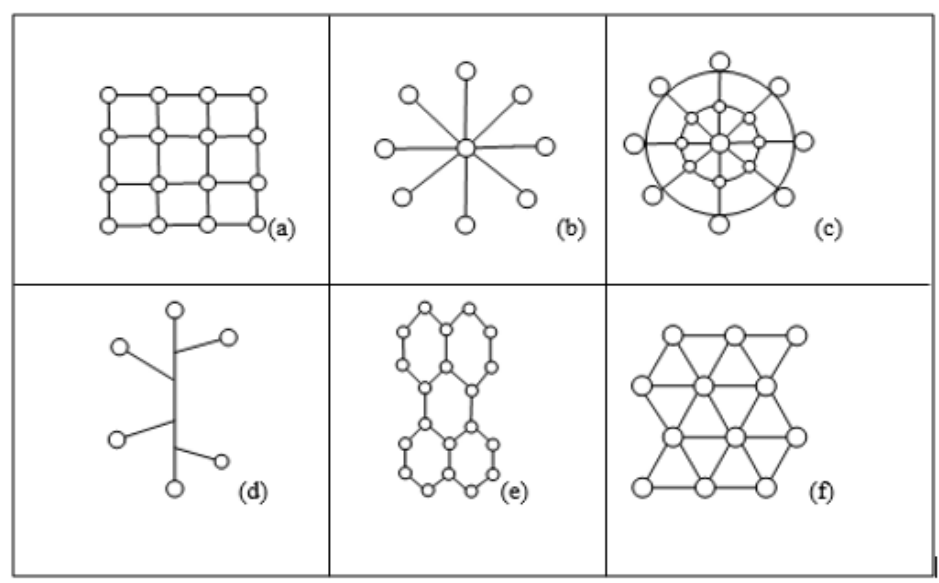

Figura 2-8 - Tipos de rede de transportes. Fonte: Morlok (1978)

A representação da infraestrutura de redes de Transporte pode ser feita através da ligação entre seus componentes de origem e destino. Tanto as ligações, para o fluxo e transporte de cargas, quanto os componentes nodais podem ser físicos e lógicos dependendo da análise de rede de transportes que se quer aplicar. A Figura 2-9 demonstra exemplo de representação gráfica de redes de transportes de modais distintos. 


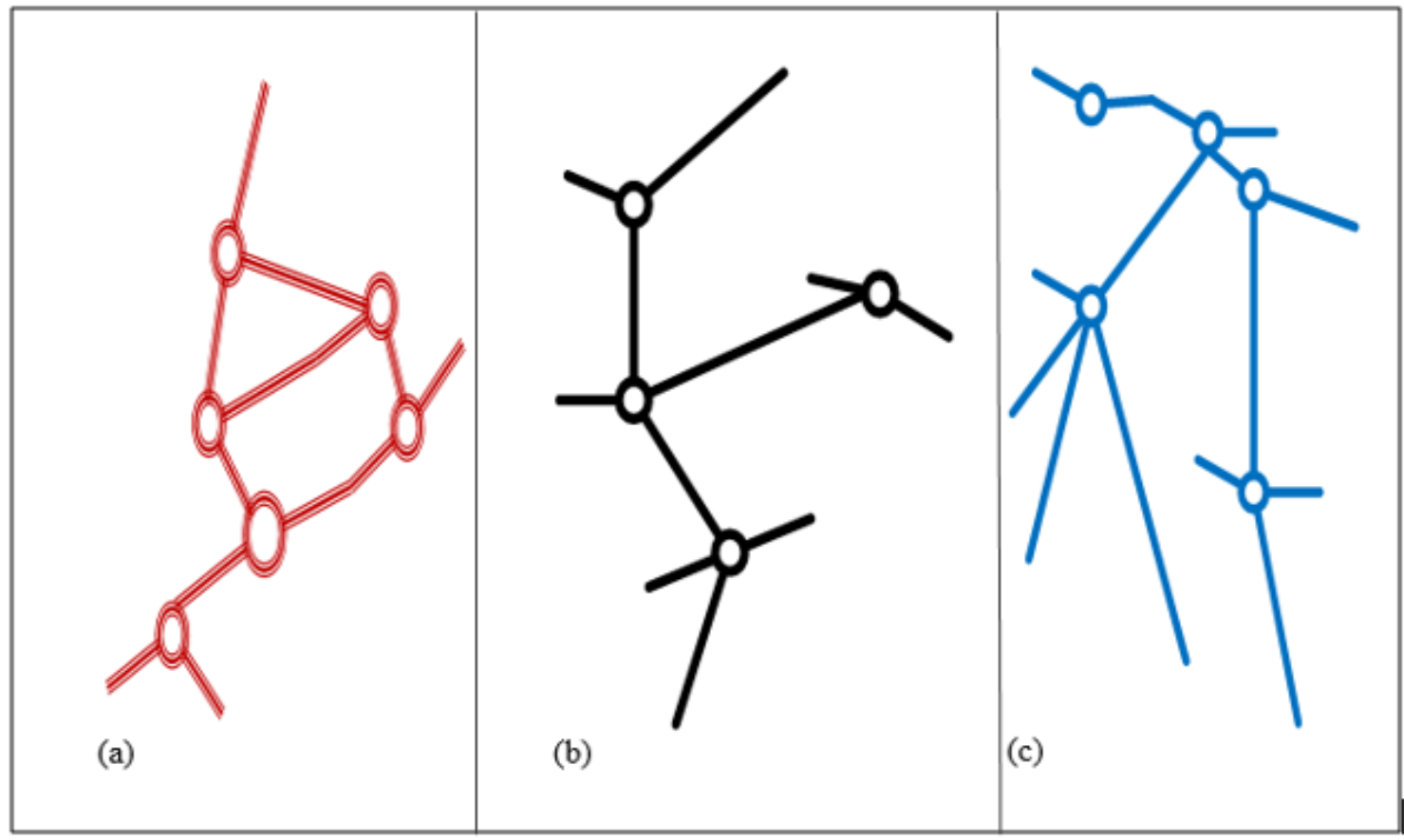

Figura 2-9 - Representação gráfica de redes de diferentes modais.

Fonte: elaborado pelo autor

Como exemplo da Figura 2-9 - Representação gráfica de redes de diferentes modais e cores, vermelho, preto e azul representam redes distintas no modo de transporte, (a) rodoviário, (b) ferroviário e (c) aquaviário, respectivamente.

Portanto, a representação grafica de redes de transportes intermodal requer destacar as caracteristicas dos sistemas de transportes que utilizam a infraestrutura física da rede. Essa representação deve distinguir os diferentes modos de transportes e os elementos de conexão entre os modos.

\subsubsection{Representação gráfica de transferências modais - Nós Intermodais}

É comum observar que em um mapa logístico de uma rede intermodal de grande escala os nós são representados pelas cidades. Um nó é conectado a outros através de pelo menos um arco. Um nó pode ser acessado por mais de um arco. As transferências modais, portanto, podem ser representadas graficamente. Este exemplo de representação envolve o modal aquaviário e os sistemas marítimos, hidroviário ou fluvial e o de cabotagem. Pela natureza da superfície aquática, a localização do nó requer propriedades inerentes ao nível d'água, regime das marés, nível do mar, entre outros fatores. 
Estudos mostram que os portos podem ser classificados tendo em vista diferentes aspectos conforme demonstrou Ferreira (2012), e, no âmbito da geografia dos transportes, Rodrigue et. al. (2006) destacam que um importante critério de classificação é dado pela sua localização e que influi também no custo total do transporte.

Em relação ao meio aquaviário, as vias de transportes na superfície aquática é um dos mais antigos meios de transportes. O termo aquaviário é mais genérico tratando-se pois de sistemas de transporte marítimo, hidroviário (fluvial) e cabotagem, todos com suas particularidades e dimensões. Pela dimensão territorial e extensão litorânea do Brasil é importante o aproveitamento do potencial do sistema de cabotagem.

A Figura 2-10 apresenta modos de representação de transferências modais diferenciando os sistemas viários: a) representação do nó por tipo de sistema viário; b) ponto intermodal com modos de transportes distintos e c) Representação de nó aquaviário para os sistemas marítimo; hidroviário ou fluvial e cabotagem.

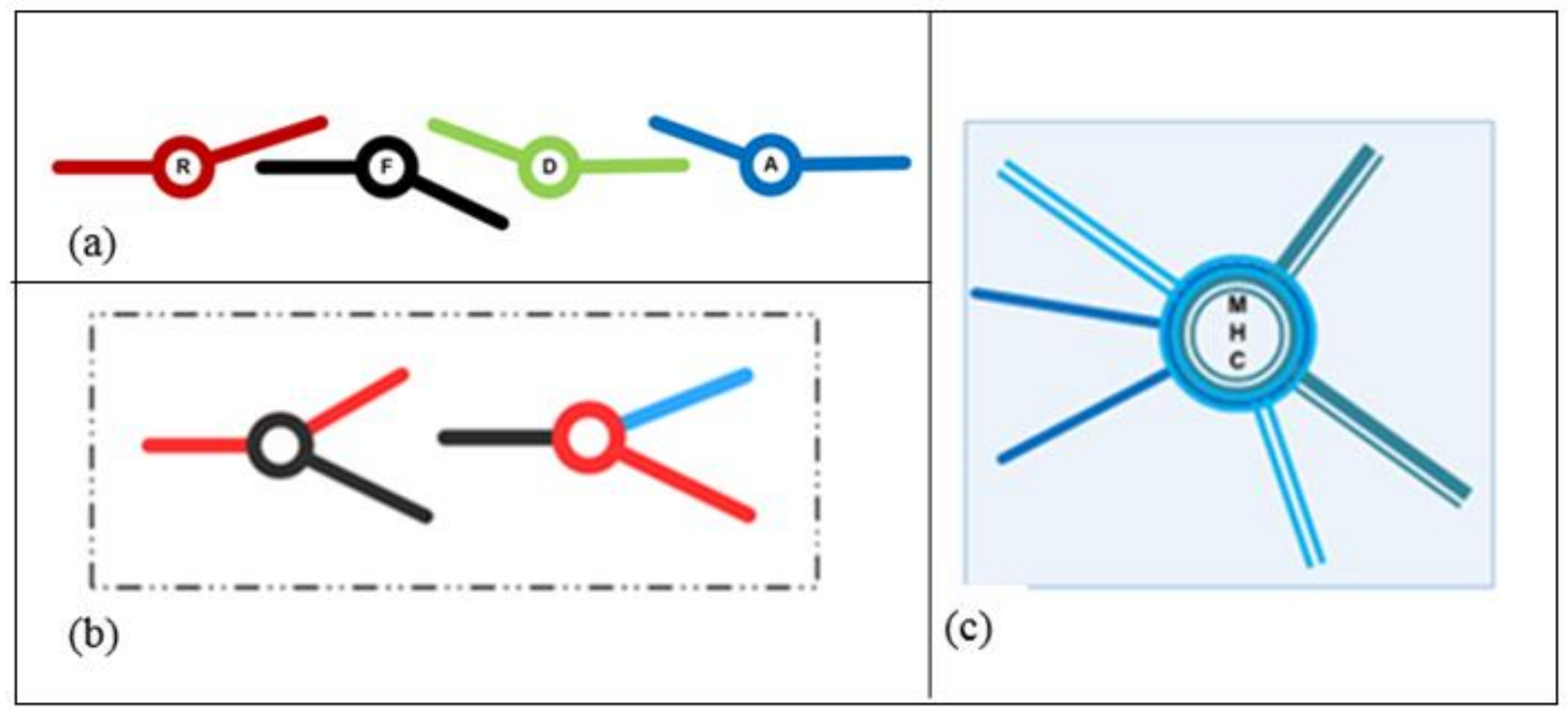

Figura 2-10 - Exemplos de representação de nós intermodais. Fonte: elaborado pelo autor.

A representação gráfica da intermodalidade busca facilitar o entendimento e classificação dos nós intermodais. Componente de diferentes sistemas de transportes, desde sistema duto-aquaviário, ilustrado por Figura 2-11 (a) e rodoferroviário ilustrado por Figura 2-11 
(b). Portanto representa nesse exemplo uma integração entre os sistemas dutoviário e aquaviário e o exemplo entre os sistemas rodoviário e ferroviário.

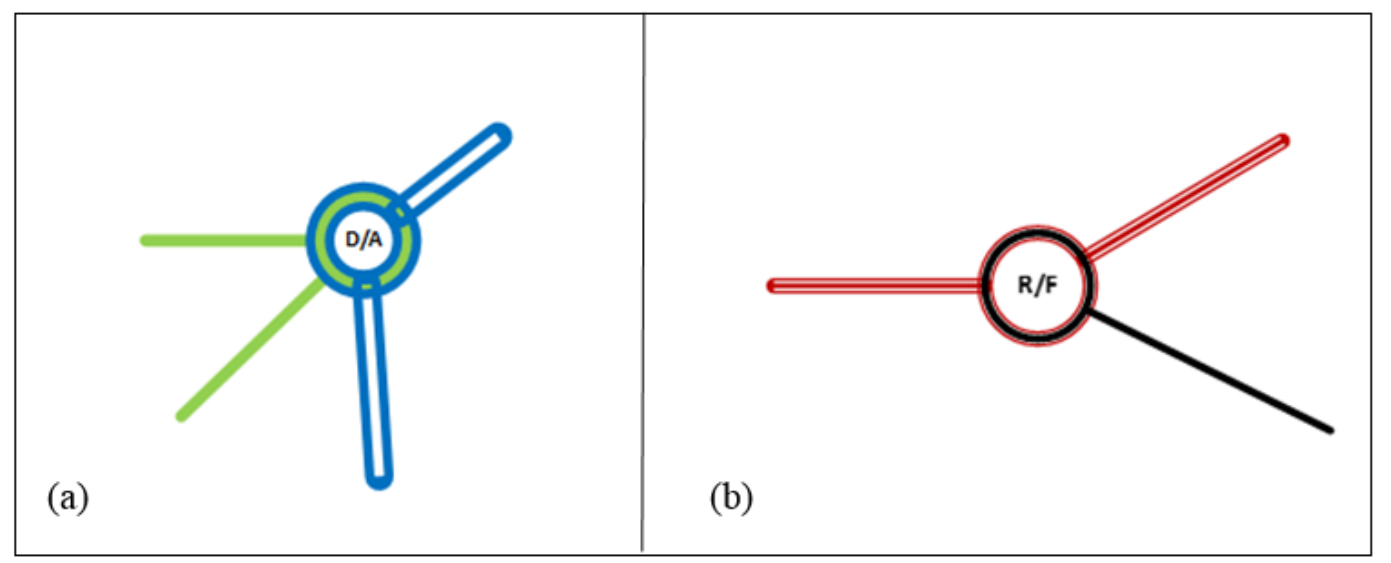

Figura 2-11 - Tipo de Nó Intermodal.

Fonte: Elaborado pelo autor

O Quadro 2-1 ilustra os exemplos de nó intermodal de grau 2, ou seja bimodal que indica o tipo conforme o sentido do fluxo, ou seja, o sentido da transferência da carga. Desta forma são seis os tipos de nó intermodal quando se utilizam os modos rodoviário, ferroviário e aquaviário do SNV.

Quadro 2-1- Tipo de intermodalidade do nós

\begin{tabular}{|l|l|}
\hline & Aquarrodoviário \\
\hline & Fodoaquaviário \\
\hline
\end{tabular}

Fonte: elaborado pelo autor 
O Quadro 2-2 ilustra a exemplificação em etapas de observação de um nó intermodal em distintas situações. As etapas e situações são ilustradas nas subfiguras que buscam representar o comportamento de fluxos de carga e nós intermodais.

Quadro 2-2 - Exemplos de representação de nós intermodais e vulnerabilidade

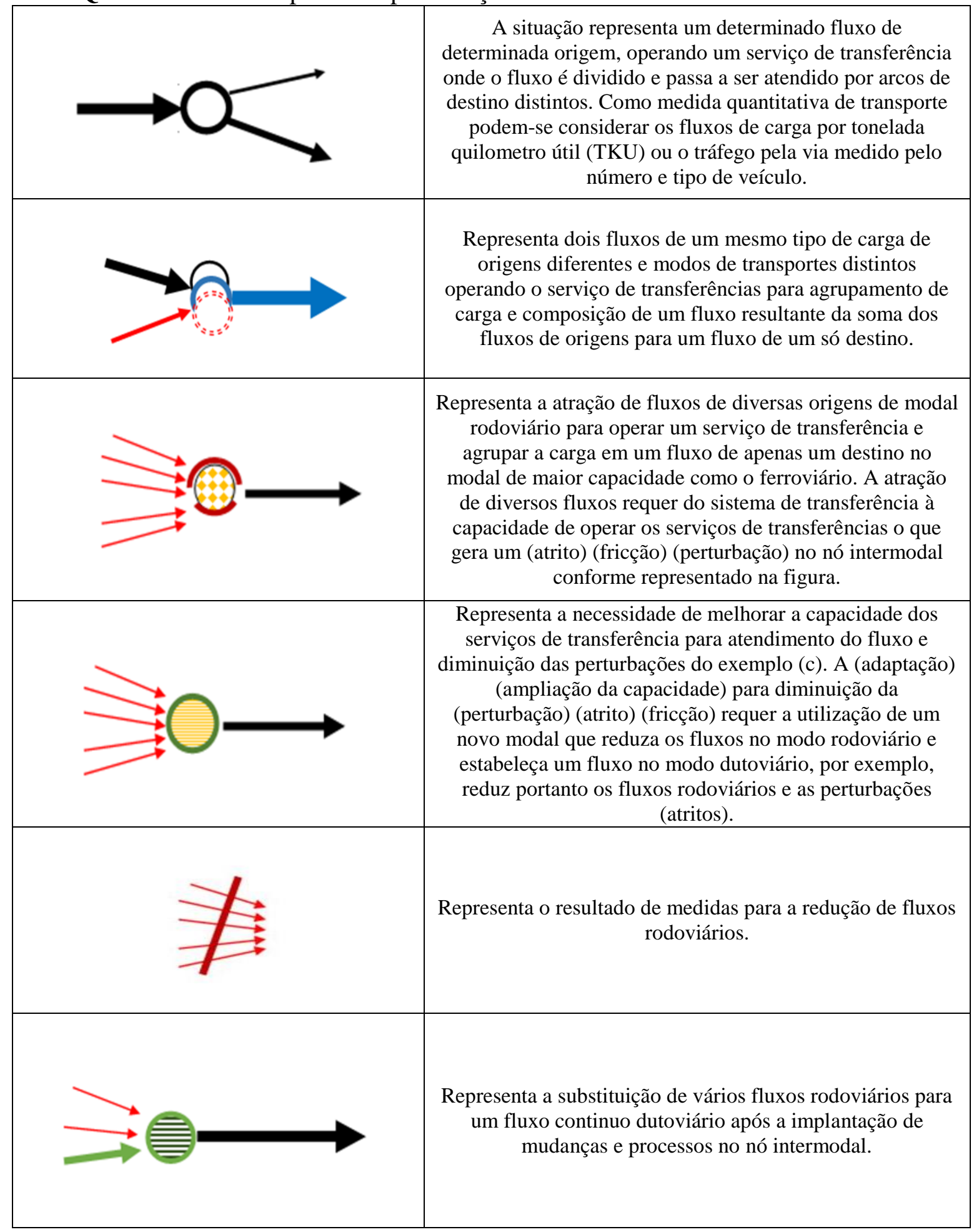

Fonte: elaborado pelo autor 


\subsection{TÓPICOS CONCLUSIVOS}

A configuração espacial dos sistemas intermodais de transportes, atuais e futuros, pode ser considerada como fundamental para o estabelecimento e manutenção dos fluxos de modo a aprimorar o transporte e alcançar custos mais competitivos. $O$ ganho com a competitividade revertido para os objetivos preconizados em Brasil (1973, 2011, 2013).

A intermodalidade é uma importante característica do SNV, devido às dimensões territoriais brasileiras. O que é importante é analisar a distribuição espacial dos elementos da rede física e a densidade da rede de transportes, tanto dos trechos que configuram os arcos quanto os pontos de transferência da carga de um modo para outro, que configuram os nós intermodais.

A função de um nó tem direta relação com os fluxos. A representação gráfica pode ser utilizada para indicar os modos de transportes, a direção do fluxo de carga, que geralmente é unidirecional quando se trata de commodities agrícolas. Os nós de origem e destinos também são representados para facilitar a análise.

O termo link é utilizado para os arcos e nós da rede de transportes. É importante destacar a característica intermodal da rede viária tratada neste trabalho. Então se convenciona chamar as transferências modais, os sistemas de transferências e transbordos entre diferentes modais, de nós intermodais. 


\section{VULNERABILIDADE E NÓS INTERMODAIS DE TRANSPORTE DE CARGA}

\subsection{APRESENTAÇÃO}

Neste capítulo, discorre-se sobre os relacionamentos entre vulnerabilidade e nós intermodais. Para isso são utilizados os conceitos e teorias sobre vulnerabilidade e rede de transportes, sistemas de transportes e transferências modais.

A vulnerabilidade é abordada através de conceitos correlatos relacionados aos fatores de localidade, acessibilidade e funcionalidade. Esses fatores são úteis para relacionar componentes do sistema de transportes como a rede, representada pela infraestrutura física implantada e os fluxos, representados pela carga. A observação desses relacionamentos entre ambiente e rede e ambiente e fluxo permite que sejam indicados critérios para analisar os nós intermodais. Para isso são investigados fatores que influenciam a vulnerabilidade do nó intermodal como sua localização e acessibilidade. A funcionalidade do nó também é investigada para a verificação de intervalos de valores para terminais de transportes de grãos.

\subsection{CONCEITUAÇÃO DA VULNERABILIDADE}

Os estudos sobre vulnerabilidade de rede de transporte têm importante base teórica nas contribuições de (Taylor e D’Este, 2003) e (Berdica, 2002), que entendem que vulnerabilidade pode ser definida como uma susceptibilidade ou sensibilidade a incidentes com prejuízos significativos.

Para determinação de links críticos de uma rede viária Oliveira (et. al., 2013) consideram que a vulnerabilidade é o atributo de desempenho relacionado ao impacto de eventos aleatórios, capazes de comprometer a capacidade de um link ou grupo de links, não recorrentes ou de baixa recorrência em uma rede viária. Entende-se que, quanto mais vulnerável for determinado elemento tanto menos confiável vai ser o funcionamento deste elemento. Quanto mais estratégico e importante um elemento for para as funções da rede 
mais confiável este deve ser, pois quanto menos vulnerável for o elemento mais confiável será operar através dele.

É importante, contudo, refletir sobre as colocações de Suchman (1990), para o qual qualquer medida específica de confiabilidade dependerá da natureza da função em análise e dos níveis de desempenho determinados. Um exemplo é a calibração do tempo de transporte que tem forte relação com o volume de carga e com o consumo de energia para o deslocamento da carga e do próprio veículo. Pode-se entender que a confiabilidade da rede de transportes está focada em confiabilidade da conectividade da ligação relacionada com o tempo, tanto para o tempo de terminal quanto para a capacidade de fluxo medida em volume por tempo.

Neste sentido, a confiabilidade pode ser vista como o grau de estabilidade de serviço que um sistema oferece. Para Berdica (2002), a confiabilidade representa a facilidade de manutenção adequada, sob as condições de operação encontradas durante um determinado período de tempo.

Segundo Husdal (2004), a confiabilidade e vulnerabilidade são considerados dois conceitos diferentes. $\mathrm{O}$ autor argumenta que diminuindo a vulnerabilidade da rede de transportes pode ser diferente de melhorar a confiabilidade da rede de transporte e que não existe nenhuma relação linear ou recíproca, entre os dois conceitos. A depender do nível da vulnerabilidade do sistema de transporte podem ocorrer perturbações que impactam na elevação de custos.

Para Erath (2011), o termo vulnerabilidade é usado para descrever a queda de acessibilidade para comunidades e regiões. A queda de acessibilidade tem como causa uma falha em um determinado arco. Esse autor entende que a vulnerabilidade é a consequência dessa falha que prejudicou a capacidade do arco. Essa consequência pode ser estimada através da atributação, ou seja, dar valor associados aos atributos dos elementos da rede com a verificação da hierarquia e criticidade dos elementos, com intuito de estimar as consequências e prejuízos da falha. 
Para Berdica (2002), a vulnerabilidade do sistema de transporte rodoviário, é considerado um problema de redução da acessibilidade, que ocorre por várias razões. Não sob o enfoque apenas do ponto de vista da segurança. A ênfase é colocada sobre a função do sistema como um todo, ao invés apenas da própria rede física. Existem frequentes razões para descontinuidades na rede viária que são realmente causadas por falhas físicas. Portanto, a vulnerabilidade refere-se à manutenção do nível de serviço.

Desta forma, a vulnerabilidade de rede de transportes tem relação com o nível de redundância das conexões. Essa redundância possibilita situações alternativas para reestabelecer conexões, após uma interrupção ou falha. A existência de redundância amplia a confiabilidade.

Pricinote (2008) identifica a vulnerabilidade nas interações entre o ambiente e a rede e o ambiente e o fluxo. Sendo a acessibilidade um atributo do ambiente, as áreas (zonas) de interações onde se pode observar a vulnerabilidade são áreas de sobreposição entre o ambiente e o fluxo e entre o ambiente e a rede.

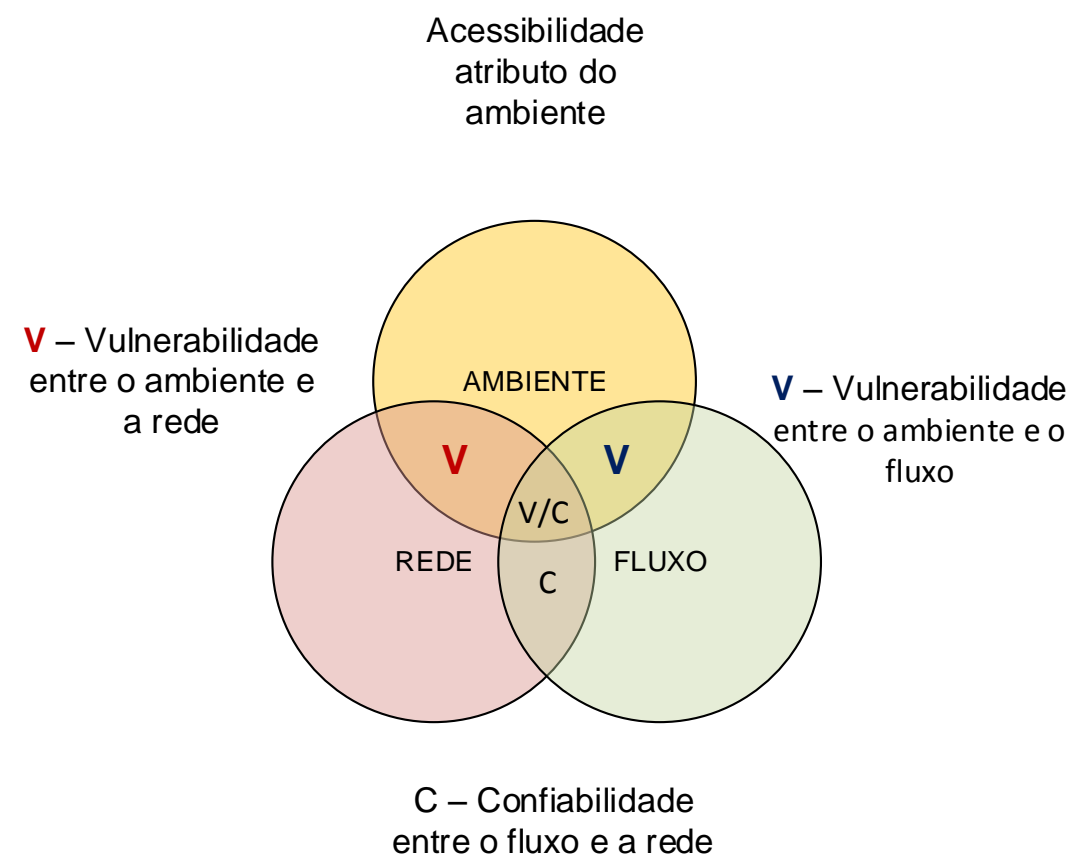

Figura 3-1 -Interações da vulnerabilidade entre ambiente-rede e ambiente-fluxo.

Fonte: Pricinote (2008), modificado. 
As interações da rede e do fluxo com o ambiente estão associadas à vulnerabilidade. É importante considerar que os nós intermodais fazem parte fisicamente da rede e provocam influências no ambiente e vice - versa, onde o ambiente exerce influência sobre os nós.

Em abordagem direcionada a cenários específicos e seus impactos, a vulnerabilidade não deve ser tratada a partir de uma perspectiva quantitativa, mas a partir de uma perspectiva qualitativa. Portanto, para análise da vulnerabilidade de nós intermodais é importante investigar as medidas qualitativas adequadas de análise e apoiar-se nas questões de Husdal (2004) sobre onde se observa a vulnerabilidade, o que se observa com vulnerabilidade e como se observa a vulnerabilidade, ou seja, quais os parâmetros que serão observados e a obtenção dos dados.

\subsection{VULNERABILIDADE E NÓS INTERMODAIS DE TRANSPORTE DE CARGA}

Como consequências das interações ambiente-rede e ambiente-fluxo para observação da vulnerabilidade em nós intermodais, as falhas na rede, sejam total ou parcialmente, se devem a eventos naturais ou elas são provocadas pelo homem. Mas tais falhas são de grande significado e não apenas em termos de impactos de transporte direto, pois a coesão social e desenvolvimento econômico também podem ser afetados. As falhas podem variar como ocorre em desastres naturais, como terremotos, e podem produzir consequências em efeito cascata, como na ocorrência de inundações e incêndios, colapso de ponte e bloqueios de tuneis, etc. Esses efeitos podem persistir por longos períodos de tempo com grandes impactos sociais e econômicos.

Conforme exposto em Taylor (2012), para uma análise efetiva tem-se a necessidade de obtenção de alto grau de realismo, em razão da complexidade da realidade e das interações diretas e indiretas. Portanto, a identificação de interações entre ambiente, rede e fluxo contribui para uma melhor compreensão, diagnóstico da realidade desses componentes no funcionamento da rede de transporte e mais especificamente no nó intermodal.

Almeida (2008) adotou a denominação Ambiente de Interação ao ambiente que interage com a rede de transportes por meio das dimensões topológica, cinética e adaptativa. Esse 
modelo observa que as interações produzem alterações de naturezas distintas: econômica, social, política e física. Tais alterações possuem características específicas que produzem efeitos no meio ambiente e na rede de transportes. Tais alterações possuem características específicas que produzem efeitos no meio ambiente e na rede de transportes. Consideramse os efeitos da rede de transportes como efeitos diretos, indiretos e econômicos.

Galindo (2009) e Vuchic (1981) afirmam, entre outros fatores, que os pontos de transbordo e cruzamento de rotas têm o papel mais importante na localização das cidades. Esse fator se refere aos pontos de transferência de carga de um modo de transporte para outro (a exemplo de portos). Ele promove, portanto, uma área de serviços e comércio em conjunto com serviços de estocagem e armazenagens, em confluências de rotas comerciais.

No ponto onde ocorre o encontro dos modos de transporte, estão localizados os terminais de transbordo e os terminais intermodais. Esses componentes do sistema logístico às vezes se apresentam como um atrativo para um determinado corredor logístico, oferecendo serviços ou armazenando a carga. Nessa escolha entre rotas, a competição entre os modais é destacada e a satisfação do cliente com os serviços logísticos prestados nos pontos de transbordo podem ser decisivos (Naves, 2012).

Exemplos podem ilustrar esse contexto de uma situação vulnerável e geradora de impactos diretos e indiretos. Contudo, o conceito de vulnerabilidade está associado com fatores que exercem relação de impactos com a rede de transportes. Destacam-se dois exemplos que relacionam vulnerabilidade e nós intermodais que ilustram interações, seus impactos e consequências, como é o caso do Porto de Santos e do terminal intermodal de Pederneiras. São casos onde esta abordagem se aplica, pois implicam questões amplas como a gestão das águas e seus usos múltiplos, sazonalidades de safra, mudanças climáticas, elevação do nível do mar e capacidade de armazenagem, acidentes industriais, etc.

\section{Exemplo 1 - Porto Intermodal de Pederneiras e a crise hídrica de 2014}

As operações da Hidrovia Tietê- Paraná e dos portos intermodais no escoamento de cargas, interligam diversos espaços, fomentam a produção e facilitam a distribuição das mercadorias aos centros de demanda. O Porto Intermodal de Pederneiras, por sua vez, está inserido no sistema hidroviário Tietê-Paraná e, através da intermodalidade, soja, farelo de 
soja, sorgo e milho são transportados até o Porto de Santos, representando novas alternativas para a reestruturação da matriz de transportes no Brasil (Silveira et al, 2007). Ele representa uma importante rota de escoamento da produção de grãos dos estados de Goiás, Minas Gerais, Mato Grosso do Sul, São Paulo e Paraná.

A crise hídrica provocada pela seca acarretou a interdição das atividades de transporte de carga, na hidrovia Tietê-Paraná. Alguns de seus trechos com navegação interrompida ocasionam elevados prejuízos na safra 2013/2014, pois as empresas precisam intensificar o uso do transporte rodoviário para escoar a safra. Essa opção de modo de transporte é mais cara e, em 2014, onerou em cerca de R \$ 37 milhões o transporte dos produtos. A estiagem prolongada, o nível do rio cada vez mais baixo e a necessidade do aumento da geração de energia nas usinas hidrelétricas de Ilha Solteira e Três Irmãos em detrimento da navegação são as principais causas da paralisação do Porto Intermodal de Pederneiras, na região centro-oeste do estado de São Paulo. O calado, que para navegação é a parte do casco que fica dentro da água, em alguns trechos da hidrovia, passou a ser de no máximo um metro.

O fluxo hidroviário foi suspenso em alguns trechos do trajeto de 2,4 mil quilômetros, como entre o km 128 do reservatório de Três Irmãos e a eclusa inferior de Nova Avanhandava, em Buritama (SP). Como consequência, atingiu-se diretamente a navegação de grandes embarcações ao longo do trecho paulista da hidrovia. O trecho paulista da hidrovia TietêParaná tem 800 quilômetros e 30 terminais de carga funcionam ao longo do rio.

A hidrovia chega a transportar por ano mais de seis milhões de toneladas de cargas e com o transporte prejudicado, muitas empresas que atuam no porto estão tomando medidas drásticas. Uma delas, além de paralisar as atividades, demitiu cerca de 500 funcionários. Atingiu-se também a funcionalidade do Terminal Intermodal nos serviços de transferência dos fluxos de carga do sistema hidroviário para o sistema ferroviário. Esses fluxos de carga têm como destino final o Porto de Santos. Verifica-se que para manutenção dos fluxos até o destino final é imposta uma sobrecarrega ao sistema rodoviário e aumentam os custos de transportes, diminuindo a competitividade brasileira.

Essa situação afeta diretamente a credibilidade do transporte hidroviário como uma alternativa viável e muitos produtores e empresas, ao fazerem o planejamento da safra 
colocarão a hidrovia como uma incerteza. Essa paralização foi o suficiente para fazer o volume médio anual de cargas transportadas, especialmente soja, farelo e milho cair de 2,5 milhões de toneladas para 500 mil toneladas, conforme ABAG (2015). Com isso, o custo médio para transportar grãos de São Simão a Santos via rodovia é da ordem de R \$ 101,00 a tonelada e por hidrovia transbordando para a ferrovia em Pederneiras é de $\mathrm{R} \$ 86,00$ por tonelada, ou seja, a diferença é de $\mathrm{R} \$ 15,00$ por tonelada.

Constata-se que a capacidade do sistema hidroviário foi reduzida. Embarcações que antes navegavam com seis mil toneladas de produtos, agora, não podem carregar mais de 500 toneladas. Os comboios usados para o transporte de cargas estão estacionados. Um comboio parado equivale a cerca de 200 caminhões a mais no sistema rodoviário e custos operacionais maiores, maior emissão de $\mathrm{CO} 2$ e impactos ambientais. Outros impactos também podem ser contabilizados como maior atrito na rede rodoviária diminuindo a vida útil da qualidade do pavimento.

\section{Exemplo 2 - Terminal da Alemoa em Santos e o incêndio na estrutura dutoviária}

Como exemplo, toma-se o caso do incêndio, ocorrido em abril de 2015, que restringiu o acesso de caminhões ao Porto de Santos. A extensão do incêndio, de grande proporção, atingiu os depósitos de álcool e gasolina no Terminal da Alemoa, em Santos, litoral paulista e durou mais de 80 horas. Foi necessária a adoção de medida de restrição ao acesso de caminhões, com destino ao Porto de Santos, pois, em decorrência do incêndio, foi bloqueada uma alça do acesso, impedindo o fluxo de cargas.

Para evitar distúrbios ainda maiores, o bloqueio da alça de acesso ao viaduto rodoviário adjacente ao Terminal da Alemoa foi a medida tomada pelas instâncias controladoras para diminuir a atração do fluxo de caminhões, que agravaria a entrada da cidade de Santos. A concessionária e a Policia Rodoviária Federal instalaram na rodovia, barreiras de veículos e um plano de comunicação foi executado para informar a situação e diminuir temporariamente o fluxo para o Porto de Santos (Agência Brasil, 2015).

Como consequência do incêndio o acesso ao porto foi interrompido entre os dias 2 e 10 de abril, o que corresponde a um longo período tendo, em vista a importância do local. O porto de Santos é caracterizado por ser multimodal, exercendo atração em fluxos através de 
dutovias, ferrovias, rodovias e hidrovias. A Figura 3-2 ilustra de distúrbio e equilíbrio entre os componentes e sistemas modais de um nó intermodal.

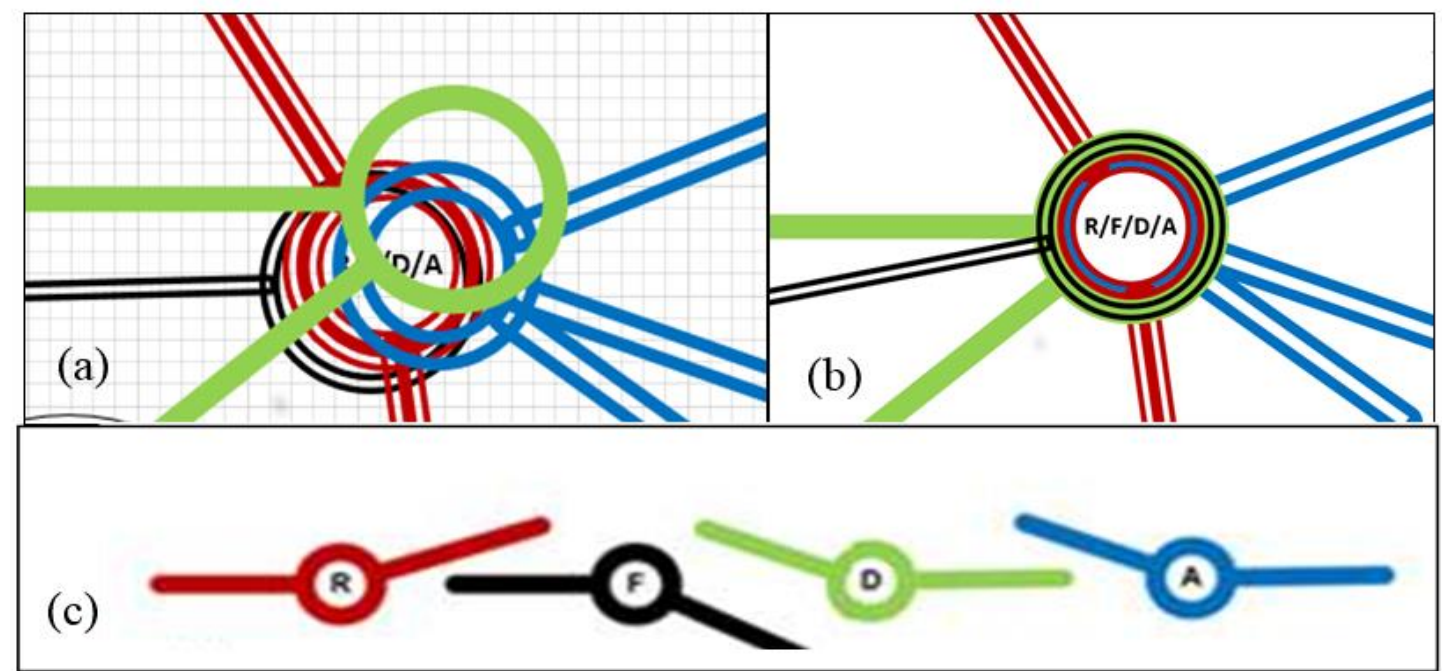

Figura 3-2 - Nó Intermodal sem distúrbios de funcionamento. Fonte: elaborado pelo autor

Na Figura 3-2 (a) é ilustrada uma situação de completo desequilíbrio nas operações do ponto intermodal com graves consequências tanto para o nó em si como também para a rede como um todo e com impactos nos diferentes sistemas viários em separado. A Figura 3-2 (b) demonstra uma situação de equilíbrio reestabelecido, entre os sistemas dutoviário, aquaviário, rodoviário e ferroviário. Em (c) são distinguidas a representação para rodoviário, ferroviário, dutoviário e aquaviário.

Esse exemplo se caracteriza como um nó intermodal de grande complexidade tendo em vista as interações de diferentes sistemas viários e sistemas de transferência. A Figura 3-2 (b) pode ilustrar o funcionamento de um importante nó intermodal devido à existência de distintos sistemas viários e sistemas de transferência que requerem um elevado grau de controle e adoção de procedimentos e medidas para redução de distúrbios que prejudiquem significativamente o nó e que impactem a normalidade de funcionamento dos sistemas viários que interagem direta ou indiretamente.

O termo link é utilizado para os arcos e nós da rede de transportes. É importante destacar a característica intermodal da rede viária tratada neste trabalho. Portanto, podemos tratar 
como links as ligações de transferência entre os modais de transportes como nós intermodais.

\subsection{FATORES CONSIDERADOS PARA A ANÁLISE DA VULNERABILIDADE EM NÓS INTERMODAIS DE TRANSPORTE DE CARGA}

Para facilitar o entendimento da vulnerabilidade e suas associações, é utilizado o conceito de acessibilidade como um atributo do ambiente, que pode ser medido através da quantidade e tipos de acessos. Com auxílio da figura em diagrama, é possível relacionar e observar as relações ambiente-rede e ambiente-fluxo.

Husdal (2004) propõe três perguntas básicas para um estudo de análise da vulnerabilidade: Onde se observa a vulnerabilidade? O que se observa com a vulnerabilidade? e Como se observa a vulnerabilidade?

Essas questões podem ser direcionadas para análise da vulnerabilidade dos nós intermodais de um sistema de transportes. Desta forma, a primeira questão, sobre onde se observa, deve considerar todo o contexto territorial do nó e também o contexto do próprio sistema de transportes que o contém. A segunda questão relativa sobre o que se observa deve considerar que a incapacidade de manutenção adequada do serviço de transporte tem direta relação com o desempenho esperado do nó intermodal diante da sua funcionalidade. A terceira questão: Como se observa a vulnerabilidade? requer uma formulação mais complexa, que exige um conhecimento e reflexão mais aprofundada a respeito da primeira questão sobre Onde e da segunda sobre $O$ Que.

Utilizam-se nesta pesquisa os conceitos e abordagens sugeridas pelos modelos propostos por Rodrigue (2006), Almeida (2008) e Pricinote (2008). A análise da vulnerabilidade de nó intermodal requer uma análise dos aspectos relacionados à localização e à acessibilidade que influenciam a funcionalidade do nó e sistema de transporte. Portanto, indicadores são elaborados para análise da vulnerabilidade de nós intermodais em função de fatores de localidade, acessibilidade e funcionalidade. 
Almeida (2008) oferece uma visão integrada e ampla das distintas dimensões do ambiente de interação da Rede de Transportes. Essas dimensões são as que moldam a rede e determinam sua funcionalidade. Rodrigue (2006) observa a identificação do atrito ou fricção entre os componentes da rede relacionados como terminais, fluxos e localidades.

\subsubsection{Vulnerabilidade entre ambiente e rede e entre ambiente e fluxo.}

Considera-se a rede física configurada na infraestrutura construída e em operação agrupada em componentes específicos como as redes, os fluxos e os ambientes. Em uma visão integrada para permitir a observação dos fatores observados em níveis de escalas, os componentes lógicos, em ampla escala, trazem as interações das dimensões políticas, sociais, econômicas e física nas estruturas adaptativa, cinética e topológica. (Almeida, 2008). No entanto, Rodrigue (2006) destaca a fricção entre a demanda (objeto), a rede (infraestrutura) e o nó (localidade).

A análise da vulnerabilidade, tendo em vista o contexto do caso de estudo, pode ser feita mediante a seleção combinada de indicadores. A utilização de variados índices leva em conta as características e necessidades do caso em estudo. Constata-se que fatores que influenciam a vulnerabilidade dos sistemas intermodais de transportes produzem reflexos e consequências no nível da eficiência do sistema de transporte que depende do funcionamento do conjunto desses componentes e de cada componente individualmente.

Estes diferentes tipos de indicadores, a depender do nível de análise, podem ser classificados em função da dimensão de referência. O uso da representação gráfica se aplica às diferentes necessidades de informação para respaldar diversos tipos de análise para os tomadores de decisão. Segundo Park (2010), os indicadores podem ser descritivos, indicadores de desempenho ou eficácia, indicadores de eficiência e indicador global. A Figura 3-1 (p. 42) busca ilustrar as interações para a identificações de indicadores relacionados aos fatores (Pricinote, 2008). 


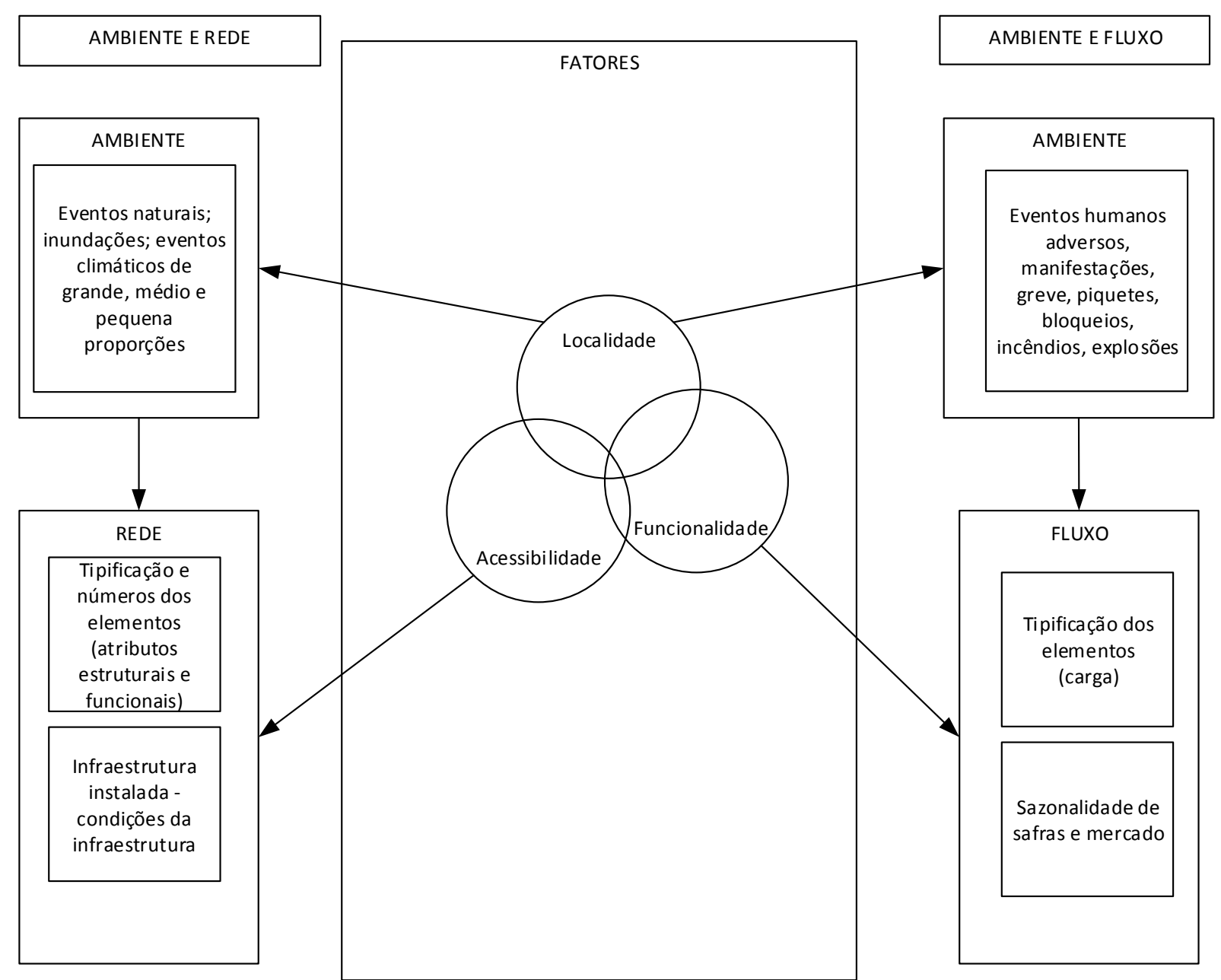

Figura 3-3 - Fatores de associação vulnerabilidade entre ambiente, rede e fluxo.

Fonte: Elaborado pelo autor

Com base no diagrama de relacionamento entre vulnerabilidade, acessibilidade e confiabilidade, mostrado na Figura 3-1 (p. 42), diagrama de interações da vulnerabilidade de Pricinote (2008), foi elaborada a Figura 3-3 que busca ilustrar os relacionamentos entre os elementos da rede, em associação aos fatores de localidade, acessibilidade e funcionalidade.

\subsubsection{Fator de Localidade}

A preocupação sobre localização de nós intermodais está presente na Política Nacional de Logística e Transporte, segundo os levantamentos de critérios realizado em Ministério dos Transportes (Brasil, 2012, 2014) para a implantação de Centro Integrado de Logísticas CIL. Os principais critérios enumerados são relacionados à proximidade de áreas ou zonas concentradoras de produção e às áreas ou polos concentradores de consumo e em áreas de 
expansão da produção. Também, apresentam-se critérios em relação a adjacências de áreas portuárias marítimas e de portos fluviais e entroncamentos intermodais.

Para a seleção dos critérios foram consultadas referências em documentos institucionais e da política de transportes e logística do Ministério dos Transportes (Brasil, 2014, 2013, 1973), e também referências acadêmicas como Cunha-Filho (2014), Almeida (2008), Pricinote (2008), Rodrigue (2006), Ferreira (2006) e Rosa (2005).

O estudo apresentado pelo Ministério dos Transportes (Brasil, 2014) destaca a importância dos critérios de funcionalidade na ponderação de serviços de logística e transportes. Esses critérios visam basicamente, aprimorar a visão sistêmica do planejamento e a revisão regulatórias para reduzir a burocracia, o tempo de estoque e o tempo na liberação das cargas nos portos, com ampliação da capacidade portuária e ampliação das operações e serviços intermodais e/ou multimodais.

A importância do transporte pode ser avaliada na escolha do lugar para implantar uma cidade. Vuchic (1981) considera entre os fatores principais que influenciam essa locação: os pontos de transbordo e cruzamentos de vias. Outros fatores como locais de mineração, considerações estratégicas (segurança nacional), locais aprazíveis, razões políticas ou representativas também são relacionadas como importantes para o surgimento de cidades.

Considerando fatores como a localização e as instalações de navegação, Rodrigue (2013) propõe tipificar os portos em tipos: costeiros naturais; costeiros com quebra mar; bacia hidrográfica; rio com eclusas; costeiro com eclusas; alto mar; rio natural; canal ou lago. A Figura 3-4 ilustra essa tipificação e evidencia a determinante influência da geografia física para localização de portos. Reforça-se, portanto, a influência da dimensão física considerada em Almeida (2008) e Ferreira (2012), que apresentaram estudos que demonstram que os portos podem ser classificados tendo em vista diferentes aspectos. 


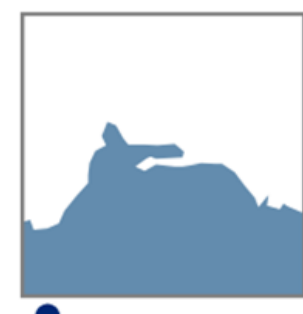

Costa Natural

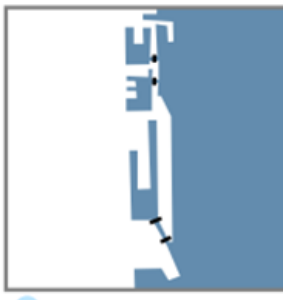

Eclusas Costeiras

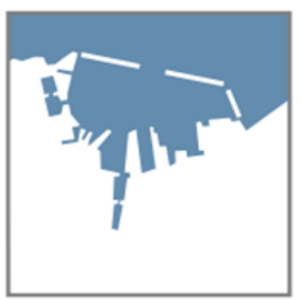

Costa Ouebra-Mar

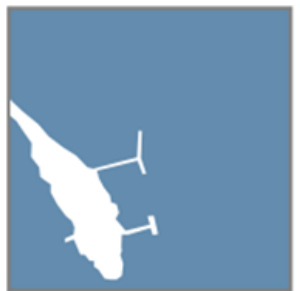

Enseada Aberta

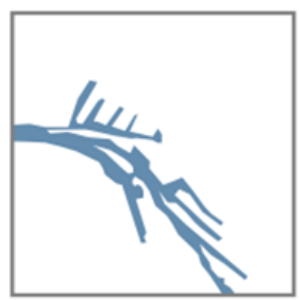

Bacia Fluvial

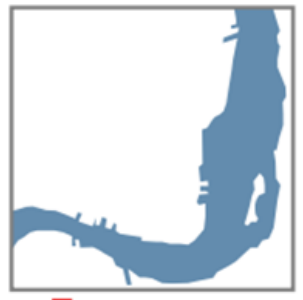

Rio Natural

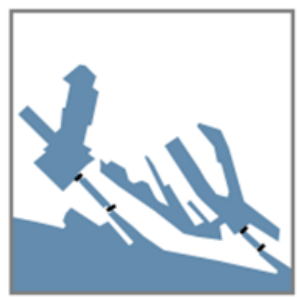

Eclusas Fluviais

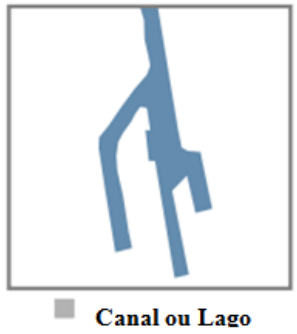

Figura 3-4 - Tipos de portos

Fonte: Rodrigue (2013)

De acordo com Erath (2011), as localizações não são iguais, pois, alguns lugares são mais acessíveis que outros, de maneira que a acessibilidade evidencia significativas desigualdades entre as localizações. No âmbito da geografia dos transportes de Rodrigue (et. al., 2006), destaca-se a localização como um importante critério de classificação, pois ela tem enorme influência no custo total do transporte.

Cunha-Filho (2014) afirma que as medidas de centralidade tentam mensurar as propriedades da localização de um arco ou nó com relação ao grafo que os compõe. Essas medidas levam em consideração diversos fatores, como meio ambiente urbano, rural, socioeconômico, relevo, clima, oferta, demanda, distâncias, para mensurar como que um nó ou arco interage com o restante da rede. Dessa forma, é possível identificar quais são aqueles considerados como mais centrais e importantes, de acordo com sua posição estratégica no grafo.

As medidas de centralidade têm sido usadas para investigar a influência dos nós em redes inter-organizacionais, redes de alimentos, mercado financeiro, fluxo de informações, combate a redes terroristas, busca em redes de internet, propagação de doenças, entre outros. Diversos investigadores e estudos em redes têm desenvolvido grande número de variações de medidas de centralidade, tendo como objetivo mensurar a diferença da importância dos nós de acordo com critérios pré-estabelecidos (Freitas, 2010). 
Nas zonas urbanas, a relação do fator de localidade com a vulnerabilidade fica mais evidente. É verificado forte atrito e interação entre as zonas urbanas com os corredores rodoviários e ferroviários. Essa interação provoca impactos adversos no crescimento urbano desordenado, abertura de acesso e vias clandestinas. Portanto, a localização de nós intermodais nas zonas urbanas e adjacências deve ser considerada como fator que influencia na vulnerabilidade.

O Quadro 3-1 apresenta critérios de localidade que correspondem a indicadores e medidas para relacionar vulnerabilidade ao fator de localidade do nó intermodal atribuindo um indicador urbano de influência na vulnerabilidade do nó.

Quadro 3-1 - Critérios de Localidade

\begin{tabular}{|c|l|c|}
\hline \multicolumn{1}{|c|}{ LOCALIDADE } & $\begin{array}{c}\text { Indicadores e medidas para relacionar } \\
\text { L1 }\end{array}$ & $\begin{array}{l}\text { A localização conforme o indicador urbano } \\
\text { Muito Denso influencia na vulnerabilidade } \\
\text { vulnerabilidade com as propriedades (atributos) } \\
\text { de localização do nó (ambiente) com relação ao } \\
\text { grafo (sistema de transporte) para o qual é } \\
\text { demandada uma função (fluxo) para o nó. } \\
\text { Critérios qualitativos sobre meio ambiente } \\
\text { urbano rural, sócio economia, relevo, clima, } \\
\text { oferta - demanda e distâncias }\end{array}$ \\
\cline { 1 - 2 } $\mathbf{L 3}$ & $\begin{array}{l}\text { A localização conforme o indicador urbano } \\
\text { Denso influencia na vulnerabilidade }\end{array}$ \\
\cline { 1 - 2 } & $\begin{array}{l}\text { A localização conforme o indicador urbano } \\
\text { Pouco Denso }\end{array}$ & \\
\hline
\end{tabular}

Esta classificação tem como base o estudo dos níveis de centralidade de cidades e localidades, apresentado no Anexo 1, níveis de centralidade, que classifica as cidades e localidades segundo seu nível de centralidade, conforme IBGE (2014).

\subsubsection{Fator de Acessibilidade}

Quanto aos critérios de acessibilidade, além da importância da localização dos pontos de origem e destinos e sua relação com o meio de circulação e infraestruturas, é importante também destacar a relação das distâncias que são derivadas da conectividade entre os pontos de origem e destino da matriz. A conectividade só existe quando existir a possibilidade de ligar dois locais ou pontos através do transporte. Medida importante para esta análise é a medida de distâncias. As distâncias podem ser atribuídas aos arcos entre os nós e expressa em unidades, tais como quilômetros ou tempo. 
Taylor e D'Este (2003) relacionam vulnerabilidade com o grau de acessibilidade de determinado nó na rede. Este grau de acessibilidade pode ser expresso com uma medida do custo requerido para acessar um nó em particular comparando as possíveis rotas e alternativas.

No ponto onde ocorre o encontro dos modos de transporte estão localizados os terminais de transbordo e os terminais intermodais. Estes componentes do sistema logístico às vezes se apresentam como um atrativo para um determinado corredor logístico, oferecendo serviços ou armazenando a carga.

A ampliação da acessibilidade está diretamente relacionada com o número de acessos que atendem determinado ponto de origem ou destino. Todavia pode-se analisar a acessibilidade em relação à distância do nó a uma rodovia pavimentada, rodovia duplicada ou corredor de grandes fluxos. Pode-se observar por meio das condições do acesso, em relação ao tipo de pavimento ou mesmo através da identificação de componentes infraestruturas para o acesso, como alças de acesso, pontes, tuneis ou interseções de vias.

Segundo dados do IBGE e DNIT, a densidade rodoviária no Brasil média é de cerca de 25 $\mathrm{km}$ de rodovia por $1.000 \mathrm{Km}^{2}$ de área, o que comparativamente aos Estados Unidos, que tem cerca de $438 \mathrm{Km}$ de rodovia por $1.000 \mathrm{Km}^{2}$, é significativamente muito baixa, segundo dados do CNT (2015). O Quadro 3-2 apresenta alguns critérios de acesibilidade identificados.

Quadro 3-2 - Critérios de Acessibilidade

\begin{tabular}{|c|c|c|}
\hline & ACESSIBILIDADE & \multirow{5}{*}{$\begin{array}{l}\text { Indicadores e medidas para relacionar } \\
\text { vulnerabilidade com a densidade rodoviária na } \\
\text { acessibilidade do nó. } \\
\text { Critérios de concentração de trechos } \\
\text { pavimentados e também a qualidade e outras } \\
\text { características (pavimentado, duplicado) dos } \\
\text { trechos rodoviários que atendem ao nó. }\end{array}$} \\
\hline A1 & Densidade rodoviária Muito Densa & \\
\hline A2 & Densidade Rodoviária Densa & \\
\hline A3 & Densidade Rodoviária Pouco Densa & \\
\hline An & $\ldots$ & \\
\hline
\end{tabular}

O Quadro 3-2 apresenta o indicador de densidade rodoviária e as medidas de valores indicadas para relacionar com a vulnerabilidade com o fator de acessibilidade do nó 
intermodal. Essa densidade rodoviária está classificada em trÊs classes: Muito Denso, Denso e Pouco Denso.

As fontes de dados geográficos vetoriais para a determinação desses indicadores de densidade são IBGE e do DNIT, conforme no Anexo 2, que apresenta as classes de densidades utilizadas e extraídas da base de trechos rodoviários do Sistema Nacional de Viação.

Nessa escolha entre rotas, a competição entre os modais é destacada e a satisfação do cliente com os serviços logísticos prestados nos pontos de transbordo podem ser decisivos. De maneira geral, os terminais apresentam diferenças em sua produtividade, não devido a aspectos relacionados ao processo produtivo, mas em função de suas localizações e dificuldades em integrar e atender eficientemente aos diversos modais de transporte (Naves, 2012). Porém, o contrário também pode ocorrer. O terminal intermodal em situação de falha ou ruptura se torna um obstáculo ao fluxo, retendo ou deslocando a carga para outro corredor. Essa perturbação no sistema de transportes pode trazer graves consequências, inclusive ao nó intermodal de destino.

Considerando o sistema aquaviário é importante destacar os critérios de navegabilidade que, conforme Almeida (2008), o simples fato da existência de rios não significa que exista, de igual forma, navegação. Segundo esse autor, os critérios de navegabilidade são definidos de acordo com o padrão da embarcação a ser usada e ressalta que para a determinação de navegabilidade de um determinado trecho de rio, é necessário considerar outros fatores, como a análise de batimetria e o regime hidrológico do rio. Tais aspectos são importantes para a especificação de uma hidrovia.

É comum rios, em seu estado natural, possuírem barreiras ao tráfego de embarcações. Os rios precisam de intervenções necessárias à navegabilidade. A navegabilidade, em alguns casos, pode ser alcançada por meio da regulação do fluxo em eclusa, dragagem, estabilização de bancos ou remoção de troncos de árvores. Alguns rios, em seus estados naturais fornecem apropriadas condições para o deslocamento de embarcações. Nesses casos, é necessário analisar o tipo de embarcação a ser usado. 


\subsubsection{Fator de Funcionalidade}

Os critérios de funcionalidade na ponderação de serviços de logística e transportes são de aprimorar visão sistêmica do planejamento e a revisão regulatórias para reduzir burocracia e reduzir tempo de estoque e reduzir tempo na liberação das cargas nos portos, com ampliação da Capacidade Portuária e ampliação das operações e serviços intermodais e/ou multimodais. Em Naves (2012) são apresentados parâmetros da funcionalidade estrutural para um conjunto de terminais intermodais representativos do sistema nacional.

A seleção foi sistematizada e a indicação de critérios de funcionalidade topológica, ou grau de intermodalidade, apresentados no Quadro 3-3, correspondem a indicadores e medidas para relacionar vulnerabilidade à funcionalidade do nó.

Quadro 3-3 - Critérios de Funcionalidade topológica

\begin{tabular}{|c|c|c|}
\hline & $\begin{array}{c}\text { FUNCIONALIDADE } \\
\text { Tipo transferência (intermodalidade) } \\
\end{array}$ & \multirow{6}{*}{$\begin{array}{c}\text { Indicadores e medidas para relacionar } \\
\text { vulnerabilidade com a função topológica } \\
\text { do nó na rede intermodal. Identificar o } \\
\text { grau de intermodalidade do nó. Quantos } \\
\text { modos de transportes o nó está capacitado } \\
\text { a operar. }\end{array}$} \\
\hline Ft1 & Atende a 2 modos de rodoviário e ferroviário & \\
\hline Ft2 & Atende a 2 modos de rodoviário e hidroviário & \\
\hline Ft3 & Atende a 2 modos de ferroviário e hidroviário & \\
\hline Ft4 & $\begin{array}{l}\text { Atende a } 3 \text { modos de hidroviário, ferroviário e } \\
\text { rodoviário }\end{array}$ & \\
\hline Ftn & & \\
\hline
\end{tabular}

Conforme visto no capítulo 2, os principais serviços de um sistema de transferência modal podem ser agrupados em serviços de transportes e serviços de armazenagem. Os serviços de armazenagem correspondem aos serviços de consolidação e desconsolidação; fracionamento de cargas e controle de estoque. E os serviços de transporte implicam, o transporte para o destino final, a disponibilidade de modais e serviços de intermodalidade, a gestão de entrega dos bens, e a própria gestão de transporte.

No Quadro 3-4, são apresentadas medidas para associar a vulnerabilidade ao fator de funcionalidade, no que se refere aos níveis de capacidade e serviços. 
Quadro 3-4 - Critérios de Funcionalidade estrutural

\begin{tabular}{|c|c|c|}
\hline & FUNCIONALIDADE - Estrutura de serviços & \multirow{11}{*}{$\begin{array}{l}\text { Indicadores e medidas para relacionar } \\
\text { vulnerabilidade com a função estrutural do nó na } \\
\text { rede intermodal. } \\
\text { Identificar a capacidade operacional e de } \\
\text { armazenagem pelo fluxo e identificar a } \\
\text { infraestrutura, pelo número de equipamentos de } \\
\text { transbordo }\end{array}$} \\
\hline Fe1 & Capacidade operacional baixa & \\
\hline $\mathrm{Fe} 2$ & Capacidade operacional média & \\
\hline $\mathrm{Fe} 3$ & Capacidade operacional alta & \\
\hline Fe4 & Capacidade de armazenagem baixa & \\
\hline $\mathrm{Fe} 5$ & Capacidade de armazenagem média & \\
\hline Fe6 & Capacidade de armazenagem alta & \\
\hline $\mathrm{Fe} 7$ & Infraestrutura em equipamentos baixa & \\
\hline Fe8 & Infraestrutura em equipamentos alta & \\
\hline Fe9 & Infraestrutura em equipamentos média & \\
\hline Fen & & \\
\hline
\end{tabular}

Entre os serviços que requerem investimentos estão os serviços de armazenagem. Esses serviços correspondem à consolidação e desconsolidação, fracionamento de cargas e controle de estoque. O nível de automação para o gerenciamento de grandes volumes de carga é responsável pelo alcance da eficiência traduzida em redução de custos.

\subsubsection{Critérios de influência e atributos do fatores na Vulnerabilidade de Nós Intermodais}

A interação entre os fatores de localidade e acessibilidade e a estimativa de influência pode ser observada pelas relações entre os atributos dos fatores de localidade e acessibilidade. Com base na Matriz de risco apresentada em Taylor e D’Este (2003) é feita uma adaptação para estimar a influência da vulnerabilidade em relação aos fatores, conforme a Figura 3-5. Essa adaptação na matriz, relacionando o indicador urbano com a densidade rodoviária permite que sejam observadas as interações entre os fatores.

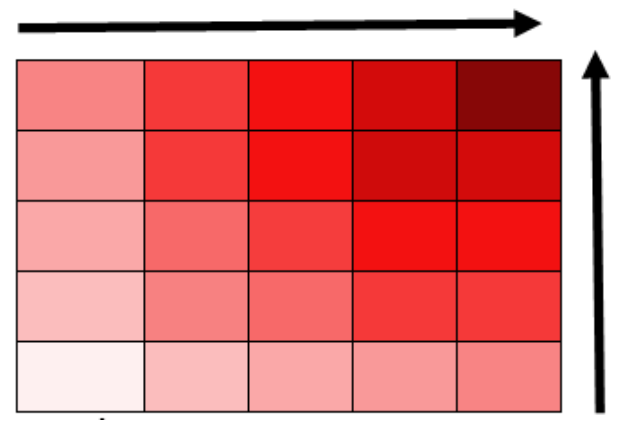

Figura 3-5 - Influência dos fatores e critérios na vulnerabilidade Fonte: Matriz de Risco - Taylor e D’Este (2003) 


\subsection{TÓPICOS CONCLUSIVOS}

Nos itens anteriores, foram vistos conceitos de vulnerabilidade associados à rede de transportes, especialmente aos nós intermodais. Os fatores selecionados para associação de influência na vulnerabilidade podem ser atributados para a caracterização dos nós intermodais. A vulnerabilidade identificada por Pricinote (2008) como resultado (fenômeno) influenciado pela localização e acessibilidade. Esta é identificada como atributo do ambiente, onde interagem a rede e o fluxo.

A caracterização da localidade e acessibilidade utiliza dados geográficos no padrão INDE, o que permite procedimentos de análise espacial no dado vetorial das rodovias para determinar as classes de densidade rodoviária. O mesmo ocorre com os dados para determinação do indicador urbano (IBGE, 2014), que corresponde a uma informação útil para o planejamento nacional, regional, urbano e o planejamento da circulação (Magalhães, 2004), tanto na esfera pública, quanto privada.

Para que seja possível uma análise baseada em dados mais próximos da realidade, sustentada na tendência do realismo, contudo, é necessário para que os diagnósticos e prognósticos dos sistemas de transportes utilize o potencial de dados e sistemas inteligentes, especialmente aos aplicados em sistema de informações e tecnologia de informações e comunicação.

Em relação aplicação das questões de Husdal (2004), a primeira, Onde se observa a vulnerabilidade?, deve considerar com bastante realismo o contexto territorial do nó e também o contexto do próprio sistema de transportes que contém o nó.

Na segunda de O que se observa na vulnerabilidade? deve considerar que a incapacidade de manutenção adequada do serviço de transporte tem direta relação com o desempenho esperado, do planejamento e da operação do nó Intermodal, ou seja a própria funcionalidade do nó intermodal no sistema de transporte. 
A terceira Como se observa a vulnerabilidade? Requer uma formulação complexa em associar a localização, o contexto geográfico com a rede de transporte, tanto a rede física quanto a rede de fluxos, portanto requer um conhecimento e reflexão a respeito da primeira questão e da segunda questão. 


\section{MÉTODO DE ANALISE DA VULNERABILIDADE DE NÓS INTERMODAIS DE TRANSPORTE DE CARGA}

\subsection{APRESENTAÇÃO}

As questões mencionadas no Capítulo 3 consideradas para análise da vulnerabilidade são utilizadas como eixo estruturante do método de análise. A primeira questão é relativa Onde se observa a vulnerabilidade? Portanto, considera a localização, o contexto territorial e geográfico e o ambiente caracterizado por seus atributos.

A segunda questão relativa sobre $O$ que se observa com vulnerabilidade, tem direta relação com os nós componentes de uma rede. Por sua vez, por estar implicada nos fluxos e direção do sistema de transporte, ela tem direta relação com o desempenho operacional do nó. Está relacionada à função (operação) do nó no sistema (rede) de transportes.

A terceira questão Como se observa a vulnerabilidade, requer a identificação das interações das duas questões anteriores, ou seja as interações do ambiente e do nó, as interações entre o ambiente e a rede e o ambiente e o fluxo. Faz-se necessária a identificação dos atributos do ambiente, como se dá a acessibilidade a ele, bem como se torna necessária a indicação dos atributos da rede e do fluxo.

Conforme o método proposto, a obtenção dos atributos de localidade e acessibilidade se dá após a delimitação da área e do corredor logístico de maneira direta. Todavia, o atributo de funcionalidade requer obtenção de dados sobre o fluxo e capacidade do corredor logístico.

Uma forma estimativa de obtenção dos coeficientes de ponderação $(x, y$ e $z)$ requer que os critérios sejam hierarquizados para que o indicador considere a influência de um fator em relação aos outros critérios.

O indicador de vulnerabilidade proposto neste método corresponde a um valor qualitativo (alto, médio ou baixo) atribuído ao nó intermodal que indica a influência relativa entre os fatores de localidade, acessibilidade e funcionalidade. A Figura 4.1 apresenta as etapas do método de análise. 


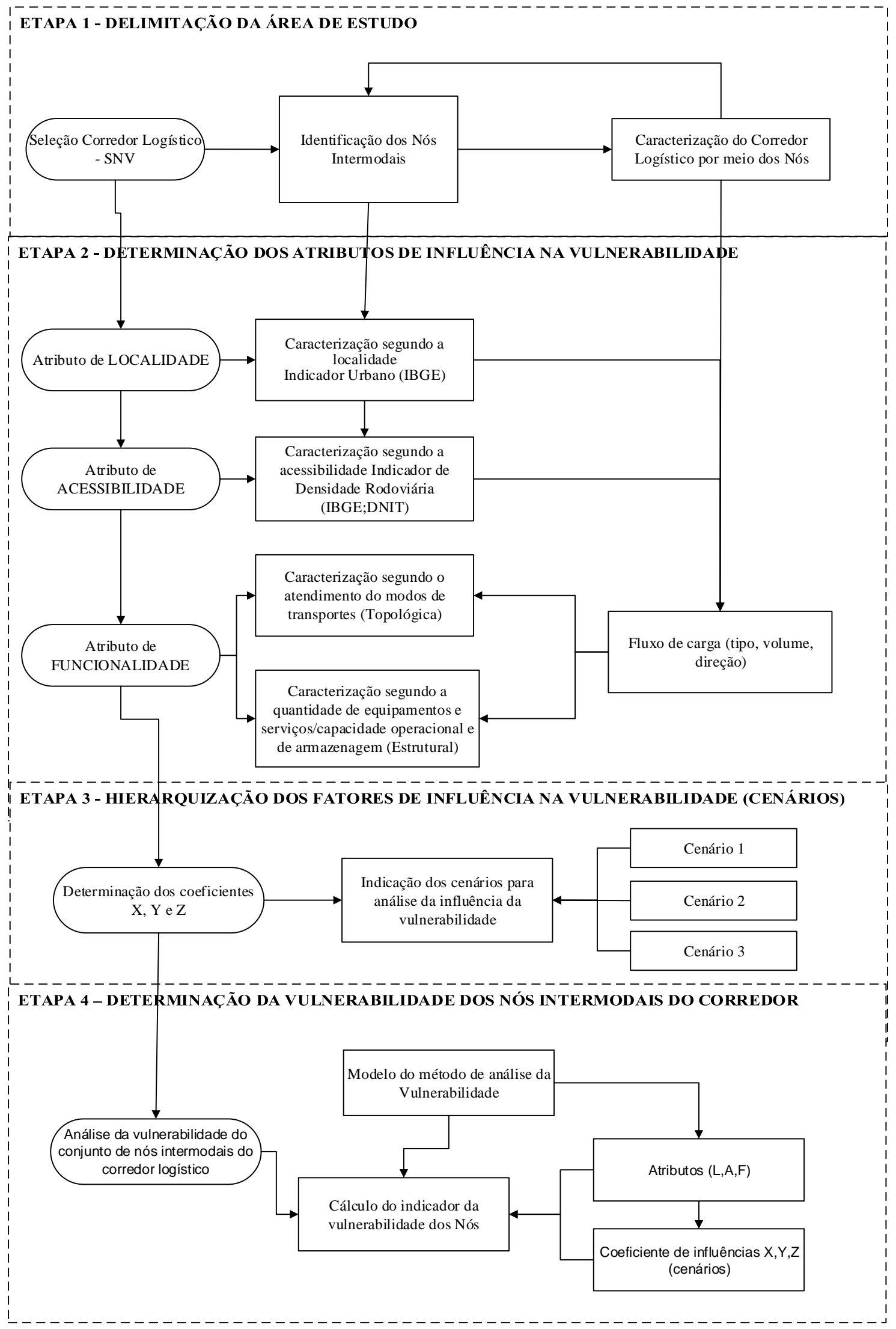

Figura 4-1 Etapas básicas do método de análise da vulnerabilidade.

Fonte: elaborado pelo autor 


\subsection{ETAPA 1 - DELIMITAÇÃO DA ÁREA DE ESTUDO}

A delimitação da área de estudo que corresponde à escolha do corredor logístico, é a primeira etapa para a análise da vulnerabilidade. Essa delimitação geográfica permite caracterizar os nós segundo os fatores de localidade e acessibilidade, visto que são fatores que exercem influência na vulnerabilidade do nó e consequentemente do corredor.

O corredor logístico onde está o conjunto de nós intermodais, deve estar inserido no SNV para se fazer uso da base de dados, e também nos planos de transportes e logísticas, para que seja possível a caracterização socioeconômica e geográfica no estudo de caso. A identificação dos nós deve considerar o sistema de transporte (tipos de carga, volume, fluxo, direção, sazonalidade).

A Figura 4-2 apresenta a divisão dos corredores logísticos do PNLT e as transferências modais. São 744 registros de transferências modais na base de dados do PNLT. Desse total, 438 transferências modais são do tipo rodoferroviário, o que representa mais da metade. Do tipo rodo-aquaviário, somando 76 do tipo rodo-hidro e 37 do tipo rodocabotagem são 113 transferências modais do tipo rodoaquaviário. O corredor logístico Sudeste é o corredor com mais transferências modais, são 290, desse total, 191 é do tipo rodoferroviário, o que corresponde a maioria, 31 são do tipo rodoaquaviário e 15 são ferroaquaviário.
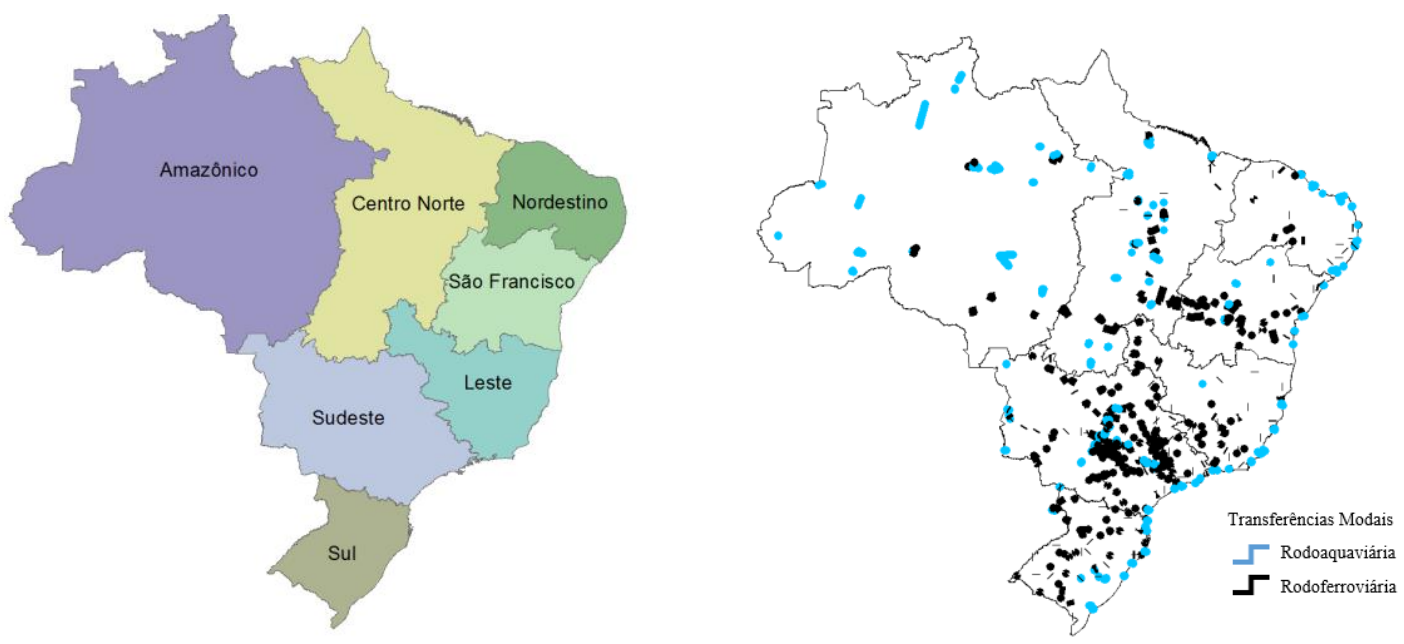

Figura 4-2 - Corredores Logísticos e Transferências Modais do PNLT. Fonte: elaborado pelo autor a partir da base de dados do PNLT 


\subsection{ETAPA 2 - DETERMINAÇÃO DOS ATRIBUTOS}

Conforme apresentado anteriormente, a vulnerabilidade inerente aos nós intermodais tem relação com os fatores de localidade e acessibilidade. Nesta etapa, a determinação do atributo de localidade está associada ao indicador urbano e a determinação da acessibilidade ao indicador de densidade rodoviária. $\mathrm{O}$ fator de funcionalidade é a combinação da intermodalidade, ou seja a Funcionalidade Topológica e o número de equipamentos e serviços, a Funcionalidade Estrutural do nó intermodal.

\subsection{1 - Atributos de Localidade}

Tomando como referência os modelos, de Rodrigue (2006) e Ferreira (2006) apresentados no capítulo 2 (Figura 2-5 e Figura 2-6) e o modelo de Pricinote (2008) apresentado no capítulo 3 (Figura 3-1), é possível observar as relações entre os componentes da rede de transportes e outros elementos num mesmo ambiente. Como a acessibilidade pode ser considerada um atributo do ambiente, então, a vulnerabilidade entre o ambiente e a rede pode ser analisada através da localização dessa rede em seu contexto geográfico e socioeconômico.

A condição física e a geomorfologia contribuem fortemente para estabelecer as condições para implantação do nó. No entanto questões políticas, sócias e de planejamento tem parcela nesta implantação.

O modelo de Pricinote (2008) sobre as interações Ambiente-Fluxo e Ambiente-Rede identifica áreas de interseção, onde se observam a vulnerabilidade da Rede e sua relação com a exposição a eventos naturais e também a eventos humanos.

O atributo de localidade indicado para essa análise é o indicador urbano instituído pelo IBGE. Trata-se de um indicador nacional, utilizado no planejamento, tanto em esferas públicas quanto em esferas privadas. O Indicador Urbano reflete as escalas de situações de pressão e atrito devido ao nível de centralidade das cidades, e, neste método está relacionado com a localização do nó. Para representação espacial da localização dos nós intermodais, utiliza-se a rede de cidades por serem classificadas através dos níveis de centralidade que são expressos no indicador urbano IBGE (2014). Através desse indicador 
é possível atribuir à localização do nó intermodal menor ou maior grau de centralidade em comparação aos outros nós.

Um elemento da rede com alto grau de centralidade tem uma localização que permite contatos diretos com muitos outros. Portanto, um atributo importante considerado na análise é a caracterização geográfica como um fator para analisar o nó intermodal. Dessa maneira é possível contextualizar geograficamente o elemento e relacionar outros dados correlatos e preponderantes para realizar análises e estudos.

$\mathrm{Na}$ vulnerabilidade de nós intermodais, o atributo (L) é determinado a partir do indicador urbano. Existem três tipos de classes em escala qualitativa de Muito Denso, Denso e Pouco Denso, que classificam as cidades e localidades segundo seu nível de centralidade. Essa classificação tem como base o estudo redes e fluxos de território do IBGE (2014) e o Mapa dos Níveis de Centralidade no Anexo 1.

\subsection{2 - Atributos de Acessibilidade}

O atributo de acessibilidade é a densidade rodoviária. Portanto, o mapa da densidade espacial é adotado como indicador de acessibilidade. Trata-se do indicador de densidade rodoviária utilizado na classificação indicada pelo IBGE e DNIT. A medida da densidade rodoviária é dada pela extensão em $\mathrm{km}$ das vias dividida pela área $(\mathrm{km} / \mathrm{km} 2)$ e visto que a acessibilidade pode ser considerada um atributo do ambiente.

O mapa de densidade espacial rodoviária é um dado matricial gerado a partir dos dados vetoriais de rodovias pavimentadas. Para a geração do mapa da densidade rodoviária foi utilizada a base de dados vetorial de rodovias. Esses dados representam a base de dados do SNV DNIT (2015). Com a utilização de técnica de análise espacial foi gerado o mapa da densidade rodoviária.

Desse modo, foi obtido um dado matricial de intervalos em três classes: Densidade Rodoviária Alta, Densidade Rodoviária Média e Densidade Rodoviária Baixa. A relação da densidade é calculada tendo-se em conta as extensões em quilômetros dos trechos rodoviários com a área em $\mathrm{km}^{2}$. No Brasil a densidade rodoviária média é de cerca de 25 $\mathrm{km}$ de rodovia pavimentada por $1.000 \mathrm{~km}^{2}$ de área territorial. $\mathrm{O}$ mapa da densidade 
rodoviária com destaque para a área de estudo está apresentado no Anexo 2.

\subsection{3 - Atributos da Funcionalidade}

O fator funcionalidade combina dois critérios para sua composição. O primeiro está associado à topologia de redes de transportes entre dois ou mais modos diferentes. $\mathrm{O}$ segundo está associado com a capacidade de funcionamento e de serviços de transportes disponíveis (fluxos). Para uma avaliação coerente da influência deste fator na vulnerabilidade do nó é imprescindível a identificação das características operacionais, tanto do nó quanto do corredor, bem como a caracterização quanto ao armazenamento, sazonalidade e direção do fluxo.

Os dados para a definição dos atributos de funcionalidade é uma combinação do atributo da funcionalidade topológica com atributos da funcionalidade estrutural dos nós intermodais, e devem ser obtidos a partir da caracterização funcional do nó.

De maneira geral a funcionalidade dos nós intermodais está associada à oferta de serviços de transporte que envolve: transporte para o destino final, disponibilidade de modais e serviços de intermodalidade, gestão de entrega dos bens e a gestão do transporte, ou seja, esta funcionalidade está associada diretamente aos fluxos de cargas nos pontos de transbordos.

Enquanto a questão de Onde se observa a vulnerabilidade tem direta relação com a localidade, a questão sobre $O$ que se observa com Vulnerabilidade tem direta relação com a funcionalidade do nó intermodal. Considera-se que esta vulnerabilidade é intrínseca ao nó e tem a ver com manutenção adequada do serviço de transporte, como também relação direta com o desempenho esperado do nó intermodal na rede de transporte.

A Figura 4-3 apresenta os atributos de funcionalidade topológica e funcionalidade estrutural utilizados para determinar a funcionalidade. 


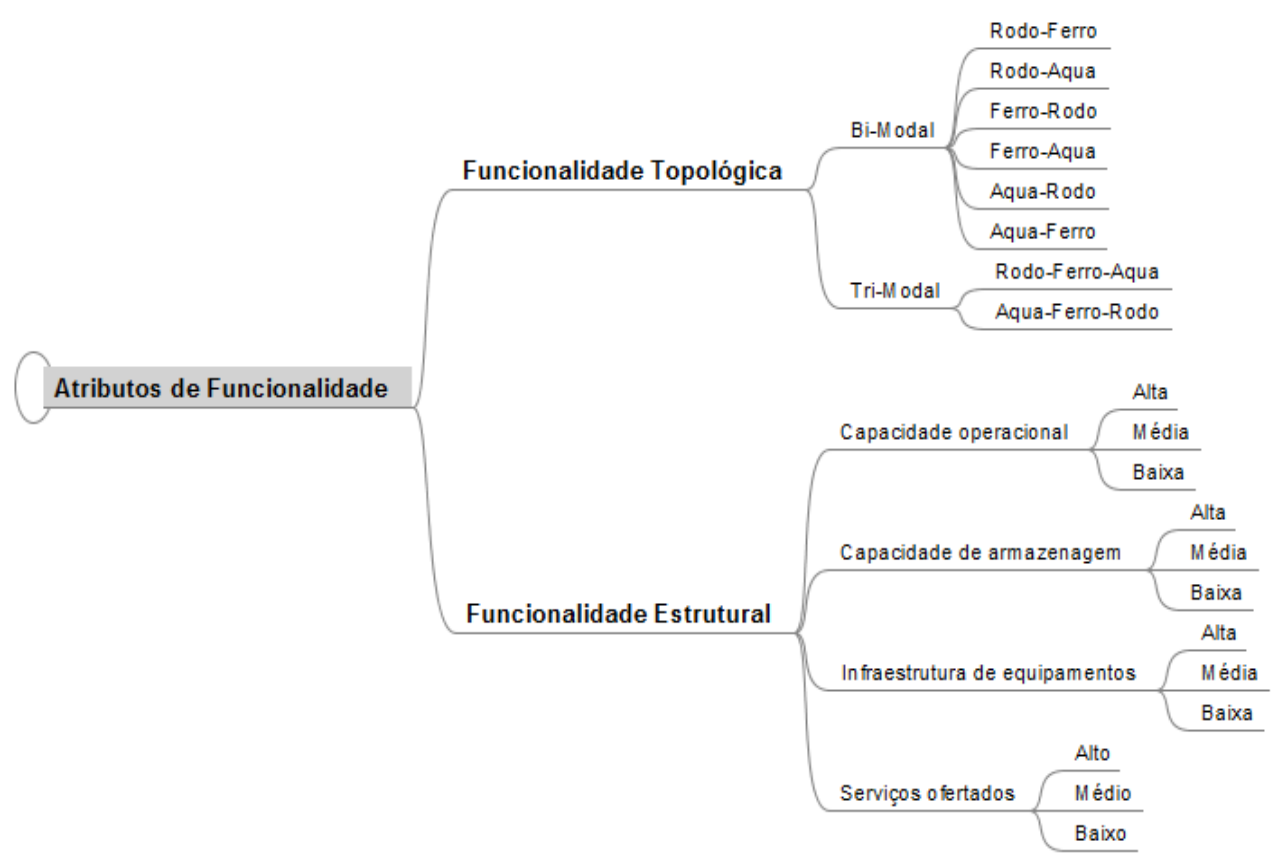

Figura 4.3 - Atributos de Funcionalidade Topológica e Estrutural. Fonte: Elaborada pelo autor.

O diagrama apresentado nessa figura pretende ilustrar a composição do atributo do fator de funcionalidade (F). Esse fator corresponde a combinação dos atributos de funcionalidade topológica $\left(\mathrm{F}_{\mathrm{t}}\right)$ com o de funcionalidade estrutural $\left(\mathrm{F}_{\mathrm{e}}\right)$. A funcionalidade topológica tem relação com o grau de intermodalidade e a funcionalidade estrutural com a capacidade, equipamentos e serviços.

A Equação 4-1 demonstra esta combinação para a determinação de (F). No entanto, para manter o fator de funcionalidade na mesma escala de valor é necessário combinar $F_{t}$ e $F_{e}$, por meio da soma e divisão por dois.

$$
\mathrm{F}=\left(\mathrm{F}_{\mathrm{T}}+\mathrm{Fe}\right) / 2
$$

Equação 4-1

A seguir é detalhada a determinação dos atributos da funcionalidade topológica e da funcionalidade estrutural. 


\subsubsection{1 - Atributo de Funcionalidade Topológica}

A funcionalidade topológica está relacionada aos serviços de transferência ofertados, a partir da quantidade de modos de transportes naquele nó intermodal pode-se estimar o valor do atributo. A funcionalidade topológica está diretamente relacionada ao grau de intermodalidade do nó, ou seja, com o número de modos de transportes atendidos pelo nó e os serviços de transporte envolvem a disponibilidade de modais e serviços de intermodalidade. A funcionalidade topológica, relacionada aos serviços de transferência, é medida a partir da quantidade de modos de transportes ofertada naquela transferência modal, com a identificação do número de modos de transportes atendidos.

Como critério adotado para a denominação do terminal é utilizado o sentido do fluxo de carga, ou seja, um sentido unidirecional da origem ao destino. Por exemplo: um terminal pode ser rodoferroviário, no entanto, se o fluxo for inverso este foi considerado ferrorodoviário. Portanto, como mostra a Figura 4-3, são possíveis seis tipos de intermodalidade: Rodoferroviária, Ferrorodoviária, Rodoaquaviária, Aquarrodoviária, Ferroaquaviária e Aquaferroviária.

\subsubsection{2 - Atributo da Funcionalidade Estrutural}

A funcionalidade estrutural está diretamente relacionada com as características dos modos de transportes, tipos da carga e volume movimentado (fluxo). Os serviços de armazenagem e outros serviços disponíveis em um sistema de transferência são atributos importantes de um nó intermodal. Basicamente os serviços de armazenagem correspondem aos serviços de consolidação e desconsolidação, fracionamento de cargas e controle de estoque, e, desta forma requer a utilização de equipamentos variados.

A funcionalidade estrutural é determinada pela quantidade dos fluxos, equipamentos e serviços disponíveis. Os dados para análise de um corredor logístico devem ser obtidos a partir de levantamento de dados primários correspondentes com a delimitação da área do estudo de caso. Para tanto, na aplicação do método utilizam-se os intervalos de valores propostos em Naves (2012). A quantidade de equipamentos reflete a capacidade das estruturas de integração entre os modais e influenciam em toda infraestrutura para o cumprimento da função do nó. 


\subsubsection{3 - Combinação entre os fatores de localidade e acessibilidade}

A interação entre os fatores de localidade e acessibilidade e a estimativa de influência podem ser observada pelas relações entre os atributos dos fatores de localidade e acessibilidade. Com base na matriz de risco, apresentada em Taylor e D’Este (2003), é feita uma adaptação para estimar a influência da vulnerabilidade em relação aos fatores, conforme a Figura 4-4.

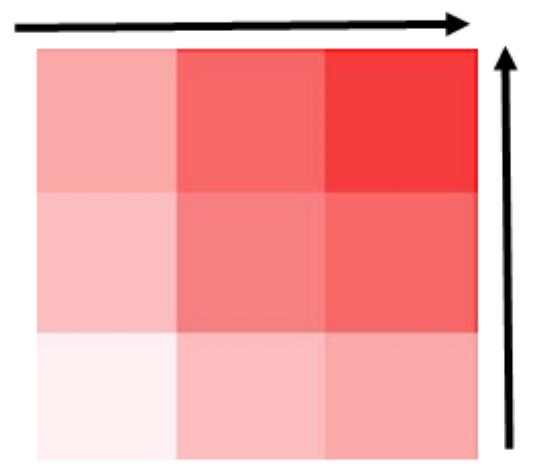

Figura 4-4 - Influência dos fatores e critérios na vulnerabilidade Fonte: Taylor e D'Este (2003), modificado

A Figura 4-3 apresenta a relação entre o indicador urbano e a densidade rodoviária, o que permite a demonstração das interações entre os fatores a partir da matriz $3 \times 3$, proporcionando a expressão dos valores em alto, médio, baixo ou equivalentes. Os graus de intensidade são representados na combinação e variação das duas dimensões, o que altera o nível de vulnerabilidade indicado nas setas sugeridas.

Esta adaptação na matriz relaciona o indicador urbano com a densidade rodoviária permite que sejam observadas as interações entre os fatores, utiliza-se uma matriz 3x3 para apresentar os valores alto, médio e baixo, ou equivalentes. Dessa forma pretende representar os graus de intensidades na variação e combinação das duas dimensões, o que altera o nível de vulnerabilidade conforme indicado pelas setas.

O Quadro 4-1 apresenta possíveis interações entre os atributos dos fatores de localidade e acessibilidade para caracterizar o nó intermodal e estimar a influência dos fatores e a Relação (interação) entre os atributos dos fatores de localidade e acessibilidade. 
Quadro 4-1 - Interação entre os fatores de localidade e acessibilidade

\begin{tabular}{|c|c|c|c|c|}
\hline & & \multicolumn{3}{|c|}{ DENSIDADE RODOVIÁRIA } \\
\hline & & Baixa & Média & Alta \\
\hline \multirow{3}{*}{$\begin{array}{c}\text { INDICADOR } \\
\text { URBANO }\end{array}$} & Muito Denso & $\begin{array}{l}\text { Influência } \\
\text { Alta }\end{array}$ & $\begin{array}{l}\text { Influência } \\
\text { Muito Alta }\end{array}$ & $\begin{array}{l}\text { Influência } \\
\text { Muito Alta }\end{array}$ \\
\hline & Denso & $\begin{array}{l}\text { Influência } \\
\text { Média }\end{array}$ & $\begin{array}{c}\text { Influência } \\
\text { Alta }\end{array}$ & $\begin{array}{c}\text { Influência } \\
\text { Alta }\end{array}$ \\
\hline & Pouco Denso & $\begin{array}{c}\text { Influência } \\
\text { Baixa }\end{array}$ & $\begin{array}{l}\text { Influência } \\
\text { Média }\end{array}$ & $\begin{array}{c}\text { Influência } \\
\text { Média } \\
\end{array}$ \\
\hline
\end{tabular}

\subsection{ETAPA 3 - HIERARQUIZAÇÃO DOS FATORES (CENÁRIOS)}

A análise de cenários é utilizada em estudos na área de planejamento, o que permite a adoção de alternativas que complementam os modelos de análise. Essas alternativas estabelecidas com a adoção de cenários são aceitas para auxiliar na análise de fatores de influência e também na tomada de decisão tanto na esfera pública quanto na esfera privada (Cunha Filho, 2014).

Para simplificar a hierarquização dos fatores assume-se que a vulnerabilidade do nó equivale a 100 (pontos) e a influência para a existência desta vulnerabilidade está distribuída entre os fatores de localidade, acessibilidade e funcionalidade. A Figura 4-4 apresenta um esquema da influência dos fatores sobre a vulnerabilidade.
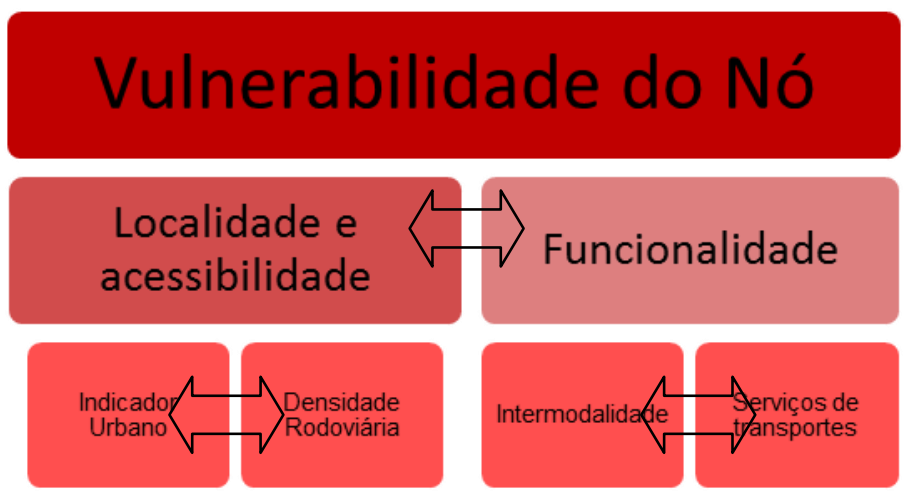

Figura 4.4 - Hierarquia dos fatores de influência na vulnerabilidade.

Essa figura sugere que a vulnerabilidade de um nó intermodal tem a influência dos fatores de localidade, acessibilidade e funcionalidade. Conforme sugerido nas setas da figura, 
esses fatores podem exercer maior ou menor influência na vulnerabilidade dependendo dos cenários em que esses forem submetidos. Essa maior ou menor influência pode ser observada de diferentes cenários. A influência do fator de localidade é analisada sob os critérios que permitem identificar quais nós intermodais são considerados mais importantes, considerando a localização com maior centralidade na hierarquia de cidades. Portanto com maior influência no corredor logístico. O indicador urbano configura uma medida de centralidade. Dessa forma, a localidade tem relação com os critérios de densidade adotados pelo indicador urbano. $\mathrm{O}$ fator de acessibilidade corresponde à densidade rodoviária que divide espacialmente o ambiente em três classes de densidade: alta, média e baixa.

O fator de funcionalidade corresponde à combinação dos critérios topológico e estrutural. Topológico pelo grau de intermodalidade do nó intermodal e estrutural pela capacidade de fluxo operado pelo nó. Esse fator está mais diretamente relacionado com o nó e os dados e intervalos de valores utilizados devem estar disponíveis em pesquisas e estudos do corredor logístico (Naves, 2012).

Para que seja possível uma análise das influências dos fatores na vulnerabilidade, faz-se necessária a adoção de diferentes cenários. Uma maneira experimental de distribuir essa influência pode ser demonstrada na Figura 4-5, onde se propõe a seguinte distribuição para o Cenário 1, foi estabelecida uma situação onde é dada maior influência para a localidade e acessibilidade, que, somadas, terão mais influência na vulnerabilidade do que a funcionalidade. A distribuição da influência na funcionalidade corresponde ao mesmo valor para o grau de intermodalidade e as capacidades (fluxo). Esse cenário tem como proporção $60 \%$ de influência da localidade e acessibilidade e $40 \%$ de influência da Funcionalidade.

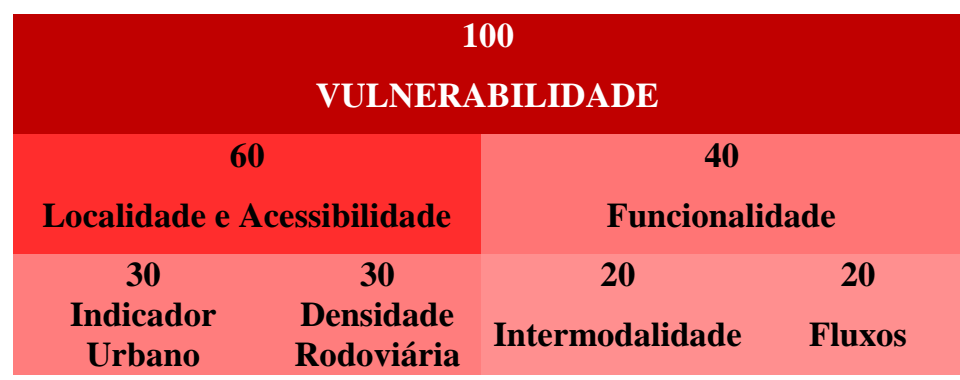

Figura 4.5- Cenário 1 - Distribuição da influência de fatores na Vulnerabilidade. Fonte: elaborado pelo autor 
O Cenário 2, portanto, propõe que a funcionalidade do nó é que tem a maior influência na sua vulnerabilidade. A influência de fatores de localidade e acessibilidade são igualmente bem menos influentes do que a funcionalidade, conforme apresentado na Figura 4-6.

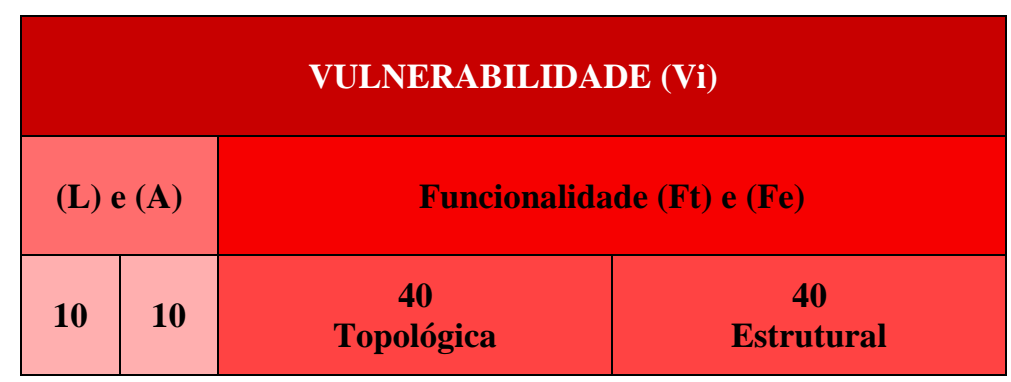

Figura 4.6 - Cenário 2 - cenário com maior influência do fator de funcionalidade. Fonte: elaborado pelo autor

O Cenário 3 apresenta uma situação inversa, onde a influência da funcionalidade é menor que a influência da localidade e da acessibilidade. Para isso, adota-se a hierarquização de fatores da funcionalidade topológica e funcionalidade estrutural como menos relevantes na influência da vulnerabilidade. A Figura 4-7 ilustra a distribuição da influência do Cenário 3.

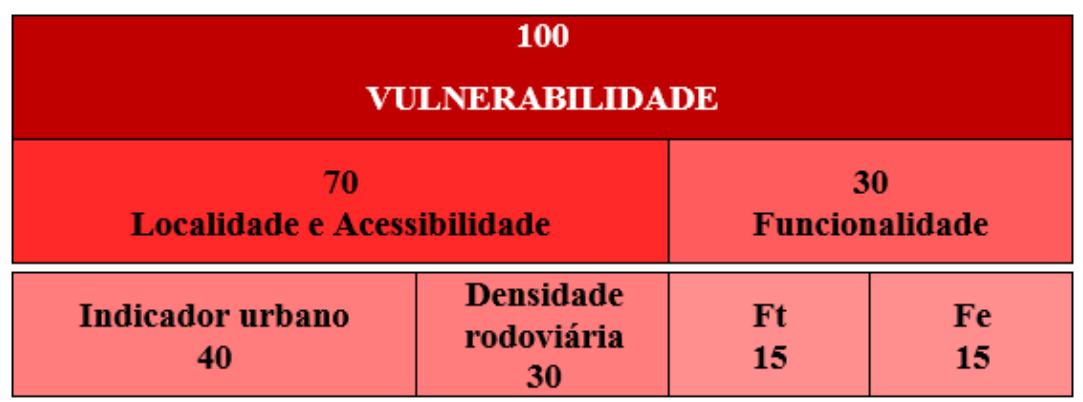

Figura 4.7 - Cenário 3 - cenário com maior influência do fator de Localidade. Fonte: elaborado pelo autor

A partir desta hierarquização arbitrária é possível estimar os valores dos coeficientes $\boldsymbol{X}, \boldsymbol{Y}$, $Z$, e depois da construção da estrutura de hierarquia gerar as matrizes de comparação para cada grupo de fatores e critérios.

O resultado obtido neste procedimento arbitrário está estabelecido na Tabela 4-1, que apresenta os valores estimados dos coeficientes de ponderação de influência para aplicação experimental do método em diferentes cenários. 
Tabela 4-1 - Valores estimados dos coeficientes a partir da hierarquização das variáveis

\begin{tabular}{c|c|c|c|c|c}
\hline COEFICIENTE & CRITÉRIOS & $\begin{array}{c}\text { VALOR } \\
\text { Cenário 1 }\end{array}$ & $\begin{array}{c}\text { VALOR } \\
\text { Cenário 2 }\end{array}$ & $\begin{array}{c}\text { VALOR } \\
\text { Cenário 3 }\end{array}$ & $\begin{array}{c}\text { VALOR } \\
\text { Cenário n }\end{array}$ \\
\hline$X$ & {$[11, \mathbf{1 2}, \mathbf{1 3}, \ldots$, In] } & $\mathbf{0 , 3 0}$ & $\mathbf{0 , 1 0}$ & $\mathbf{0 , 4 0}$ & (a) \\
\hline$Y$ & {$[\mathrm{a} 1, \mathbf{a} 2, \mathrm{a3}, \ldots$, an] } & $\mathbf{0 , 3 0}$ & $\mathbf{0 , 1 0}$ & $\mathbf{0 , 3 0}$ & (b) \\
\hline$Z$ & {$[\mathbf{f 1} 1 \mathrm{f2}, \mathbf{f 3}, \ldots, \mathrm{fn}]$} & $\mathbf{0 , 4 0}$ & $\mathbf{0 , 8 0}$ & $\mathbf{0 , 3 0}$ & (C) \\
\hline
\end{tabular}

Fonte: elaborado pelo autor

Conforme apresentado na Tabela 4-1, a análise da influência dos fatores por meio dos cenários adotados tem como condição a observação das possíveis distribuições dos fatores na vulnerabilidade dos nós do corredor logístico. No estabelecimento dos cenários é importante estabelecer pelo menos três situações, para então se verificar se houve mudança no nível de vulnerabilidade e se observar o comportamento dos indicadores da vulnerabilidade dos nós.

\subsection{ETAPA 4 - DETERMINAÇÃO DA VULNERABILIDADE DOS NÓS INTERMODAIS DE TRANSPORTE DE CARGA}

\subsection{1 - Definição da Equação do Modelo de Análise da Vulnerabilidade}

A formulação do modelo de análise da vulnerabilidade adota um indicador que considera as influências por meio dos atributos de localidade e acessibilidade inerentes aos nós, obtidos com dados disponíveis no Instituto Brasileiro de Geografia e Estatística - IBGE e Departamento Nacional de Infraestrutura de Transporte - DNIT. Adota também atributos de funcionalidade topológica e estrutural inerentes aos nós que são obtidos por meio de dados secundários oriundos de estudos e pesquisas do corredor logístico.

A formulação proposta do indicador de vulnerabilidade em razão da influência exercida pelos fatores citados é estimada em função dos critérios de localização, acessibilidade e funcionalidade dos nós intermodais, conforme apresentada na Equação 4-2.

$$
V=f(L, A, F)
$$


Para amparar metodologicamente a construção do indicador da vulnerabilidade, é necessário ponderar os valores atribuídos aos fatores. Importante estabelecer uma ponderação, ou seja, dar valor relativo aos critérios em relação à vulnerabilidade. Portanto, é estabelecido um coeficiente para cada parâmetro, conforme expresso na Equação 4.3. Os coeficientes representam o recurso matemático para a ponderação dos fatores para indicar quais os pesos dos fatores diante do indicador de vulnerabilidade.

$$
\mathrm{V}_{\mathrm{i}}=\text { Li. } . \mathrm{X}+\text { Ai. } \mathrm{Y}+\text { Fi.Z }
$$

Equação 4-3

Onde:

$\mathrm{V}_{\mathrm{i}}$ é a vulnerabilidade atribuída ao Nó i;

L é o indicador urbano e $x$ é o coeficiente de ponderação do fator de Localidade

A é o indicador de densidade rodoviária e y é o coeficiente do fator de Acessibilidade

F é o indicador da funcionalidade e z é o coeficiente do fator de Funcionalidade

\subsection{2 - Cálculo do indicador de vulnerabilidade dos nós}

É necessário ponderar os valores atribuídos aos fatores para aplicar a formulação proposta para uma análise da vulnerabilidade. Para que cada variável da Equação 4-2 entre com um valor de mesma ordem de grandeza, é necessário transformar as classes do indicador urbano em notas. Por se tratar de um estudo sobre uma rede de grande larga escala foi definida a utilização de três valores inteiros pelo o método matemático de tercil.

Para atribuir as notas elaborou-se o Quadro 4-2, que relaciona os tipos de indicador de cada variável com uma nota de valor inteiro e estabelece os dados ordenados em três subconjuntos de dados de mesma dimensão.

Para os tipos de indicador urbano foram atribuídas as notas 1, 2 e 3 que correspondem aos valores de $L_{i}$ na Equação 4-2 e o valor de $L$ é atribuído a partir da identificação do indicador urbano. 
Quadro 4-2 - Densidade Urbana e atribuição de Notas

\begin{tabular}{|c|c|c|c|}
\hline INDICADOR & \multicolumn{3}{|c|}{ ATRIBUTO } \\
\hline $\begin{array}{c}\text { Indicador Urbano } \\
\text { Nível de centralidade }\end{array}$ & MUITO DENSO & DENSO & POUCO DENSO \\
\hline NOTA & 3 & 2 & 1 \\
\hline
\end{tabular}

Para os tipos de densidade rodoviária foram atribuídas as notas 1, 2 e 3 que correspondem aos valores de $A_{i}$ na Equação 4-2 e o valor de A é atribuído a partir da identificação da Densidade Rodoviária. O Quadro 4-3 apresenta os intervalos de densidade e as respectivas notas.

Quadro 4-3- Densidade Rodoviária, atributos e notas

\begin{tabular}{|c|c|c|c|}
\hline INDICADOR & \multicolumn{3}{|c|}{ ATRIBUTOS } \\
\hline $\begin{array}{c}\text { Densidade } \\
\text { Rodoviária }\end{array}$ & ALTA & MEDIA & BAIXA \\
\hline NOTA & 1 & 2 & 3 \\
\hline
\end{tabular}

Fonte: elaborado pelo autor

Em relação as notas referentes aos tipos de transferências modais, ou seja a intermodalidade do nó, a utilização do método de tercil de adoção de valores inteiros de 1, 2 ou 3, não será considerado a nota 1 , pois seria atribuída para nós (mono) modais. $\mathrm{O}$ Quadro 4-4 relaciona os tipos de transferências modais e as respectivas notas.

Quadro 4-4 - Tipos de transferências e nota de integração

\begin{tabular}{|c|c|c|c|c|c|}
\hline & $\begin{array}{c}\text { Transferência } \\
\text { monomodal }\end{array}$ & \multicolumn{4}{|c|}{ Nós Intermodais de transporte de carga } \\
\hline $\begin{array}{c}\text { Integração } \\
\text { Modal }\end{array}$ & Não se aplica & $\begin{array}{c}\text { Rodoferroviário } \\
\text { ou } \\
\text { Ferrorrodoviário }\end{array}$ & $\begin{array}{c}\text { Rodoaquaviári } \\
\text { o ou } \\
\text { Aquarrodoviári } \\
\text { o }\end{array}$ & $\begin{array}{c}\text { Ferroaquaviário } \\
\text { ou } \\
\text { Aquaferroviário }\end{array}$ & $\begin{array}{c}\text { Rodoferro- } \\
\text { aquaviário ou } \\
\text { Aquaferro- } \\
\text { rodoviário }\end{array}$ \\
\hline $\begin{array}{c}\text { Atende 2 } \\
\text { modos }\end{array}$ & NÃO & SIM & SIM & SIM & SIM \\
\hline $\begin{array}{c}\text { Atende 3 } \\
\text { modos }\end{array}$ & NÃO & NÂO & NÂO & NÂO & SIM \\
\hline NOTA & $\mathbf{1}$ & $\mathbf{2}$ & $\mathbf{2}$ & $\mathbf{2}$ & $\mathbf{3}$ \\
\hline
\end{tabular}

Fonte: elaborado pelo autor 
$\mathrm{O}$ atributo de funcionalidade $(\mathrm{F})$ é a combinação da funcionalidade topológica $\left(\mathrm{F}_{\mathrm{T}}\right)$ e da funcionalidade estrutural $\left(\mathrm{F}_{\mathrm{E}}\right)$. Os procedimentos para obtenção de $\left(\mathrm{F}_{\mathrm{T}}\right)$ considera o tipo de nó intermodal quanto aos modos de transportes atendidos. Nesse caso, a nota 1 é desprezada, pois não são utilizados nós monomodais, para o qual o valor 1 estaria indicado. Portanto faremos uso apenas dos valores 2 e 3 , para dois modos de transportes e três modos de transportes respectivamente.

Para funcionalidade estrutural $\left(\mathrm{F}_{\mathrm{E}}\right)$ que correspondem às capacidades e serviços do nó para e que devem ser somadas e divididas por 3, número que corresponde ao número de atributos considerados (fluxo, equipamentos e serviços). Para determinar a funcionalidade estrutural optou-se por utilizar as notas e intervalos dispostos em Naves (2012) e adaptados para esse método. Os intervalos e notas adaptados estão apresentados no Quadro 4-5. São atribuídas notas 1, 2 ou 3 de acordo com os intervalos para que sejam valorados os principais atributos da funcionalidade estrutural.

Quadro 4-5 - Notas atribuídas a cada intervalo dos atributos de funcionalidade.

\begin{tabular}{|c|c|c|c|c|}
\hline Atributos & $\begin{array}{c}\text { Unidade de } \\
\text { medida }\end{array}$ & \multicolumn{2}{c|}{ Intervalos de valores observados } \\
\hline $\begin{array}{c}\text { Capacidade } \\
\text { operacional }\end{array}$ & Toneladas/hora & Abaixo de 280 & Entre 280 e 720 & Acima de 720 \\
\hline $\begin{array}{c}\text { Capacidade de } \\
\text { armazenagem }\end{array}$ & Toneladas & Abaixo de 25.000 & $\begin{array}{c}\text { De } 25.000 \text { até } \\
105.000\end{array}$ & Acima de 105.000 \\
\hline $\begin{array}{c}\text { Infraestrutura em } \\
\text { equipamentos }\end{array}$ & $\begin{array}{c}\text { Número de } \\
\text { equipamentos } \\
\text { Número de } \\
\text { serviços }\end{array}$ & Abaixo de 11 & Entre 11 e 19 & Acima de 19 \\
\hline $\begin{array}{c}\text { Serviços ofertados } \\
\text { NOTA }\end{array}$ & $\mathbf{1}$ & Entre 5 e 6 & Acima de 6 \\
\hline \multicolumn{2}{|c|}{} & $\mathbf{2}$ & $\mathbf{3}$ \\
\hline
\end{tabular}

Fonte: Naves (2012) - modificado

\subsection{TÓPICOS CONCLUSIVOS}

Sob o ponto de vista da vulnerabilidade a importância dos nós demonstra também que os nós mais importantes são aqueles que, no caso de falha ou diminuição de sua capacidade de funcionamento, são eles responsáveis por maiores prejuízos e danos ante os objetivos do Sistema de Transportes. Por isso, há necessidade de selecionar critérios mais associados e específicos em relação ao corredor logístico. 
Portanto, o indicador de vulnerabilidade de um único nó intermodal não é de grande utilidade, pois indicar a vulnerabilidade de um nó isoladamente. O indicador de vulnerabilidade do nó só se aplica quando analisado num contexto abrangente da rede intermodal da qual o ele é elemento componente. Para isso a aplicação do método é apresentada no Capítulo 5, no estudo de caso de um corredor logístico do Sistema Nacional de Viação com adoção de três cenários da distribuição da influência da vulnerabilidade.

No entanto ainda é necessário ponderar os valores atribuídos aos fatores para aplicar a formulação proposta para uma análise da vulnerabilidade mais próxima da realidade o que requer informações que são inerentes aos operadores de carga no determinado corredor logístico.

Para isso é importante identificar os operadores logísticos que atuam na área de estudo. A identificação dos operadores de transporte multimodal é importante para ponderar, ou seja, para atribuir valor relativo aos critérios em relação à vulnerabilidade. É também necessário para equacionar os parâmetros do indicador de vulnerabilidade e estimar um valor qualitativo da influência mais próximo da realidade por meio da validação e opinião de planejadores da esfera pública e também agentes (atores) da esfera privada, o que permite a hierarquização dos critérios para determinar (verificar) quais os fatores de maior influência na determinação da vulnerabilidade do nó. 


\section{ESTUDO DE CASO - ANÁLISE DA VULNERABILIDADE DE NÓS INTERMODAIS DE TRANSPORTE DE CARGA DO CORREDOR LOGÍSTICO SUDESTE}

\subsection{APRESENTAÇÃO}

Neste capítulo apresenta-se a aplicabilidade do modelo de análise da vulnerabilidade de Nós Intermodais de transporte de carga de corredor logístico. Para aplicação do método, foi adotado um conjunto de nós da rede intermodal de escoamento de grãos da região Centro-Oeste, a maioria desses nós estão localizados no Corredor Logístico Sudeste definido pelo PNLT. A seleção desse conjunto de nós também é devido à disponibilidade de dados sobre terminais intermodais em Naves (2012).

Foram estabelecidos três cenários para se observar as alterações no comportamento dos indicadores da vulnerabilidade dos nós.

\subsection{DELIMITAÇÃO DE ÁREA DO ESTUDO DE CASO}

Atualmente a produtividade do cultivo de soja no Estado do Mato Grosso é referência mundial, chegando a 3190 quilogramas por hectare. Numa projeção para 2019, a produção nacional deve representar $40 \%$ do comércio mundial de grãos e $73 \%$ do óleo de soja. Em 2011 foi registrada uma produção de 69,23 milhões de toneladas, sendo que 55\% deste total foram produzidas na região Centro-Oeste. Só o Estado do Mato Grosso, por exemplo, produz atualmente mais de $30 \%$ de toda a produção brasileira de soja (CONAB, 2012).

Apesar dos números apresentados, o agronegócio brasileiro esbarra em deficiências encontradas na infraestrutura de transporte. Os altos gastos com logística representam um dos principais limitantes para o crescimento da economia da região Centro-Oeste e do Brasil. Os custos logísticos no Brasil em relação aos de outros países são mais elevados, o que torna a produção menos rentável para o produtor, causando perda de competitividade (Naves, 2012).

O corredor de transporte do Centro-Oeste é o responsável pelo escoamento da safra agrícola produzidas nesta região para as regiões processadoras e exportadoras desses produtos. Abrange os estados de Mato Grosso, Mato Grosso do Sul, Goiás, São Paulo, 
Minas Gerais e Paraná. Este corredor é composto pelos seguintes elementos: modais de transporte, terminais de transbordo de mercadorias, armazéns de carga, operadores de transportes, entre outros serviços associados (Teixeira, 2010). O modo rodoviário é o mais utilizado para o escoamento da safra agrícola na região Centro Oeste, comparativamente aos modais hidroviário e ferroviário, o modo rodoviário tem o maior custo de transporte e maior emissão de poluentes e o nível de acidentes do modo rodoviário também maior entre os demais modos.

O transporte de carga por meio ferroviário, no Corredor Logístico do Centro Sudeste, representa aproximadamente $4,3 \%$ da movimentação nacional e está concentrado principalmente na ferrovia ALL Malha Norte, anteriormente denominada Ferronorte. O modal hidroviário, nesse corredor, compreende a Hidrovia Tietê-Paraná, que interliga cinco estados brasileiros (Goiás, Minas Gerais, Mato Grosso do Sul, Paraná e São Paulo) por cerca de 1.650 quilômetros de vias fluviais navegáveis. Desta maneira se delimita a área do estudo de caso. A Figura 5-1 ilustra a área selecionada para o estudo de caso.

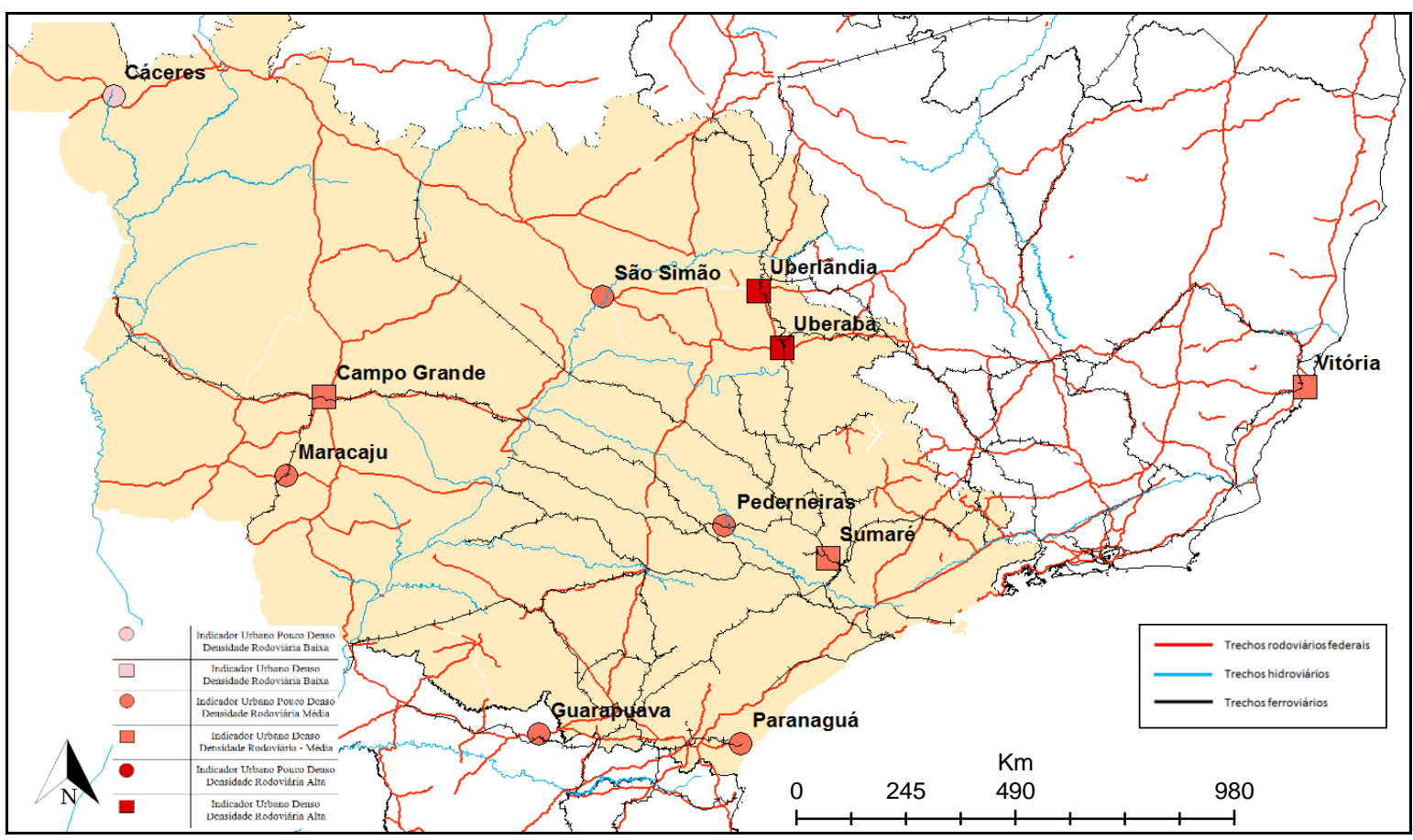

Figura 5-1 - Delimitação de área do estudo de caso Corredor Logístico Sudeste Fonte: elaborado pelo autor a partir da base de dados DNIT e Teixeira (et al., 2010)

As principais rodovias do corredor são BR-163, BR-364, BR 262, BR 153 e, como parte da reorientação do escoamento da produção regional, concluiu-se recentemente o 
prolongamento e a pavimentação das rodovias BR-070 e BR-174. O sistema hidroviário é composto pela hidrovia do rio Paraguai com extensão navegável no trecho brasileiro com cerca de $890 \mathrm{~km}$ e pela hidrovia do rio Paraná que possui extensão navegável da ordem de $1.020 \mathrm{~km}$.

Em relação aos trechos ferroviários a região conta com a Ferronorte e a Novoeste, que ligam o Estado do Mato Grosso e o Estado do Mato Grosso do Sul ao Porto de Santos, respectivamente. A Ferroban, que atua no Estado de São Paulo, e também com a Ferroeste e a Ferropar, que ligam Londrina e Maringá, respectivamente ao Porto de Paranaguá.

Segundo ANTT (2015), o Brasil conta com cerca de 510 empresas cadastradas como operadoras de transporte multimodal (OTM). Deve-se portanto selecionar aqueles atuantes no corredor em estudo. Os Nós Intermodais e as respectivas localizações estão relacionados no Quadro 5-1. Correspondem aos terminais entrevistados na pesquisa de campo apresentada em Naves (2012).

Quadro 5-1 - Localidade e intermodalidade do nós Intermodais da área de estudo

\begin{tabular}{|c|c|c|c|c|}
\hline & $\begin{array}{c}\text { Localização } \\
\text { (Município) }\end{array}$ & $\begin{array}{c}\text { Código } \\
\text { NAVES } \\
(2012)\end{array}$ & $\begin{array}{c}\text { Código } \\
\text { Vulnerabilidade }\end{array}$ & Intermodalidade \\
\hline 1 & Alto Araguaia & 4 CO & V1 & R-F \\
\hline 2 & Cáceres & $1 \mathrm{CO}$ & V2 & R-A \\
\hline 3 & Cáceres & $2 \mathrm{CO}$ & V3 & R-A \\
\hline 4 & Campo Grande & $5 \mathrm{CO}$ & V4 & R-F \\
\hline 5 & Guarapuava & $11 \mathrm{~S}$ & V5 & R-F \\
\hline 6 & Maracaju & $8 \mathrm{CO}$ & V6 & R-F \\
\hline 7 & Paranaguá & $13 \mathrm{~S}$ & V7 & F-R \\
\hline 8 & Paranaguá & $14 \mathrm{~S}$ & V8 & R-F \\
\hline 9 & Pederneiras & $27 \mathrm{SE}$ & V9 & A-F \\
\hline 10 & São Simão & $6 \mathrm{CO}$ & V10 & R-A \\
\hline 11 & São Simão & $7 \mathrm{CO}$ & V11 & R-A \\
\hline 12 & Sumaré & $28 \mathrm{SE}$ & V12 & F-R \\
\hline 13 & Uberaba & $22 \mathrm{SE}$ & V13 & R-F \\
\hline 14 & Uberaba & $24 \mathrm{SE}$ & V14 & R-F \\
\hline 15 & Uberlândia & $21 \mathrm{SE}$ & V15 & R-F \\
\hline 16 & Uberlândia & $23 \mathrm{SE}$ & V16 & R-F \\
\hline 17 & Uberlândia & $29 \mathrm{SE}$ & V17 & R-F \\
\hline 18 & Vitória & $26 \mathrm{SE}$ & V18 & F-A \\
\hline
\end{tabular}




\subsection{DETERMINAÇÃO DOS ATRIBUTOS POR MEIO DA CARACTERIZAÇÃO DOS NÓS INTERMODAIS}

O Quadro 5-2 apresenta as interações entre os atributos dos fatores de localidade e acessibilidade, o que corresponde a interação de sobreposição entre os atributos desses fatores. O Indicador Urbano é tipificado em Muito Denso; Denso e Pouco Denso e a Densidade Rodoviária em Baixa; Média e Alta. Uma interação entre esses atributos resulta em um tipo de influência na vulnerabilidade que pode ser Baixa; Média; Alta ou Muito Alta.

Quadro 5-2 - Interação entre os atributos de localidade e acessibilidade

\begin{tabular}{|c|c|c|c|c|}
\hline & & \multicolumn{3}{|c|}{ Densidade Rodoviária } \\
\hline & & Baixa & Média & Alta \\
\hline \multirow{3}{*}{$\begin{array}{c}\text { Indicador } \\
\text { Urbano }\end{array}$} & Muito Denso & $\begin{array}{c}\text { Influência } \\
\text { Alta }\end{array}$ & $\begin{array}{l}\text { Influência } \\
\text { Muito Alta }\end{array}$ & $\begin{array}{l}\text { Influência } \\
\text { Muito Alta }\end{array}$ \\
\hline & Denso & $\begin{array}{l}\text { Influência } \\
\text { Média }\end{array}$ & $\begin{array}{c}\text { Influência } \\
\text { Alta }\end{array}$ & $\begin{array}{c}\text { Influência } \\
\text { Alta }\end{array}$ \\
\hline & Pouco Denso & $\begin{array}{c}\text { Influência } \\
\text { Baixa }\end{array}$ & $\begin{array}{l}\text { Influência } \\
\text { Média }\end{array}$ & $\begin{array}{l}\text { Influência } \\
\text { Média }\end{array}$ \\
\hline
\end{tabular}

O Quadro 5-3 apresenta a caracterização dos Nós Intermodais e atribuição dos indicadores realizados com dados disponibilizados no Anexo 1 e Anexo 2.

Quadro 5-3 - Caracterização do Indicador Urbano e Densidade Rodoviária dos Nós

\begin{tabular}{|c|c|c|c|}
\hline Localização & $\begin{array}{c}\text { Indicador } \\
\text { Urbano }\end{array}$ & $\begin{array}{c}\text { Densidade } \\
\text { Rodoviária }\end{array}$ \\
\hline 1 & Alto Araguaia & Pouco denso & Baixa \\
\hline 2 & Cáceres & Pouco denso & Baixa \\
\hline 3 & Cáceres & Pouco denso & Baixa \\
\hline 4 & Campo Grande & Denso & Média \\
\hline 5 & Guarapuava & Denso & Media \\
\hline 6 & Maracaju & Pouco Denso & Baixa \\
\hline 7 & Paranaguá & Pouco denso & Média \\
\hline 8 & Paranaguá & Pouco denso & Média \\
\hline 9 & Pederneiras & Pouco denso & Media \\
\hline 10 & São Simão & Pouco denso & Média \\
\hline 11 & São Simão & Pouco denso & Média \\
\hline 12 & Sumaré & Denso & Media \\
\hline 13 & Uberaba & Denso & Média \\
\hline 14 & Uberaba & Denso & Média \\
\hline 15 & Uberlândia & Denso & Média \\
\hline 16 & Uberlândia & Denso & Média \\
\hline 17 & Uberlândia & Denso & Média \\
\hline 18 & Vitória & Denso & Média \\
\hline
\end{tabular}


A Figura 5-2 representa a rede de nós com amostra 18 nós que compõe a base de dados desse estudo de caso. Optou-se em selecionar nós localizados para atender o a produção de grãos do centro - oeste chamado de corredor centro-oeste (Teixeira et. al., 2010).

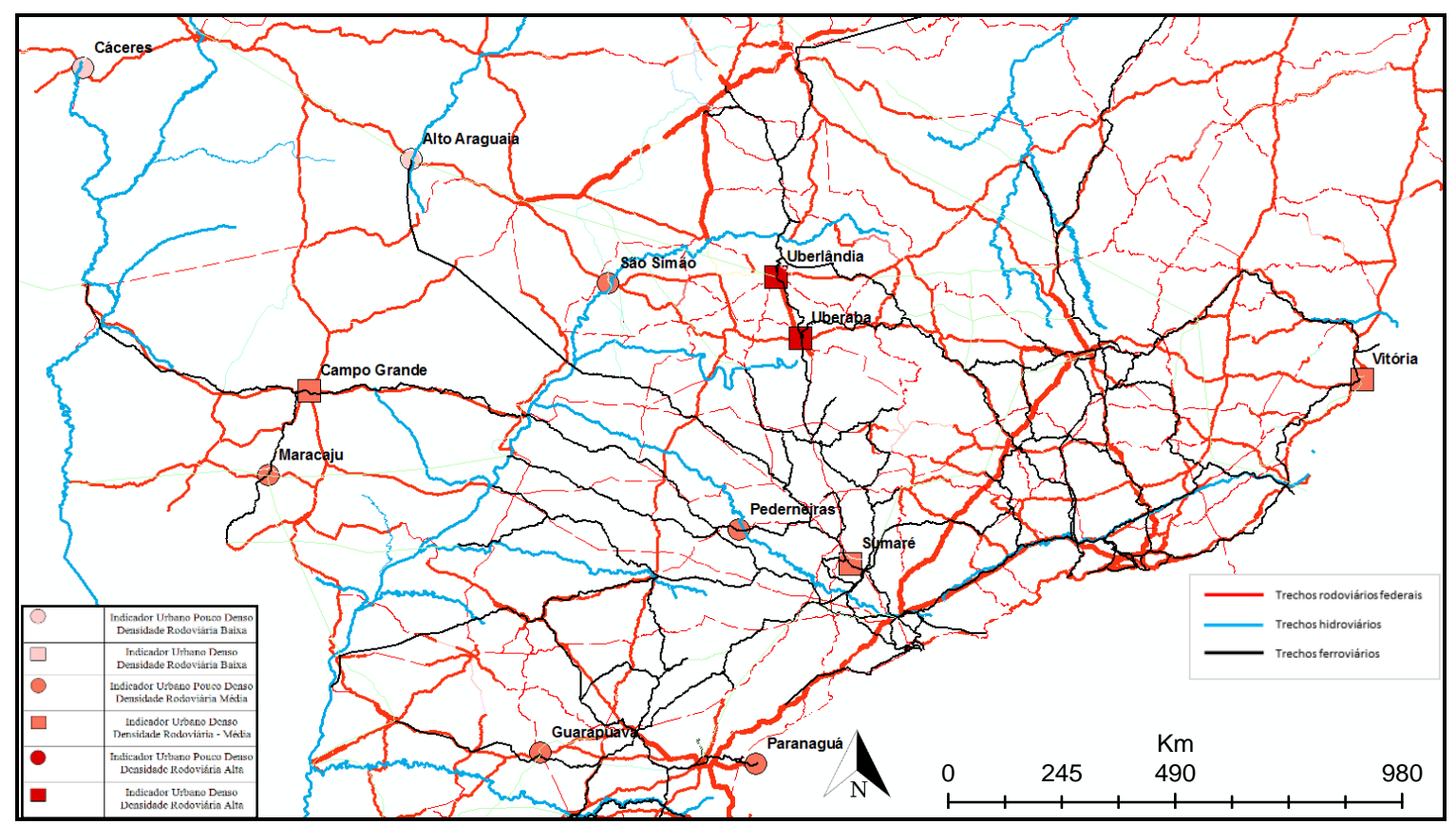

Figura 5-2 - Mapa de localização dos nós intermodais do estudo de caso Fonte: elaborado pelo autor a partir da base de dados do DNIT

Outro importante critério é que o terminal que correspondem ao nó intermodal da pesquisa deve ter sido submetido à coleta de dados de mesma fonte. Esse critério permite aplicar com mais segurança os intervalos de valores para determinar a funcionalidade estrutural, pois requer informações operacionais como o número de equipamentos.

\subsubsection{Determinação dos atributos de Localidade e de Acessibilidade}

Utilizando a relação de nós intermodais do Quadro 5-1, foram atribuídas as notas do Quadro 5-4 dos os tipos de indicador urbano e densidade rodoviária e determinados os valores de $\mathrm{L}_{1-18}$ e de $\mathrm{A}_{1-18}$ e a Tabela 5-2 apresenta o resultado numérico.

Quadro 5-4 - Tipos de indicador urbano e densidade rodoviária e notas atribuídas

\begin{tabular}{|l|c|c|c|}
\hline Nota & $\mathbf{3}$ & $\mathbf{2}$ & $\mathbf{1}$ \\
\hline Indicador Urbano & Muito Denso & Denso & Pouco Denso \\
\hline Densidade Rodoviária & Alta & Média & Baixa \\
\hline
\end{tabular}


Tabela 5-2 - Resultado das determinações de (L) e (A) e atribuição de notas

\begin{tabular}{c|c|c|c}
\hline & $\begin{array}{c}\text { Localização } \\
\text { (Município) }\end{array}$ & $\begin{array}{c}\text { Indicador } \\
\text { Urbano (L) }\end{array}$ & $\begin{array}{c}\text { Densidade } \\
\text { Rodoviária (A) }\end{array}$ \\
\hline 1 & Alto Araguaia & 1 & 1 \\
\hline 2 & Cáceres & 1 & 1 \\
\hline 3 & Cáceres & 1 & 2 \\
\hline 4 & Campo Grande & 2 & 2 \\
\hline 5 & Guarapuava & 2 & 2 \\
\hline 6 & Maracaju & 1 & 2 \\
\hline 7 & Paranaguá & 1 & 2 \\
\hline 8 & Paranaguá & 1 & 2 \\
\hline 9 & Pederneiras & 1 & 2 \\
\hline 10 & São Simão & 1 & 2 \\
\hline 11 & São Simão & 1 & 2 \\
\hline 12 & Sumaré & 2 & 2 \\
\hline 13 & Uberaba & 2 & 2 \\
\hline 14 & Uberaba & 2 & 2 \\
\hline 15 & Uberlândia & 2 & 2 \\
\hline 16 & Uberlândia & 2 & \\
\hline 17 & Uberlândia & 2 & 2 \\
\hline 18 & Vitória & 2 & 2 \\
\hline
\end{tabular}

\subsubsection{Determinação dos atributos de Funcionalidade topológica}

Com auxílio do Quadro 4-5 e dos dados secundários de (Naves, 2012), no Anexo 3, são atribuídas as notas da funcionalidade topológica de cada nó. A Tabela 5-3 apresenta o resultado dessa determinação da funcionalidade topológica e foi atribuída nota 2 para todos os nós.

Tabela 5-3 - Determinação da funcionalidade topológica

\begin{tabular}{c|c|c|c|c}
\hline & $\begin{array}{c}\text { Localização } \\
\text { Município) }\end{array}$ & $\begin{array}{c}\text { Código } \\
\text { NAVES } \\
(\mathbf{2 0 1 2})\end{array}$ & \multicolumn{2}{|c}{ Intermodalidade } \\
\hline 1 & Alto Araguaia & 4 CO & 2 & R-F \\
\hline 2 & Cáceres & 1 CO & 2 & R-A \\
\hline 3 & Cáceres & 2 CO & 2 & R-A \\
\hline 4 & Campo Grande & 5 CO & 2 & R-F \\
\hline 5 & Guarapuava & $11 \mathrm{~S}$ & 2 & R-F \\
\hline 6 & Maracaju & $8 \mathrm{CO}$ & 2 & R-F \\
\hline 7 & Paranaguá & $13 \mathrm{~S}$ & 2 & F-R \\
\hline 8 & Paranaguá & $14 \mathrm{~S}$ & 2 & R-F \\
\hline 9 & Pederneiras & $27 \mathrm{SE}$ & 2 & A-F \\
\hline 10 & São Simão & $6 \mathrm{CO}$ & 2 & R-A \\
\hline 11 & São Simão & $7 \mathrm{CO}$ & 2 & R-A \\
\hline 12 & Sumaré & $28 \mathrm{SE}$ & 2 & F-R \\
\hline 13 & Uberaba & $22 \mathrm{SE}$ & 2 & R-F \\
\hline 14 & Uberaba & $24 \mathrm{SE}$ & 2 & R-F \\
\hline 15 & Uberlândia & $21 \mathrm{SE}$ & 2 & R-F \\
\hline 16 & Uberlândia & $23 \mathrm{SE}$ & 2 & R-F \\
\hline 17 & Uberlândia & $29 \mathrm{SE}$ & 2 & R-F \\
\hline 18 & Vitória & $26 \mathrm{SE}$ & 2 & F-A \\
\hline & & & & 2 \\
\hline
\end{tabular}


A Figura 5-3 apresenta os dezoitos nós da amostra com a representação de sua intermodalidade e direção do fluxo unidirecional de carga.

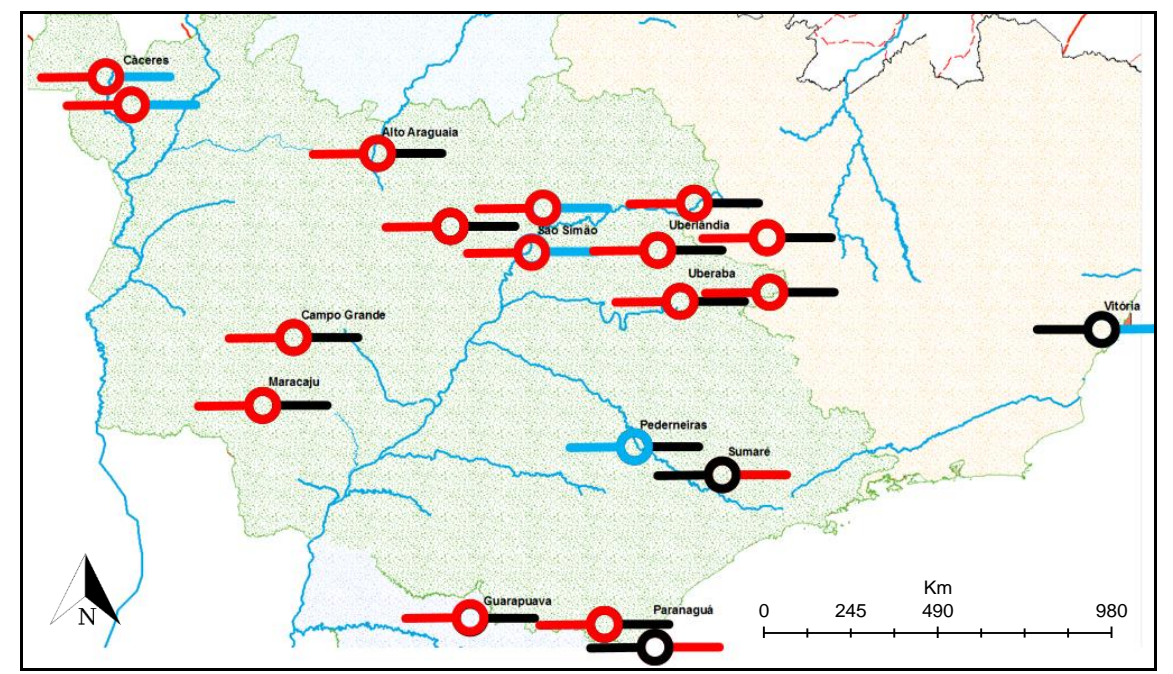

Figura 5-3 - Rede de nós do corredor Sudeste e tipo de intermodalidade Fonte: elaborado pelo autor a partir da base de dados do DNIT

\subsubsection{Determinação dos atributos de Funcionalidade estrutural}

Para determinação dos atributos de funcionalidade estrutural são utilizados a capacidade operacional de armazenagem e o número de equipamentos disponibilizados e dos serviços de intermodalidade oferecidos. A Tabela 5-4 apresenta o resultado para cada nó Intermodal

Tabela 5-4 - Valores da Funcionalidade Estrutural

\begin{tabular}{r|l|r|r|r|r|r|r|r}
\hline & $\begin{array}{c}\text { Localização } \\
\text { (Município) }\end{array}$ & $\begin{array}{c}\text { Código } \\
\text { NAVES } \\
(\mathbf{2 0 1 2})\end{array}$ & $\begin{array}{c}\text { Cap. } \\
\text { Oper. }\end{array}$ & $\begin{array}{c}\text { Cap. } \\
\text { Armaz. }\end{array}$ & $\begin{array}{c}\text { Infr. } \\
\text { Equip. }\end{array}$ & Serv. & Total & $\mathbf{F}_{\mathbf{E i}}$ \\
\hline 1 & Alto Araguaia & $4 \mathrm{CO}$ & 3 & 2 & 2 & 1 & 8 & $\mathbf{2}$ \\
\hline 2 & Cáceres & $1 \mathrm{CO}$ & 2 & 1 & 1 & 1 & 5 & $\mathbf{1 , 2 5}$ \\
\hline 3 & Cáceres & $2 \mathrm{CO}$ & 1 & 1 & 1 & 1 & 4 & $\mathbf{1}$ \\
\hline 4 & Campo Grande & $5 \mathrm{CO}$ & 1 & 2 & 3 & 2 & 8 & $\mathbf{2}$ \\
\hline 5 & Guarapuava & $11 \mathrm{~S}$ & 2 & 2 & 3 & 3 & 10 & $\mathbf{2 , 5}$ \\
\hline 6 & Maracaju & $8 \mathrm{CO}$ & 1 & 1 & 2 & 2 & 6 & $\mathbf{1 , 5}$ \\
\hline 7 & Paranaguá & $13 \mathrm{~S}$ & 2 & 2 & 3 & 2 & 9 & $\mathbf{2 , 2 5}$ \\
\hline 8 & Paranaguá & $14 \mathrm{~S}$ & 2 & 2 & 3 & 2 & 9 & $\mathbf{2 , 2 5}$ \\
\hline 9 & Pederneiras & $27 \mathrm{SE}$ & 2 & 2 & 2 & 1 & 7 & $\mathbf{1 , 7 5}$ \\
\hline 10 & São Simão & $6 \mathrm{CO}$ & 2 & 2 & 3 & 3 & 10 & $\mathbf{2 , 5}$ \\
\hline 11 & São Simão & $7 \mathrm{CO}$ & 2 & 1 & 1 & 3 & 7 & $\mathbf{1 , 7 5}$ \\
\hline 12 & Sumaré & $28 \mathrm{SE}$ & 2 & 3 & 3 & 2 & 10 & $\mathbf{2 , 5}$ \\
\hline 13 & Uberaba & $22 \mathrm{SE}$ & 1 & 3 & 2 & 2 & 8 & $\mathbf{2}$ \\
\hline 14 & Uberaba & $24 \mathrm{SE}$ & 1 & 1 & 2 & 3 & 7 & $\mathbf{1 , 7 5}$ \\
\hline 15 & Uberlândia & $21 \mathrm{SE}$ & 1 & 3 & 3 & 2 & 9 & $\mathbf{2 , 2 5}$ \\
\hline 16 & Uberlândia & $23 \mathrm{SE}$ & 1 & 2 & 2 & 3 & 8 & $\mathbf{2}$ \\
\hline 17 & Uberlândia & $29 \mathrm{SE}$ & 1 & 3 & 2 & 2 & 8 & $\mathbf{2}$ \\
\hline 18 & Vitória & $26 \mathrm{SE}$ & 2 & 3 & 3 & 1 & 9 & $\mathbf{2 , 2 5}$ \\
\hline
\end{tabular}


O Quadro 4-6, no Capítulo 4, apresenta os intervalos de valores e com o auxílio daquele quadro são atribuídas as notas para cada intervalo de valores de (Naves, 2012).

Para a determinação dos atributos de Funcionalidade são utilizados basicamente dados da movimentação de carga em toneladas movimentadas por ano e do tipo de transferência modal que o terminal opera, bem como a relação dos equipamentos de apoio ao transbordo. A Tabela 5-1 apresenta o resultado da determinação de (F). Para o alcance do resultado de $(\mathrm{F})$ os valores $(\mathrm{Ft})$ e $(\mathrm{Fe})$ foram somados e divididos por dois.

Tabela 5-1 - Valores da Funcionalidade

\begin{tabular}{|c|c|c|c|c|}
\hline & $\begin{array}{l}\text { Localização } \\
\text { (Município) }\end{array}$ & $\begin{array}{c}\text { Código } \\
\text { NAVES } \\
(\mathbf{2 0 1 2})\end{array}$ & Ft & $\mathbf{F}_{\mathbf{E i}}$ \\
\hline 1 & Alto Araguaia & $4 \mathrm{CO}$ & 2 & 2 \\
\hline 2 & Cáceres & $1 \mathrm{CO}$ & 2 & 1,25 \\
\hline 3 & Cáceres & $2 \mathrm{CO}$ & 2 & 1 \\
\hline 4 & Campo Grande & $5 \mathrm{CO}$ & 2 & 2 \\
\hline 5 & Guarapuava & $11 \mathrm{~S}$ & 2 & 2,5 \\
\hline 6 & Maracaju & $8 \mathrm{CO}$ & 2 & 1,5 \\
\hline 7 & Paranaguá & $13 \mathrm{~S}$ & 2 & 2,25 \\
\hline 8 & Paranaguá & $14 \mathrm{~S}$ & 2 & 2,25 \\
\hline 9 & Pederneiras & $27 \mathrm{SE}$ & 2 & 1,75 \\
\hline 10 & São Simão & $6 \mathrm{CO}$ & 2 & 2,5 \\
\hline 11 & São Simão & $7 \mathrm{CO}$ & 2 & 1,75 \\
\hline 12 & Sumaré & $28 \mathrm{SE}$ & 2 & 2,5 \\
\hline 13 & Uberaba & $22 \mathrm{SE}$ & 2 & 2 \\
\hline 14 & Uberaba & $24 \mathrm{SE}$ & 2 & $\mathbf{1 , 7 5}$ \\
\hline 15 & Uberlândia & $21 \mathrm{SE}$ & 2 & 2,25 \\
\hline 16 & Uberlândia & $23 \mathrm{SE}$ & 2 & 2 \\
\hline 17 & Uberlândia & $29 \mathrm{SE}$ & 2 & 2 \\
\hline 18 & Vitória & $26 \mathrm{SE}$ & 2 & 2,25 \\
\hline
\end{tabular}

Da Equação 4-2 proposta de indicador da vulnerabilidade de um nó intermodal, após a determinação dos atributos (L), (A) e (F) obtém-se a Equação 5-1, a equação de influência de fatores na vulnerabilidade.

$$
\mathrm{V}_{1-18}=\left(\mathrm{X} \cdot \mathrm{L}_{1-18}\right)+\left(\mathrm{Y} \cdot \mathrm{A}_{1-18}\right)+\left(\mathrm{Z} \cdot \mathrm{F}_{1-18}\right)
$$

\section{Equação 5-1}

Além dos componentes já conhecidos, a Equação 5-1 apresenta o número de nós intermodais do estudo de caso, para estimar a vulnerabilidade $\mathrm{V}_{1-18}$. No entanto, para que 
essa equação alcance como resultados a estimativa de vulnerabilidade para cada nó intermodal é necessário a hierarquização dos fatores através da indicação de cenários.

O resultado da determinação dos valores de (Li); (Ai) e (Fi) estão apresentados na Tabela 5-2 que apresenta também a equação da vulnerabilidade para cada nó.

Tabela 5-2 - Valores dos fatores e equações da vulnerabilidade por nó.

\begin{tabular}{|c|c|c|c|c|c|c|}
\hline Nós & $\begin{array}{l}\text { Localização } \\
\text { (Município) }\end{array}$ & $\begin{array}{c}\text { Código } \\
\text { Vulnerabilidade }\end{array}$ & $\mathbf{L}$ & $\mathbf{A}$ & $\mathbf{F}$ & $\begin{array}{c}\text { Equação de } \\
\text { influência na } \\
\text { vulnerabilidade } \\
\text { (Vi) }\end{array}$ \\
\hline 1 & Alto Araguaia & V1 & 1 & 1 & 2 & $\mathrm{X} .1+\mathrm{Y} .1+\mathrm{Z} .2$ \\
\hline 2 & Cáceres & $\mathrm{V} 2$ & 1 & 1 & 1,25 & $\mathrm{X} .1+\mathrm{Y} .1+\mathrm{Z} .1,25$ \\
\hline 3 & Cáceres & V3 & 1 & 1 & 1 & X.1+Y.1+Z.1 \\
\hline 4 & Campo Grande & V4 & 2 & 2 & 2 & X.2+Y.2+Z.2 \\
\hline 5 & Guarapuava & V5 & 2 & 2 & 2,5 & X.2+Y.2+Z.2,5 \\
\hline 6 & Maracaju & V6 & 2 & 1 & 1,5 & $X .2+Y .1+Z .1,5$ \\
\hline 7 & Paranaguá & V7 & 1 & 2 & 2,25 & $\mathrm{X} .1+\mathrm{Y} .2+\mathrm{Z} .2,25$ \\
\hline 8 & Paranaguá & V8 & 1 & 2 & 2,25 & $\mathrm{X} .1+\mathrm{Y} .2+\mathrm{Z} .2,25$ \\
\hline 9 & Pederneiras & V9 & 1 & 1 & 1,75 & $\mathrm{X} .1+\mathrm{Y} .1+\mathrm{Z} .1 .75$ \\
\hline 10 & São Simão & V10 & 1 & 2 & 2,5 & X.1 $1+Y .2+Z .2,5$ \\
\hline 11 & São Simão & V11 & 1 & 2 & 1,75 & $X .1+Y .2+Z .1 .75$ \\
\hline 12 & Sumaré & V12 & 2 & 2 & 2,5 & X.2+Y.2+Z.2,5 \\
\hline 13 & Uberaba & V13 & 2 & 2 & 2 & X.2+Y.2+Z.2 \\
\hline 14 & Uberaba & V14 & 2 & 2 & 1,75 & $\mathrm{X} .1+\mathrm{Y} .1+\mathrm{Z} .1,75$ \\
\hline 15 & Uberlândia & V15 & 2 & 2 & 2,25 & $\mathrm{X} .1+\mathrm{Y} .1+\mathrm{Z} .2,25$ \\
\hline 16 & Uberlândia & V16 & 2 & 2 & 2 & $\mathrm{X} .1+\mathrm{Y} .1+\mathrm{Z} .2$ \\
\hline 17 & Uberlândia & V17 & 2 & 2 & 2 & X. $2+Y .2+Z .2$ \\
\hline 18 & Vitória & V18 & 2 & 2 & 2,25 & X.1 $1+$ Y.2 $2+$ Z.2,25 \\
\hline
\end{tabular}

\subsection{HIERARQUIZAÇÃO DOS FATORES - INDICAÇÃO DE CENÁRIOS}

As análises de cenários são utilizadas em estudos na área de planejamento, o que permite a adoção de alternativas que complementam os modelos de análise. Essas alternativas estabelecidas com a adoção de cenários são adotadas para auxiliar na análise de fatores de influência e também na tomada de decisão, tanto na esfera pública quanto na esfera privada (Cunha Filho, 2014).

No Cenário 1 os fatores Localidade e Acessibilidade presumem maior influência na vulnerabilidade do que a Funcionalidade. A distribuição da influência na Funcionalidade 
corresponde ao mesmo valor para o grau de intermodalidade e as capacidades, de armazenagem e operacional, relacionadas ao fluxo. A influência dos dois fatores Localidade e Acessibilidade - tem proporção de $60 \%$ em relação a Funcionalidade que tem $40 \%$ do valor referente. Neste Cenário os coeficientes atribuídos são: $X=0,30 ; Y=0,30$ e $\mathrm{Z}=$ 0,40. A Equação 5-2 expressa a formulação do Cenário 1.

$$
\mathrm{V}_{1-18}=\left(0,3 \cdot \mathrm{L}_{1-18}\right)+\left(0,3 \cdot \mathrm{A}_{1-18}\right)+\left(0,4 \cdot \mathrm{F}_{1-18}\right)
$$

Equação 5-2

O Cenário 2 propõe que a Funcionalidade do nó tem maior influência na vulnerabilidade. A influência de fatores de Localidade e Acessibilidade são igualmente bem menos influentes do que a Funcionalidade. No Cenário 2 os coeficientes atribuídos são: $X=0,10$; $\mathrm{Y}=0,10$ e $\mathrm{Z}=$ 0,80. A Equação 5-3 expressa a formulação do Cenário 2.

$$
\mathrm{V}_{1-18}=\left(0,1 \cdot \mathrm{L}_{1-18}\right)+\left(0,1 \cdot \mathrm{A}_{1-18}\right)+\left(0,8 \cdot \mathrm{F}_{1-18}\right)
$$

Equação 5-3

O Cenário 3 apresenta uma situação inversa em que a influência da Funcionalidade é menor que a influência da Localidade e da Acessibilidade, para isso, adota-se a hierarquização de fatores da Funcionalidade Topológica e Funcionalidade Estrutural como menos relevantes na influência da vulnerabilidade. No Cenário 3 os coeficientes atribuídos são: $X=0,10 ; Y=0,10$ e $Z=0,80$. A Equação 5-4 expressa a formulação do Cenário 3.

$$
\mathrm{V}_{1-18}=\left(0 \cdot 4 \cdot \mathrm{L}_{1-18}\right)+\left(0 \cdot 3 \cdot \mathrm{A}_{1-18}\right)+\left(0,3 \cdot \mathrm{F}_{1-18}\right)
$$

Equação 5-4

A partir desta hierarquização arbitrária é possível estimar os valores dos coeficientes $\boldsymbol{X}, \boldsymbol{Y}$, Z. e depois da construção da estrutura de hierarquia gerar as matrizes de comparação para cada grupo de fatores e critérios. O resultado obtido neste procedimento está estabelecido na Tabela 4-1 que apresenta os valores estimados dos coeficientes de ponderação de influência para aplicação experimental do método em diferentes cenários. 


\subsection{DETERMINAÇÃO DA VULNERABILIDADE DOS NÓS INTERMODAIS DO CORREDOR SUDESTE}

Para a determinação dos fatores adota-se os valores de coeficientes conforme indicado na Tabela 5-3, a análise da influência dos fatores por meio dos cenários tem como condição a observação das possíveis distribuições dos fatores na vulnerabilidade dos nós.

Tabela 5-3 - Valores estimados dos coeficientes a partir da hierarquização das variáveis

\begin{tabular}{c|c|c|c|c|c}
\hline Coeficiente & Critérios & $\begin{array}{c}\text { Valor } \\
\text { Cenário 1 }\end{array}$ & $\begin{array}{c}\text { Valor } \\
\text { Cenário 2 }\end{array}$ & $\begin{array}{c}\text { Valor } \\
\text { Cenário 3 }\end{array}$ & $\begin{array}{c}\text { Valor } \\
\text { Cenário n }\end{array}$ \\
\hline$X$ & {$[11,12,13, \ldots, \mathrm{ln}]$} & 0,30 & 0,10 & 0,40 & (a) \\
\hline$Y$ & {$[\mathrm{a} 1, \mathrm{a} 2, \mathrm{a} 3, \ldots, \mathrm{an}]$} & 0,30 & 0,10 & 0,30 & (b) \\
\hline$Z$ & {$[\mathrm{f} 1, \mathrm{f} 2, \mathrm{f} 3, \ldots, \mathrm{fn}]$} & 0,40 & 0,80 & 0,30 & (c) \\
\hline
\end{tabular}

A Determinação da vulnerabilidade dos Nós Intermodais com base nos atributos (L), (A) e (F) que caracterizam os nós aplicados na Equação 5-1 e dos Cenários 1, 2 e 3 indicados nas Equações 5-2, 5-3 e 5-4 são apresentados na Tabela 5-6, Tabela 5-7 e Tabela 5-8.

Tabela 5-4 - Cálculo da vulnerabilidade dos nós intermodais Cenário 1

\begin{tabular}{|c|c|c|c|}
\hline $\begin{array}{l}\text { Localização } \\
\text { (Município) }\end{array}$ & $\begin{array}{c}\text { Código } \\
\text { Vulnerabilidade } \\
\end{array}$ & CENARIO 1 & Equação 5-2 \\
\hline Alto Araguaia & $\mathrm{V} 1$ & 1,4 & $X .1+Y .1+Z .2$ \\
\hline Cáceres & $\mathrm{V} 2$ & 1,1 & X.1 + Y.1+Z.1,25 \\
\hline Cáceres & V3 & 1,0 & $X .1+Y .1+Z .1$ \\
\hline Campo Grande & V4 & 2,0 & $\mathrm{X} .2+\mathrm{Y} .2+\mathrm{Z} .2$ \\
\hline Guarapuava & V5 & 2,2 & $X .2+Y .2+Z .2,5$ \\
\hline Maracaju & V6 & 1,51 & $X .2+Y .1+Z .1,5$ \\
\hline Paranaguá & V7 & 1,8 & $X .1+Y .2+Z .2,25$ \\
\hline Paranaguá & V8 & 1,8 & $X .1+Y .2+Z .2,25$ \\
\hline Pederneiras & V9 & 1,3 & $X .1+Y .1+Z .1 .75$ \\
\hline São Simão & V10 & 1,9 & $X .1+Y .2+Z .2,5$ \\
\hline São Simão & V11 & 1,6 & $X .1+Y .2+Z .1 .75$ \\
\hline Sumaré & V12 & 2,2 & X.2 + Y.2 + Z.2,5 \\
\hline Uberaba & V13 & 2,0 & $\mathrm{X} .2+\mathrm{Y} .2+\mathrm{Z} .2$ \\
\hline Uberaba & V14 & 1,9 & $\mathrm{X} .1+\mathrm{Y} .1+\mathrm{Z} .1,75$ \\
\hline Uberlândia & V15 & 2,1 & $\mathrm{X} .1+\mathrm{Y} .1+\mathrm{Z} .2,25$ \\
\hline Uberlândia & V16 & 2,0 & $\mathrm{X} .1+\mathrm{Y} .1+\mathrm{Z} .2$ \\
\hline Uberlândia & V17 & 2,0 & X.2+Y.2+Z.2 \\
\hline Vitória & V18 & 2,2 & X.1 $1+$ Y.2 + Z.2,25 \\
\hline
\end{tabular}


Tabela 5-5 - Cálculo da vulnerabilidade dos nós intermodais Cenário 2

\begin{tabular}{|c|c|c|c|}
\hline $\begin{array}{l}\text { Localização } \\
\text { (Município) }\end{array}$ & $\begin{array}{c}\text { Identificador } \\
\text { Vulnerabilidade }\end{array}$ & CENÁRIO 2 & Equação 5-3 \\
\hline Alto Araguaia & V1 & 1,8 & X.1 + Y.1 + Z.2 \\
\hline Cáceres & $\mathrm{V} 2$ & 1,2 & $\mathrm{X} .1+\mathrm{Y} .1+\mathrm{Z} .1,25$ \\
\hline Cáceres & V3 & 1,0 & X.1+Y.1+Z.1 \\
\hline Campo Grande & $\mathrm{V} 4$ & 2,0 & X.2 $.2 .2+Z .2$ \\
\hline Guarapuava & V5 & 2,4 & $X .2+Y .2+Z .2,5$ \\
\hline Maracaju & V6 & 1,51 & X.2+Y.1+Z.1,5 \\
\hline Paranaguá & V7 & 2,1 & $X .1+Y .2+Z .2,25$ \\
\hline Paranaguá & V8 & 2,1 & X.1 $1+Y .2+Z .2,25$ \\
\hline Pederneiras & V9 & 1,6 & $\mathrm{X} .1+\mathrm{Y} .1+\mathrm{Z} .1 .75$ \\
\hline São Simão & V10 & 2,3 & $X .1+Y .2+Z .2,5$ \\
\hline São Simão & V11 & 1,7 & $X .1+Y .2+Z .1 .75$ \\
\hline Sumaré & V12 & 2,4 & X.2+Y.2+Z.2,5 \\
\hline Uberaba & V13 & 2,0 & X.2+Y.2+Z.2 \\
\hline Uberaba & V14 & 1,8 & $X .1+Y .1+Z .1,75$ \\
\hline Uberlândia & V15 & 2,2 & $X .1+Y .1+Z .2,25$ \\
\hline Uberlândia & V16 & 2,0 & $\mathrm{X} .1+\mathrm{Y} .1+\mathrm{Z} .2$ \\
\hline Uberlândia & V17 & 2,0 & X. $2+$ Y. $.2+Z .2$ \\
\hline Vitória & V18 & 2,2 & $X .1+Y .2+Z .2,25$ \\
\hline
\end{tabular}

Tabela 5-6 - Cálculo da vulnerabilidade dos nós intermodais Cenário 3

\begin{tabular}{|c|c|c|c|}
\hline $\begin{array}{l}\text { Localização } \\
\text { (Município) }\end{array}$ & $\begin{array}{c}\text { Código } \\
\text { Vulnerabilidade } \\
\end{array}$ & CENÁRIO 3 & Equação 5-4 \\
\hline Alto Araguaia & V1 & 1,3 & X.1 + Y.1+Z.2 \\
\hline Cáceres & $\mathrm{V} 2$ & 1,08 & X.1 + Y.1 + Z.1,25 \\
\hline Cáceres & V3 & 1,0 & X.1 + Y.1 + Z.1 \\
\hline Campo Grande & V4 & 2,0 & $\mathrm{X} .2+\mathrm{Y} .2+\mathrm{Z} .2$ \\
\hline Guarapuava & V5 & 2,15 & $\mathrm{X} .2+\mathrm{Y} .2+\mathrm{Z} .2,5$ \\
\hline Maracaju & V6 & 1,45 & $X .2+Y .1+Z .1,5$ \\
\hline Paranaguá & V7 & 1,68 & $X .1+Y .2+Z .2,25$ \\
\hline Paranaguá & V8 & 1,68 & X.1 + Y.2+Z.2,25 \\
\hline Pederneiras & V9 & 1,23 & $X .1+Y .1+Z .1 .75$ \\
\hline São Simão & V10 & 1,75 & $X .1+Y .2+Z .2,5$ \\
\hline São Simão & V11 & 1,53 & $X .1+Y .2+Z .1 .75$ \\
\hline Sumaré & $\mathrm{V} 12$ & 2,15 & X.2+Y. Y $2+Z .2,5$ \\
\hline Uberaba & V13 & 2,0 & X.2+Y.2+Z.2 \\
\hline Uberaba & V14 & 1,93 & $\mathrm{X} .1+\mathrm{Y} .1+\mathrm{Z} .1,75$ \\
\hline Uberlândia & $\mathrm{V} 15$ & 2,08 & $X .1+Y .1+Z .2,25$ \\
\hline Uberlândia & V16 & 2,0 & X.1 + Y.1 + Z.2 \\
\hline Uberlândia & V17 & 2,0 & $X .2+Y .2+Z .2$ \\
\hline Vitória & V18 & 2,08 & X.1 + Y.2+Z.2,25 \\
\hline
\end{tabular}


A Tabela 5-7 apresenta a consolidação dos resultados para os três cenários. Foram obtidos a vulnerabilidade de cada nó, da amostra de nós do corredor logístico, para cada cenário. A partir dos valores obtidos é identificado o menor valor (1,0 e o maior valor 2,4). Estes valores são os parâmetros para a utilizar a representação gráfica da vulnerabilidade do nó intermodal por meio da influência dos fatores ou seja da hierarquização dos fatores de influência.

Tabela 5-7 - Determinação da vulnerabilidade dos nós intermodais por cenário

\begin{tabular}{|c|c|c|c|c|}
\hline Id & Equação & $\begin{array}{c}\text { Cenário } \\
1 \\
\end{array}$ & $\begin{array}{c}\text { Cenário } \\
2 \\
\end{array}$ & $\begin{array}{c}\text { Cenário } \\
3 \\
\end{array}$ \\
\hline V1 & X.1 + Y.1 + Z.2 & 1,4 & 1,8 & 1,3 \\
\hline $\mathrm{V} 2$ & $X .1+Y .1+Z .1,25$ & 1,1 & 1,2 & 1,08 \\
\hline $\mathrm{V} 3$ & X.1 + Y.1 + Z.1 & 1,0 & 1,0 & 1,0 \\
\hline V4 & $\mathrm{X} .2+\mathrm{Y} .2+\mathrm{Z} .2$ & 2,0 & 2,0 & 2,0 \\
\hline V5 & $\mathrm{X} .2+\mathrm{Y} .2+\mathrm{Z} .2,5$ & 2,2 & 2,4 & 2,15 \\
\hline V6 & $X .2+Y .1+Z .1,5$ & 1,51 & 1,51 & 1,45 \\
\hline V7 & $X .1+Y .2+Z .2,25$ & 1,8 & 2,1 & 1,68 \\
\hline V8 & $X .1+Y .2+Z .2,25$ & 1,8 & 2,1 & 1,68 \\
\hline V9 & $X .1+Y .1+Z .1 .75$ & 1,3 & 1,6 & 1,23 \\
\hline V10 & $X .1+Y .2+Z .2,5$ & 1,9 & 2,3 & 1,75 \\
\hline V11 & $X .1+Y .2+Z .1 .75$ & 1,6 & 1,7 & 1,53 \\
\hline V12 & $\mathrm{X} .2+\mathrm{Y} .2+\mathrm{Z} .2,5$ & 2,2 & 2,4 & 2,15 \\
\hline V13 & $\mathrm{X} .2+\mathrm{Y} .2+\mathrm{Z} .2$ & 2,0 & 2,0 & 2,0 \\
\hline V14 & $X .1+Y .1+Z .1,75$ & 1,9 & 1,8 & 1,93 \\
\hline V15 & $X .1+Y .1+Z .2,25$ & 2,1 & 2,2 & 2,08 \\
\hline V16 & $\mathrm{X} .1+\mathrm{Y} .1+\mathrm{Z} .2$ & 2,0 & 2,0 & 2,0 \\
\hline V17 & X.2+Y.2+Z.2 & 2,0 & 2,0 & 2,0 \\
\hline V18 & $\mathrm{X} .1+\mathrm{Y} .2+\mathrm{Z} .2,25$ & 2,2 & 2,2 & 2,08 \\
\hline
\end{tabular}

\subsection{TÓPICOS CONCLUSIVOS}

A aplicação do método demonstrou que é possível estender para outros conjuntos de nós intermodais. No entanto é importante considerar a necessidade de obtenção de dados primários e também calibrar os intervalos adotados quando em aplicação a outra área de interesse. No que se refere aos fatores de localidade e acessibilidade é perfeitamente aplicável para a base de dados do PNLT tem cerca de 700 transferências modais 
(implantadas ou planejadas) que pode passar por esse procedimento para atribuição da localidade e acessibilidade primeiramente.

A utilização de cenários teve uma resposta metodológica adequada para os fins da pesquisa. Com adoção de três cenários, apenas, foi possível observar o comportamento dos fatores na influência da vulnerabilidade. A análise dos cenários e dos nós submetidos aos diferentes cenários demonstra o comportamento do nó. Conhecendo as variáveis do cenário é possível observar quais os fatores que mais contribuem para a vulnerabilidade do determinado nó.

No entanto o método para a hierarquização dos critérios pode ser aprimorado adotando-se um instrumento para a percepção da influência dos fatores a partir dos atores diretamente envolvidos na operação dos transportes de carga por meio da rede intermodal. De forma que é importante incrementar e validar os critérios adotados para cada fator e adequá-los a realidade de cada corredor logístico. 


\section{ANÁLISE DOS RESULTADOS}

\subsection{APRESENTAÇÃO}

A aplicação do método possibilitou uma análise da vulnerabilidade de nós intermodais. Esses nós foram selecionados por operarem no escoamento das safras de grãos da região Centro Oeste. O conjunto de nós foi submetido a três cenários distintos de influência na vulnerabilidade. Para cada cenário foi estimada uma ordem de valor entre os intervalos de 1 a 3 .

As questões de apoio à análise: onde se observa a vulnerabilidade, o que se observa com vulnerabilidade e como se faz essa observação, são, de certa forma, adaptadas para análise da vulnerabilidade dos nós intermodais, por meio da observação da influência de fatores associados à rede e ao fluxo. Portanto, a observação da vulnerabilidade no sistema nacional de viação considera as características de intermodalidade e da escala territorial.

Essa observação dos nós intermodais de transporte de carga é dada através do indicador de vulnerabilidade. Esse indicador combina três fatores importantes que influenciam a vulnerabilidade dos nós, que são: localidade, acessibilidade e funcionalidade.

Para facilitar a análise foram definidas três classes de valores para vulnerabilidade dos nós em três intervalos: alta, média e baixa. A participação dessa influência foi indicada através de três cenários de influência e os resultados são apresentados a seguir.

\subsection{RESULTADOS DA APLICAÇÃO DO ESTUDO DE CASO}

Com base nestas três classes de valores e com a representação gráfica proposta foi elaborada a Tabela 6-1 que apresenta a vulnerabilidade estimada dos nós intermodais para cada cenário indicado. Desta forma é possível a observação do comportamento dos nós em relação aos tipos de vulnerabilidade. Os intervalos têm como referência o maior e o menor valor de vulnerabilidade observado no nó intermodal. O menor valor foi observado em V3 localizado em Cáceres que obteve 1,0 nos três cenários e o maior foi observado em V5 localizado em Guarapuava com valor de 2,4 no Cenário 2. 
Tabela 6-1 - Classes de vulnerabilidade dos nós intermodais e intervalos de valores

\begin{tabular}{c|c}
\hline Representação Simbólica & Intervalos da Vulnerabilidade (Vi) \\
\hline 1 & $2,1<\mathrm{Vi}<2,6$ \\
\hline 2 & $1,51<\mathrm{Vi}<2,0$ \\
\hline 3 & $1,1<\mathrm{Vi}<1,5$ \\
\hline
\end{tabular}

A partir dessa escala foi elaborada a Tabela 6-2 que apresenta o comportamento da vulnerabilidade dos nós por cenários.

Tabela 6-2 - Representação das classes de vulnerabilidade dos nós por cenário

\begin{tabular}{|c|c|c|c|c|c|}
\hline & $\begin{array}{l}\text { Localização } \\
\text { (Município) }\end{array}$ & $\begin{array}{c}\text { Código } \\
\text { Vulnerabilidade } \\
\end{array}$ & Cenário 1 & Cenário 2 & Cenário 3 \\
\hline 1 & Alto Araguaia & V1 & & & \\
\hline 2 & Cáceres & $\mathrm{V} 2$ & & & \\
\hline 3 & Cáceres & V3 & & & \\
\hline 4 & Campo Grande & V4 & & & \\
\hline 5 & Guarapuava & V5 & & & \\
\hline 6 & Maracaju & V6 & & & \\
\hline 7 & Paranaguá & V7 & & & \\
\hline 8 & Paranaguá & V8 & & & \\
\hline 9 & Pederneiras & V9 & & & \\
\hline 10 & São Simão & V10 & & & \\
\hline 11 & São Simão & V11 & & & \\
\hline 12 & Sumaré & V12 & & & \\
\hline 13 & Uberaba & V13 & & & \\
\hline 14 & Uberaba & V14 & & & \\
\hline 15 & Uberlândia & V15 & & & \\
\hline 16 & Uberlândia & V16 & & & \\
\hline 17 & Uberlândia & V17 & & & \\
\hline 18 & Vitória & V18 & & & \\
\hline
\end{tabular}


Os resultados apresentados identificam que onze nós da amostra não modificaram o tipo de vulnerabilidade quando submetidos aos diferentes cenários e que os nós de Guarapuava, Sumaré e o Uberlândia V16 registraram o nível alto de vulnerabilidade. O nó São Simão V10 registrou um tipo diferente de vulnerabilidade para cada cenário analisado.

A seguir, é apresentada análise por cenário, por nó intermodal e pelo conjunto de nós do corredor logístico, buscando compreender as relações que influenciam sobre vulnerabilidade do nó intermodal.

\subsection{ANÁLISE DOS CENÁRIOS}

A análise dos cenários tem como objetivo verificar as faixas ou classes de influências dos fatores de localidade, acessibilidade e funcionalidade como atributos de caracterização do nó intermodal. A análise dessas influências permite observar os tipos estimados de vulnerabilidade de cada nó em diferentes cenários.

O método aplicado no capítulo 5 utilizou três cenários, e os critérios para a indicação dos cenários foi para o cenário 1 igualar os dois fatores de localidade e acessibilidade e atribuir abaixo da metade da influência para funcionalidade. No cenário 2, foram igualadas as influências dos fatores localidade e acessibilidade, e atribuída mais que a metade da influência para o fator de funcionalidade. No cenário 3 foi igualada a influência dos fatores de acessibilidade e funcionalidade e atribuída uma influência acima da metade para o fator de localidade.

Como a indicação dos cenários se limitou a três, então foram percebidas alterações no comportamento dos indicadores da vulnerabilidade dos nós. No entanto, era possível seguir na indicação de cenários, ora lançando equilíbrio e ora atribuindo discrepância de influência dos fatores na vulnerabilidade dos nós. As Figuras 6-1, 6-2 e 6-3, que apresentam a influência dos fatores localidade e acessibilidade na vulnerabilidade, foram elaboradas com base em matriz de risco apresentada em Taylor e D’Este (2003). A seguir são apresentados os principais resultados da aplicação do método para análise da vulnerabilidade de nós intermodais com ênfase nos três cenários indicados. 


\subsubsection{Cenário 1}

O Cenário 1 foi estabelecido com maior influência para a localidade e acessibilidade que somadas terão mais influência na vulnerabilidade do que a funcionalidade. Os nós que apresentaram Influência Baixa na vulnerabilidade são os de Alto Araguaia, os dois nós de Cáceres e o nó intermodal localizado em Pederneiras. Essa influência baixa é devida ao indicador urbano pouco denso e a densidade rodoviária baixa. Neste cenário, a distribuição da influência na funcionalidade corresponde ao mesmo valor de influência do grau de intermodalidade e da capacidade de fluxo. Em relação a intermodalidade, ou seja, a funcionalidade topológica os nós em Cáceres são do tipo bimodal (Rodo-Ferro), assim como os de Uberlândia e Sumaré e o de Guarapuava.

\section{V5, V12, V15, V18}

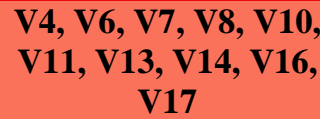

V1, V2, V3, V9

Figura 6-1- Escala de influência na vulnerabilidade do nó intermodal Cenário 1.

\subsubsection{Cenário 2}

No Cenário 2, a funcionalidade do nó tem a maior influência na sua vulnerabilidade, e a influência de fatores de localidade e acessibilidade são igualmente bem menos influentes do que a funcionalidade. O nó com maior valor é o localizado em Guarapuava. A Figura 62 apresenta a posição dos nós submetidos ao cenário 2 com base na escala de influência na vulnerabilidade.
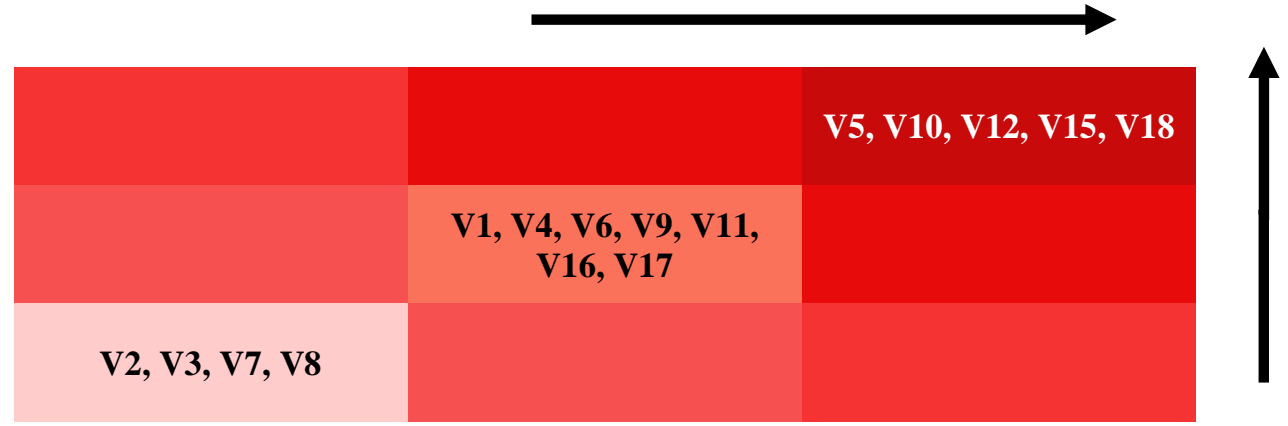

Figura 6-2 - Escala de influência na vulnerabilidade do nó intermodal Cenário 2. 


\subsubsection{Cenário 3}

O Cenário 3 apresenta uma situação inversa onde a influência da funcionalidade é menor que a influência da localidade e da acessibilidade. Para isso, adota-se a hierarquização de fatores da funcionalidade topológica e funcionalidade estrutural como menos relevantes na influência da vulnerabilidade. A Figura 6-3 apresenta a posição dos nós submetidos ao cenário 3 com base na escala de influência na vulnerabilidade.

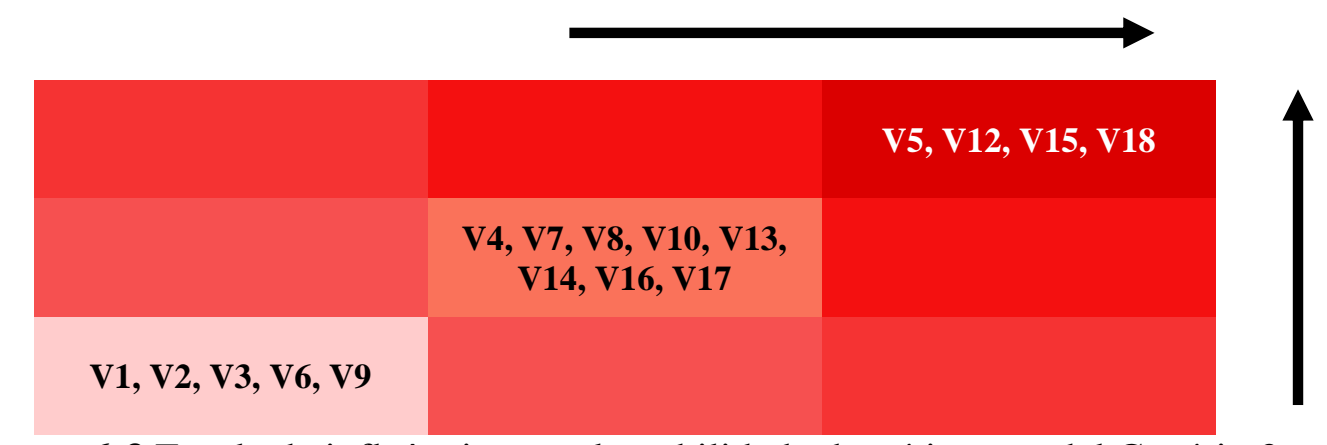

Figura 6-3 Escala de influência na vulnerabilidade do nó intermodal Cenário 3.

A observação do comportamento e alteração da vulnerabilidade dos nós ante as alterações na influência dos fatores permite identificar os nós que permanecem no mesmo nível de vulnerabilidade apesar da mudança das influências dos fatores. Também é possível identificar os nós intermodais que tiveram alterações do nível de vulnerabilidade quando submetidos a outras condições de influência indicada por outro cenário.

\subsection{ANÁLISE DOS NÓS INTERMODAIS}

As análises da vulnerabilidade dos nós intermodais, representativos do corredor logístico do centro oeste, têm como apoio a representação gráfica dos indicadores dos fatores de localidade e acessibilidade.

Os nós intermodais que apresentam maior valor são os de Guarapuava seguidos de Sumaré e Uberlândia, que apresentam influência alta devido ao indicador urbano denso e à densidade rodoviária média. 


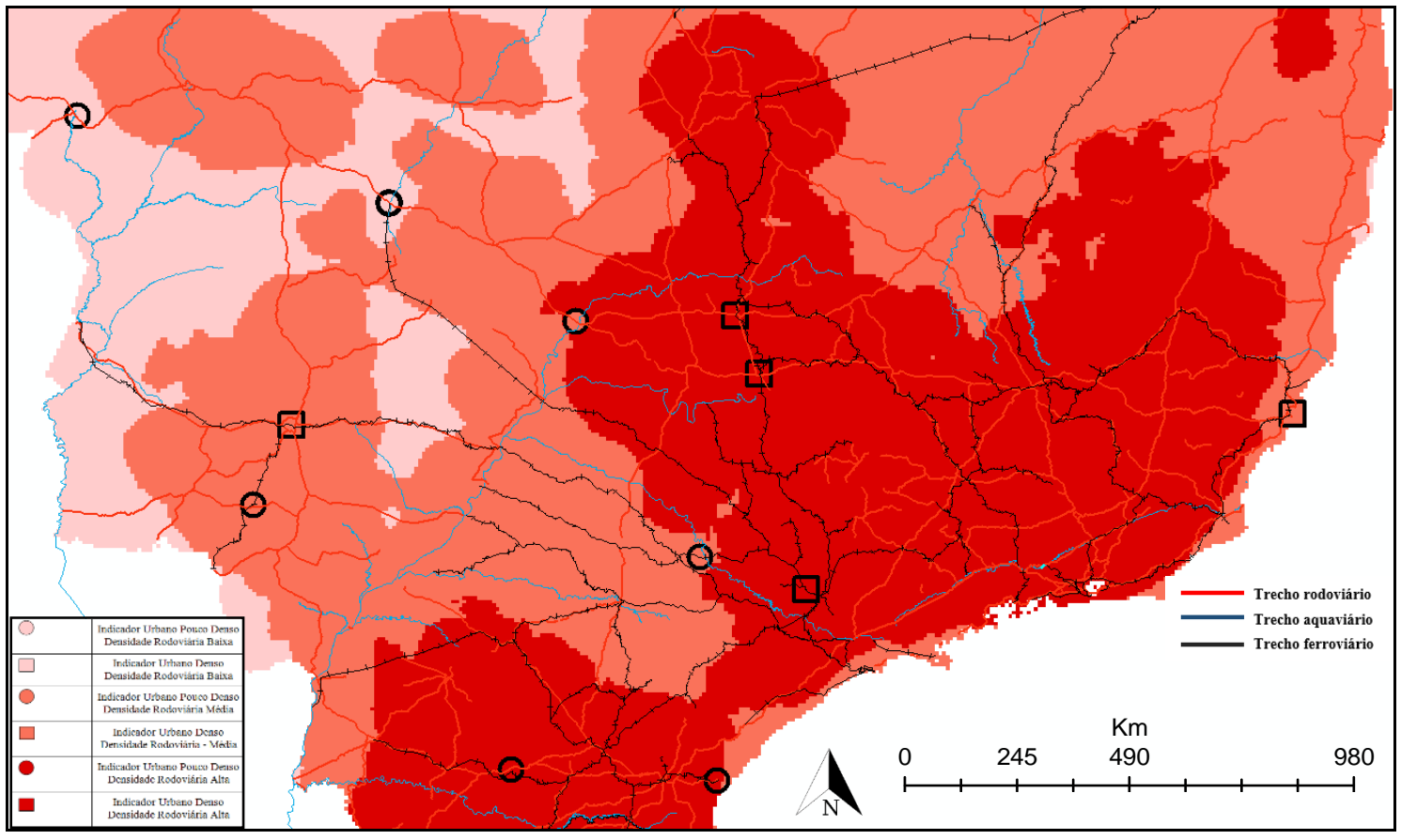

Figura 6-4 - Localização dos nós e densidade rodoviária federal Fonte: elaborado pelo autor a partir da base de dados do DNIT

A Figura 6-4 mostra os trechos rodoviários do DNIT, os trechos ferroviários e aquaviários do PNLT e a densidade rodoviária obtida conforme o Anexo 2.

O Quadro 6-1 apresenta os exemplos observados na caracterização dos 18 nós intermodais da amostra de dados.

Quadro 6-1 - Escala Indicador Urbano e Densidade Rodoviária

\begin{tabular}{|c|c|}
\hline$\bigcirc$ & $\begin{array}{c}\text { Indicador Urbano Pouco Denso } \\
\text { Densidade Rodoviária Baixa }\end{array}$ \\
\hline$\square$ & $\begin{array}{c}\text { Indicador Urbano Denso } \\
\text { Densidade Rodoviária Baixa }\end{array}$ \\
\hline$\square$ & $\begin{array}{c}\text { Indicador Urbano Pouco Denso } \\
\text { Densidade Rodoviária Média }\end{array}$ \\
\hline$\square$ & $\begin{array}{c}\text { Indicador Urbano Denso } \\
\text { Densidade Rodoviária - Média }\end{array}$ \\
\hline$\bigcirc$ & $\begin{array}{c}\text { Indicador Urbano Pouco Denso } \\
\text { Densidade Rodoviária Alta }\end{array}$ \\
\hline$\square$ & $\begin{array}{c}\text { Indicador Urbano Denso } \\
\text { Densidade Rodoviária Alta }\end{array}$ \\
\hline
\end{tabular}




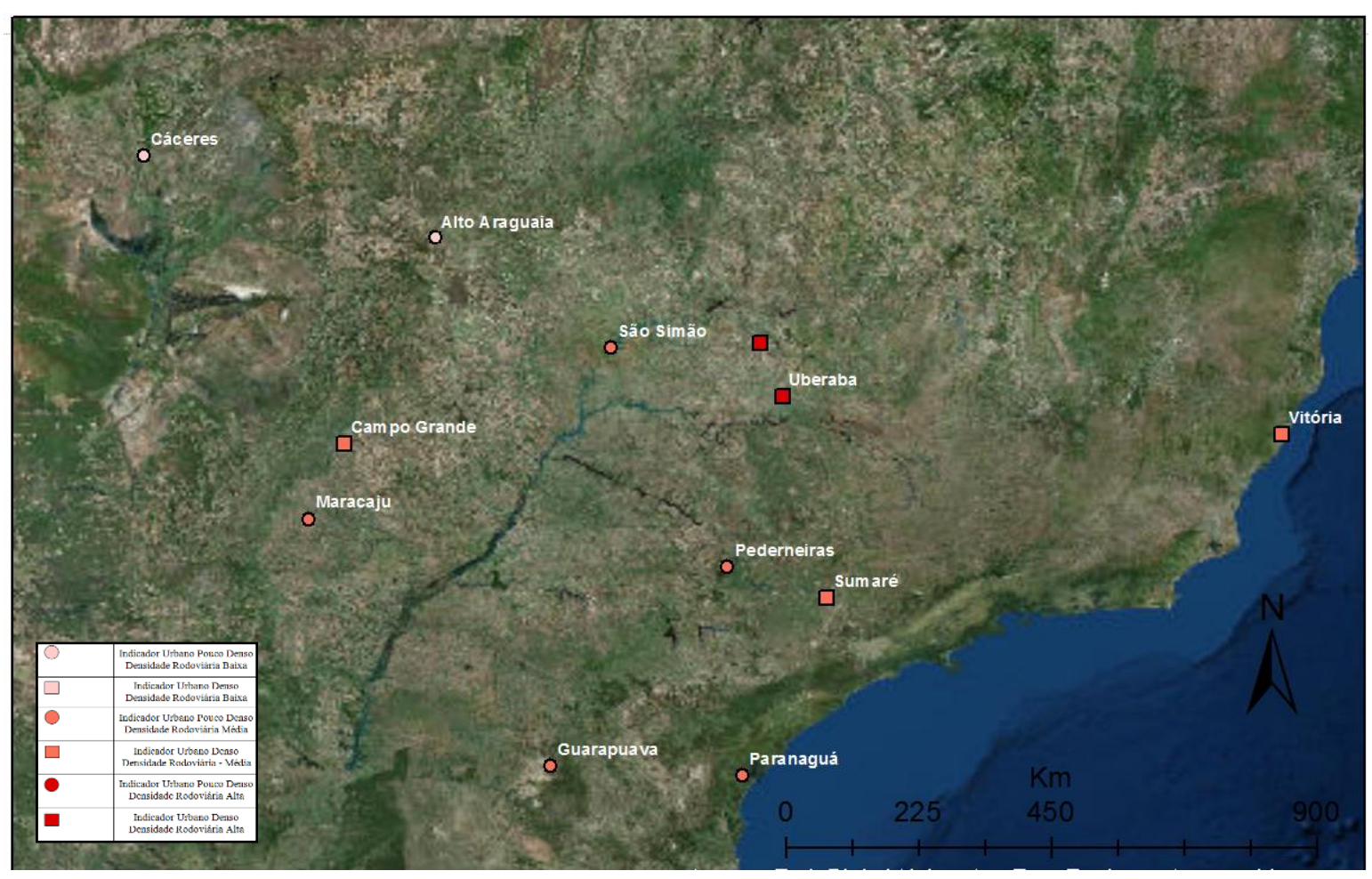

Figura 6-5 - Localização dos nós intermodais

Fonte: elaborado pelo autor a partir da base de dados do DNIT e Google Earth

A Figura 6-5, obtida a partir do Google-Earth, mostra trechos rodoviários DNIT, trechos ferroviários e aquaviários PNLT e a localização dos nós intermodais da amostra. A seguir, são apresentadas a análises por nós e as imagens correspondem aos zooms na localidade dos nós intermodais e com a indicação de escala gráfica para a observação dos sistemas viários correspondentes aos nós intermodais.

\subsubsection{Alto Araguaia V1}

O nó localizado em Alto Araguaia recebeu a vulnerabilidade V1 e caracteriza-se pelo indicador urbano pouco denso e densidade rodoviária baixa. O grau de intermodalidade e bimodal (rodoferroviário) a funcionalidade estrutural no nível Médio.

Esse nó possui uma capacidade de fluxo de 7.560.000 toneladas de grãos anuais, sendo o nó intermodal de maior fluxo da amostra de dados. Esse volume no fluxo exerce considerável influência na vulnerabilidade Pode-se verificar pela quantidade de equipamentos disponíveis para as operações do transbordo rodo ferroviários, são 16 equipamentos no total. A Figura 6-6 apresenta a representação da localidade e acessibilidade do nó. 


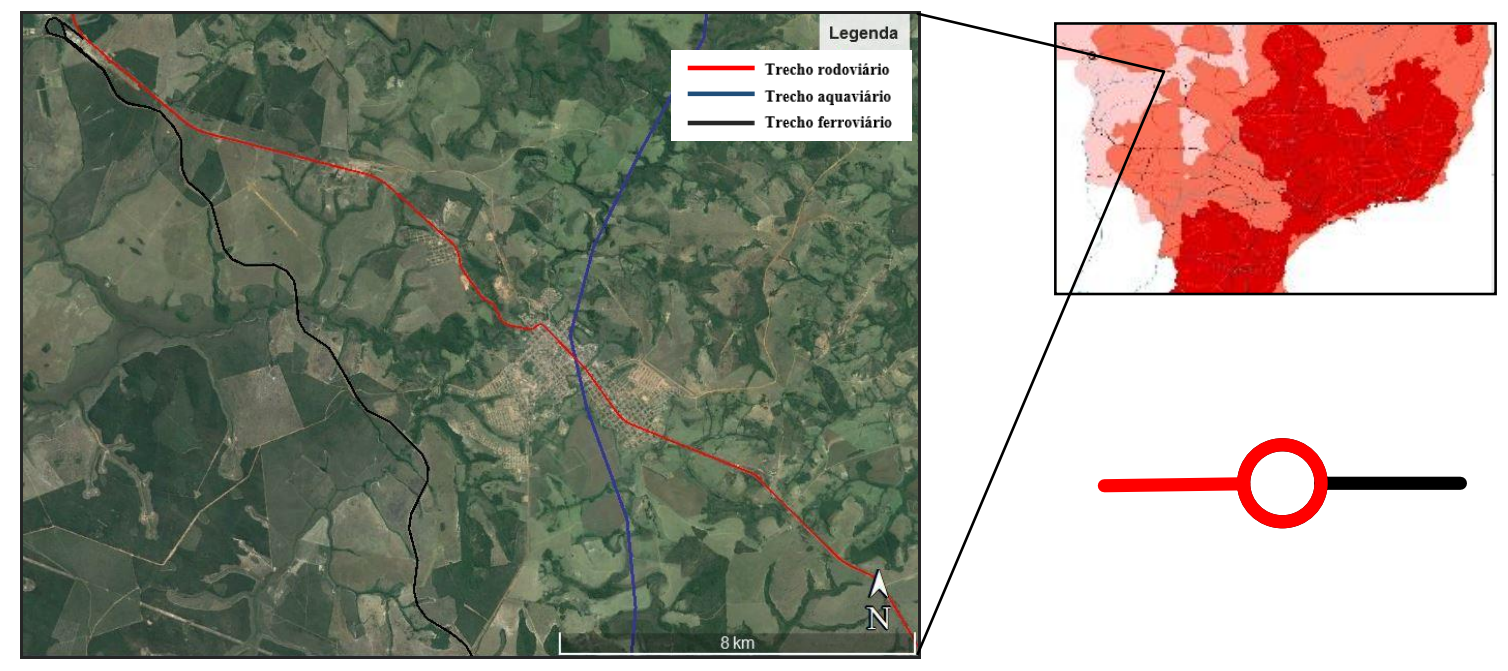

Figura 6-6 - Alto Araguaia V1 - Localidade e Acessibilidade.

Fonte: elaborado pelo autor a partir da base de dados do DNIT e Google Earth

Em relação aos cenários houve mudanças na classe da vulnerabilidade do nó quando submetido ao cenário 2, passando do nível 3 para o nível 2. Isso em razão de o cenário 2 estimar maior influência no fator funcionalidade diante da localidade e da acessibilidade. No cenário 3, o nó recebe a vulnerabilidade no nível 3. O Quadro 6-2 apresenta as mudanças e o tipo de vulnerabilidade do nó por meio da combinação dos cenários.

Quadro 6-2 - Tipo de vulnerabilidade por combinação dos cenários em V1

\begin{tabular}{|c|c|c|c|}
\hline \multicolumn{3}{|c|}{ Cenários } & Tipo de vulnerabilidade \\
\cline { 1 - 2 } $30-30-40$ & $10-10-80$ & $40-30-30$ & \\
\cline { 1 - 2 } & 2 & 3 \\
\hline
\end{tabular}

\subsubsection{Cáceres V2 e Cáceres V3}

Em Cáceres localizam-se dois nós da amostra de dados. Foi atribuída a vulnerabilidade V2 e vulnerabilidade V3 para os nós. Portanto, ambos com o mesmo indicador urbano pouco denso e a densidade rodoviária Baixa. A Figura 6-7 ilustra a localização dos nós na área do estudo de caso, e indica os valores com a representação do indicador urbano e a escala de cores da densidade rodoviária.

No que se refere à funcionalidade, a vulnerabilidade V2 é atribuída à média intermodalidade (rodoaquaviário) e à baixa funcionalidade estrutural, devido ao nível 
baixo de equipamentos. No entanto, V2 tem a funcionalidade um pouco acima da funcionalidade de V3, pois, V2 tem um fluxo anual de 240.000 toneladas diante das 64.000 toneladas correspondente ao fluxo do nó com a vulnerabilidade V3.

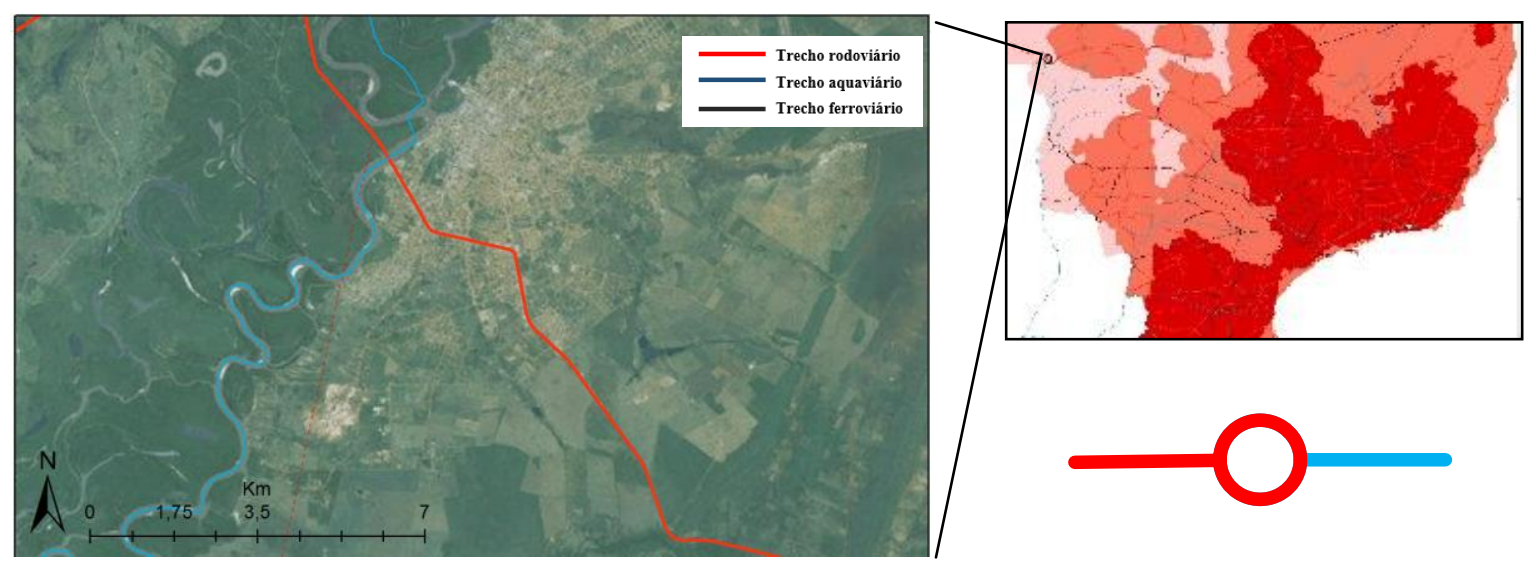

Figura 6-7 - Cáceres V2 e V3 - Localidade, Acessibilidade e Funcionalidade Fonte: elaborado pelo autor a partir da base de dados do DNIT e Google Earth

Com auxílio da imagem de satélite é possível identificar os eixos rodoviário federais e o trecho aquaviário. Na imagem é possível perceber um deslocamento entre os eixo da base de dados vetorial a o meandros característicos de rios naturais.

Em relação aos cenários não houve mudança na escala da vulnerabilidade do nó tanto V2 quanto V3. Em os cenários prevaleceu a estimativa de vulnerabilidade classe Baixa, ou seja código 3. O Quadro 6-5 apresenta o tipo de vulnerabilidade por combinação dos cenários

Quadro 6-3 - Tipo de vulnerabilidade por combinação dos cenários em V2 e V3

\begin{tabular}{|c|c|c|c|c|}
\hline \multirow{2}{*}{$\mathbf{V i}$} & \multirow{2}{*}{ Tipo de vulnerabilidade } & \multicolumn{3}{|c|}{ Cenários } \\
\hline & & $30-30-40$ & $10-10-80$ & $40-30-30$ \\
\hline $\mathrm{V} 2, \mathrm{~V} 3$ & & & & \\
\hline
\end{tabular}

\subsubsection{Campo Grande V4}

A caracterização do nó localizado em Campo Grande apresentou o indicador urbano denso, e a densidade rodoviária baixa. Quanto à funcionalidade apresenta nível baixo com fluxo 
anual de 34.200 toneladas e intermodalidade rodoferroviária. No entanto, com quantidade de trinta e cinco equipamentos, o que eleva a influência da funcionalidade.

A Figura 6-8 ilustra a localidade e a acessibilidade do nó intermodal e com auxílio da imagem de satélite e possível perceber que os trechos rodoviários federais forma uma anel na área urbana de Campo Grande.

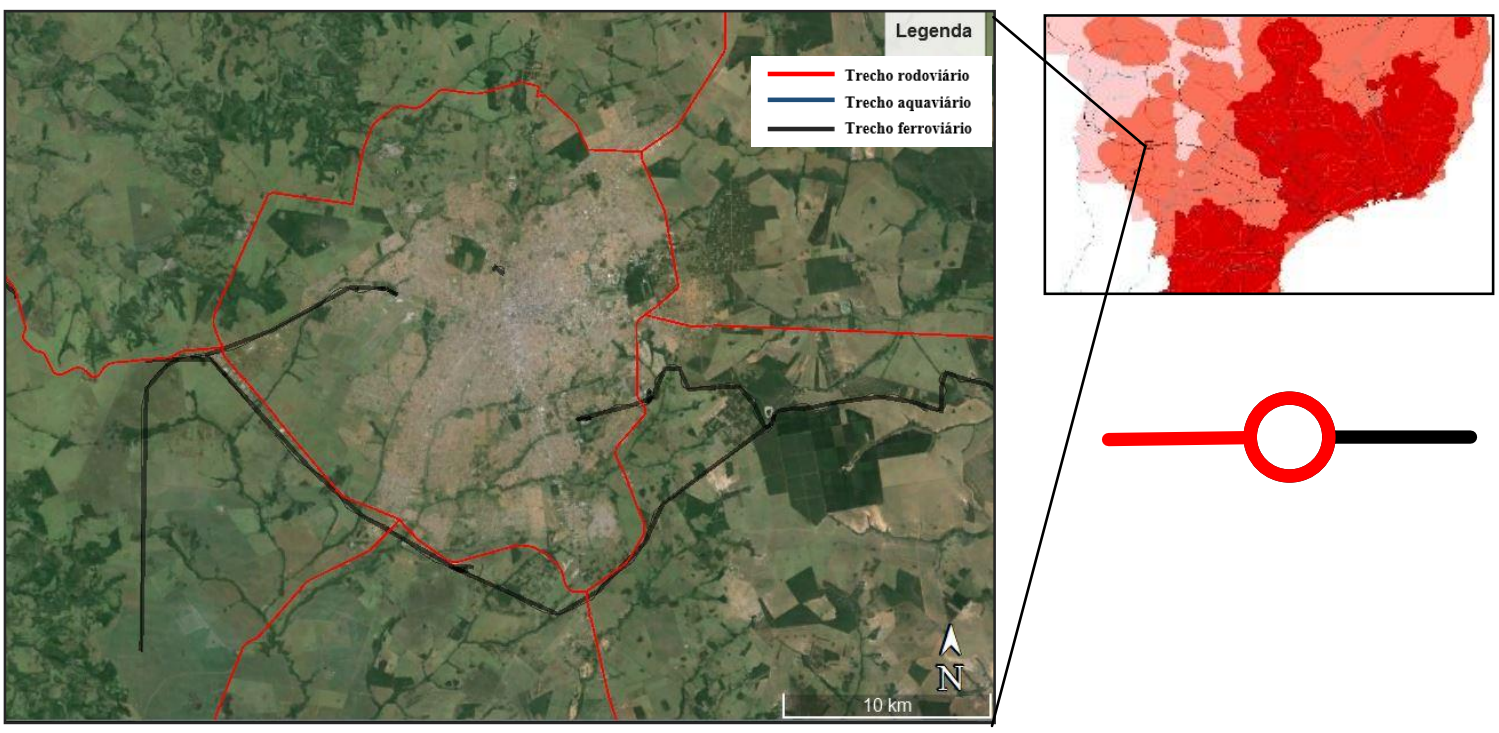

Figura 6-8 -Campo Grande V4 - Localidade e Acessibilidade

Fonte: elaborado pelo autor a partir da base de dados do DNIT e Google Earth

Em relação aos cenários não houve mudança na escala da vulnerabilidade do nó V4. Nos cenários prevaleceu a estimativa de vulnerabilidade classe média, ou seja, número 2 . O Quadro 6-7 apresenta o tipo de vulnerabilidade V4 por combinação dos cenários.

Quadro 6-4 - Tipo de vulnerabilidade por combinação dos cenários em V4

\begin{tabular}{|c|c|c|c|c|}
\hline \multirow{2}{*}{ Vi } & \multirow{2}{*}{ Tipo de vulnerabilidade } & \multicolumn{3}{|c|}{ Cenários } \\
\cline { 3 - 5 } & & $30-30-40$ & $10-10-80$ & $40-30-30$ \\
\hline \multirow{2}{*}{ V4 } & & 2 & 2 & 2 \\
\hline
\end{tabular}

\subsubsection{Guarapuava V5}

O nó localizado em Guarapuava foi caracterizado com o indicador urbano denso e à densidade rodoviária média. Em relação à funcionalidade topológica, devido à 
intermodalidade tipo rodoferroviária, esse nó foi caracterizado com o valor médio. No entanto, devido ao número de equipamentos, foi atribuída uma funcionalidade estrutural alta. Essa alta capacidade estrutural, pelo número de equipamentos, combinados com a localidade e acessibilidade no nível médio de influência, amplia a influência na vulnerabilidade.

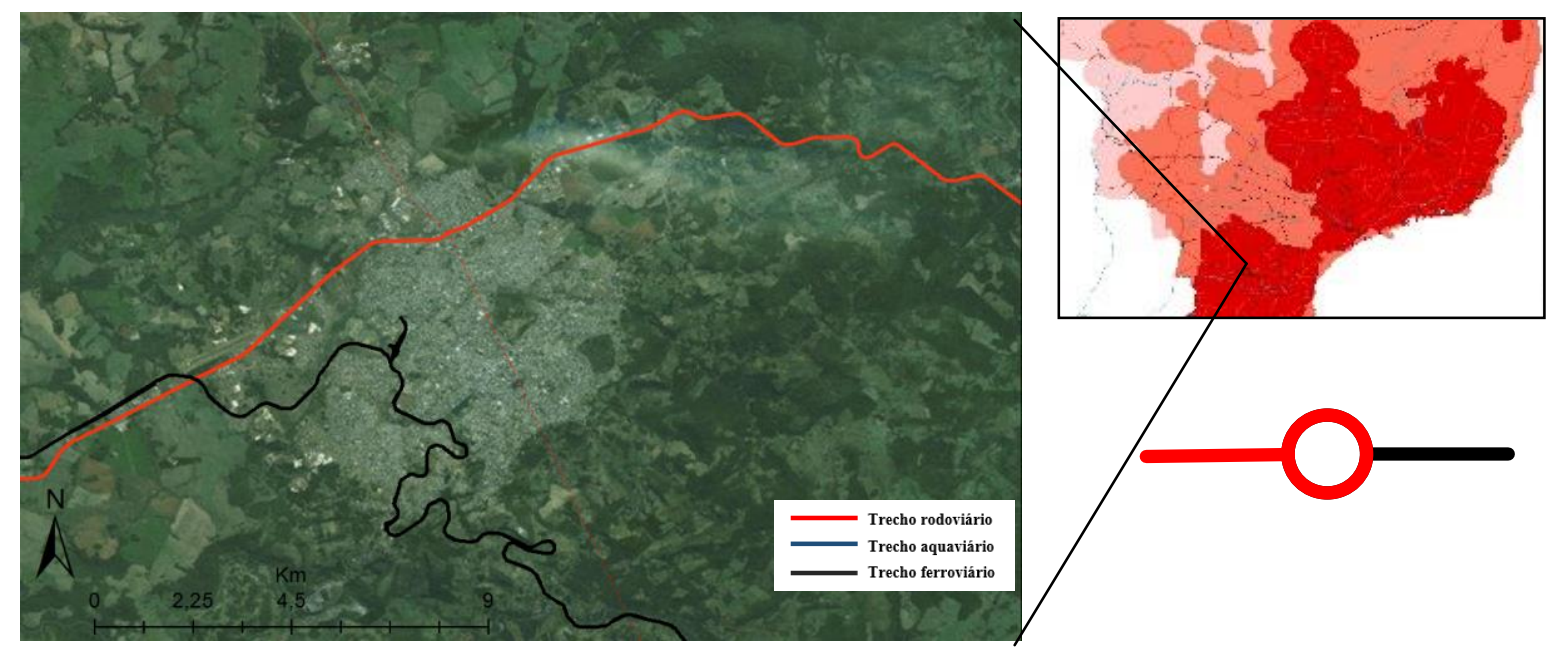

Figura 6-9 - Guarapuava V5 - Localidade e Acessibilidade Fonte: elaborado pelo autor a partir da base de dados do DNIT e Google Earth

A imagem na figura mostra a topologia dos trechos rodoviários federais pavimentados da BR 277 e os trechos planejados da BR 466, que atualmente são coincidentes com o sistema rodoviário estadual do Paraná. Os trechos ferroviários fazem interação na parte sudoeste da mancha urbana de Guarapuava.

Em relação aos cenários não houve mudança na escala da vulnerabilidade do nó tanto V5. Nos cenários prevaleceu a estimativa de vulnerabilidade classe alta, ou seja número $1 \mathrm{em}$ vulnerabilidade. O Quadro 6-5 apresenta o tipo de vulnerabilidade por combinação dos cenários em V5.

Quadro 6-5 - Tipo de vulnerabilidade por combinação dos cenários em V5

\begin{tabular}{|c|c|c|c|c|c|}
\hline \multirow{2}{*}{ Vi } & \multirow{2}{*}{ Tipo de vulnerabilidade } & \multicolumn{3}{|c|}{ Cenários } \\
\cline { 3 - 5 } V5 & & 1 & $30-30-40$ & $10-10-80$ & $40-30-30$ \\
\hline & & 1 & 1 & 1 \\
\hline
\end{tabular}




\subsubsection{Maracaju V6}

O nó localizado em Maracaju apresentou o indicador urbano denso e a densidade rodoviária baixa. Em relação à funcionalidade, V6 apresentou nível médio, menos pelo fluxo e mais pelo número de equipamentos e serviços oferecidos, 16 e 6 respectivamente. O fluxo anual é de 34.200 toneladas, e a intermodalidade é rodoferroviária.

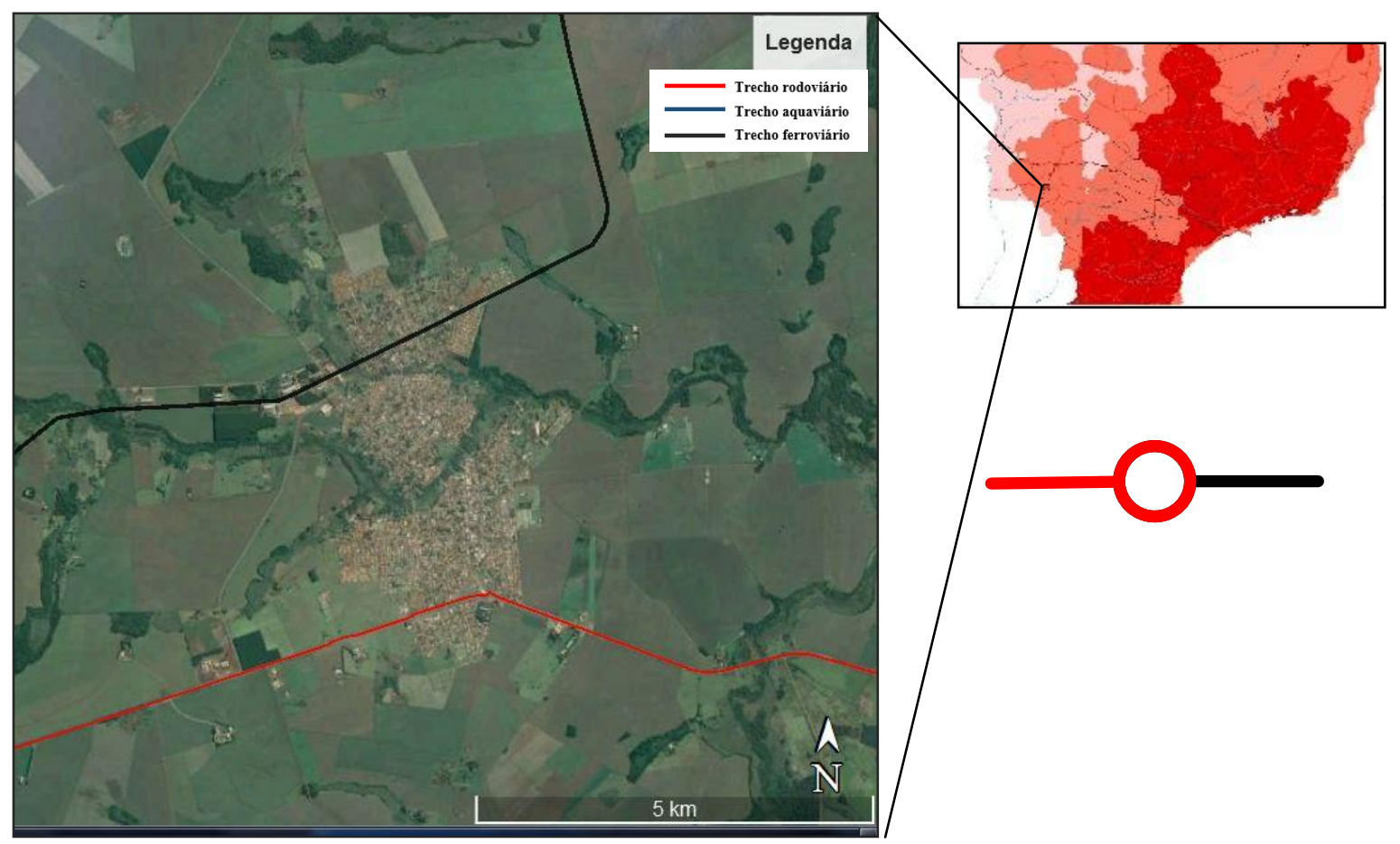

Figura 6-10 - Maracaju V6 - Localidade e Acessibilidade.

Fonte: elaborado pelo autor a partir da base de dados do DNIT e Google Earth

A imagem de satélite da figura mostra que a BR 267 corta na transversal a mancha urbana na parte sul da sede municipal de Maracaju e o trecho ferroviário corta transversalmente na parte norte.

Em relação aos cenários, houve mudança na escala da vulnerabilidade do nó V6. No cenário 1 e 3, foram estimadas vulnerabilidades no nível 2. No entanto, no cenário 2, a vulnerabilidade estimada apresentou-se como de classe 3. Importante destacar que o cenário 2 atribuiu maior importância para o fator funcionalidade em relação às influências dos fatores de localidade e acessibilidade. O Quadro 6-6 apresenta o tipo de vulnerabilidade por combinação de cenários para V6. 
Quadro 6-6 - Tipo de vulnerabilidade por combinação dos cenários em V6

\begin{tabular}{|c|c|c|c|c|}
\hline \multirow{2}{*}{$\mathbf{V i}$} & \multirow{2}{*}{ Tipo de vulnerabilidade } & \multicolumn{3}{|c|}{ Cenários } \\
\hline & & $30-30-40$ & $10-10-80$ & $40-30-30$ \\
\hline V6 & & & & \\
\hline
\end{tabular}

\subsubsection{Paranaguá V7 e V8}

Em Paranaguá, estão localizados dois nós intermodais da amostra de dados da aplicação do método para análise da vulnerabilidade. Portanto ambos têm a mesma caracterização de localidade com indicador urbano pouco denso e de acessibilidade com a densidade rodoviária baixa e funcionalidade com nível alta.

Quanto à funcionalidade topológica a intermodalidade em V7 e V8 é ferro-rodoviária e no que se refere à funcionalidade, o nó apresenta estrutura com 21 equipamentos e o fluxo anual de 900.000 toneladas. Configura-se, portanto uma influência considerável da funcionalidade estrutural na influência da vulnerabilidade desses nós em Paranaguá. A Figura 6-11 apresenta a representação da caracterização de localidade e acessibilidade dos nós.

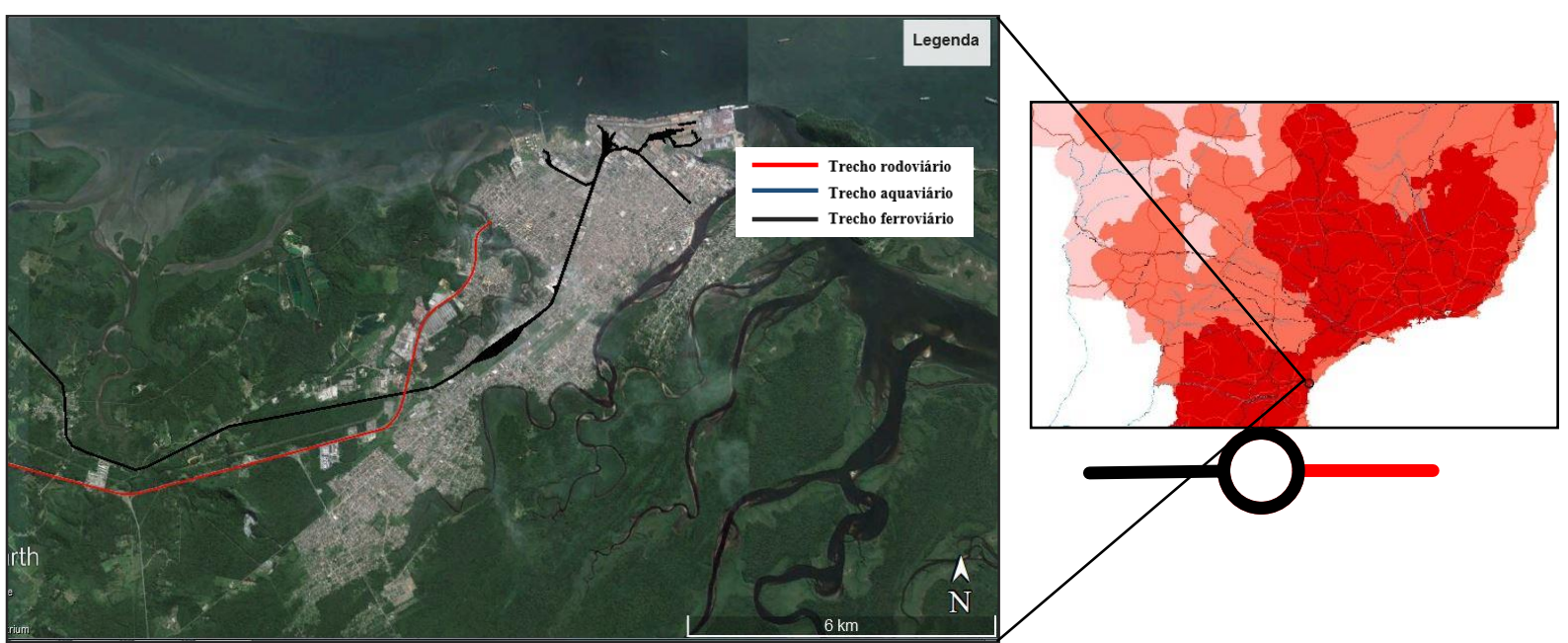

Figura 6-11 - Paranaguá V7 e V8 - Localidade e Acessibilidade.

Em relação aos cenários, V7 recebeu a vulnerabilidade nível 2 tanto no cenário 1 quanto no cenário 3. O cenário 2, com maior influência da funcionalidade, apresentou nível 2 de vulnerabilidade, o mesmo foi observado para V8. Devido ao número de equipamentos (16) 
e ao número de serviços (6) a funcionalidade estrutural de V8 é ligeiramente alta. O nível alto da funcionalidade estrutural se repete no V7, conforme mostrado no Quadro 6-7.

Quadro 6-7 - Tipo de vulnerabilidade por combinação dos cenários em V7 e V8

\begin{tabular}{|c|c|c|c|c|}
\hline \multirow{2}{*}{ Vi } & \multirow{2}{*}{ Tipo de vulnerabilidade } & $30-30-40$ & $10-10-80$ & $40-30-30$ \\
\cline { 3 - 5 } & V7, V8 & & & \\
\hline
\end{tabular}

\subsubsection{Pederneiras V9}

Ao nó localizado em Pederneiras foi atribuída a vulnerabilidade V9 e caracterizado com Indicador urbano pouco denso e a densidade rodoviária média, em relação aos fatores de localidade e acessibilidade, respectivamente. Em relação a funcionalidade V9 caracterizase com nível alto, devido à intermodalidade aquaferroviário considerada no nível médio e a funcionalidade de estrutura de equipamentos para um fluxo anual de 467.000 toneladas, o que como estrutura é considerado alto e eleva a funcionalidade no total. A Figura 6-12 localiza o nó e indica a caracterização do indicador urbano e da densidade rodoviária.

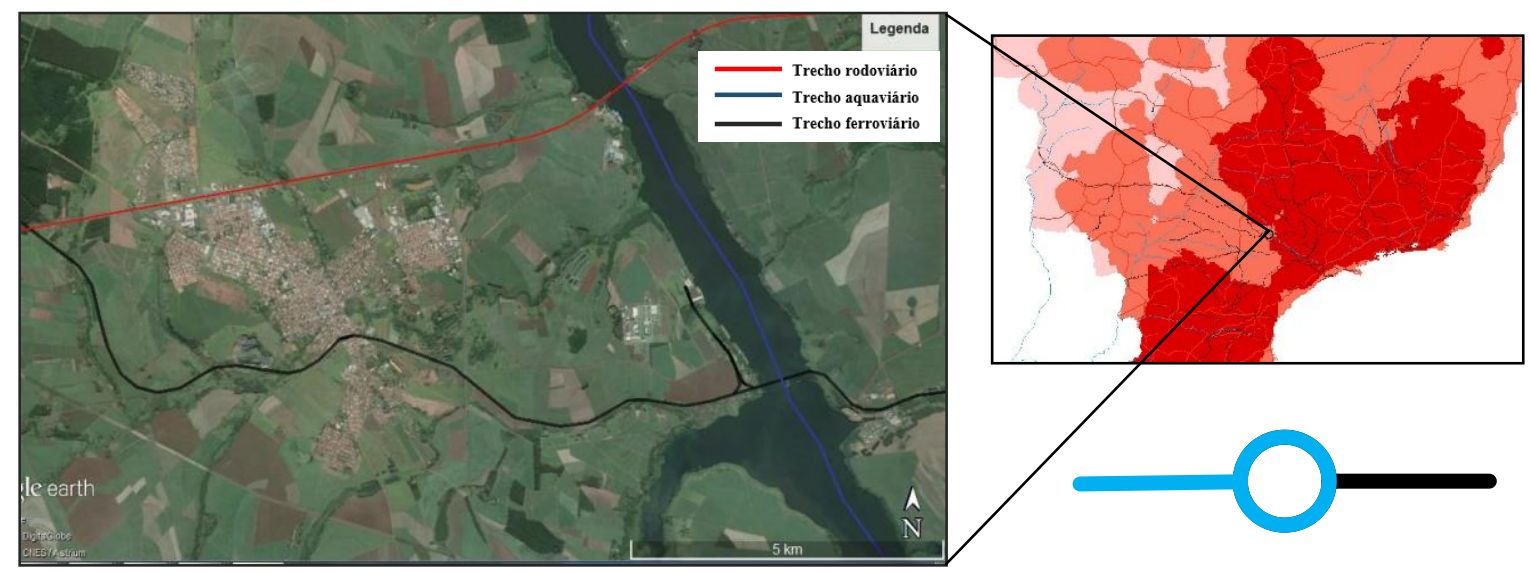

Figura 6-12 - Pederneiras V9 - Localidade e Acessibilidade.

Fonte: elaborado pelo autor a partir da base de dados do DNIT e Google Earth

Em relação aos cenários houve mudança na escala da vulnerabilidade do nó com vulnerabilidade V9, localizado em Pederneiras. Sob os cenários 1 e 3, prevaleceu a estimativa de vulnerabilidade classe baixa. 
No entanto no cenário 2 a estimativa da vulnerabilidade foi do nível médio. Em relação aos cenários o nó em Pederneiras ficou situado nos níveis 2 de vulnerabilidade no Cenário 1 e Cenário 3, porém em relação ao Cenário 3 com maior influência da funcionalidade o nó ficou situado no nível 1 de vulnerabilidade.

Quadro 6-8 - Tipo de vulnerabilidade por combinação dos cenários em V9

\begin{tabular}{|c|c|c|c|c|}
\hline \multirow{2}{*}{$\mathbf{V i}$} & \multirow{2}{*}{ Tipo de vulnerabilidade } & \multicolumn{3}{|c|}{ Cenários } \\
\hline & & $30-30-40$ & $10-10-80$ & $40-30-30$ \\
\hline V9 & & & & \\
\hline
\end{tabular}

\subsubsection{São Simão V10 e V11}

Os nós em São Simão receberam as vulnerabilidades V10 e V11 e ambos foram caracterizados com Indicador urbano pouco denso e a densidade rodoviária baixa. Em relação à funcionalidade foi caracterizada em funcionalidade topológica média do tipo rodoaquaviária em relação àcapacidade estrutural que permite um fluxo de 467.000 toneladas anuais e a quantidade de 20 equipamentos, foi considerada em nível alto para o fator o total da funcionalidade, em V10.

No entanto, a V11 foi atribuída uma caracterização de funcionalidade com nível médio devido à capacidade do nó permitir um fluxo de 80.000 toneladas anuais. A funcionalidade topológica rodoaquaviária e a capacidade estrutural de 8 equipamentos, apresentam uma funcionalidade estrutural média.

A Figura 6-13 apresenta a localização e a representação da caracterização do nós e o tipo de intermodalidade dos nós intermodais em São Simão. A imagem mostra a interação dos trechos rodoviários das BR 164 e BR 165 e a ligação de ponte sobre o rio Paranaíba, trecho hidroviário dotado de eclusa. 


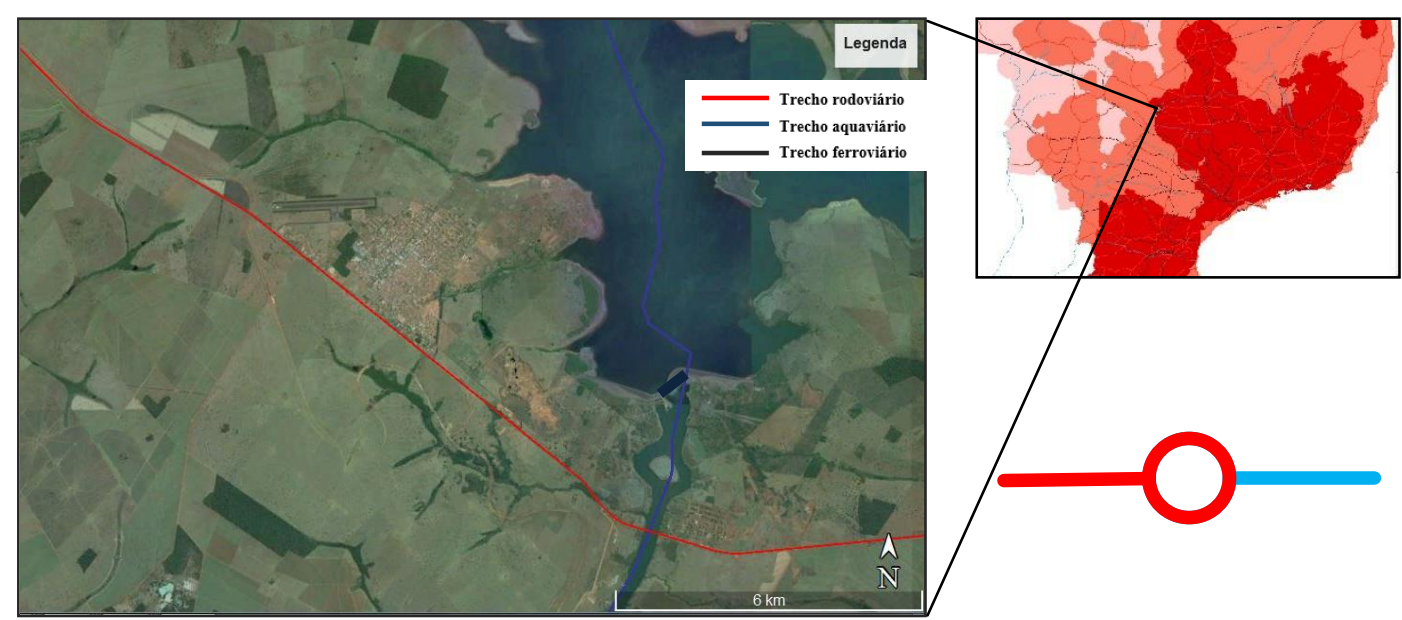

Figura 6-13 - São Simão V10 e São Simão V11 - Localidade e Acessibilidade. Fonte: elaborado pelo autor a partir da base de dados do DNIT e Google Earth

Em relação aos cenários, o primeiro nó analisado localizado em São Simão, V10, apresentou mudança no nível de vulnerabilidade o segundo nó, com V11, não alterou o nível de vulnerabilidade diante dos três cenários.

O fator de funcionalidade exerce considerável influência visto que o volume superior do fluxo em V10 cerca de três vezes maior que fluxo em doze meses em V11.Em nenhum cenário houve observação de vulnerabilidade do nível 3, tanto no primeiro quanto no segundo nó localizados em São Simão.

Quadro 6-9 - Tipo de vulnerabilidade por combinação dos cenários em V10 e V11

\begin{tabular}{|c|c|c|c|c|}
\hline \multirow{2}{*}{ Vi } & \multirow{2}{*}{ Tipo de vulnerabilidade } & \multicolumn{3}{|c|}{ Cenários } \\
\cline { 3 - 5 } V10 & & $30-30-40$ & $10-10-80$ & $40-30-30$ \\
\hline V11 & & 2 & 1 & 2 \\
\hline
\end{tabular}

\subsubsection{Sumaré V12}

O nó localizado em Sumaré recebeu a vulnerabilidade V12. Indicador urbano denso e a densidade rodoviária média. A capacidade do nó permite um fluxo de 80.000 toneladas anuais. A funcionalidade topológica média do tipo ferrorrodoviária e a funcionalidade estrutural alta, devido ao número de equipamentos compatível para o fluxo em 12 meses de 
80.000 toneladas segundo Naves (2012). A Figura 6-14 apresenta a caracterização do fator de localidade e acessibilidade do nó.

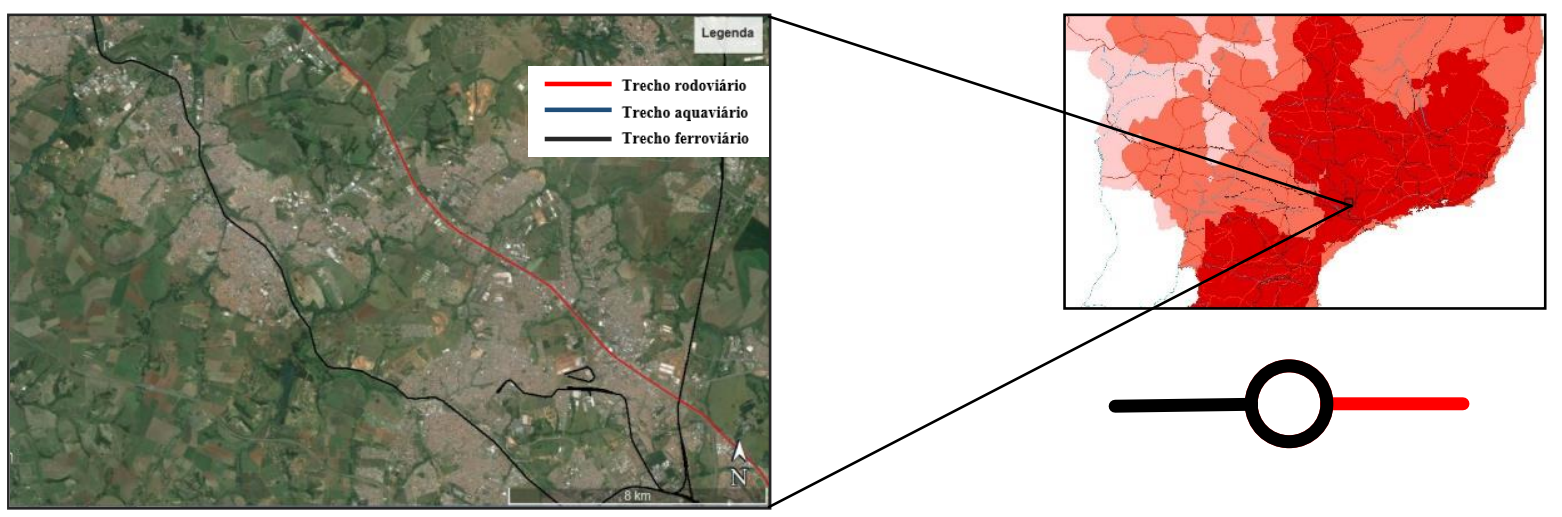

Figura 6-14 - Sumaré V12 - Localidade e Acessibilidade

Fonte: elaborado pelo autor a partir da base de dados do DNIT e Google Earth

A imagem mostra a interação do trecho rodoviário federal da BR 050 que é coincidente com o tredo estadual SP - 330, Sumaré apresenta uma mancha urbana bastante densa e conturbada com outras localidades.

Em relação aos cenários, o nó recebeu a vulnerabilidade nível 1. Portanto alto nível de vulnerabilidade nos três cenários. O Quadro 6-18 apresenta o tipo de vulnerabilidade por combinação dos cenários em V12. Esse tipo de vulnerabilidade também foi observado em Guarapuava.

Quadro 6-10 - Tipo de vulnerabilidade por combinação dos cenários em V12

\begin{tabular}{|c|c|c|c|c|}
\hline \multirow{2}{*}{ Vi } & \multirow{2}{*}{ Tipo de vulnerabilidade } & \multicolumn{3}{|c|}{ Cenários } \\
\cline { 3 - 5 } V12 & & $30-30-40$ & $10-10-80$ & $40-30-30$ \\
\hline & & 1 & 1 & 1 \\
\hline
\end{tabular}

\subsubsection{Uberaba V13 e V14}

Em Uberaba, estão os nós intermodais com V13 e V14. Ambos com indicador urbano denso e densidade rodoviária média, no que se refere aos fatores de localidade e funcionalidade. Em relação à funcionalidade topológica ambos operam no tipo rodoferroviário. A Figura 6-15 apresenta a caracterização dos fatores referente aos nós. 


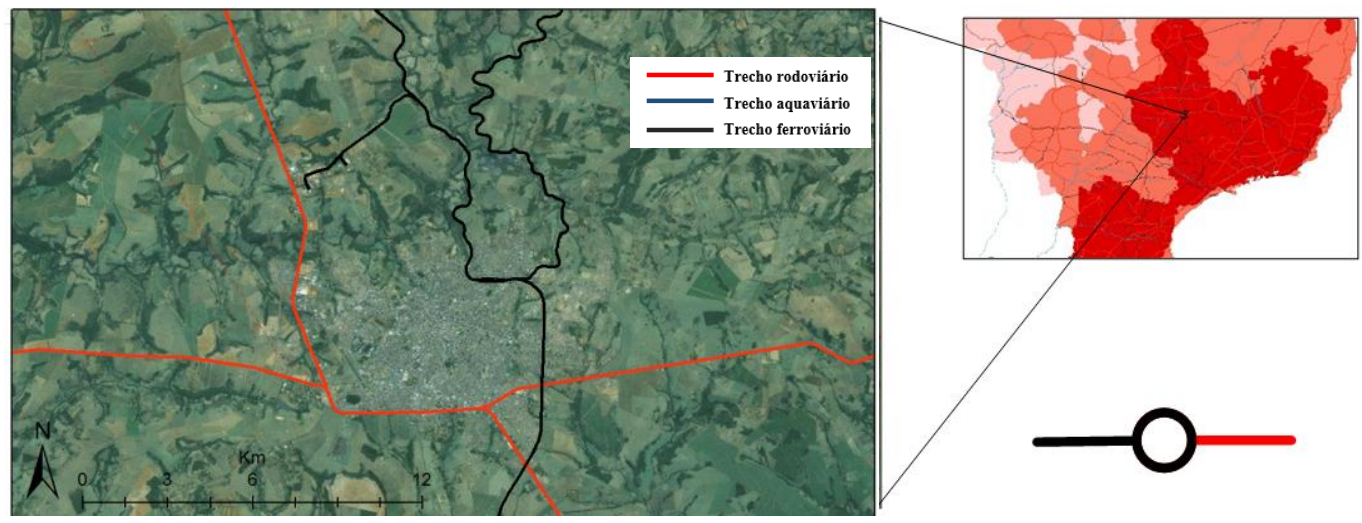

Figura 6-15 - Uberaba V13 e Uberaba v14 - Localidade e Acessibilidade Fonte: elaborado pelo autor a partir da base de dados do DNIT e Basemap

A imagem de satélite e os vetores representando os trechos rodoviários e ferroviários demonstram a interações dos sistemas viários com a mancha urbana de Uberaba, tem apresenta em sua parte sudoeste o encontro da BR 050 com a BR 464, que apresentam trechos coincidentes com rodovias estaduais além de indica trecho planejados da BR 464 no lado oeste da mancha urbana.

Em relação aos cenários não houve mudança na escala da vulnerabilidade do nó com V13 e V14. Nos três cenários prevaleceu a estimativa de vulnerabilidade classe média.

Quadro 6-11 - Tipo de vulnerabilidade por combinação dos cenários em V13 e V14

\begin{tabular}{|c|c|c|c|c|}
\hline \multirow{2}{*}{ Vi } & \multirow{2}{*}{ Tipo de vulnerabilidade } & \multicolumn{3}{|c|}{ Cenários } \\
\cline { 3 - 5 } V13, V14 & & $30-30-40$ & $10-10-80$ & $40-30-30$ \\
\hline & & 2 & 2 & 2 \\
\hline
\end{tabular}

\subsubsection{Uberlândia V15, V16 e V17}

Em Uberlândia os nós receberam as vulnerabilidades V15, V16 e V17. Em relação aos fatores de localidade e acessibilidade, foram atribuídos o indicador urbano denso e a densidade rodoviária média. Em relação à funcionalidade, foi atribuído nível médio, devido ao grau de intermodalidade rodoferroviária. 


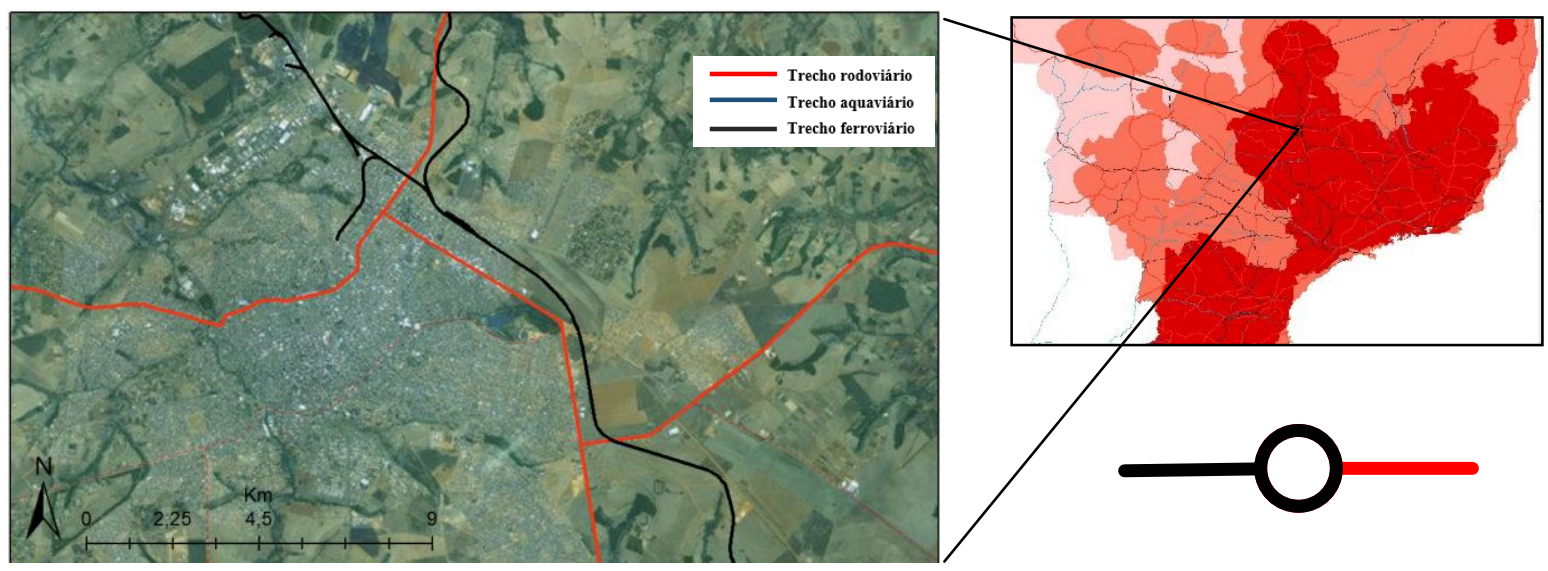

Figura 6-16 - Uberlândia V15, V16 e V17 - Localidade e Acessibilidade Fonte: elaborado pelo autor a partir da base de dados do DNIT e basemap

A imagem mostra a interação dos trechos rodoviários formados por trechos da BR 365, BR 497 com trechos planejados coincidentes com trechos estaduais, os trechos rodoviários da BR 165 e BR 497, coincidente com trechos rodoviários estaduais, estão localizados na parte leste e norte da mancha urbana e o trecho da BR 452 na parte norte.

Em relação aos cenários, não houve mudança na escala da vulnerabilidade dos nós quando submetidos aos três cenários. No entanto, a V15 foi estimada em vulnerabilidade de nível alto, e para os nós com V16 e V17 prevaleceram estimativas de vulnerabilidade classe média nos três cenários.

A alta vulnerabilidade observada em V15 é devida à funcionalidade alta em razão do fluxo de 1.500.000 toneladas em 12 meses. Em relação ao volume de fluxo de V16 e V17, foi registrado volume abaixo de 500.000 toneladas em doze meses.

Quadro 6-12 - Tipo de vulnerabilidade por combinação dos cenários em V15,V16, V17

\begin{tabular}{|c|c|c|c|c|}
\hline \multirow{2}{*}{ Vi } & \multirow{2}{*}{ Tipo de vulnerabilidade } & \multicolumn{3}{|c|}{ Cenários } \\
\cline { 3 - 5 } V15 & & $30-30-40$ & $10-10-80$ & $40-30-30$ \\
\hline V16, V17 & & 1 & 1 & 1 \\
\hline
\end{tabular}




\subsubsection{Vitória V18}

O nó localizado em Vitória foi caracterizado com vulnerabilidade V18, com indicador urbano denso e a densidade rodoviária Baixa. A Figura 6-15 apresenta a representação da caracterização do nó quanto aos fatores de localidade e acessibilidade.

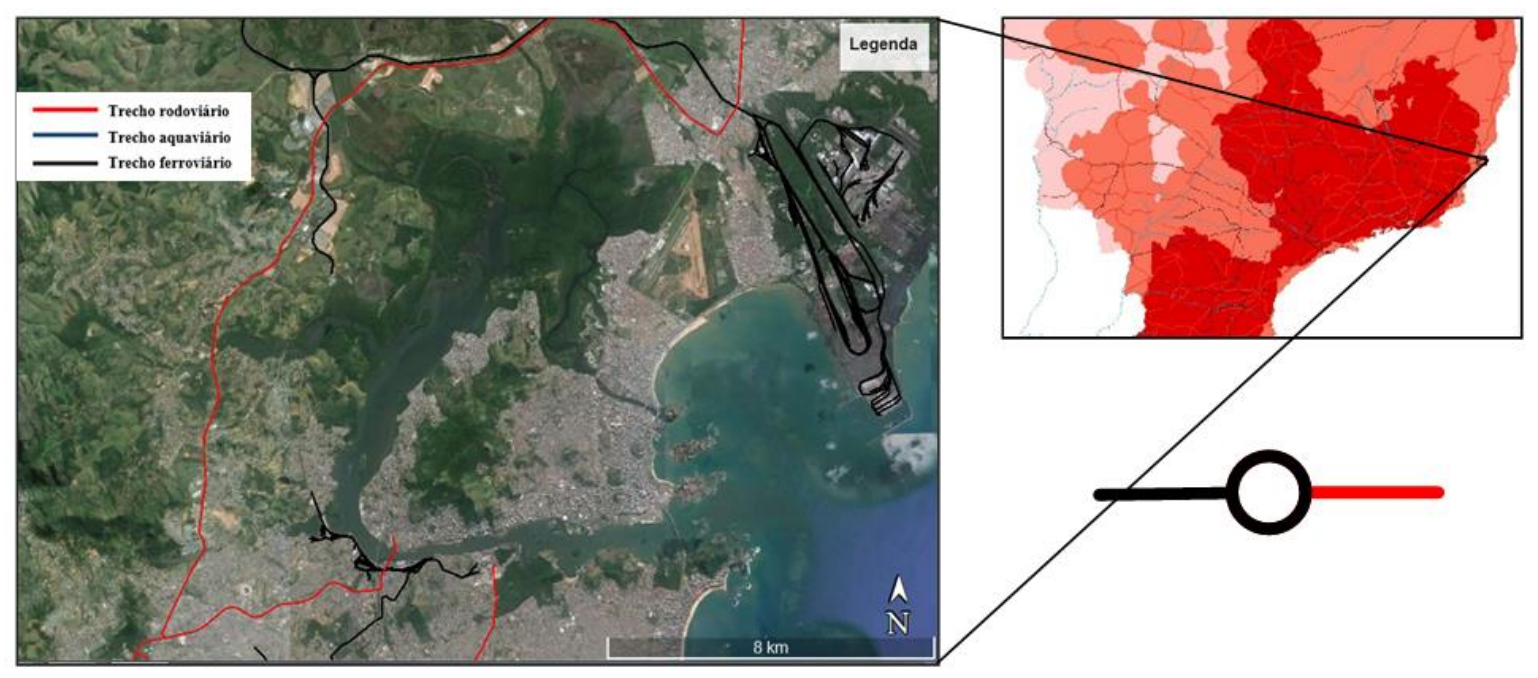

Figura 6-17 - Vitória V18 - Localidade e Acessibilidade Fonte: elaborado pelo autor a partir da base de dados do DNIT e Google Earth

A funcionalidade apresenta-se com nível alto devido à influência da funcionalidade estrutural com estrutura de 25 equipamentos e o fluxo anual de 4.670 .000 toneladas. A funcionalidade topológica apresentou o nível dois de influência com intermodalidade do tipo ferroaquaviário.

Em relação aos cenários, o nó recebeu a vulnerabilidade nível 1 em todos os cenários. O Quadro 6-25 apresenta o tipo de vulnerabilidade por combinação dos cenários em V18, e também apresenta o fluxo em 12 meses com cerca de 4.670.000 toneladas de grãos, o que contribui para uma funcionalidade alta e número de 25 equipamentos compatível com esta funcionalidade.

Quadro 6-13 - Tipo e representação de vulnerabilidade em V18

\begin{tabular}{|c|c|c|c|c|}
\hline \multirow{2}{*}{$\mathbf{V i}$} & \multirow{2}{*}{ Tipo de vulnerabilidade } & \multicolumn{3}{|c|}{ Cenários } \\
\hline & & $30-30-40$ & 10-10-80 & $40-30-30$ \\
\hline V18 & & & & \\
\hline
\end{tabular}




\subsection{ANÁLISE DA VULNERABILIDADE DO CORREDOR LOGÍSTICO}

A análise da vulnerabilidade do corredor logístico pode ser estimada por meio da vulnerabilidade atribuídas aos nós. Nessa análise é importante considerar os aspectos espaciais e territoriais do corredor logístico e como a vulnerabilidade dos nós e os seus tipos derivados são distribuídas geograficamente. $\mathrm{Na}$ amostra de 18 nós intermodais é possível extrair informações relevantes para análise da vulnerabilidade dos nós intermodais. No entanto, não podemos afirmar que a aplicação do método para análise da vulnerabilidade nesse estudo de caso traduz-se uma análise mais completa do corredor logístico. A Figura 6-18, apresenta a distribuição no Cenário 1, sendo 30\% - Localidade, $30 \%$ - Acessibilidade e $40 \%$ - Funcionalidade.

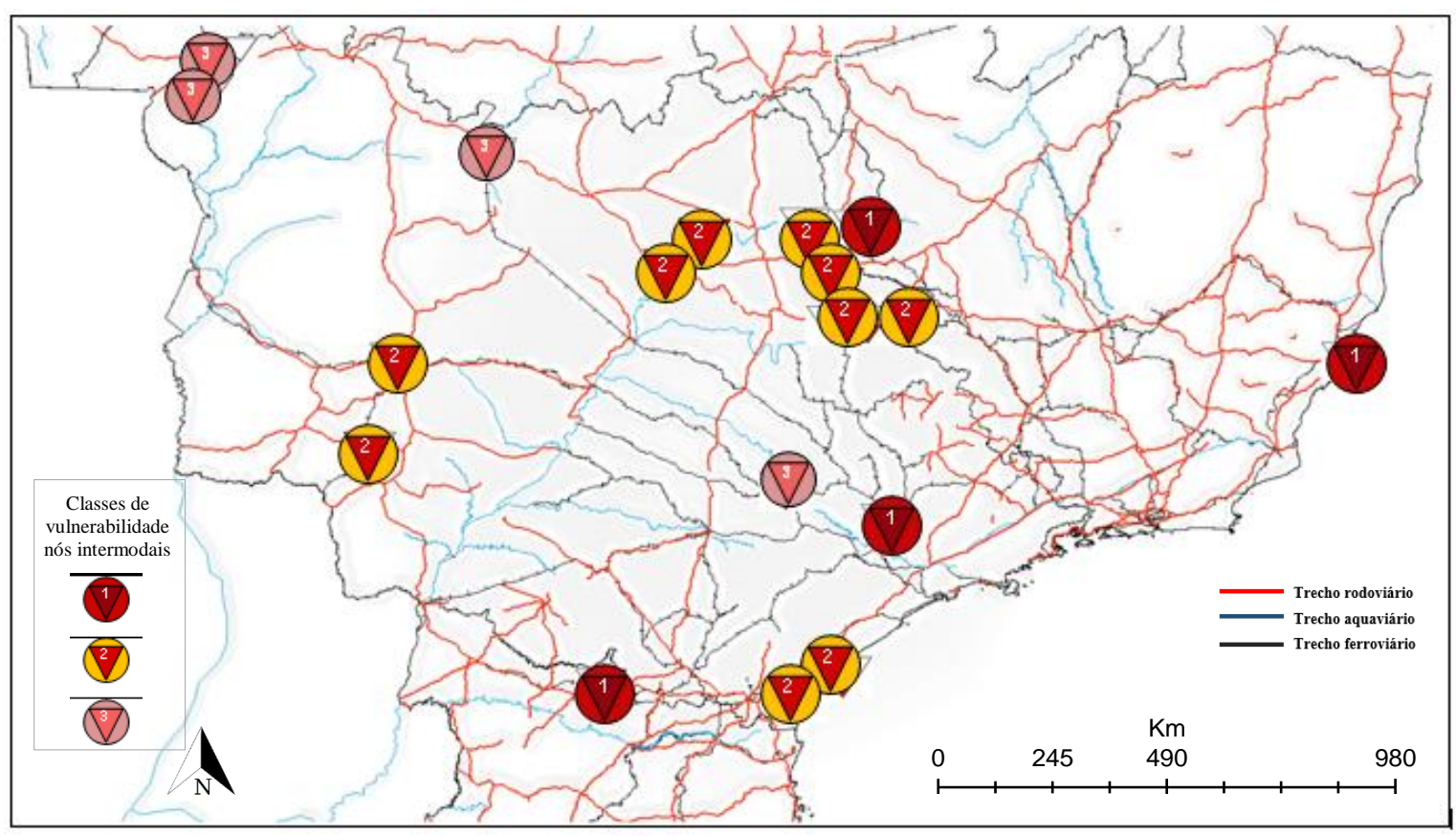

Figura 6-18 - Cenário 1 - distribuição espacial dos níveis de vulnerabilidade Fonte: elaborado pelo autor

No cenário 2, a distribuição espacial da vulnerabilidade mostrada na Figura 6-19 indica que os nós que modificaram o nível de vulnerabilidade quando a situação indicada corresponde a $80 \%$ de influência da funcionalidade e os $20 \%$ restantes divididos igualmente pela localidade e acessibilidade. 
Os nós que tiveram sua condição de vulnerabilidade alterada para cima foram: Alto Araguaia- V1 e Pederneiras do nível 3 para o 2 e São Simão - V10 do nível 2 para o nível 1. Os nós em Paranaguá V7 e V8 tiveram os níveis alterados para baixo indo do nível 2 para o nível 3.

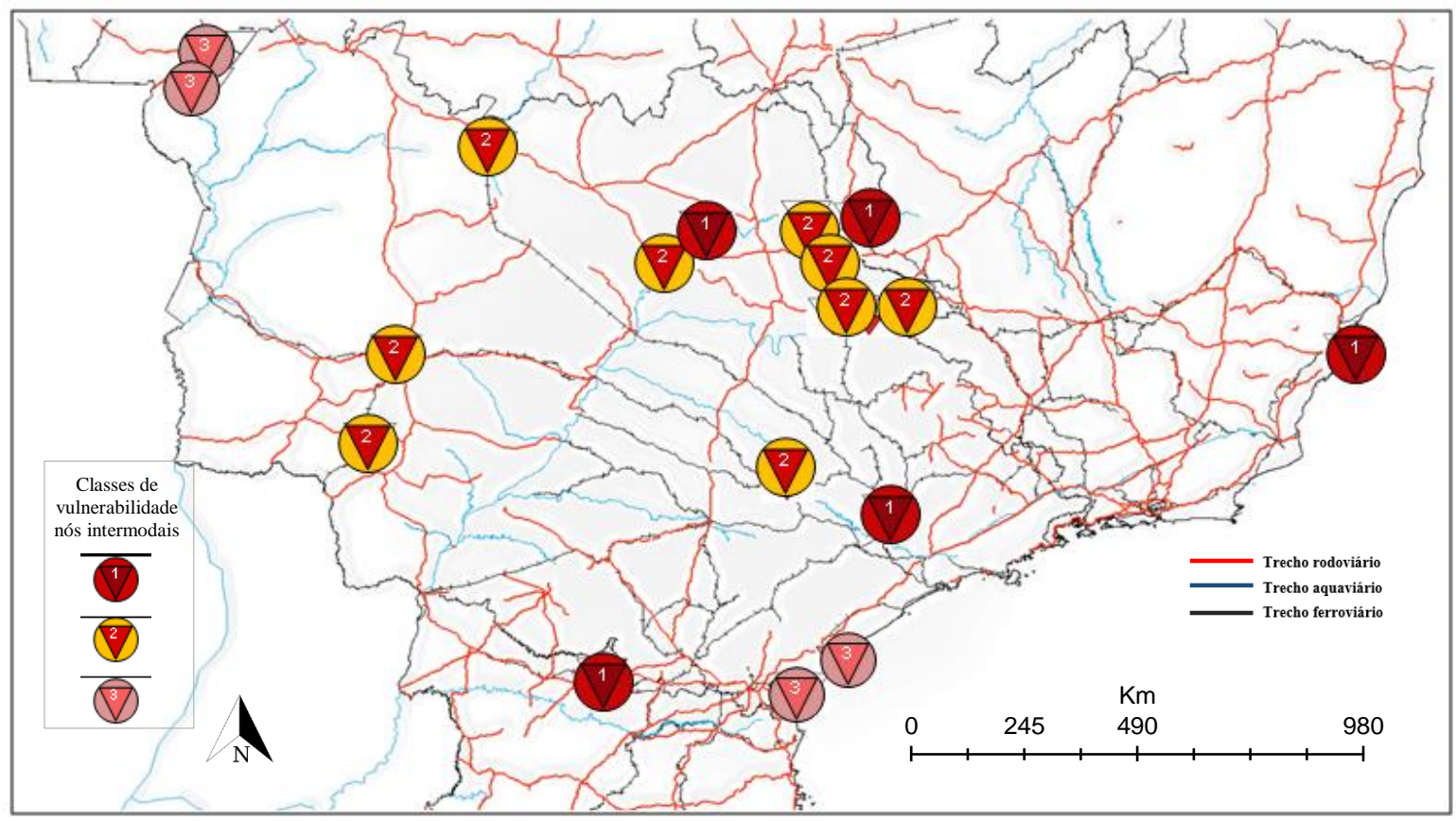

Figura 6-19 - Cenário 2 - distribuição espacial dos níveis de vulnerabilidade Fonte: elaborado pelo autor

No cenário 3, observa-se que o comportamento dos nós diante desse cenário que é diferente do cenário 2 , volta a equilibrar os fatores inidcando uma proporção de $40 \%$ para o indicador urbano, 30\% para densidade rodoviária e 30\% para funcionalidade. Os nós de Alto Araguaia e Pederneiras retornaram à condição de nível 3 de vulnerabilidade.

No entanto, o nó em Maracaju teve alterado o nível de vulnerabilidade do nível 2 para o nível 3. A Figura 6-20 demonstra a distribuição espacial da vulnerabilidade do nós submetidos ao cenário 3 .

A observação do comportamento dos tipos de vulnerabilidades atribuídas aos nós nos três cenários do estudo de caso sugere uma concentração e distribuição espacial de localidades com tipo mais homogêneos de vulnerabilidade, revela padrões de vulnerabilidade 
associado aquelas localidades onde os nós não obtiveram mudança no padrão de vulnerabilidade quando submetidos aos três cenários.

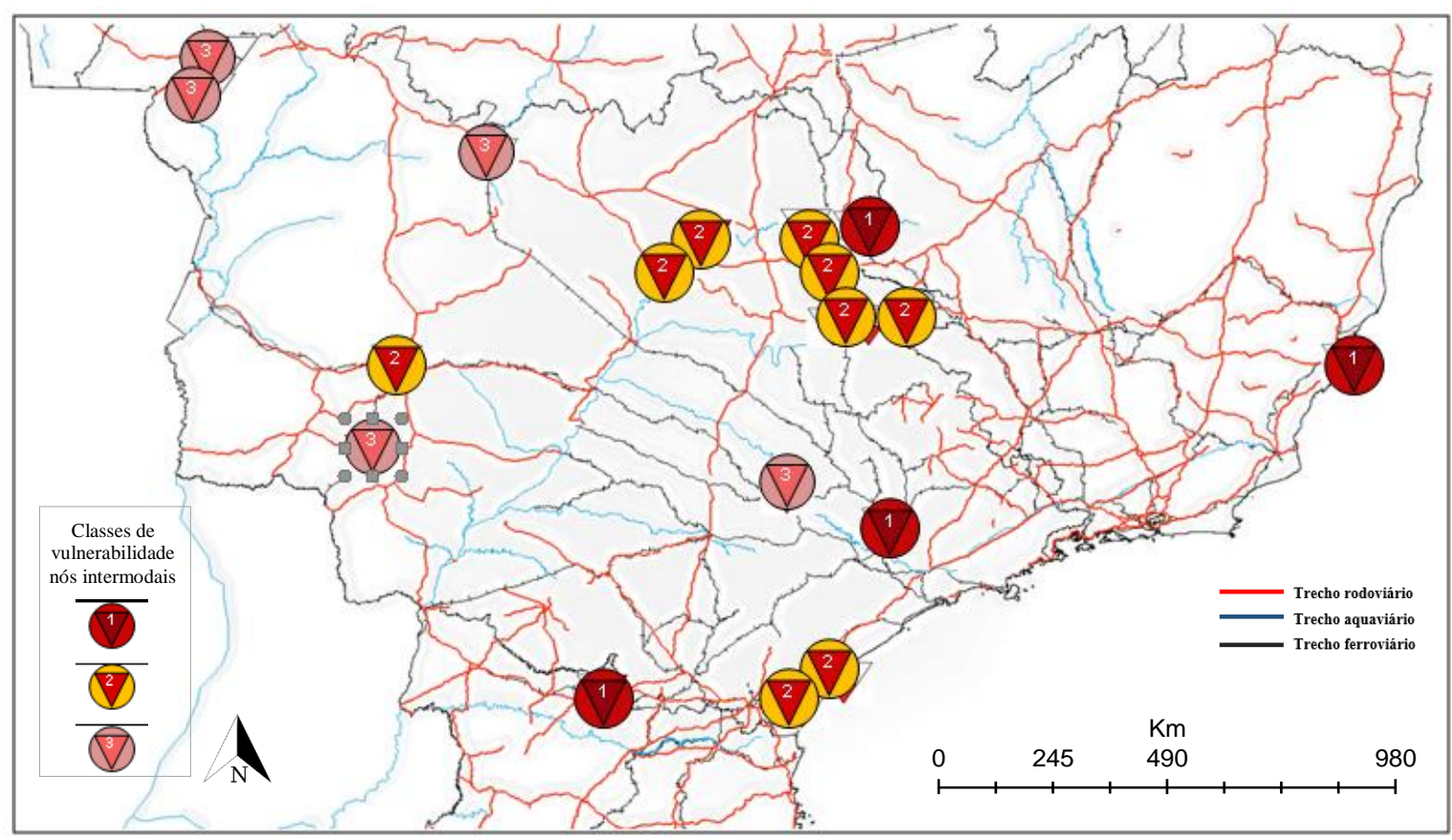

Figura 6-20 - Cenário 3 - distribuição espacial dos níveis de vulnerabilidade Fonte: elaborado pelo autor

A distribuição espacial de nós com classe 2 está concentrada mais ao centro do corredor logístico, enquanto que nós com nível 3 mais ao noroeste do corredor. 


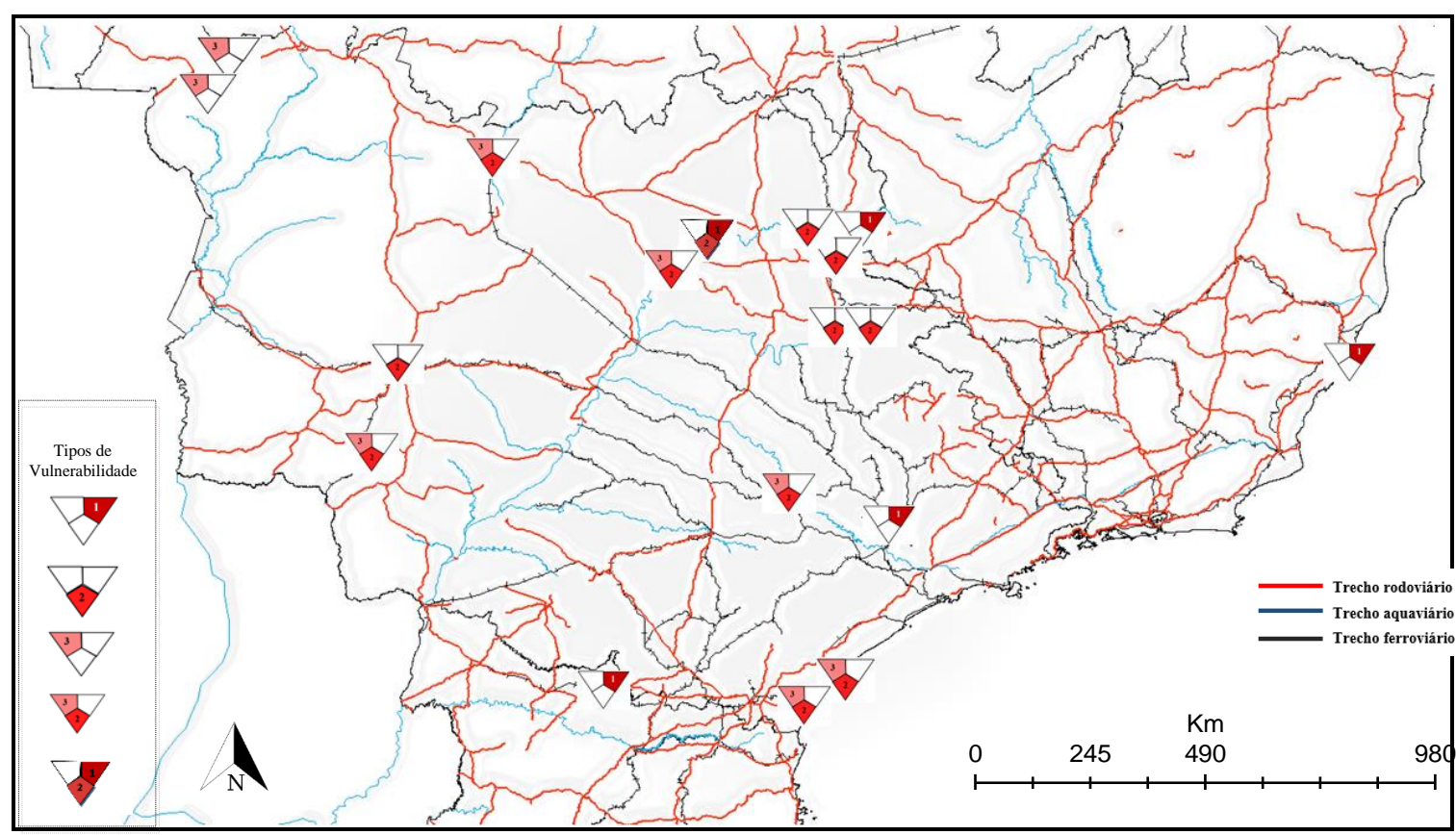

Figura 6-21 - Distribuição espacial da vulnerabilidade dos nós no corredor

Fonte: elaborado pelo autor

Na Figura 6-21, da distribuição das vulnerabilidades dos nós intermodais submetidos à situação dos três cenários descritos, destaca-se áreas onde são observadas apenas um de nível vulnerabilidade.

\subsection{TÓPICOS CONCLUSIVOS}

A classificação da vulnerabilidade de um conjunto de nós, por meio, da combinação de fatores de localidade, acessibilidade e funcionalidade pode ser considerada um indicador estimativo da vulnerabilidade do nó intermodal. Essa classificação pode indicar quais pontos de determinado corredor que requerem investimentos ou medida de controle ou mitigação da vulnerabilidade. O método para análise da vulnerabilidade dos nós é aplicável para caracterização dos nós intermodais do SNV, que levanta as características intermodais dos nós e do corredor logístico, em relação à vulnerabilidade e à influência desses fatores. A seleção dos critérios e fatores de localidade e acessibilidade permitiu que a disponibilidade de dados não fosse problema, visto que os dados necessários são dados publicados e estão disponíveis no IBGE e DNIT. 
No entanto para caracterização funcional é necessária disponibilidade de dados de pesquisa primária junto aos terminais que correspondem aos nós intermodais do corredor em estudo. Portanto, essa disponibilidade é um fator relevante para determinar a quantidade de equipamentos disponíveis no nó. A localização de origem das cargas, o volume e a sazonalidade estão diretamente relacionadas aos fluxos de entradas e saídas nos nós intermodais. Desta forma, para o planejamento, a estrutura dos nós, bem como para a infraestrutura da rede física, interessa que sejam compatíveis e bem dimensionados.

A utilização de imagens de satélites permite uma análise visual da interação entre o ambiente e a rede, representada pelos padrões de uso do solo observado nas imagens e pelos eixos viários existentes na localidade dos nós intermodais.

A indicação de cenários para estimar a distribuição da influência entre os fatores de localidade, acessibilidade e funcionalidade pode ser utilizada para calibrar a acessibilidade, indicando os nós que podem ter reduzida sua vulnerabilidade com a ampliação da acessibilidade do ambiente.

Portanto, associando vulnerabilidade com funcionalidade é possível expressar que um nó exposto à baixa vulnerabilidade significa dizer que diante de circunstâncias contrárias e adversas a funcionalidade adequada é minimamente mantida com auxílio de medidas de contingências e medidas preventivas. A adoção dessas medidas requer o entendimento da exposição da vulnerabilidade e o nível de exposição e funcionalidade do nó.

No que se refere à funcionalidade do nó, tanto no aspecto topológico, quanto no aspecto estrutural é possível observar a medida da influência na vulnerabilidade de maneira a apoiar tomadas de decisão de investimentos, para ampliar e/ou manter os níveis de funcionamento do nó, ou seja, os níveis fluxos de carga e as medidas aceitáveis de custo e tempo. 


\section{CONCLUSÕES E RECOMENDAÇÕES}

\subsection{APRESENTAÇÃO}

Neste capítulo final, são apresentadas as principais conclusões dessa pesquisa sobre vulnerabilidade e nós intermodais. As questões de Onde se observa a vulnerabilidade? $O$ que se observa com vulnerabilidade? e Como se observa essa vulnerabilidade? São utilizadas para reflexão das conclusões. Uma breve avaliação do método e da sua aplicação e apresentada, e seguida de linhas gerais de recomendações.

\subsection{AVALIAÇÃO DO MÉTODO PROPOSTO}

Quanto ao objetivo de desenvolver um método para análise da vulnerabilidade dos nós intermodais de rede intermodal de corredor logístico, por meio dos fatores de localidade, acessibilidade e funcionalidade, demonstrou-se ser aplicável para os estudos e análises de nós intermodais.

O método para análise da vulnerabilidade de nós intermodais possibilitou realizar basicamente três tipos de análises. A análise dos cenários indicados, as análises dos fatores de influência da vulnerabilidade de nós intermodais, e uma análise mais global do conjunto de nós do corredor. Para isso, é importante identificar os nós intermodais dos operadores logísticos que atuam na área de estudo.

\subsection{CONCLUSÕES}

As principais conclusões apresentadas consideram que o Plano Nacional de Viação representa a primeira questão de Onde se observa a vulnerabilidade?. O principal objetivo do PNV é estabelecer a infraestrutura de um sistema viário integrado com bases para planos globais de transporte que atendam, pelo menor custo, às necessidades do país. Contudo, tendo em vista a competitividade, é razoável supor que o SNV, como um instrumento de estruturação da intermodalidade no território, necessita estruturar os elementos nós intermodais no território nacional. Os corredores logísticos são as unidades territoriais para regionalizar as transferências modais. 
Dessa forma, o elemento nó intermodal corresponde à segunda questão sobre $O$ que se observa com vulnerabilidade?. Constatou-se que a utilização de indicadores nacionais foi bastante útil para caracterização dos nós intermodais. Dessa forma o estudo demonstra aplicabilidade visto que são os nós intermodais elementos representativos do SNV e estruturantes dos corredores logísticos e de sistemas de transporte de carga.

Sobre os fatores utilizados para a composição do indicador de vulnerabilidade é importante ressaltar as relações ambiente-rede e ambiente fluxo. A primeira mais próxima dos fatores de localidade e acessibilidade e a segunda mais próxima dos fatores de localidade e funcionalidade. Portanto o uso de dados de pesquisas básicas pode estabelece as relações de influência mais próximas da realidade de cada corredor logístico e/ou sistema de transporte. Através desses fatores foi possível propor e aplicar um indicador de vulnerabilidade do nó intermodal. O uso dos cenários se demonstrou eficiente para estabelecer as influências com base na influência da localidade, acessibilidade e funcionalidade. Esses fatores permitiram observar características importantes do nó intermodal com relação a sua vulnerabilidade.

A localidade é fortemente influenciada pela dimensão física, como é o caso de Vitória e Paranaguá, de condição costeira. Conforme se observa em relação aos nós situados em rio natural, eclusas fluviais e bacia fluvial, como são os exemplos de Cáceres, Pederneiras e São Simão, respectivamente. De maneira a permitir a caracterização dos nós intermodais em relação a sua localidade.

A acessibilidade é um atributo do ambiente. Portanto, a elaboração do indicador de acessibilidade utiliza a densidade rodoviária. Essa densidade, dividida em classes, demonstrou-se aplicável e adequada para relacionar com o indicador de localidade e de funcionalidade. Ampliar a acessibilidade sem que se aumente o indicador urbano requer medidas planejadas de gestão do território articulada nos três níveis de governo. Essas medidas além de bem articuladas na esfera pública deve também ser bem articulada com a iniciativa privada, desta forma pode ser criado um cenário de influência de fatores favorável para diminuição da vulnerabilidade, através do aumento, ou mesmo por meio de ações para garantir a plena manutenção da acessibilidade. 
No que se refere a funcionalidade do nó, tanto no aspecto topológico, quanto no aspecto estrutural é possível observar a medida de sua influência e apoiar tomadas de decisão de investimentos para ampliar e/ou manter os níveis de funcionamento do nó, ou seja, os níveis fluxos de carga e as medidas aceitáveis de custo e tempo.

Portanto, associando vulnerabilidade com funcionalidade é possível expressar que um nó exposto à baixa vulnerabilidade significa dizer que diante de circunstâncias contrárias e adversas a funcionalidade adequada é minimamente mantida com auxílio de medidas de contingências e medidas preventivas. A adoção dessas medidas requer o entendimento da exposição da vulnerabilidade e o nível de exposição e funcionalidade do nó.

A terceira questão Como se observar a vulnerabilidade? apoiou a indicação dos critérios associados aos fatores e também na sua hierarquização no que se refere à influência na vulnerabilidade do nó intermodal. Com a utilização desses critérios, foi possível classificar os nós intermodais do corredor logístico com base no indicador de vulnerabilidade.

A análise de cenários quando utilizada na área de planejamento, permite estabelecer situações e verificar o comportamento das variáveis envolvidas. Muitas vezes são estabelecidos cenários desfavoráveis, favoráveis e medianos para determinada observação e análise de alternativas.

No que concerne em analisar os fatores de localidade, acessibilidade e funcionalidade associados à vulnerabilidade dos nós intermodais, conclui-se que a indicação de cenários foi acertada na medida em que foi possível distribuir a influência na vulnerabilidade, bem como a escolha desses fatores e permitiu analisar as relações entre o ambiente e a rede, ou seja, relacionar os critérios indicados de localidade e acessibilidade, e a funcionalidade do nó, que corresponde às relações entre o ambiente e o fluxo.

No entanto, o método para a hierarquização dos critérios pode ser aprimorado, adotando-se um instrumento para a percepção da influência dos fatores a partir dos atores diretamente envolvidos na operação dos transportes de carga por meio da rede intermodal. As operadoras de transporte multimodal podem compor o público para pesquisa básica de 
percepção da influência dos fatores. Desse modo é importante incrementar os critérios adotados para cada fator e adequá-los à realidade de cada corredor logístico.

Uma observação global pode ser feita em relação à ênfase colocada na função do sistema como um todo, ao invés apenas da própria rede física ao considerar as interações entre o ambiente e o fluxo, e os critérios de localidade. As redes de transporte não são definidas somente pela existência de infraestrutura física, Por considerar que tais entidades não dizem respeito apenas à entidade rede, mas sim a um conjunto maior de forças, adotou-se a denominação Ambiente de Interação ao ambiente que interage com a rede de transportes por meio das dimensões topológica, cinética e adaptativa.

Visto que as razões para descontinuidades na rede viária que são causadas muitas vezes por falhas físicas, o que remete a falhas na manutenção e a redução do nível de serviço, portanto, tem-se que a vulnerabilidade da rede intermodal de transporte é considerada como um problema que envolve outros fatores e a redução do nível de sérvio pode ocorrer devido a razões associadas aos fatores que exercem influência na vulnerabilidade. Como medida extrema a mudança da localização de determinado elemento pode se fazer necessária, para diminuir ou evitar o aumento da vulnerabilidade.

A observação de padrões de vulnerabilidade nos nós intermodais pode ser útil para analisar o corredor logístico e verificar ações relativas a promover a redundância de componentes do sistema de transporte para diminuir a vulnerabilidade e diminuir a dependência da rede em relação aos componentes críticos.

\subsection{LIMITAÇÕES}

A disponibilidade de dados operacionais dos terminais limitou a escolha da amostra de dados correspondentes aos nós intermodais do corredor logístico. A amostra de 18 nós intermodais corresponde cerca de $3 \%$ do total de operadores multimodais cadastrados na ANTT, em 2014, havia 507 empresas no cadastro. 
A obtenção de dados para caracterizar os fatores de localidade e acessibilidade foi mais facilitada, pois estão disponíveis no sites institucionais do IBGE e DNIT e no padrão de interoperabilidade INDE. Por outro lado, como o fator de funcionalidade está estritamente ligado ao funcionamento do nó intermodal e ao tipo de carga transportada no sistema de transporte à obtenção de dados para caracterização desse fator requer acesso aos dados de pesquisas básicas sobre o funcionamento e regime dos fluxos nos nós intermodais.

\subsection{RECOMENDAÇÕES}

A principal recomendação que se destaca é a importância de promover estudos e pesquisas sobre métodos e procedimentos para ampliar o conhecimento sobre a vulnerabilidade da rede intermodal de transportes, visto que a rede intermodal brasileira é configurada pelo SNV, de maneira que se relaciona com a terceira questão: Onde se quer observar a vulnerabilidade. Essa rede de transporte em grande escala representa um enorme desafio para a competitividade e o desenvolvimento do país. Em relação à localidade, podem-se incrementar critérios para que sejam registrados os nós intermodais que estão localizados em zonas estaduais e municipais onde podem incidir incentivos e políticas industriais e logísticas.

Neste contexto do SNV de onde se observa destaca-se $O$ Que se observa, para esse estudo, são os componentes nós intermodais que são pontos estruturantes da rede de transporte e do território, um objeto de convergência de ações em diversas esferas de governança.

Um estudo mais aprofundado pode utilizar todo o universo de transferências modais (cerca de 750) e também os operadores de transportes multimodais. Dessa forma, a aquisição de dados sobre a funcionalidade estrutural dos nós teria maior cobertura e mais qualidade. Isso ampliaria o componente lógico da rede de transporte, ou seja, o SNV.

O indicador de acessibilidade, que corresponde à densidade rodoviária federal, pode ser aperfeiçoado com a utilização de atributos qualitativos dos trechos rodoviários, esses atributos podem indicar se o trecho é duplicado, ou mesmo o Índice da Condição de Pavimento - ICS, índice levantado pelo Sistema de Gerência de Pavimentos - SGP do DNIT. Entre outros atributos qualitativos pode ser relacionado com a identificação de 
acessos e das condições do acesso, qualidade e tipos de pavimentação, bem como outros elementos da infraestrutura como a existência de pontes, tuneis ou interseções de vias.

É importante inserir a escala de tempo para as análises de vulnerabilidade da infraestrutura da rede nacional de transportes. As concepções de projetos e suas implantações muitas vezes requerem décadas de estudos, licenças, recursos financeiros, etapas de construção até a efetiva implantação e funcionamento daquela infraestrutura para a operação de sistemas de transportes. Além disso, a viabilidade de muitas infraestruturas tem relação com o tempo de funcionamento, como, por exemplo, uma ferrovia que atendeu aos fluxos de exportação de minério e que perde sua funcionalidade quando este minério se exaure nas jazidas. Outro exemplo são as sazonalidades das safras e o mercado internacional de commodities, e muito importante também é a questão do clima, dos níveis da água e pluviosidade das regiões.

Vulnerabilidade de nós intermodais não é apenas um tema interessante para a pesquisa por modeladores de rede de transporte. É também um tema de relevância na sociedade moderna. O painel internacional de mudanças climáticas indica que fatores que contribuem para o aumento da vulnerabilidade relacionada a fatores de pressão demográfica, crescimento urbano desordenado, a pobreza e a migração rural, baixo investimento em infraestrutura e serviços e problemas relacionados à governança. Esse conceito de vulnerabilidade utilizado pelo Painel Internacional de Mudanças Climáticas - IPCC é um conceito mais amplo e diretamente relacionado com os eventos e anomalias climáticas. (IPCC, 2014).

É importante aperfeiçoar a modelagem e representação do SNV e consequentemente da rede nacional intermodal de transportes de carga, de modo a contribuir para o planejamento dos transportes no nível nacional. Uma análise mais próxima da realidade requer informações mais confiáveis. A base de cadastro dos operadores multimodais de carga corresponde a uma fonte de dados importantes para a continuidade da pesquisa sobre vulnerabilidade e nós intermodais. A identificação dos operadores de transporte multimodal é importante para ponderar, ou seja, dar valor relativo aos critérios em relação à vulnerabilidade e permitir a hierarquização dos critérios para determinar quais os fatores de maior influência na determinação da vulnerabilidade do nó. 


\section{REFERÊNCIAS BIBLIOGRÁFICAS}

ABAG Associação Brasileira do Agronefócio (2015) www.abag.com.br, 2015. Vol. acessado em 22 de março de 2015.

ABCR (2015) Associação Brasileira de Concessionárias de Rodovias http://www.abcr.org.br/Conteudo/Secao/22/indice+abcr.aspx. Acessado em 22 de março de 2015

AGÊNCIA BRASIL (2015) Incêndio restringe acesso de caminhões ao Porto de Santos. [ed.] MOREIRA, M. e MASSALI, F. Santos, São Paulo, Brasil : UDOP, 6 de abril de 2015.

ALMEIDA, C. F. (2008) Elaboração de rede de transporte multimodal de carga para a região amazônica sob o enfoque de desenvolvimento econômico. UnB. Brasília : s.n., 2008. Tese de Doutorado.

ANTAQ. (2013) Anuário Estatístico Aquaviário. BRASILIA: Agência Nacional de Transportes Aquaviário

ANTT (2015) Agência Nacional de Transportes Terrestres, 2015. http://www.antt.gov.br/index.php/content/view/20271/Transportadores__Frota__Tipo_de_Veicul o.html.

BERDICA, K. (2002) An introduction to road vulnerability. Transport Policy. Departament of infraestructure, Royal Institute of Technology. Stocolmo : PERGAMON, p. 117-127.

BERTALANFFY (1968) General Theory System: Foundations, Development, Applications. [ed.] Universit of Alberta. Edmontom, Canadá : George Braziller, New York.

BRASIL (2001) Lei $\mathrm{n}^{\circ}$ 10.233. Dispõe sobre a reestruturação dos transportes aquaviário e terrestre e cria o CONIT. Brasília : s.n.

(1973) Plano Nacional de Viação. Lei $n^{o}$ 5.917, de 10 de setembro de 1973. Brasília, Distrito Federal, Brasil :

(2011) Sistema Nacional de Viação. LEI 12.379, institui o Sistema Nacional de Viação. Brasilia, Distrito Federal, Brasil : Brasil.

(2012) Projeto de Reavaliação de Estimativas e Metas do PNLT. Secretaria de Política Nacional de Transporte, Ministério dos Transportes. Brasilia : Secretaria de Política Nacional de Transportes SPNT/MT.

(2014) Desenvolvimento de Metodologia para Implementação de Centros de Integração Logística CIL. [ed.] UFRJ/COPPE. Brasília : Ministérios dos Transportes.

CEFTRU/UnB. (2007) Metodologia para desenvolvimento e seleção de indicadores para planejamento de transportes. CEFTRU, UnB. Brasília : ANPET, 2007. p. 12.

CFA (2013) Conselho Federal de Administração. Plano Brasil de Infraestrutura Logística- Uma abordagem Sistêmica. Brasília : s.n., 2013. Vol. Sistema CFA/CRAs. CDU 652.7.03.(811/817)(047).

CNT (2015) Entraves logísticos ao escoamento de soja e milho. Transporte e Desenvolvimento. Brasília: CNT. (2014) Pesquisa CNT Rodovias 2014. Brasília : s.n.

CONAB (2012) Acompanhamento da Safra Brasileira - Grãos. www.conab.gov.br Brasília : Ministério da Agricultura e Abastecimento.

CORRÊAA, R. L. (1997) Interações espaciais. [ed.] I. E de ASTRO, P. C da C. GOMES e R. L. (Orgs.) CORRÊA. Explorações geográficas. Rio de Janeiro, Rio de Janeiro : Bertrand Brasil, p. 279-318.

CUNHA-FILHO, M. S. (2014) Avaliação da Vulnerabilidade da Rede de Transporte. Engenharia Civil e Ambiental. Brasilia : PPGT/UnB, Dissertação de Mestrado.

DER/SP (2014) Mapa Rodoviário do Estado de São Paulo. [ed.] DER. São Paulo, SP : Departamento de Estradas de Rodagem , 2014.

DNIT (2015). Sistema Nacional de Viação. [www.dnit.gov.br] 2015.

DIAS, L. C.(2005) Os sentidos da rede: notas para discussão. [ed.] Leila Christina DIAS, SILVEIRA e Rogério Leandro Lima da (Org.). Redes, sociedades e territórios. Santa Cruz do Sul : Edunisc, p.1128.

DRUMOND, A. R., P, COELHO T. e ENNES, R. (2011) O Modal Dutoviário no Transporte de Petróleo e Derivados. [ed.] Professor Humberto Rocha. s.l. : Universidade Estácio de Sá - UNESA Logística do Petróleo.

ERATH, A. L. (2011) VULNERABILITY ASSESSMENT OF ROAD TRANSPORT INFRASTRUCTURE. s.1. : ETH ZURICH.

FERREIRA, E. O. (2006) Desenvolvimento de Sistema de Indicadores de Avaliação da Infra=Estrutura Rodoviária no Contexto do Desenvolvimento Regional. Dissertação de Mestrado. Brasilia, Distrito Federal : Departamento de Engenharia Civil e Ambiental, T.DM-014A/2006. 
FERREIRA, J. J. (2012) Classificação de Portos Organizados: Um estudo de caso no Brasil [Distrito Federal] xv, 95p., 210 x $297 \mathrm{~mm}$ (ENC/FT/UnB, Mestre, Transportes). Dissertação de Mestrado Universidade de Brasília. Faculdade de Tecnologia. Departamento de Engenharia Civil e Ambiental.

FOUCALT, M. (1963) The Birth of the Clinic An archaeology of medical perception. First published in Routledge Classics 2003 [ed.] London: Routledge. [trad.] A. M. Sheridan. Naissance de la Clinique: Une Archéologie du Regard Médical. Paris, França: s.n., 1963. Vol. 1, pp. xx-xxii. ISBN -41530772-4

FREITAS, L. Q. (2010) Medidas de Centralidade em Grafos. [ed.] Programa de Engenharia da Produção. Dissertação de Mestrado. Rio de Janeiro, Rio de Janeiro : UFRJ/COPPE,

GALINDO, E. P. (2009) Análise Comparativa do Entendimento do Transporte como Objeto de Planejamento. ENC/FT, UnB. Brasília.

GLOBO RURAL (2014) Seca prejudica navegação e transporte de cargas é interrompido. Perderneiras, São Paulo, Brasil : G1, 30 de maio de 2014.

HUSDAL. (2004) Reliability, vulnerability, costs and benefits. INSTR2004 - the Second International Symposium on Transportation Network Reliability. s.1., New Zeland : Husdal.com, 20-24 de August de 2004.

IBGE. (2014) Redes e Fluxos do Território. Níveis de centralidade das cidades - Notas explicativas. Rio de Janeiro : IBGE, 2014.

IPCC. (2014) Climate Change 2014: Impacts, Adaptation, and Vulnerability. Summary for policymakers. Cambridge, United Kingdom and New York : Cambridge University Press, In: p. 1-32.

MAGALHÃES, M. T. Q. (2004) Metodologia para Desenvolvimento de Sistemas de Indicadores: Uma Aplicação no Planejamento e Gestão da Política Nacional de Transportes. Brasilia.

MANHEIN, M. L. (1980) The Challenge of Transportion Systems Analysis. s.l. : Cambridge, MIT Press.

MORLOK, E. K. (1978) Introduction to transportation engineering and planning. Tokio, Japão : McGRAWHILL Kogakusha, CAP 3 pgs 75-114.

MURRAY, A. T. e GRUBESIC, T. H. (2007) Critical Infraestructure - Reliability and Vulnerability. [ed.] A. T. MURRAY e T. H. GRUBESIC. Ohio : Springer.

NAVES, J. P. P. (2012) Modelo de Atratividade de Terminais Intermodais de Grãos. Departamento de Engenharia Civil e Ambiental. Brasília: Universidade de Brasília, 2012. Publicação T.DM019A/2012.

NUNES, A. O. (2007) Dissertação de Mestrado. Análise da Oferta de Operadores de Transportes Multimodal de Cargas no Brasil: Uma Aplicação da Teoria dos Custos de Transação. Brasilia, Distrito Federal : Departamento de Engenharia Civil e Ambiental, Universidade de Brasília, 2007. T.DM-011 A/2007.

OLIVEIRA, E. L., PORTUGAL, L. S. e PORTO-JUNIOR, W. (2013) Determinando links críticos em uma rede viária: indicadores de vulnerabilidade. [ed.] XXVII Congresso de Ensino e Pesquisa em Transporte. Belém, Pará : ANPET, 2013.

PANT, S. B. (2012) Transportation Network Resiliency: A Study of Self-Annealing. s.l. : Digitalcommons,

PAPACOSTAS, C. S. (1987) Fundamentals of Transportation Engineering. [ed.] Simon\&Shuster. Englewood Cliffs : Prentice-Hall.

PARK, N. (2010) Urban Sustainability and Vulnerability Indicators: How Do We Evaluate Our Sustainability and Vulnerability? International Workshop on Sustainable City-Region Project Assistant Professor. Tainan, Taiwan : University of Tokyo.

PEREIRA, M. F. V. (2009) Redes, sistemas de transportes e as novas dinâmicas do território no período atual: notas sobre o caso brasileiro. Sociedade\&Natureza. Uberlândia: Revista Sociedade\&Natureza, Vols. v. 21, n. 1, pp. 121-129. ISSN:1982-4513.

PIPICANO, E. F. M. (2014) Análise da vulnerabilidade da rede de transporte de sistemas de operação exclusiva em corredores de ônibus - BRT com base na medida de centralidade. ENC/FT/UnB. Brasilia : s.n., 2014. Dissertação de Mestrado.

PRICINOTE, M. A. (2008) Metodologia para Identificação da Confiabilidade Topológica da Rede de Transportes Público Urbano. Dissertação de Mestrado em Transportes. Brasília : Departamento de Engenharia Civil e Ambiental, 2008. T. DM - 007A/2008.

QUEIROZ, M. P. (2014) Definição de diretrizes para autorizações de voos para empresas aéreas. [ed.] Universidade de Brasília. Tese de Doutorado. Brasília, Distrito Federal: Departamento de Engenharia Civil e Ambiental, 2014. p. 146. T.D - 004A/2014.

RODRIGUE, J. P. (2013) The Geography of Transport Systems. THIRD EDITION New York : Routledge, 2013. p. 416. ISBN 978-0-415-82254-1.

RODRIGUE, J. P. CONTOIS, C.; SLACK, B. (2006) The geography of transport system. New York : Taylor $\&$ Francis e-library. 
RAZZOLINI-FILHO. (2009) Transportes e Modais com suporte de TI e SI. Curitiba, PR: Ibpex, 2009.

ROSA, D. (2004) Plataforma logístico-cooperativa: integração horizontal das cadeias de abastecimento. Rio de Janeiro : XXVIII Congresso de Pesquisa e Ensino em Transportes, 2004.

SAATY, T. L. (1991) Método de Análise Hierárquica. Rio de Janeiro, RJ : Makron Books do Brasil Editora Ltda; Editora McGraw- Hill do Brasil, 1991. SAATY, T. L.

SANTOS, J. S. C. (2012) Investimentos Logísticos e Produção Industrial: uma análise sobre o gargalo log'sitico brasileiro. Desenvolvimento Sustentável e Responsabilidade Social: as contribuições da Engenharia de Produção. Bento Gonçalves, Rio Grande do Sul : XXXII Encontro Nacional de Engenharia de Produção, 2012.

SILVA. (1994) Teoria do Fluxo de Tráfego. [ed.] Departamento de Engenharia Civil e Ambiental. 2007, Brasília: Engenharia de Tráfego- Apostila, 1994.

SILVEIRA, M. R. e FELIPE-JUNIOR, N. F. (2007) A Intermodalidade na Europa e no Brasil: o porto de Perdeneiras-SP como ponto nodal. Geografia em Atos. Presidente Prudente : s.n., 2007. Vols. V.2, n.7.

SILVEIRA, M. R. (2007). Estradas de ferro no Brasil: das primeiras construções às parcerias público=privadas. Rio de Janeiro : Interciência, 2007.

SUCHMAN, L. A. (1990) Representing practice in cognitive science. [ed.] Michael Lynch and Steve Woolgar. Representation in scientific practice. First MIT Press edition; Human Studies. Cambridge : The MIT Press, 1990, Vol. 11, pp. 301-321.

SUDAKOV, B e VU, V.H. (2007) Local resiliense of Graphs. Princeton, New Jersey : Wiley InterScience (www.interscience.wiley.com)., 2007. DOI 10.1002/rsa.20235.

TAAFFE, E. J., GAUTHIER, H. L. e O'KELLY, M. L. (1996) Geography of Transportation. [ed.] Paul Corey. Second Edition. Upper Saddle River : Prentice Hall, 1996. 0133685721.

TAYLOR, M. A. P. e D'Este, G. M. (2003) Concepts of network vulnerability and applications to the identification of critical elements of transport infrastructure. 26th Australasiam Transport Research Forum Wellington New Zealand. Welligton, New Zealand : ATRF03, 2003.

TAYLOR, M. A. P. (2012) Network vulnerability in large-scale transport networks. Transportation Research Part A 46. s.1. : Elsevier, 2012. pp. 743-745.

TEIXEIRA, P. E. F. e CAMPEÃO, P. (2010) ANÁliSE DE DESEMPENHO PRODUTIVO DOS TERMINAIS INTERMODAIS. Artigo. [ ISSN 1984-6983 (Revista online)]. Belo Horizonte : PRETEXTO 2010, 2010. Vols. v. 11 n. 4 p. 09 - 26 out. / dez.

WEF. 2013. The Global Competitiveness Report 2013-2014. [ed.] Klaus Schwab. Geneva, Suiça : World Economic Forum, 2013.

WOLF, ERICH. (2012). Análise de vulnerabilidade em redes de transportes público Urbano. ENC/FT/UnB, Departamento de Engenharia Civil e Ambiental - Universidade de Brasília. Brasilia : PPGT, 2012. Monografiade projeto final em transportes. 
ANEXO 1 - Nível de Centralidade das Cidades e Localidades

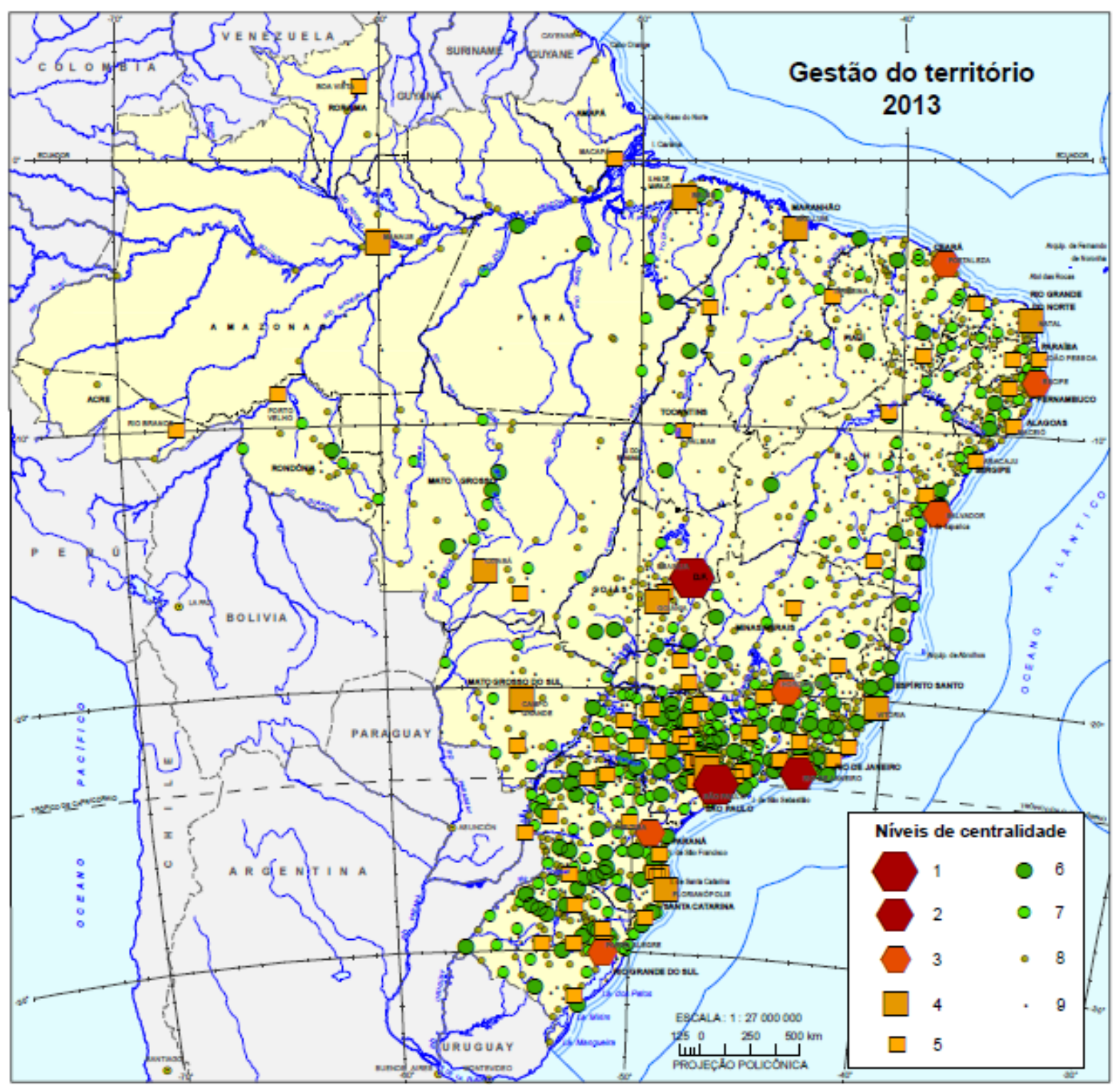

Link na web:

ftp://geoftp.ibge.gov.br/redes_e_fluxos_do_territorio/gestao_do_territorio/mapas/mapa22.p $\underline{\mathrm{df}}$ 


\section{Notas:}

\section{Áreas Urbanizadas}

O IBGE disponibiliza para download o produto Áreas Urbanizadas do Brasil - 2005. Tal produto refere-se ao mapeamento (vetorização) de áreas urbanizadas a partir de imagens de satélite CBERS-2B em escala de 1:100.000.

O objetivo deste produto é retratar o estágio de urbanização no território brasileiro na década de 2000. A data da maioria das imagens que serviram de base para o mapeamento está compreendida entre os anos de 2005 e 2007.

As manchas urbanizadas foram classificadas em três categorias: muito densa, densa e pouco densa. As manchas muito densas normalmente correspondem às áreas centrais de grandes aglomerações urbanas, caracterizando-se por um adensamento acentuado das construções, com presença de verticalização e quase ausência de solo não impermeabilizado.

As manchas classificadas como densas caracterizam-se por uma ocupação urbana contínua, baixa verticalização, com predominância de casas, com pouco espaçamento entre as construções, porém, com maior presença de solo não impermeabilizado.

As manchas classificadas como pouco densas caracterizam-se pela presença de feições urbanas (ruas, quadras, etc.), porém com uma ocupação esparsa. As manchas poucos densas podem representar loteamentos ainda em processo de ocupação ou uma transição entre a paisagem urbana e a paisagem rural, situando-se geralmente nas bordas das manchas densas. Também há casos onde são encontradas manchas pouco densas em pequenas ocupações isoladas, como, por exemplo, sedes de distritos municipais.

O produto está dividido em três conjuntos:

a) Áreas urbanizadas das grandes aglomerações urbanas brasileiras:

Tal conjunto foi utilizado como a unidade urbana básica da pesquisa Região de Influência das Cidades - REGIC (2007). Essas unidades agregam todas as aglomerações urbanas ou municípios isolados com população superior a 350 mil habitantes no ano 2000 e foram 
identificadas a partir de critérios de coesão territorial, medidos através do deslocamento de pessoas para trabalho e estudo (Censo Demográfico 2000), e da identificação de conurbação das áreas urbanizadas.

\section{b) Manchas urbanizadas dos municípios da Zona Costeira do Brasil.}

Neste conjunto estão mapeadas as manchas urbanizadas dos municípios costeiros definidos pelo Anexo A do Plano Nacional de Gerenciamento Costeiro II (Lei 7.661 de 16/05/1988). Essas manchas foram utilizadas em mapas do Atlas Geográfico das Zonas Costeiras e Oceânicas do Brasil (IBGE, 2011), retratando o estado da urbanização da zona costeira brasileira.

\section{c) Manchas urbanizadas dos municípios com mais de 100.000 habitantes.}

Neste conjunto foram vetorizadas as manchas urbanizadas dos municípios com mais de 100.000 habitantes, de acordo com a estimativa de população do IBGE para o ano de 2005. Cabe lembrar, por fim, que a repetição de alguns polígonos ocorrerá sempre que um mesmo município pertencer, ao mesmo tempo, a mais de um conjunto.

Arranjos Populacionais e Concentrações Urbanas do Brasil

A identificação e a delimitação das maiores aglomerações de população no País têm sido objeto de estudo do IBGE desde a década de 1960, quando o fenômeno da urbanização se intensificou, e assumiu, ao longo dos anos, formas cada vez mais complexas. A necessidade de fornecer conhecimento atualizado desses recortes impõe a identificação e a delimitação de formas urbanas que surgem a partir de cidades de diferentes tamanhos, face à crescente expansão urbana, não só nas áreas de economia mais avançada, mas também no Brasil como um todo.

Com o propósito de fornecer um modelo territorial das relações econômicas e sociais, intrínsecas ao processo de urbanização, o presente estudo apresenta um quadro dos arranjos populacionais no Brasil e em suas médias e grandes concentrações urbanas. Utilizando-se critérios comuns para todo o País, adotou-se uma abordagem que privilegiou elementos de integração, medidos pelos movimentos pendulares para trabalho e estudo e/ou pela contiguidade da mancha urbanizada. 
Como resultado, foram identificados 294 arranjos populacionais, formados por 938 municípios, que abrangem 55,9\% da população residente no Brasil, a partir dos quais foram definidas, por meio de cortes populacionais, as médias e grandes concentrações urbanas. Representando o alto escalão da urbanização brasileira, com mais de 750000 habitantes, destacaram-se 26 grandes concentrações urbanas, nas quais 12 têm papel metropolitano. Acima de 100000 habitantes até 750000 habitantes, foram identificadas 158 médias concentrações urbanas que atuam como centros intermediários na articulação do sistema urbano nacional.

As manchas urbanizadas são classificadas em três categorias:

a) Áreas urbanizadas das grandes aglomerações urbanas brasileiras:

Tal conjunto foi utilizado como a unidade urbana básica da pesquisa Região de Influência das Cidades - REGIC (2007). Essas unidades agregam todas as aglomerações urbanas ou municípios isolados com população superior a 350 mil habitantes no ano 2000 e foram identificadas a partir de critérios de coesão territorial, medidos através do deslocamento de pessoas para trabalho e estudo (Censo Demográfico 2000), e da identificação de conurbação das áreas urbanizadas.

\section{b) Manchas urbanizadas dos municípios da Zona Costeira do Brasil.}

Neste conjunto estão mapeadas as manchas urbanizadas dos municípios costeiros definidos pelo Anexo A do Plano Nacional de Gerenciamento Costeiro II (Lei 7.661 de 16/05/1988). Essas manchas foram utilizadas em mapas do Atlas Geográfico das Zonas Costeiras e Oceânicas do Brasil (IBGE, 2011), retratando o estado da urbanização da zona costeira brasileira.

\section{c) Manchas urbanizadas dos municípios com mais de 100.000 habitantes.}

Neste conjunto foram vetorizadas as manchas urbanizadas dos municípios com mais de 100.000 habitantes, de acordo com a estimativa de população do IBGE para o ano de 2005. Dados vetoriais de áreas urbanizadas a partir de imagens de satélite CBERS-2B em escala de 1:100.000. A maioria das imagens que serviram de base para o mapeamento está compreendida entre os anos de 2005 e 2007. 
ANEXO 2 -Densidade Rodoviária

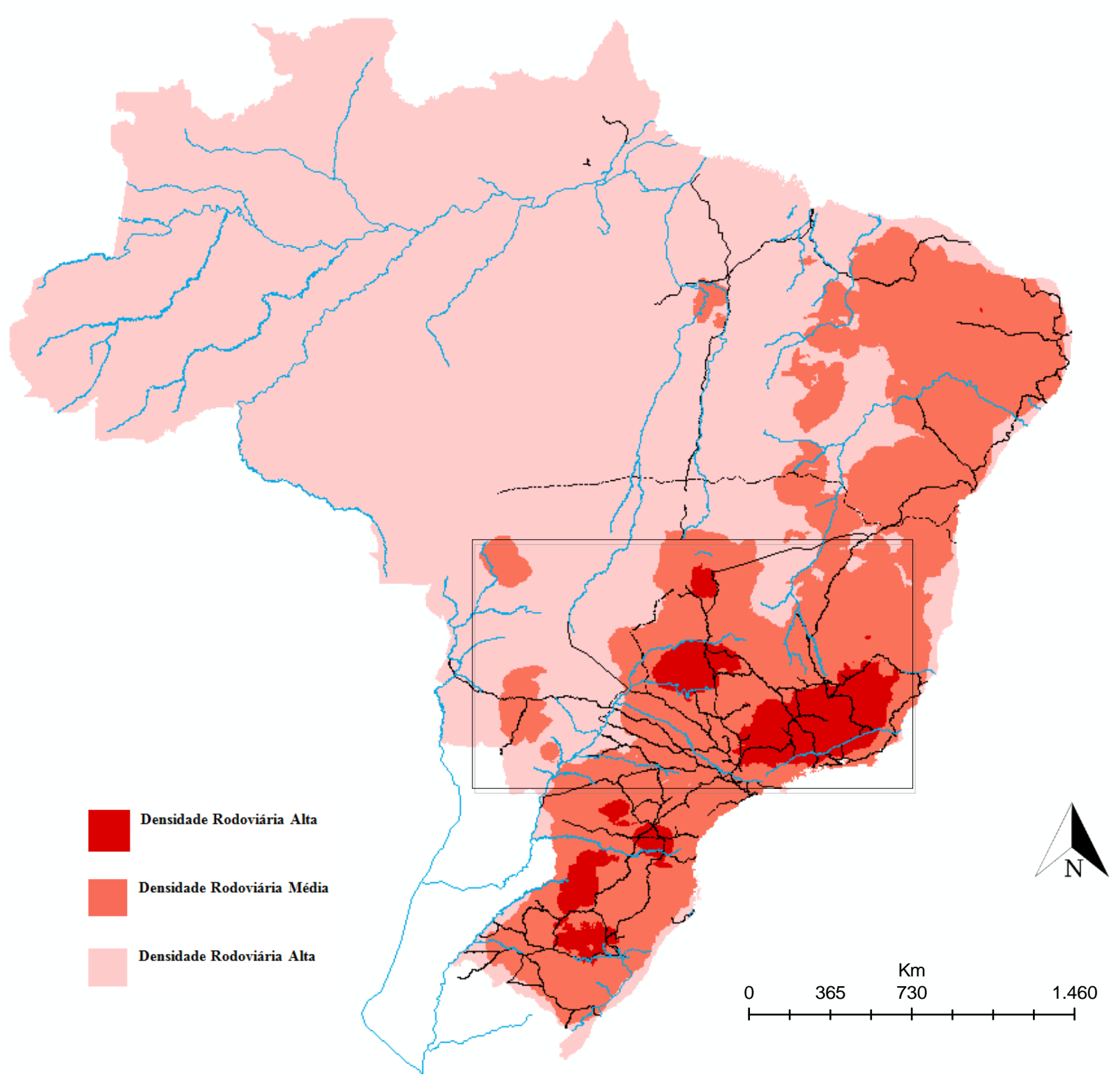

O Indicador de Densidade Rodoviária utilizou a geração da densidade com ferramenta de SIG e base de dados do DNIT e Ministério dos Transportes. A ferramenta Calcular Densidade cria um mapa de densidade a partir das feições de ponto ou linha, espalhando quantidades conhecidas de algum fenômeno (representado como atributos de pontos ou linhas) através do mapa. O resultado é uma camada de áreas classificada a partir da menos densa até a mais densa.

Os dados vetorias e temáticos das rodovias federais estão disponíveis em http://servicos.dnit.gov.br/vgeo/ 
ANEXO 3 -Dados de Terminais Intermodais

\begin{tabular}{|c|c|c|c|c|c|c|c|c|c|c|}
\hline & \multicolumn{2}{|c|}{$\begin{array}{l}\text { Capacidade } \\
\text { operacional } \\
\text { de expedição }\end{array}$} & \multicolumn{2}{|c|}{$\begin{array}{l}\text { Capacidade } \\
\text { estática de } \\
\text { armazenagem }\end{array}$} & \multicolumn{2}{|c|}{ INFRAESTRUT. } & \multicolumn{2}{|l|}{$\begin{array}{l}\text { Tempo de } \\
\text { operação }\end{array}$} & \multicolumn{2}{|l|}{$\begin{array}{l}\text { Serviços } \\
\text { oferecidos }\end{array}$} \\
\hline & $\begin{array}{l}\text { Tonel } \\
\text { adas/ } \\
\text { hora }\end{array}$ & $\begin{array}{c}\text { Not } \\
\text { a }\end{array}$ & $\begin{array}{c}\text { Tonelada } \\
\mathrm{s}\end{array}$ & $\begin{array}{c}\text { Not } \\
\text { a }\end{array}$ & $\begin{array}{c}\text { Número } \\
\text { Equipamento } \\
\mathrm{s}\end{array}$ & $\begin{array}{c}\text { Not } \\
\text { a }\end{array}$ & $\begin{array}{c}\text { Tempo } \\
\text { oper.mi } \\
\text { n }\end{array}$ & $\begin{array}{c}\text { Not } \\
\text { a }\end{array}$ & $\begin{array}{c}\text { Serviços } \\
\text { Oferecido } \\
\text { s }\end{array}$ & $\begin{array}{c}\text { Not } \\
\text { a }\end{array}$ \\
\hline $1 \mathrm{CO}$ & 500 & 2 & 10000 & 1 & 6 & 1 & 400 & 1 & 2 & 1 \\
\hline $2 \mathrm{CO}$ & 250 & 1 & 2700 & 1 & 5 & 1 & 360 & 1 & 2 & 1 \\
\hline $3 \mathrm{CO}$ & 700 & 2 & 24000 & 1 & 11 & 2 & 545 & 1 & 4 & 1 \\
\hline $4 \mathrm{CO}$ & 1140 & 3 & 37000 & 2 & 16 & 2 & 230 & 2 & 2 & 1 \\
\hline $5 \mathrm{CO}$ & 150 & 1 & 47900 & 2 & 35 & 3 & 320 & 1 & 6 & 2 \\
\hline $6 \mathrm{CO}$ & 450 & 2 & 97700 & 2 & 20 & 3 & 260 & 1 & 8 & 3 \\
\hline $7 \mathrm{CO}$ & 450 & 2 & 14000 & 1 & 8 & 1 & 540 & 1 & 7 & 3 \\
\hline $8 \mathrm{CO}$ & 80 & 1 & 16000 & 1 & 16 & 2 & 35 & 3 & 6 & 2 \\
\hline $9 \mathrm{~S}$ & 3750 & 3 & 502000 & 3 & 39 & 3 & 240 & 2 & 5 & 2 \\
\hline $10 \mathrm{~S}$ & 900 & 3 & 38000 & 2 & 51 & 3 & 35 & 3 & 6 & 2 \\
\hline $11 \mathrm{~S}$ & 400 & 2 & 60000 & 2 & 39 & 3 & 40 & 2 & 8 & 3 \\
\hline $12 \mathrm{~S}$ & 3000 & 3 & 115000 & 3 & 13 & 2 & 20 & 3 & 2 & 1 \\
\hline $13 \mathrm{~S}$ & 135 & 1 & 50000 & 2 & 21 & 3 & 45 & 2 & 2 & 1 \\
\hline $14 \mathrm{~S}$ & 2500 & 3 & 148 & 1 & 78 & 3 & 144 & 2 & 3 & 1 \\
\hline $15 \mathrm{~S}$ & 500 & 2 & 250000 & 3 & 66 & 3 & 75 & 2 & 8 & 3 \\
\hline $16 \mathrm{NE}$ & 700 & 2 & 9300 & 1 & 7 & 1 & 445 & 1 & 2 & 1 \\
\hline $17 \mathrm{NE}$ & 750 & 3 & 6000 & 1 & 7 & 1 & 30 & 3 & 6 & 2 \\
\hline $18 \mathrm{NE}$ & 300 & 2 & 60000 & 2 & 8 & 1 & 480 & 1 & 7 & 3 \\
\hline $19 \mathrm{NE}$ & 3500 & 3 & 187000 & 3 & 15 & 2 & 370 & 1 & 5 & 2 \\
\hline $20 \mathrm{NE}$ & 2000 & 3 & 240000 & 3 & 16 & 2 & 195 & 2 & 3 & 1 \\
\hline $21 \mathrm{SE}$ & 200 & 1 & 244000 & 3 & 60 & 3 & 30 & 3 & 6 & 2 \\
\hline $22 \mathrm{SE}$ & 90 & 1 & 130000 & 3 & 11 & 2 & 1455 & 1 & 6 & 2 \\
\hline $23 \mathrm{SE}$ & 240 & 1 & 96000 & 2 & 17 & 2 & 140 & 2 & 8 & 3 \\
\hline $24 \mathrm{SE}$ & 90 & 1 & 23500 & 1 & 19 & 2 & 40 & 2 & 10 & 3 \\
\hline $25 \mathrm{SE}$ & 380 & 2 & 100000 & 2 & 18 & 2 & 35 & 3 & 2 & 1 \\
\hline $26 \mathrm{SE}$ & 600 & 2 & 420000 & 3 & 25 & 3 & 0 & 3 & 4 & 1 \\
\hline $27 \mathrm{SE}$ & 500 & 2 & 60000 & 2 & 11 & 2 & 8 & 3 & 4 & 1 \\
\hline $28 \mathrm{SE}$ & 350 & 2 & 405000 & 3 & 41 & 3 & 30 & 3 & 5 & 2 \\
\hline $29 \mathrm{SE}$ & 200 & 1 & 150000 & 3 & 18 & 2 & 80 & 2 & 6 & 2 \\
\hline $30 \mathrm{~N}$ & 1000 & 3 & 40000 & 2 & 13 & 2 & 390 & 1 & 4 & 1 \\
\hline $31 \mathrm{~N}$ & 240 & 1 & 8 & 1 & 6 & 1 & 37 & 3 & 3 & 1 \\
\hline $32 \mathrm{~N}$ & 180 & 1 & 30 & 1 & 5 & 1 & 75 & 2 & 4 & 1 \\
\hline
\end{tabular}




\begin{tabular}{|c|c|c|}
\hline Terminal & $\begin{array}{c}\text { Quantidade de gräos } \\
\text { movimentada nos } \\
\text { últimos } 12 \text { meses em } \\
\text { Toneladas }\end{array}$ & $\begin{array}{l}\text { Combinaçăo } \\
\text { Intermodal }\end{array}$ \\
\hline 100 & 240.000 & Rodo-aquaviário \\
\hline $2 \mathrm{CO}$ & 64.800 & Rodo-aquaviário \\
\hline $3 \mathrm{CO}$ & 1.470 .000 & Rodo-ferroviário \\
\hline $4 \mathrm{CO}$ & 7.560 .000 & Rodo-ferroviário \\
\hline $5 C 0$ & 34.200 & Rodo-ferroviánio \\
\hline $6 \mathrm{CO}$ & 466.955 & Rodo-aquaviário \\
\hline $7 \mathrm{CO}$ & 150.000 & Rodo-aquaviário \\
\hline $8 \mathrm{CO}$ & 13.000 & Rodo-ferroviário \\
\hline 95 & 5.000 .000 & Rodo-ferro-aqua \\
\hline $10 \mathrm{~S}$ & 145.000 & Rodo-ferro-aqua \\
\hline 115 & 50.000 & Rodo-ferroviário \\
\hline $12 S$ & 3.700 .000 & Rodo-ferro-aqua \\
\hline 135 & 900.000 & Ferro-rodoviário \\
\hline $14 \mathrm{~S}$ & 1.742 & Rodo-ferroviário \\
\hline $15 S$ & 400.000 & Rodo-ferroviário \\
\hline $16 \mathrm{NE}$ & 300.000 & Rodo-ferroviário \\
\hline $17 \mathrm{NE}$ & 120.000 & Rodo-ferroviário \\
\hline $18 \mathrm{NE}$ & 350.000 & Rodo-ferroviário \\
\hline $19 \mathrm{NE}$ & 2.500 .000 & Rodo-ferro-aqua \\
\hline $20 \mathrm{NE}$ & 1.200 .000 & Rodo-aquaviário \\
\hline 21SE & 244.000 & Rodo-ferroviário \\
\hline 22SE & 93.000 & Rodo-ferroviário \\
\hline 23SE & 1.500 .000 & Rodo-ferroviário \\
\hline $24 \mathrm{SE}$ & 34.013 & Rodo-ferroviário \\
\hline 25SE & 924.000 & Rodo-ferroviánio \\
\hline $26 \mathrm{SE}$ & 4.672 .528 & Ferro-aquaviário \\
\hline 27 SE & 466.955 & Aqua-ferroviário \\
\hline $28 \mathrm{SE}$ & 80.000 & Ferro-rodoviário \\
\hline 29SE & 500.000 & Rodo-ferroviário \\
\hline $30 \mathrm{~N}$ & 2.500 .000 & Rodo-aquaviário \\
\hline $31 \mathrm{~N}$ & 40.000 & rodo-rodo \\
\hline $32 \mathrm{~N}$ & 60.000 & rodo-rodo \\
\hline média & 1.118 .131 & \\
\hline
\end{tabular}

\begin{tabular}{|c|c|c|}
\hline Terminal & Cidade & Estado \\
\hline $1 \mathrm{CO}$ & Cáceres & MT \\
\hline $2 \mathrm{CO}$ & Cáceres & MT \\
\hline $3 \mathrm{CO}$ & Alto Taquari & MT \\
\hline $4 \mathrm{CO}$ & Alto Araguaia & MT \\
\hline $5 \mathrm{CO}$ & Campo Grande & MS \\
\hline $6 \mathrm{CO}$ & São Simão & GO \\
\hline $7 \mathrm{CO}$ & São Simão & GO \\
\hline $8 \mathrm{CO}$ & Maracajú & MS \\
\hline $9 \mathrm{~S}$ & Rio Grande & RS \\
\hline $10 \mathrm{~S}$ & Estrela & RS \\
\hline $11 \mathrm{~S}$ & Guarapuava & PR \\
\hline $12 \mathrm{~S}$ & São Francisco do Sul & SC \\
\hline $13 \mathrm{~S}$ & Paranaguá & PR \\
\hline $14 \mathrm{~S}$ & Paranaguá & PR \\
\hline $15 \mathrm{~S}$ & Passo Fundo & RS \\
\hline $16 \mathrm{NE}$ & Porto Franco & MA \\
\hline $17 \mathrm{NE}$ & Porto Franco & MA \\
\hline $18 \mathrm{NE}$ & Porto Franco & MA \\
\hline $19 \mathrm{NE}$ & São Luís & MA \\
\hline $20 \mathrm{NE}$ & Salvador & $\mathrm{BA}$ \\
\hline $21 \mathrm{SE}$ & Uberlândia & MG \\
\hline $22 \mathrm{SE}$ & Uberaba & MG \\
\hline $23 \mathrm{SE}$ & Uberlândia & MG \\
\hline $24 \mathrm{SE}$ & Uberaba & MG \\
\hline $25 \mathrm{SE}$ & Araguari & MG \\
\hline $26 \mathrm{SE}$ & Vitória & ES \\
\hline $27 \mathrm{SE}$ & Pederneiras & $\mathrm{SP}$ \\
\hline $28 \mathrm{SE}$ & Sumaré & SP \\
\hline $29 \mathrm{SE}$ & Uberlândia & MG \\
\hline $30 \mathrm{~N}$ & Porto Velho & RO \\
\hline $31 \mathrm{~N}$ & Porto Nacional & TO \\
\hline $32 \mathrm{~N}$ & Porto Nacional & то \\
\hline
\end{tabular}

FONTE: Naves (2012) 